


\section{Safe telephone triage of acute cardiovascular symptoms in out-of-hours primary care}


Safe telephone triage of acute cardiovascular symptoms in out-of-hours primary care

PhD thesis, Utrecht University, the Netherlands

ISBN:

978-94-6421-007-1

Cover design: Tamara Pruis | Le Concepteur

Lay-out:

Stijn Eikenaar | persoonlijkproefschrift.nl

Printing:

Ipskamp Printing | proefschriften.net

Copyright (C) 2020 D.C.A. Erkelens

All rights reserved. No part of this thesis may be reproduced, stored or transmitted in any way or by any means without the prior permission of the author, or when applicable, of the publishers of the scientific papers.

The printing of this thesis was financially supported by SBOH, employer of GP trainees, and the Julius Center for Health Sciences and Primary Care. 


\title{
Safe telephone triage of acute cardiovascular symptoms in out-of-hours primary care
}

\author{
Veilige telefonische triage van acute cardiovasculaire \\ klachten op de huisartsenpost \\ (met een samenvatting in het Nederlands)
}

\begin{abstract}
Proefschrift
ter verkrijging van de graad van doctor aan de Universiteit Utrecht op gezag van de rector magnificus, prof. dr. H.R.B.M. Kummeling, ingevolge het besluit van het college voor promoties

in het openbaar te verdedigen op
\end{abstract}

vrijdag 27 november 2020

des ochtends te 11.15 uur

door

Daphne Carmen Aimée Erkelens

geboren op 21 september 1990

te Rotterdam 


\section{PROMOTOREN:}

Prof. dr. F.H. Rutten

Prof. dr. R.A.M.J. Damoiseaux

\section{COPROMOTOREN:}

Dr. D.L.M. Zwart

Dr. E. de Groot 


\section{Contents}

Chapter 1 Introduction

Chapter 2 Optimisation of telephone triage of callers with symptoms suggestive of acute cardiovascular disease in out-of-hours primary care: Observational design of the Safety First study

Chapter 3 Accuracy of telephone triage in suspected transient ischaemic attack or 40 stroke: A cross-sectional study

Chapter 4 Is the time of calling helpful for differentiating transient ischaemic attack and stroke from mimics in primary care out-of-hours services? A cross-sectional study

Chapter 5 Development of a diagnostic prediction model for detecting transient ischaemic attack and stroke in out-of-hours primary care: A cross-sectional study

Chapter 6 Missed acute coronary syndrome during telephone triage at out-of-hours primary care: Lessons from a case-control study

Chapter 7 Limited reliability of experts' assessment of telephone triage in primary care 124 patients with chest discomfort

Chapter 8 Interactional implications of either/or-questions during telephone triage of callers with chest discomfort in out-of-hours primary care: A conversation analysis

Summary

Nederlandse samenvatting

Curriculum vitae

List of publications 203

Dankwoord 


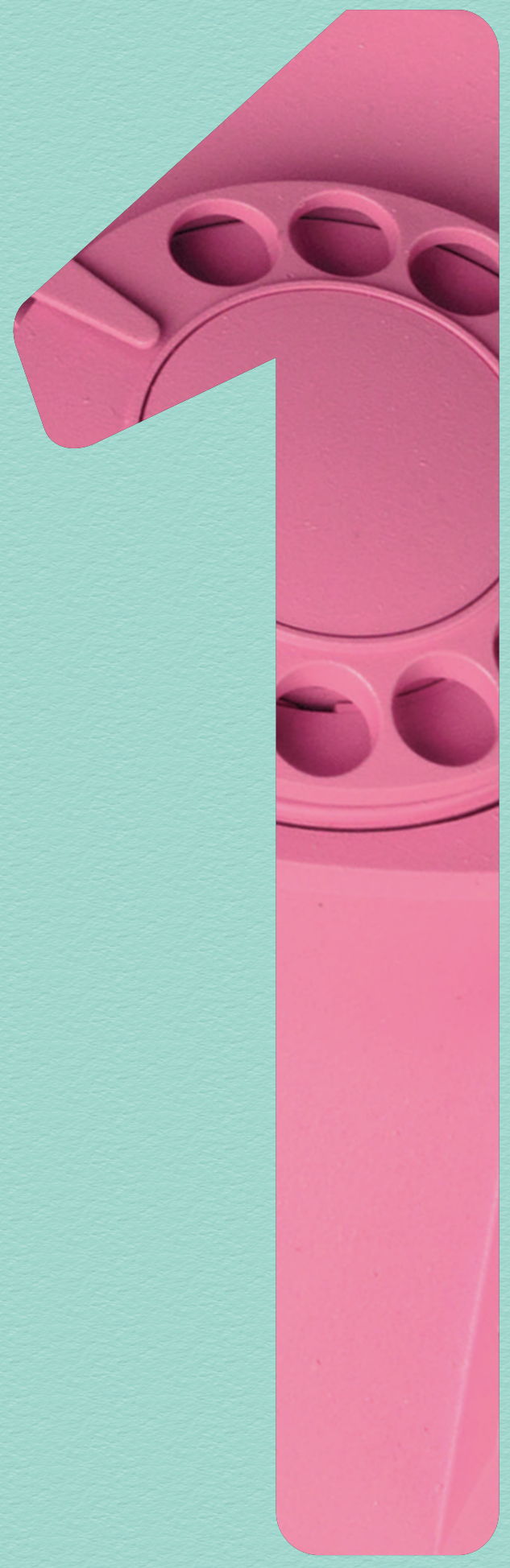




\title{
Introduction
}

\author{
D.C. Erkelens
}




\section{Case}

It is Sunday morning, and 67-year old Mrs. Elders calls the out-of-hours service in primary care (OHS-PC). The triage nurse on the phone asks her how she could be of help. Mrs. Elders tells her that she experienced some strange feelings that started abruptly while reading a book last evening. She felt dizzy, somewhat unbalanced, could not read the words properly anymore, and felt a tingling sensation in her left cheek. She decided to go to bed early, and she felt relieved that this morning the sensations were gone. It was her husband, however, who urged her to call the OHS-PC because she mispronounced some words during breakfast. A symptom Mrs. Elders had not yet noticed herself before.

Meanwhile, the triage nurse had opened the 'Netherlands Triage Standard' (NTS), a semi-automatic computer decision support tool. "What is the main complaint of Mrs. Elders?" A question the triage nurse needs to address before she can continue after having selected one of the 56 'main complaints' options within the NTS. Should she choose 'dizziness', 'blurred vision', or 'neurological deficit'? The latter because of Mrs. Elders' unbalance, tingling in the face and speaking problems. The triage nurse knows her decision may have considerable implications for the urgency allocation generated by the NTS, and thus on the (timing of the) following diagnostic and therapeutic steps. The hierarchically ordered questions that pop up in the NTS and guide the triage nurse are different for each of the 'main complaints', and positive answers result in lower urgency if she chooses for 'dizziness' or 'blurred vision' than the option 'neurological deficit'.

The telephone contact with Mrs. Elders is such that there is no risk for an immediately life-threatening event; that is, there is no evident 'ABC problem' (airway, breathing, circulation). The triage nurse decided to select 'neurological deficit', as she was trained to apply the 'main complaint' that provides the highest urgency; "one can better be safe than sorry." Hereafter, the triage nurse follows the hierarchically ordered questions that pop up now in the NTS and asks Mrs. Elders "Did you experience sudden or gradual onset of face drooping or arm weakness or leg weakness or impaired sensibility?" Mrs. Elders hesitates for a moment and then answers: "Uhm no, no, I don't think so". The triage nurse follows with asking Mrs. Elders if she had speaking problems, vision problems or headache. Mrs. Elders answers not to experience any of these symptoms. Based on these answers, the NTS generated urgency level U3 which means that a physician should see Mrs. Elders within three hours.

However, the triage nurse is in doubt. Reflecting all what was said, she is not sure how to interpret the speaking problems. How to interpret "according to my husband I still make some mistakes with the pronunciation"? If she would interpret this as speaking problems that occurred less than six hours ago and still being present during the call, than the NTS would generate a U1 urgency level (Mrs. Elders should be seen within 15 minutes). She asks Mrs. Elders to hold for a second because she wants to consult the 
supervising general practitioner (GP). She recapitulates the symptoms of Mrs. Elders, and that the NTS's urgency was U3 in the one case and U1 in the other. The GP asks her "What exactly do you want me to do?" "To take over the call" says the triage nurse.

Bearing in mind some potential diagnoses, e.g. transient ischemic attack (TIA) or minor stroke, migraine with aura, and Bell's palsy, the GP asks Mrs. Elders: "Did your husband notice changes in your facial expression?" Mrs. Elders replies: "He thinks the left part of my face looks a little bit drooped". The GP asks about problems closing her eyes, sensory or motor problems of the arms or legs, and about a medical history of hypertension, diabetes or migraine. Mrs. Elders is known with well-controlled hypertension, but also with migraine with attacks every few months. However, her migraine attacks are different from last night's symptoms. Moreover, her oldest sister was recently diagnosed with a TIA, and her younger brother suffered from a myocardial infarction when he was 59 years old.

At this point, the GP thinks a minor stroke can't be ruled out, notably, the face drooping worries her. Therefore, the GP decides to scale up the urgency to U2 (patient to be seen by a GP within one hour). U1 seems 'overshooting' because the first symptoms started more than six hours ago, and there is no immediate life-threatening situation. She tells Mrs. Elders: "I think it's wise a colleague of mine will see you in about 45 minutes. If your symptoms increase in the meantime, please call us back straightaway on the emergency line."

\section{Telephone triage during out-of-hours primary care}

Over the last two decades, out-of-hours primary care in the Netherlands has been organised into large-scale services that provide care during evenings, nights, weekends and holidays. Patients are urged to primarily contact the out-of-hours services in primary care (OHS-PC) by telephone. At the OHS-PC, telephone triage is performed by triage nurses, who are supervised by GPs.(1) The purpose of telephone triage is to prioritize callers according to the urgency of their complaints.(2) Triage nurses need to assess the urgency based on the telephone contact only. They are supported by a semi-automatic digital support tool called the "Netherlands Triage Standard" (NTS). The NTS was developed by an expert panel and derived from the already existing (i) Dutch national telephone guidelines for office hours in family practice ('NHG triage index'), (ii) the Dutch national standard for ambulance dispatch centers and (iii) the Manchester Triage System criteria. Since the introduction of the NTS in 2011, almost all Dutch OHS-PCS use this five-level triage system for telephone triage.(3-5) The NTS comprises 56 'main complaints' existing of algorithms with hierarchically ordered questions, intended to ask for the most critical symptoms first. The triage nurses fill out the caller's responses in the NTS system, which automatically generates an urgency level that is linked to a specified response 
time for medical help. The urgency levels range from $\cup 0$ (resuscitation) to U5 (telephone advice) (see table 1).(4, 5) The NTS urgency level can be scaled up or down by the triage nurse. This most often occurs after consulting the supervising GP.

Table 1. NTS levels of urgency

\begin{tabular}{|c|c|c|c|}
\hline NTS Urgency level & Definition & Response time & Medical help \\
\hline U0-Resuscitation & Loss of vital functions & Immediately & Ambulance \\
\hline U1 - Life-threatening & $\begin{array}{l}\text { Unstable vital } \\
\text { functions }\end{array}$ & $\begin{array}{l}\text { As soon as possible, } \\
\text { within } 15 \text { minutes }\end{array}$ & $\begin{array}{l}\text { Ambulance or direct } \\
\text { emergency visit by GP }\end{array}$ \\
\hline U2-Emergent & $\begin{array}{l}\text { Vital functions in } \\
\text { danger or organ } \\
\text { damage }\end{array}$ & Within 1 hour & $\begin{array}{l}\text { Home visit by GP } \\
\text { or appointment at } \\
\text { OHS-PC }\end{array}$ \\
\hline U3-Urgent & $\begin{array}{l}\text { Possible risk of } \\
\text { damage, human } \\
\text { reasons }\end{array}$ & Within 3 hours & $\begin{array}{l}\text { Home visit by GP } \\
\text { or appointment at } \\
\text { OHS-PC }\end{array}$ \\
\hline U4-Non-urgent & $\begin{array}{l}\text { Marginal risk of } \\
\text { damage }\end{array}$ & Within 24 hours & $\begin{array}{l}\text { Appointment at } \\
\text { OHS-PC or telephone } \\
\text { advice }\end{array}$ \\
\hline U5 - Advice & No risk of damage & $\begin{array}{l}\text { Advice, not time } \\
\text { related }\end{array}$ & Telephone advice \\
\hline
\end{tabular}

\section{Telephone triage of acute cardiovascular disease}

Callers with symptoms suggestive of acute cardiovascular disease (CVD), e.g. an acute coronary syndrome (ACS) or stroke, generally receive high urgency allocations.(6) A previous Dutch study reported that chest pain was the most common reason for allocating the highest urgency level (60.7\% of all U1) at the OHS-PC.(7) In the Netherlands, the majority of patients with chest pain evaluated in the hospital first call their GP or the OHS-PC ( $80 \%$ of all cases). Only $20 \%$ consists of self-referrals or people who directly called the emergency number 112 and were transported with the ambulance.(8) Of the people calling the GP or OHS-PC for chest pain, discomfort or pressure, about $70 \%$ was referred to the hospital and transported by an ambulance, and around $10 \%$ of them had an ACS. $(7,9)$ Suspected stroke concerns a much lower number of U1 urgencies; $6 \%$ of all U1 at the OHS-PC. Over the years 2013-2016, there was an increasing trend in U1 urgencies (compared to other urgencies) for patients calling the OHS-PC with 'neurological deficit'. (6) This may be due to the introduction of thrombolysis and percutaneous intervention for certain cases of stroke, which was initially considered possible within 4.5 hours after initiation of symptoms, and later within 6 hours (10), and is now even considered for those presenting between 6-24 hours. $(11,12)$ 
Assigning high urgency levels to patients with ACS is pivotal for treatment of lifethreatening ventricular tachycardia or fibrillation, which may occur in the early hours of myocardial infarction.(13) Also, high urgency is vital for both suspected cases of ACS and stroke to enable early initiation of (invasive) treatment and intensified antiplatelet therapy on top of already directly initiated aspirin by the GP or ambulance personnel. (14-16) Although less pressing, timely diagnosis of TIA also is worthwhile for treatment reasons. Previous studies showed that rapid diagnostic assessment of TIA/minor stroke followed by a timely start of stroke preventive treatment the same day substantially decreased the risk of an early recurrent stroke. $(14,15,17)$ Reduction of recurrent stroke ranged from $60 \%$ in six weeks to $80 \%$ in three months after the early start of antiplatelet therapy. $(14,17)$ A sufficiently high urgency allocation which results in consultation within a few hours, i.e. U2 or U3, is needed to safely achieve this early treatment goal.

Knowing the potential harm of missing out a timely diagnosis of acute CVD makes telephone triage very challenging in the domain of patients suspected of acute CVD. Symptoms are not specific and may also be caused by multiple other (less urgent) disorders. Moreover, undisputed and adequate diagnostic prediction models are lacking. It has been shown to be challenging to discriminate patients with different aetiology from each other based on symptoms only.(18-22) Furthermore, in case of suspected TIA, symptoms may be short-lasting and already resolved by the time a patient seeks medical help.(23) In case of suspected ACS, one also has to realize that missing an acute myocardial infarction is barely accepted and only missing rates $<1 \%$ seem satisfactory, at least to cardiologists.(24) Such missing rates are inevitably linked to assigning high urgencies only and high referral rates, resulting in over triage at the OHS-PC.

\section{Performance of decision support tools for triage}

Many studies assessed the validity of five-level triage systems; however, these were mainly targeted on one of the four worldwide most commonly used triage systems, which all incorporated face-to-face items (i.e. Manchester Triage System, Canadian Triage and Acuity Scale, Emergency Severity Index, and the Australasian Triage System).(25) Moreover, these triage systems were used and evaluated in secondary care settings with a relatively high prevalence of disorders needing emergency care. More information than from telephone contact only, and higher prevalence of emergencies result in better accuracy (notably, sensitivity and positive predictive value) than possible with a telephone triage system for the general population. Also, different ways of validation were applied, with various reference standards for the outcomes. Validation of triage systems against a reference standard for urgency included using other triage systems already in use or standards developed by expert panels a priori. Validation of triage system against measures included patient prognosis, costs and/or resource use (e.g. hospital admission, length of stay at emergency department (ED), mortality).(25-27) Some studies assessed the performance of triage systems for patients presenting with 
acute cardiovascular symptoms against the final clinical outcomes (e.g. ACS or stroke), as the reference.(28-35)

In a systematic review on the performance of the Manchester Triage System (MTS) six studies on ACS were included (28), however, with a very heterogeneous population because of varying inclusion criteria for study populations; patients with established ACS (31-34), patients with non-traumatic chest pain (30), and patients who sought emergency care for any complaint (i.e. not only symptoms suggestive of ACS).(29) These varying study populations are associated with a wide range of prior chance (prevalence) of ACS, i.e. from $0.58 \%$ to $9.4 \%$, and reported sensitivity values ranged from 0.70 (95\% confidence interval 0.60-0.79) to $0.80(0.74-0.86)$.(28) The study evaluating patients with non-traumatic chest pain best reflects the domain of patients with symptoms suggestive of ACS in primary care settings, and had a prevalence of $9.4 \%$ ACS, a sensitivity of 0.77 (0.55-0.92), a specificity of 0.59 (0.52-0.66), a positive predictive value of 0.16 (0.10-0.25) and a negative predictive value of 0.96 (0.91-0.98).(30) In another systematic review on the performance of triage systems in the ED, the sensitivity of a high urgency allocation by the Canadian Triage and Acuity Scale (CTAS) for ST elevation myocardial infarction (STEMI) was reported.(36) The prevalence ranged from $30.8 \%$ to $45.9 \%$, sensitivity values ranged from $0.57(0.54-0.59)$ to $0.74(0.72-0.76)$, specificity from $0.37(0.35-0.38)$ to 0.56 (0.54-0.59), positive and negative predictive values from 0.34 (0.33-0.36) to 0.52 (0.50$0.55), 0.60(0.58-0.63)$ to $0.76(0.74-0.78)$, respectively.(36-38)

Regarding neurological symptoms, only one study assessed the MTS specifically for patients suspected of neurological disease. This prospective cohort study at the ED evaluated the association between a high urgency allocation by the MTS and neurological disease (not otherwise specified) as primary ED diagnosis. Showing a fair discrimination (area under the curve 0.73), high MTS urgency allocation was significantly associated with neurological disease (odds ratio 3.0, 95\% Cl 2.4-3.8, p<0.001). In comparison, the overall performance of the MTS, in terms of area under the curve, for high urgency allocation was 0.71 with and odds ratio of 2.8 (2.4-3.2). (26)

The aforementioned performance results of the MTS and CTAS are not generalizable to the primary care setting (lower prevalence of emergent diseases, and in general less severe cases) or to the NTS, with only symptoms and patient characteristics obtained through telephone triage. One single study evaluated the NTS in the OHS-PC setting using surrogate endpoints for adequate urgency allocation. That is, (i) referral to the ED and (ii) telephone self-care advice.(4) Independent of the final diagnosis related to the OHS-PC contact, patients referred to the ED were considered to be correctly categorised as high urgency and patients receiving self-care advice as correctly low urgency. In this study, the researchers found an association between high urgencies and ED referrals and low urgency and self-care advices, respectively. The NTS urgency allocation was, however, never evaluated against final clinical outcomes. 


\section{A trade-off between safety and efficiency with telephone triage}

The Institute of Medicine defined quality of health care as "the degree to which health services for individuals and populations increase the likelihood of desired health outcomes, and are consistent with current professional knowledge." $(39,40)$ Quality can be further described based on six domains or attributes; i.e. (i) healthcare should be safe, (ii) effective, (iii) patient-centered, (iv) timely, (v) efficient, and (vi) equitable.(41, 42) Often, safety is regarded as the foundation upon which other domains are built, and the majority of quality measures address safety. $(41,43)$

The 'efficiency-thoroughness trade-off' (ETTO) principle describes the challenging balance between efficiency and thoroughness (often combined with safety), stating that it is impossible to maximise both at the same time. "If demands to productivity or performance are high, thoroughness is reduced until the productivity goals are met. If demands to safety are high, efficiency is reduced until the safety goals are met."(44) The ETTO principle can be applied to NTS telephone triage; however, balancing efficiency with safety appears more appropriate. Specifically, the trade-off between efficiency and safety with telephone triage of acute cardiovascular disease seems challenging, as an adequate allocation of urgency and prompt diagnosis are crucial for the patient's prognosis. However, overestimation of urgency results in unnecessary high workload, high referral rates and high costs. Also, defensive measures, undertaken after the occurrence of serious adverse events, may trigger iatrogenic damage of the patient and cause harm by burdening the healthcare system.(45-47)

\section{Efficiency}

Over the last years, the number of patient contacts with the OHS-PC in the Netherlands increased up to a total of 4,3 million OHS-PC contacts in 2018 (an increase of 3.5\% compared to 2017). Notably, the number of telephone consultations (compared to consultations at the OHS-PC and home visits) increased (1,8 million in 2018, an increase of 7.4\% compared to 2017). As a result, a higher out-of-hours workload for both GPs and triage nurses in the Netherlands arose. $(48,49)$ Though, the OHS-PC was intended initially for urgent health problems that could not wait until the next working day, a recent Dutch study reported in 2017 that $45 \%$ of the contacts could be considered non-urgent according to experts' opinion. $(1,50)$ As such, OHS-PC care probably resembles 'regular' GP care more, but outside office hours, and thus with low numbers of urgent health problems. A semi-automatic triage tool such as the NTS designed for high-level urgency care may therefore be inadequate for the OHS-PC. Nevertheless, at the introduction of the NTS at the OHS-PC, it was claimed that both efficient and safe care would be 'guaranteed'. Still, as argued before, the NTS will likely result in overestimation of urgency ('over triage' or defensive triage), especially in patients with symptoms suggestive of acute cardiovascular disease. $(1,5)$ 
Implementation of the NTS in the Dutch OHS-PC setting in 2011 has resulted in an increase in allocation of high urgencies, notably U2.(51) This is in contrast to the declined risk of cardiovascular events and cardiovascular mortality $(52,53)$ in the same period and, it thus might reflect a defensive triage strategy. Possibly, increased attention to prevent serious adverse events at the OHS-PC and the way in which protocol-based triage is used contributed to more defensive triage.(51) A national questionnaire among 428 GPs in 2016 revealed that $83.9 \%$ believed that the introduction of NTS-supported telephone triage at the OHS-PC had resulted in many unnecessary consultations and home visits.(54) In two other Dutch studies applying questionnaires GPs evaluated the medical necessity of face-to-face contacts afterwards, thus with a high risk of hindsight bias. $(55,56)$ GPs considered respectively $21 \%$ of 485 face-to-face contacts(55), and $32 \%$ of 302 face-to-face contacts at the OHS-PC medically unnecessary, and almost half of all contacts as non-urgent health problems.(56)

\section{Safety}

Despite the defensiveness of the NTS, telephone triage may result in too low urgencies and serious adverse events (SAEs). SAEs are defined by the Dutch Healthcare Quality, Complaints and Disputes Act (Wet Kwaliteit, Klachten en Geschillen Zorg) as: "an unintended or unexpected event related to the quality of care and resulting in death or a severe harmful event for the patient".(57) For each SAE, the Dutch law requires instant reporting and an elaborate root cause analysis, which consists of multiple approaches and tools used to analyse that specific event in detail and focusses on determining how and why the particular SAE could have occurred based on causal reasoning.(58,59) At Dutch OHS-PC almost half of all SAEs concern missed acute cardiovascular diseases, notably ACS/acute cardiac death (30.4\%), stroke (7.9\%), and ruptured abdominal aortic aneurysm (7.9\%).(60) Root cause analyses often point to triage-related problems such as a too low urgency allocations or assignment of the incorrect type of care (e.g. consultation at OHS-PC while a home visit was considered appropriate).(60) Such evaluations (further) underline the need for safe( $r$ ) telephone triage considered to be found in a more defensive strategy. Root cause analyses and defensive recommendations arising from them are aimed at preventing SAEs and improving patient safety. $(46,58,59)$ However, such recommendations have never been evaluated whether they result in better care.

A systematic review on patient safety in the Dutch OHS-PC setting concluded that $10 \%$ of all OHS-PC calls could be considered as 'unsafe'. (61) However, this claim of 'unsafety' was based on surrogate measures (e.g. expert's opinion with hindsight bias, and referrals to the ED) and not on patients' clinical outcomes. These $10 \%$ 'unsafe' calls heavily contrast with the very low incidence of serious adverse events $(0.006 \%)$. (60) This large gap indirectly suggests that experts or referrals as the reference easily overestimate unsafety. 
In conclusion, the ultimate goal of telephone triage at the OHS-PC is an optimal balance between efficiency and safety. Yet, it is currently still rather unknown how telephone triage with the NTS really performs. Previous attempts have been made to structure triage at the OHS-PC, but these attempts were all based on triage instruments from other settings and validated with uncertain outcome measures. In addition, professionals in the field indicate that they have the impression that telephone triage with NTS leads to 'over triage'. Still, studies on the performance, efficiency and safety of telephone triage in OHS-PC based on the actual clinical outcomes are lacking. Therefore, the studies published in this thesis were carried out.

\section{Main objectives and outline of this thesis}

This thesis aims to address the following research questions:

(i) What is the accuracy of the urgency allocation with the NTS in callers with symptoms suggestive TIA/stroke?

(ii) Which (clinical) determinants are predictive of a TIA/stroke diagnosis?

(iii) How is the NTS used, and how can it be improved in view of optimally balancing efficiency and safety?

In chapter $\mathbf{2}$ we described the protocol of the 'Safety First' study, aimed at describing, understanding and improving the diagnostic process and urgency allocation with the NTS in callers with symptoms suggestive of acute cardiovascular disease who contact the OHS-PC. The rationale, design and methods of the study were outlined in more detail.

In chapter $\mathbf{3}$ we assessed whether a certain time period, e.g. early mornings or at night, is more predictive of TIA/stroke than other time periods. This because in literature, a circadian rhythm is proposed with a higher risk of TIA and stroke in the morning hours compared to other hours. We evaluated this in patients calling the OHS-PC with strokelike symptoms.

In chapter 4 the accuracy of the Netherlands Triage Standard (in terms of sensitivity, specificity, positive and negative predictive values) for telephone triage of patients with symptoms suggestive of TIA or stroke was assessed. Besides, we described how often the NTS was overruled by the triage nurse and if this was overall beneficial.

In chapter 5, we evaluated (candidate) predictors to build the best diagnostic prediction model for TIA/stroke using multivariable logistic regression analysis.

In chapter $\mathbf{6}$ we present a case-control study of serious adverse events at the OHS-PC.

We compared 15 triage calls of missed ACS 1:8 with matched controls with chest discomfort but without a missed ACS. We aimed to identify possible predictors of missed ACS without hindsight bias.

In chapter 7 we assessed whether 15 experienced GP experts, blinded to the outcome, assess triage calls of patients calling the OHS-PC with chest discomfort in whom an ACS was missed (SAE) differently than triage calls of others calls with chest discomfort, but in 
whom the call did not end in a SAE (the same 135 triage calls of chapter 6). In addition, their inter-rater reliability was assessed.

In chapter $\mathbf{8}$ we evaluated the interactional implications of multiple-choice either/orquestions during telephone triage of callers with chest discomfort. We used conversation analysis to study questions like: "Is it an oppressive or stabbing or stinging pain?".

Finally, in chapter 9, the general discussion, we elaborate on the main findings of this thesis, provide final comments on the case, and discuss future research on telephone triage. 


\section{References}

1) Smits M, Rutten M, Keizer E, Wensing M, Westert G, Giesen P. The Development and Performance of After-Hours Primary Care in the Netherlands: A Narrative Review. Annals of internal medicine. 2017;166(10):737-42.

2) Blank L, Coster J, O'Cathain A, Knowles E, Tosh J, Turner J, et al. The appropriateness of, and compliance with, telephone triage decisions: a systematic review and narrative synthesis. J Adv Nurs. 2012;68(12):2610-21.

3) National guidelines for telephone triage and advice in Family Practice [cited 2018 June 22]. Available from: https://www.nhg.org/winkel/producten/nhg-triagewijzer-versie-2016.

4) van lerland $Y$, van Veen $M$, Huibers $L$, Giesen $P$, Moll HA. Validity of telephone and physical triage in emergency care: the Netherlands Triage System. Family practice. 2011;28(3):33441.

5) Netherlands Triage Standard [Nederlandse Triage Standaard], 2019. Accessed at www. de-nts.nl on 7 October 2019.

6) Smits M, Verheij R. Changes in urgency of contacts with the out-of-hours services in primary care 2013-2016. [Veranderingen in de urgentie van contacten met de huisartsenpost 20132016.]. NIVEL, 2017.

7) Plat FM, Peters YAS, Loots FJ, de Groot CJA, Eckhardt T, Keizer E, et al. Ambulance dispatch versus general practitioner home visit for highly urgent out-of-hours primary care. Family practice. 2017(Dec 20).

8) Mol KA, Smoczynska A, Rahel BM, Meeder JG, Janssen L, Doevendans PA, et al. Non-cardiac chest pain: prognosis and secondary healthcare utilisation. Open Heart. 2018;5(2):e000859.

9) Hoorweg BB, Willemsen RT, Cleef LE, Boogaerts T, Buntinx F, Glatz JF, et al. Frequency of chest pain in primary care, diagnostic tests performed and final diagnoses. Heart. 2017;103(21):1727-32.

10) Powers WJ, Derdeyn CP, Biller J, Coffey CS, Hoh BL, Jauch EC, et al. 2015 American Heart Association/American Stroke Association Focused Update of the 2013 Guidelines for the Early Management of Patients With Acute Ischemic Stroke Regarding Endovascular Treatment: A Guideline for Healthcare Professionals From the American Heart Association/ American Stroke Association. Stroke. 2015;46(10):3020-35.

11) European Stroke Organisation. ESO Guidelines Session 2018 [23 July 2020]. Available from: https://eso-stroke.org/esoc-2018-eso-guidelines-session-2018/.

12) Powers WJ, Rabinstein AA, Ackerson T, Adeoye OM, Bambakidis NC, Becker K, et al. 2018 Guidelines for the Early Management of Patients With Acute Ischemic Stroke: A Guideline for Healthcare Professionals From the American Heart Association/American Stroke Association. Stroke. 2018;49(3):e46-e110.

13) Al-Khatib SM, Stebbins AL, Califf RM, Lee KL, Granger CB, White HD, et al. Sustained ventricular arrhythmias and mortality among patients with acute myocardial infarction: results from the GUSTO-III trial. American heart journal. 2003;145(3):515-21.

14) Rothwell PM, Giles MF, Chandratheva A, Marquardt L, Geraghty O, Redgrave JN, et al. Effect of urgent treatment of transient ischaemic attack and minor stroke on early recurrent stroke (EXPRESS study): a prospective population-based sequential comparison. Lancet. 2007;370(9596):1432-42. 
15) Lavallee PC, Meseguer E, Abboud H, Cabrejo L, Olivot JM, Simon O, et al. A transient ischaemic attack clinic with round-the-clock access (SOS-TIA): feasibility and effects. Lancet Neurol. 2007;6(11):953-60.

16) Bosner S, Haasenritter J, Becker A, Karatolios K, Vaucher P, Gencer B, et al. Ruling out coronary artery disease in primary care: development and validation of a simple prediction rule. CMAJ : Canadian Medical Association journal = journal de l'Association medicale canadienne. 2010;182(12):1295-300.

17) Rothwell PM, Algra A, Chen Z, Diener HC, Norrving B, Mehta Z. Effects of aspirin on risk and severity of early recurrent stroke after transient ischaemic attack and ischaemic stroke: time-course analysis of randomised trials. Lancet. 2016;388(10042):365-75.

18) Burman RA, Zakariassen E, Hunskaar S. Management of chest pain: a prospective study from Norwegian out-of-hours primary care. BMC family practice. 2014;15:51.

19) Rawshani N, Rawshani A, Gelang C, Herlitz J, Bang A, Andersson JO, et al. Could ten questions asked by the dispatch center predict the outcome for patients with chest discomfort? International journal of cardiology. 2016;209:223-5.

20) Nadarajan $V$, Perry RJ, Johnson J, Werring DJ. Transient ischaemic attacks: mimics and chameleons. Pract Neurol. 2014;14(1):23-31.

21) Hand PJ, Kwan J, Lindley RI, Dennis MS, Wardlaw JM. Distinguishing between stroke and mimic at the bedside: the brain attack study. Stroke. 2006;37(3):769-75.

22) Ay H, Buonanno FS, Rordorf G, Schaefer PW, Schwamm LH, Wu O, et al. Normal diffusionweighted MRI during stroke-like deficits. Neurology. 1999;52(9):1784-92.

23) Sheehan OC, Merwick A, Kelly LA, Hannon N, Marnane M, Kyne L, et al. Diagnostic usefulness of the $A B C D 2$ score to distinguish transient ischemic attack and minor ischemic stroke from noncerebrovascular events: the North Dublin TIA Study. Stroke. 2009;40(11):3449-54.

24) Than $M$, Herbert $M$, Flaws $D$, Cullen $L$, Hess E, Hollander JE, et al. What is an acceptable risk of major adverse cardiac event in chest pain patients soon after discharge from the Emergency Department?: a clinical survey. International journal of cardiology. 2013;166(3):752-4.

25) Kuriyama A, Urushidani S, Nakayama T. Five-level emergency triage systems: variation in assessment of validity. Emergency medicine journal : EMJ. 2017;34(11):703-10.

26) Steiner D, Renetseder F, Kutz A, Haubitz S, Faessler L, Anderson JB, et al. Performance of the Manchester Triage System in Adult Medical Emergency Patients: A Prospective Cohort Study. J Emerg Med. 2016;50(4):678-89.

27) Grouse Al, Bishop RO, Bannon AM. The Manchester Triage System provides good reliability in an Australian emergency department. Emergency medicine journal : EMJ. 2009;26(7):484-6.

28) Nishi F, de Oliveira Motta Maia F, de Souza Santos I, de Almeida Lopes Monteiro da Cruz D. Assessing sensitivity and specificity of the Manchester Triage System in the evaluation of acute coronary syndrome in adult patients in emergency care: a systematic review. JBI Database of Systematic Reviews and Implementation Reports. 2017;15(6):1747-61.

29) Pinto D, Lunet N, Azevedo A. Sensitivity and specificity of the Manchester Triage System for patients with acute coronary syndrome. Rev Port Cardiol. 2010;29(6):961-87.

30) Leite L, Baptista R, Leitao J, Cochicho J, Breda F, Elvas L, et al. Chest pain in the emergency department: risk stratification with Manchester triage system and HEART score. BMC cardiovascular disorders. 2015;15:48.

31) Trigo J, Gago P, Mimoso J, Santos W, Marques N, Gomes V. In-hospital delay in ST-segmentelevation myocardial infarction after Manchester Triage. Rev Port Cardiol. 2008;27(10):12519. 
32) Matias $C$, Oliveira R, Duarte R, Bico P, Mendonca $C$, Nuno L, et al. The Manchester Triage System in acute coronary syndromes. Rev Port Cardiol. 2008;27(2):205-16.

33) Providencia R, Gomes PL, Barra S, Silva J, Seca L, Antunes A, et al. Importance of Manchester Triage in acute myocardial infarction: impact on prognosis. Emergency medicine journal : EMJ. 2011;28(3):212-6.

34) Gouvea VET, Reis MAM, Gouvea GM, Lima HdN, Abaulara A. Evaluation the Manchester Triage System in the acute coronary syndrome. Int J Cardiovasc Sci. 2015;28(2):107-13.

35) Nishi FA, Polak C, Cruz D. Sensitivity and specificity of the Manchester Triage System in risk prioritization of patients with acute myocardial infarction who present with chest pain. Eur J Cardiovasc Nurs. 2018;17(7):660-6.

36) Hinson JS, Martinez DA, Cabral S, George K, Whalen M, Hansoti B, et al. Triage Performance in Emergency Medicine: A Systematic Review. Ann Emerg Med. 2019;74(1):140-52.

37) Atzema CL, Austin PC, Tu JV, Schull MJ. ED triage of patients with acute myocardial infarction: predictors of low acuity triage. Am J Emerg Med. 2010;28(6):694-702.

38) Atzema CL, Schull MJ, Austin PC, Tu JV. Temporal changes in emergency department triage of patients with acute myocardial infarction and the effect on outcomes. American heart journal. 2011;162(3):451-9.

39) Institute of Medicine. IOM definition of quality 2013. Available from: http://iom. nationalacademies.org/Global/News\%20Announcements/Crossing-the-Quality-ChasmThe-IOM-Health-Care-Quality-Initiative.

40) Chassin MR, Galvin RW. The urgent need to improve health care quality. Institute of Medicine National Roundtable on Health Care Quality. Jama. 1998;280(11):1000-5.

41) Institute of Medicine (IOM). Crossing the Quality Chasm: A New Health System for the 21st Century. Washington, D.C.: National Academy Press: 2001.

42) Agency for Healthcare Research and Quality. Six Domains of Healthcare Quality. 2015 [updated November 2018]. Available from: https://www.ahrq.gov/talkingquality/measures/ six-domains.html.

43) Institute of Medicine (IOM). Performance Measurement: Accelerating Improvement. Washington, D.C.: National Academy Press: 2005.

44) Hollnagel E. The ETTO Principle: Efficiency-Thoroughness Trade-Off. Why Things That Go Right Sometimes Go Wrong. Farnham (UK): Ashgate; 2009.

45) Coster JE, Turner JK, Bradbury D, Cantrell A. Why Do People Choose Emergency and Urgent Care Services? A Rapid Review Utilizing a Systematic Literature Search and Narrative Synthesis. Acad Emerg Med. 2017;24(9):1137-49.

46) Peerally MF, Carr S, Waring J, Dixon-Woods M. The problem with root cause analysis. BMJ Qual Saf. 2017;26(5):417-22.

47) Kellogg KM, Hettinger Z, Shah M, Wears RL, Sellers CR, Squires M, et al. Our current approach to root cause analysis: is it contributing to our failure to improve patient safety? BMJ Qual Saf. 2017;26(5):381-7.

48) Smits M, Keizer E, Huibers L, Giesen P. GPs' experiences with out-of-hours GP cooperatives: a survey study from the Netherlands. The European journal of general practice. 2014;20(3):196-201.

49) InEen. Benchmark Out-of-Hours Services in Primary Care 2018. [Ineen. Benchmark Huisartsenposten 2018]. Utrecht.

50) O'Malley AS, Samuel D, Bond AM, Carrier E. After-hours care and its coordination with primary care in the U.S. J Gen Intern Med. 2012;27(11):1406-15. 
51) Jansen T, de Hoon S, Hek K, Verheij R. Developments at the out-of-hours services in primary care. Changes in care demand and health care issues in 2013-2015. [Ontwikkelingen op de huisartsenpost. Veranderingen in zorgvraag en gezondheidsproblemen in 2013-2015.]. NIVEL, 2017.

52) Deckers J, Kraaijenhagen R. Country report the Netherlands. Prepared for the EACPR "Country of the Month" initiative. Feb 2014. Available from: https://www.escardio.org/ static_file/Escardio/Subspecialty/EACPR/netherlands-country-report.pdf.

53) OECD and the European Observatory on Health Systems and Policies, in cooperation with the European Commission. State of Health in the EU: Netherlands Country Health Profile 2017. Available from: http://www.euro.who.int/__data/assets/pdf_file/0005/355991/ Health-Profile-Netherlands-Eng.pdf?ua=1.

54) Keizer E, Maassen I, Smits M, Wensing M, Giesen P. Reducing the use of out-of-hours primary care services: A survey among Dutch general practitioners. The European journal of general practice. 2016;22(3):189-95.

55) Smits M. Medical necessity of face-to-face contacts at Dutch OOH GP cooperative. Presented at EurOOHnet Annual Meeting 2016, Bled, Slovenia, 26-27 May 2016. Accessed at: http://euroohnet.eu/docs/Presentatie\%20Marleen.pdf on 5 November 2019.

56) Mout P, Giesen P, Müskens R, Smits M. Meeste consulten op HAP medisch noodzakelijk [Most consultations at OHS-PC are medically necessary]. Med Contact. 2014;22:1102-4.

57) Healthcare Quality, Complaints and Disputes Act (WKKGZ), 2016.

58) Reason J. Human error. Cambridge University Press, 1990.

59) Vincent C, Taylor-Adams S, Stanhope N. Framework for analysing risk and safety in clinical medicine. BMJ. 1998;316(7138):1154-7.

60) Rutten MH, Kant J, Giesen P. What can we learn from calamities at out-of-hours services in primary care? [Wat kunnen we leren van calamiteiten op de huisartsenpost?]. Huisarts Wet. 2018;6(61).

61) Huibers L, Smits M, Renaud V, Giesen P, Wensing M. Safety of telephone triage in out-ofhours care: a systematic review. Scandinavian journal of primary health care. 2011;29(4):198209. 





Optimisation of telephone triage of callers with symptoms suggestive of acute cardiovascular disease in out of hours primary care: Observational design of the Safety First study

D.C. Erkelens*

L.T. Wouters*

D.L. Zwart

R.A. Damoiseaux

E. de Groot

A.W. Hoes

F.H. Rutten

*Shared first authorship

Published: BMJ Open 2019 


\section{Abstract}

Introduction: In the Netherlands, the "Netherlands Triage Standard" (NTS) is frequently used as digital decision support system for telephone triage at out-of-hours primary care services (OHS-PC). Aim of NTS is to guarantee accessible, efficient and safe care. However, there are indications that current triage is inefficient, with overestimation of urgency, notably in suspected acute cardiovascular disease. In addition, in primary care setting the NTS has only been validated against surrogate markers, and diagnostic accuracy with clinical outcomes as the reference is unknown. In the Safety First study, we address this gap in knowledge by describing, understanding and improving the diagnostic process and urgency allocation in callers with symptoms suggestive of acute cardiovascular disease, in order to improve both efficiency and safety of telephone triage in this domain.

Methods and analysis: An observational study in which 3,000 telephone triage recordings (period 2014-2016) will be analysed. Information is collected from the recordings including caller- and symptom characteristics and urgency allocation. The callers' own general practitioners are contacted for the final diagnosis of each contact. We included recordings of callers with symptoms suggestive of acute coronary syndrome (ACS) or transient ischemic attack (TIA)/stroke. With univariable and multivariable logistic regression analyses the diagnostic accuracy of caller- and symptom characteristics will be analysed in terms of predictive values with urgency level, and ACS and TIA/stroke as outcomes, respectively. To further improve our understanding of the triage process at OHS-PC, we will carry out additional studies applying both quantitative and qualitative methods; (i) case-control study on calamities, (ii) conversation analysis study, and (iii) interview study with triage nurses.

Ethics and dissemination: The Medical Ethics Committee of the University Medical Centre Utrecht, the Netherlands endorsed this study (National Trial Register identification: NTR7331). Results will be disseminated at scientific conferences, regional educational sessions, and publication in peer-reviewed journals.

\section{Strengths and limitations of this study:}

- We will assess the accuracy of the telephone triage in the OHS-PC setting in the domain of patients with symptoms suggestive of acute cardiovascular disease.

- We will apply the actual clinical outcome as the reference, not just 'expert opinion'.

- New insights retrieved by our 'holistic approach' will help improve both patient safety and efficiency.

- Use of routine care data and therefore missing data on some variables of interest.

- Routine care diagnoses and therefore the risk of missing some cases with an unrecognized acute cardiovascular disease. 


\section{Introduction}

Digital decision support systems for telephone triage are widely used, also in primary care out of hours settings. For these settings, telephone triage systems were derived from triage systems applied in emergency department (ED) settings. An important difference, however, is that telephone triage systems do not include items related to face-to-face contact and physical examination. (1) In the Netherlands, a digital decision support system for telephone triage called the "Netherlands Triage Standard" (NTS) was introduced in 2011. (2) The NTS was constructed by an expert panel using (i) the Dutch national telephone guidelines for office hours in family practice ('NHG triage index') and (ii) a modified version of the Manchester Triage System (MTS) developed in the ED setting. (3) Since its introduction in 2011, the NTS has been used by most out-of-hours services in primary care (OHS-PC), and by approximately half of the ambulance dispatch centres in the Netherlands. (4) An important argument for using the same system within the 'critical care chain' was that it would facilitate communication during care transitions, and potentially improve transitional safety. (5)

Many studies assessed the diagnostic accuracy of triage systems in the ED setting. (6-9) Yet, comparable studies on validity of telephone triage systems in primary care settings are limited. (5) The validity of the five-level triage system for physical triage in the ED setting was evaluated in a systematic review of 57 studies. (1) Various reference standards for the assessment of validity were used; researchers' own creation of a reference standard or combining severity with resource measures, e.g. hospital admissions. (1) Only one of the included studies in this review assessed the validity of the NTS, for both physical triage in the ED and for telephone triage in the OHS-PC. (5) For the assessment of telephone triage in OHS-PC, 6,668 patients were evaluated. Referrals to the ED and self-care advices were the two surrogate markers used as best proxies for adequate urgency allocation. Consequently, patients referred to the ED were considered as being correctly labelled as high urgency and those receiving a self-care advice as correctly low urgency, independent of the final diagnosis related to the episode. Not surprisingly, the researchers found an association between high urgencies and ED referrals and between low urgency level allocation by the triage nurse and self-care advices. Information on whether the urgency allocation was in line with the clinical outcomes is lacking. (5) There are no other studies available that assessed the validity of the NTS for telephone triage in the OHS-PC setting or validated the NTS to the final diagnosis instead of to surrogate markers. $(5,10)$ Our study addressess this current knowledge gap.

Over the last decade, out of hours primary care in the Netherlands has been reorganised from small practices into larger OHS-PC. (4) Patients primarily contact the OHS-PC when they need medical help outside office hours. In case of life-threatening symptoms, however, patients can also directly contact the emergency number of the ambulance dispatch centres or directly visit the ED. At the OHS-PC, triage nurses trained in using the 
NTS handle all incoming calls, under supervision of a general practitioner (GP). (4) The goal of this telephone triage is to identify callers with the most urgent need of care. (11) With urgent clinical situations in mind the experts formulated the NTS questions in a hierarchically ordered algorithm; questions focusing on the symptoms and circumstances considered most critical first, followed by questions about less critical symptoms. (2) The triage nurse fills out the caller's responses in the semi-automatic NTS system, which then automatically generates urgency allocations. Within the NTS six possible urgency levels can be distinguished that are linked to the response time within which a caller should receive medical help (see table 1). The urgency level generated by the NTS can be adjusted by the triage nurse if the nurse disagrees with the NTS allocation (upgrading or downgrading). (11) Most often such adjustments are preceded by consultation of the supervising GP, who has the final responsibility for the urgency level allocation.

Table 1. NTS levels of urgency

\begin{tabular}{llll} 
NTS Urgency level & Definition & Response time & Medical help \\
\hline U0 - Resuscitation & Loss of vital functions & Immediately & Ambulance \\
\hline U1 - Life threatening & $\begin{array}{l}\text { Unstable vital } \\
\text { functions }\end{array}$ & $\begin{array}{l}\text { As soon as possible, } \\
\text { within 15 minutes }\end{array}$ & Ambulance \\
\hline U2-Emergent & $\begin{array}{l}\text { Vital functions in } \\
\text { danger or organ } \\
\text { damage }\end{array}$ & Within 1 hour & $\begin{array}{l}\text { Home visit by GP } \\
\text { Or appointment at } \\
\text { OHS-PC }\end{array}$ \\
\hline U3- Urgent & $\begin{array}{l}\text { Possible risk of } \\
\text { damage, human } \\
\text { reasons }\end{array}$ & Within 3 hours & $\begin{array}{l}\text { Home visit by GP } \\
\text { or appointment at } \\
\text { OHS-PC }\end{array}$ \\
\hline U4- Non-urgent & Marginal risk of & Within 24 hours & $\begin{array}{l}\text { Appointment at } \\
\text { OHS-PC or telephone } \\
\end{array}$ \\
damage & & advice \\
\hline U5 - Advice & No risk of damage & Advice, not time & Telephone advice \\
& & related & \\
\hline
\end{tabular}

The aim of the NTS is to guarantee both efficient and safe care. Questions have been raised, however, about the current efficiency.(4) A national report showed an increase in high urgency allocations after the implementation of the NTS at the Dutch OHS-PC, notably U2 urgencies. (12) This is in contrast to the unchanged distribution of diseases, and suggests an increase of a more defensive triage strategy. In addition, a survey in 2016 among GPs revealed that the large majority (83.9\%) believed that telephone triage with NTS resulted in (i) many unnecessary consultations and home visits in patients with non-urgent problems, and (ii) a high workload at the OHS-PC. (13) The authors of this survey speculated that overconsumption of care at the OHS-PC was attributable to certain characteristics of the users of the NTS. (11) Previous studies on OHS-PC telephone triage in the United Kingdom described that the clinical background of triage nurses, the range of their experience, their gender and their attitudes to risk did not affect the triage decisions made. $(14,15)$ More insight in the users of the NTS (triage nurse) could help 
improve the system. Yet, it is currently unknown how triage nurses actually use the NTS in their clinical reasoning process and how this affects the performance of the triage system. Also, media coverage of (fatal) adverse events has grown, and adverse event reports and investigation by the Dutch Health and Youth Care Inspectorate have been made publically available. (16) The increasing attention for (fatal) adverse events might possibly be related to more defensive triage to avoid such (fatal) adverse events, which could potentially worsen efficiency. Thus, thorough research on the accuracy and use of the NTS is needed in order to assess whether improvements in the balance between efficiency and safety are required.

Callers with symptoms suggestive of acute cardiovascular diseases, e.g. acute coronary syndrome (ACS), or transient ischemic attack (TIA)/stroke generally receive high urgency allocations. (17) Chest pain is the most common reason for dispatching an ambulance (U1) with $60.7 \%$ of all ambulance rides deployed from the OHS-PC. (18) However, the incidence of ACS among patients experiencing chest discomfort in the Dutch primary care setting and referred to the hospital is low with around 10\%. (19-21) The trade-off between efficiency and patient safety of telephone triage is particularly challenging in these cases. On the one hand, prompt detection of ACS or TIA/stroke is crucial to initiate interventions as early as possible and prevent myocardial or brain necrosis, and improve prognosis. (22-24) On the other hand, overestimation of urgency results in unnecessary high workload, high referral rates, high costs, and potentially in iatrogenic damage of the caller. (25) The discussion about balancing efficiency and safety is especially complicated because missing an acute myocardial infarction is the most common reason for malpractice claims worldwide. (26-28)

Our ultimate goal is to improve the efficiency and safety of the triage of callers with symptoms suggestive of ACS or TIA/stroke who contact the OHS-PC, and to improve diagnosis. In the Safety First study we will evaluate real-life telephone triage recordings with corresponding urgency allocations, and patients' final clinical outcomes. Our research questions are (i) what is the diagnostic accuracy of the urgency allocation in callers with symptoms suggestive of ACS or TIA/stroke, (ii) which (clinical) determinants are predictive of an ACS or TIA/stroke diagnosis, and (iii) how is the NTS triage system used and how can it be improved in view of balancing efficiency and safety.

\section{Methods and analysis}

\section{Design}

An observational study in which telephone triage recordings from nine OHS-PC will be evaluated against the clinical outcomes. The researchers will listen to 3,000 real-life recordings, and collect information on the medical history (e.g. history of heart failure, hypertension, ACS, TIA/stroke, diabetes, etc.), caller and symptom characteristics (e.g. 
onset, duration and severity of symptom(s), additional symptoms (e.g. transpiration, nausea, vomiting, pale skin), pain score in case of chest discomfort, etc.) discussed between the caller and triage nurse during the telephone triage conversations. We will also collect call characteristics (i.e. time of calling, duration of the call, and who calls) and triage information such as the urgency allocation, available from the registered notes of the OHS-PC (i.e. notes from both triage nurses and the supervising GP). All information will be collected on an electronic case record form. Because there is no national Dutch database containing information about diagnoses, we will ask the callers' own GPs to provide the final diagnosis related to the OHS-PC contact, which is based on the patient's medical record, and includes medical specialist's and hospital discharge letters.

\section{Setting}

The foundation 'Primair Huisartsenposten' is a collaboration of six different OHS-PC locations in the central part of the Netherlands that provides out-of-hours primary care for approximately 1,5 million residents. It is one of the largest OHS-PC collaborations in the Netherlands and it covers both rural and urban areas. Every OHS-PC location has its own telephone triage centre.

\section{Data collection}

All telephone calls are routinely recorded and archived for training, quality control, and research purposes in a computer program called 'Callmanager' (i.e. electronic patient record of the OHS-PC). Archiving is based on the International Classification of Primary Care (ICPC) code. (29) ICPC codes allow for classification of symptoms and diagnoses in the electronic patient records. The standardisation of the coding facilitates (inter) national comparison of primary care diagnoses. At Dutch OHS-PC both triage nurses and GPs assign ICPC codes to patient contacts manually. The study sample will be derived retrospectively from all triage recordings in the years 2014 to 2016 and will contain calls linked to the ICPC codes reflecting our study domain: symptoms suggestive of ACS (i.e. K01, K02, K03, K24, K74, K75, K76, K77, K93, L04, P74, R02, R98) and symptoms suggestive of TIA/stroke (i.e. K89, K90, N17, N18, N19, N29, N89, N91). The distribution of sampling of ICPC codes within our study was based on the actual distribution of ICPC codes at the OHS-PC in 2014, and thus best reflects current practice. Per ICPC code a random sample will be taken.

\section{Inclusion and exclusion criteria}

Telephone triage recordings of callers of the OHS-PC with complaints that lead to suspicion of ACS or TIA/stroke will be included. The selection of recordings is based on (i) specific ICPC codes and (ii) a selection of keywords used in Callmanager (Figure 1). As the specific ICPC codes may not cover all eligible callers due to inter-rater variability as a result of ICPC coding by different triage nurses and GPs $(30,31)$, we choose to select cases not only on ICPC codes, but also on keywords in the free text, in order to include a broad but nevertheless clinically realistic' range of patients with possibly typical and 
less typical symptoms that could be considered to be caused by underlying ACS or TIA/ stroke. A major exclusion criterion is other recordings than triage conversations, e.g. calls between colleagues. All exclusion criteria are displayed in table 2.

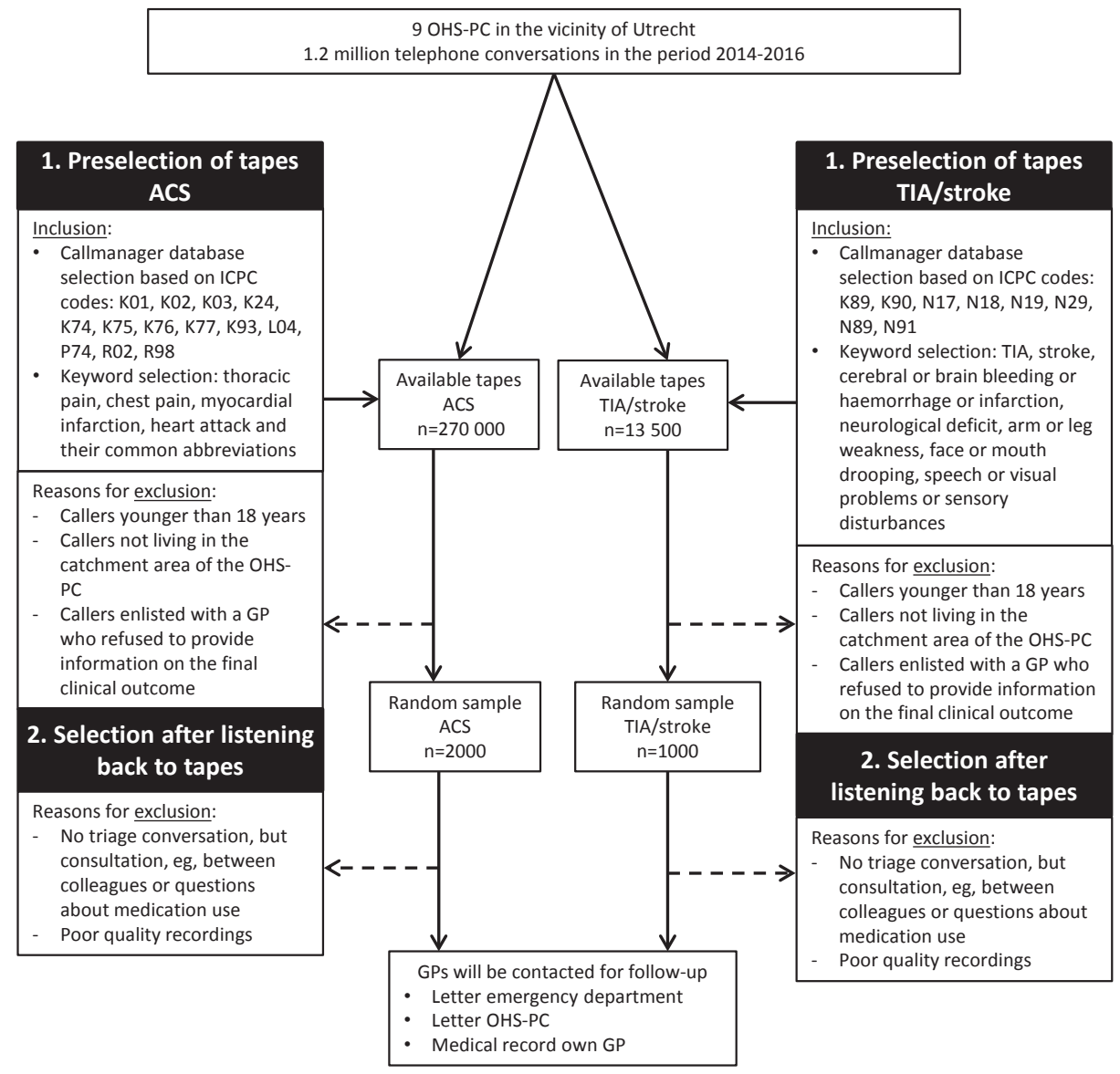

Figure 1. Flowchart of the Safety First study 
Table 2. Inclusion and exclusion criteria for participation in the Safety First study

\begin{tabular}{ll} 
Inclusion criteria & Exclusion criteria \\
\hline Recordings of triage conversations of callers with & No triage conversation, but consultation \\
symptoms suggestive of ACS based on (i) the between colleagues or questions about \\
following ICPC codes in 'Callmanager': K01, K02, medication use \\
K03, K24, K74, K75, K76, K77, K93, L04, P74, R02, Poor quality recordings \\
R98; and (ii) key word selection: thoracic pain, \\
chest pain, myocardial infarction, heart attack and \\
their commonger than 18 years \\
\hline Recordings of triage conversations of callers with Callers enlisted with a GP who refused to \\
symptoms suggestive of TIA or stroke based on provide information on the final clinical \\
(i) the following ICPC codes in 'Callmanager': outcome \\
K89, K90, N17, N18, N19, N29, N89, N91; and \\
(ii) key word selection: TIA, stroke, cerebral or \\
brain bleeding or haemorrhage or infarction, \\
neurological deficit, arm or leg weakness, face \\
or mouth drooping, speech or visual problems or \\
sensory disturbances.
\end{tabular}

\section{Data analysis}

(i) The diagnostic accuracy of the urgency allocation on two separate outcomes: ACS, or TIA/stroke, will be calculated in terms of sensitivity, specificity, positive and negative predictive values. In addition, we will perform sensitivity analyses; a) also considering other emergency cases with chest discomfort, e.g. pulmonary embolism, acute heart failure, and thoracic aortic dissection, or in the domain symptoms suggestive of TIA/stroke; b) other emergency cases with neurological symptoms, e.g. subarachnoidal haemorrhage (SAH), epilepsy.

(ii) Multivariable logistic regression analysis will be applied to identify history items or caller characteristics that independently predict either ACS or TIA/ stroke. In addition, multivariable models will be developed that predict the presence of respectively ACS, or TIA/stroke, and the C-statistic with the 95\% confidence interval will be calculated after bootstrapping to correct for overoptimism. (32) Before multivariable analysis, multiple imputation techniques will be applied for missing values. Variables with more than $50 \%$ missings will not be considered. Variable selection will be based on literature review (known diagnostic predictors in both domains) and on univariable analysis (inclusion of variables with $p<0.15$. Special attention will be paid to gender and age, either as interaction term or by calculating gender and/or age-specific prediction models. All data analyses will be performed using SPSS statistical software program version 25.0. 


\section{Blinding of researchers}

All researchers listening to the recordings, and filling out the electronic case record forms or who are otherwise involved in the Safety First study, e.g. the expert panel of one of our additional studies, will be blinded to the callers' clinical outcomes.

\section{Power calculation}

For the power calculation we used the recommendations that apply to diagnostic studies. (21) Records of 2014-2016 were used and after application of the exclusion criteria two random samples of 2,000 recordings with 'symptoms suggestive of ACS' and 1,000 recordings with 'symptoms suggestive of TIA/stroke' will be drawn. A prior pilot study showed that 1 out of 9 callers symptoms suggestive of ACS is, after diagnostic workup, diagnosed with ACS and 1 out of 2 callers symptoms suggestive for TIA-stroke is diagnosed with TIA or stroke. Based on Harrell's rule of thumb, for ACS 2,000 audiotapes allow for the analysis of 22 variables and for TIA-stroke 1,000 audio tapes allow for the analysis of 50 diagnostic items. We speculated that more variables would be needed to evaluate suspected TIA/stroke cases than patients in the domain 'suspicion of ACS' because the former patients may present themselves with a larger variety of symptoms. (33)

\section{Additional studies}

We explicitly chose to describe the observational cross-sectional study in more detail and not the other three studies because it is the largest study within the Safety First project, and for readability. As part of the Safety First project, three additional but smaller studies will be carried out to further expand the knowledge about the triage process at OHS-PC.

\section{(i) A case-control study on calamities}

A calamity is defined as an adverse event with serious permanent patient harm or death as a consequence. (34) By Dutch law, root cause analysis (RCA) of every single calamity is required. RCA often points at flaws in the triage process as root causes for such calamities (35), resulting in an array of improvement measures for daily practice. However, it is unknown whether cases that result in a calamity really differ from those not evolving into a calamity, as all only have been evaluated as individual cases by experts knowing they evaluated a calamity and their assessment is thus prone to hindsight bias. $(36,37)$ In the OHS-PC setting calamities are very rare $(0.006 \%)$ and the majority is of cardiovascular origin, e.g. missed acute myocardial infarction (AMI). (35) The aim of this additional study is to provide a more thorough view on missed or too late diagnosed AMls that resulted in calamities by comparing these cases with matched controls in the domain of callers with chest pain, either due to ACS or not. The main question is whether the calamity cases actually differ from controls with respect to call and patient characteristics. For this additional study we will collect new data (calamity cases) and use data from the larger observational study described earlier for sampling our controls. 
Archived triage conversations from the period January 2013 - December 2017 of the calamity cases (defined as a missed diagnosis of AMI) will be compared with triage conversations of controls not meeting the calamity definition but also contacting the OHS-PC with symptoms suggestive of ACS. Per calamity case 8 controls will be matched to the case according to age, gender and symptom presentation. A researcher blinded to the outcome will extract information regarding call characteristics, caller and symptom characteristics (including medical history) and urgency allocation, by re-listening the archived triage calls and by using the registered information. All data will be inserted in a database. An expert panel of experienced GPs blinded to the final outcome (calamity or no calamity), thus without case specific hindsight bias, will evaluate the quality and safety of triage conversations, and the diagnostic accuracy (sensitivity, specificity, predictive values) of safe triage handling according to the expert panel will be calculated against the final outcome (calamity or no calamity).

\section{(ii) Conversation analysis study}

In this additional study we will assess how conversation aspects may affect the urgency allocation during telephone triage. The ways in which obligatory NTS questions and other questions are formulated by the triage nurse (i.e. suggestive questions), and responded to by the conversation partner may provide more thorough insight into question-answer sequences at the OHS-PC that can be helpful to improve the (use of) the NTS. We will transcribe a sample of the conversations from the case-control study following the Jefferson conventions. These transcripts that can be considered as new data will then be qualitatively analysed with established conversation analysis techniques. (38-40) We will specifically focus on either/or questions and their various formats (e.g. two-choice, multiple choice, open-ended or tag format) in the urgency decision phase of the triage calls.

(iii) Interview study with triage nurses

Finally, we will perform a qualitative interview study of triage nurses with the aim to gain more knowledge on triage nurses' reasoning during telephone triage of callers with symptoms suggestive of ACS or TIA/stroke, and how they use the NTS for decision making in these two domains. We will conduct semi-structured audio-stimulated recall interviews. (41) Per interview one or two recordings from a recent shift at the OHS-PC will be used to stimulate triage nurses' reflections. The interviews will be transcribed and the transcripts will be qualitatively analysed according to the principles of the grounded theory approach. (42)

\section{Patient and public involvement}

Patients were not directly involved in the design of this study, but representatives participate in the stakeholders meetings every 6 months together with other representatives, i.e. of the local and national OHS-PC organization and the Dutch Health 
and Youth Care Inspectorate. They provide crucial input that helps us with formulating additional, clinically relevant research questions.

\section{Ethics and dissemination}

The Medical Ethics Committee of the University Medical Centre Utrecht, the Netherlands endorsed this study (National Trial Register (NTR) identification number: NTR7331). All personal data, as well as all research data were stored anonymized according to the European General Data Protection Regulation. Data collection started in January 2016 and will last until December 2020. Communications and publications on the results will not enable identification of individual callers. Results will be disseminated to relevant primary care communities in peer-reviewed journals, and at scientific conferences. In addition, this research project will also result in two PhD theses.

\section{Discussion}

The Safety First study will provide diagnostic accuracy data on ACS and TIA/stroke in the primary care setting. The efficiency and safety of the NTS in the out-of-hours primary care setting will be evaluated for callers with symptoms suggestive of ACS or TIA/stroke. In a case-control study we will explore calamities (missed acute myocardial infarctions) and assess whether they differ from controls (other patients with symptoms suggestive of ACS but not fulfilling the calamity criteria) with respect to call and patient characteristics. With qualitative studies we will generate more thorough knowledge on how triage nurses work and how the NTS is used.

\section{Efficiency and patient safety}

A systematic review about patient safety in the OHS-PC setting concluded that $10 \%$ of all OHS-PC calls could be considered as 'unsafe'. (43) However, the claim of 'unsafe' calls was based on surrogate markers, and not on patients' clinical outcomes, and clearly contrasts with the very low incidence of calamities (0.006\%). (35) By using the patients' final clinical outcomes as the reference, the Safety First study will address an important knowledge gap on diagnostic accuracy of telephone triage. In addition, our study will provide a more complete view on the patient safety of the NTS than can be achieved with root cause analysis of individual cases only, often resulting in the conclusion that the urgency level is underestimated. $(35,44)$ It is difficult to define when telephone triage at the OHS-PC is safe. Our case-control study will provide deeper knowledge on telephone conversations that resulted in calamities and their matched controls. This knowledge might put the general view on (i) analysing calamities, and (ii) the weight that is assigned to improvement measures in a different perspective. 


\section{Users of the NTS}

A questionnaire among Dutch GPs working at the OHS-PCs reported that a majority of GPs (83.9\%) believe that nowadays telephone triage contributes to overconsumption of care at OHS-PC. About $85 \%$ of responders consider this to be at least partly attributable to the level of experience and education, and the attitude and personality of the triage nurses. (13) As the performance of the NTS is inextricably linked to its users, we want to include conversation analysis and interview studies with triage nurses. The quality of telephone triage is highly dependent on the quality of communication between the triage nurse and the caller, and therefore the communication skills of triage nurses. $(27,45)$ Moreover, they have to deal with callers who greatly vary in their ability to communicate effectively and coherently. $(46,47)$ Additionally, the telephone triage is necessarily only based on oral information provided by the caller, lacking any visual cues or diagnostic information from physical examination. Our additional study on conversation analysis will add knowledge on the ways in which questions and answers are formulated by triage nurses and callers, and how this affects the triage conversation.

Secondly, we will also focus on the obligatory question structure within the NTS, and how this affects the users. The NTS is a semi-automatic support system that is heavily dependent on the input of the triage nurses themselves; which 'main presenting problem' he/she chooses is based on the initial information from the caller, and each of the in total 57 'presenting problems' are linked to a separate algorithm of hierarchically organized, pre-specified questions. These questions need to be filled out before the NTS generates an urgency allocation. (48) Previous studies suggested that triage nurses may experience interactional dilemmas while working with a computer decision support. (49) Our interview study will provide more insight into triage nurses' clinical reasoning process during telephone triage, and how they use the NTS for decision making within the domains of callers with symptoms suggestive of ACS or TIA/stroke. This information can help improve the workability of NTS in daily practice. Furthermore, in these domains the knowledge that 'time is muscle' or 'time is brain' puts extra strain on the triage nurse, because unnecessary delays directly affect morbidity and mortality of patients who actually show to have ACS or TIA/stroke. $(22,23)$ Beside this stress factor, other factors such as shiftwork, fatigue, multitasking and understaffing can attribute to the risk of errors during the triage process. (27) In our interview study we want to include these risk factors, and their possible influence on the reasoning process of triage nurses.

\section{Conclusion}

Our Safety First study will provide diagnostic accuracy data on ACS and TIA/stroke, and new insights on efficiency, patient safety and the use of the NTS by triage nurses during telephone triage of callers with symptoms suggestive of ACS or TIA/stroke at the OHS- 
PC. Results from our study will help to improve the telephone triage in these important domains and improve both efficiency and safety for callers.

\section{List of abbreviations}

ACS: Acute Coronary Syndrome; AMI: Acute Myocardial Infarction; ED: Emergency Department; TIA: Transient Ischemic Attack; GP: General Practitioner; NTS: Netherlands Triage Standard, OHS-PC: Out-Of-Hours Services in Primary Care.

\section{Declarations}

\section{Competing interests}

The authors declare that they have no competing interests.

\section{Funding}

This work was supported by the department of general practice of the University Medical Centre Utrecht, Associate Professorship-promotion grant of D.L. Zwart, MD, PhD, the foundation 'Netherlands Triage Standard' and the foundation 'StoffelsHornstra'. The views expressed are those of the authors and not necessarily those of the foundations. This research was conducted without direct involvement from both funding foundations.

\section{Authors' contributions}

DLZ and FHR conceived the idea for the study and gained funding. DLZ, FHR, RAD, EDG and AWH designed the study. LTW and DCE prepared the manuscript and wrote the first draft, supervised by FHR. DLZ, FHR, RAD, EDG and AWH provided intellectual input and critically reviewed the manuscript. All authors read and approved the final manuscript.

\section{Acknowledgements}

The authors thank the OHS-PC foundation 'Primair Huisartsenposten' and all employees of the participating locations for their cooperation in this study, notably for providing data and technical support. 


\section{References}

1) Kuriyama A, Urushidani S, Nakayama T. Five-level emergency triage systems: variation in assessment of validity. Emergency medicine journal : EMJ. 2017;34(11):703-10.

2) Netherlands Triage Standard [Nederlandse Triage Standaard], 2019. Accessed at www. de-nts.nl on 7 October 2019.

3) National guidelines for telephone triage and advice in Family Practice [cited 2018 June 22]. Available from: https://www.nhg.org/winkel/producten/nhg-triagewijzer-versie-2016.

4) Smits M, Rutten M, Keizer E, Wensing M, Westert G, Giesen P. The Development and Performance of After-Hours Primary Care in the Netherlands: A Narrative Review. Annals of internal medicine. 2017;166(10):737-42.

5) van lerland $Y$, van Veen $M$, Huibers $L$, Giesen $P$, Moll HA. Validity of telephone and physical triage in emergency care: the Netherlands Triage System. Family practice. 2011;28(3):33441.

6) Nishi F, de Oliveira Motta Maia F, de Souza Santos I, de Almeida Lopes Monteiro da Cruz D. Assessing sensitivity and specificity of the Manchester Triage System in the evaluation of acute coronary syndrome in adult patients in emergency care: a systematic review. JBI Database of Systematic Reviews and Implementation Reports. 2017;15(6):1747-61.

7) Steiner D, Renetseder F, Kutz A, Haubitz S, Faessler L, Anderson JB, et al. Performance of the Manchester Triage System in Adult Medical Emergency Patients: A Prospective Cohort Study. J Emerg Med. 2016;50(4):678-89.

8) Grouse Al, Bishop RO, Bannon AM. The Manchester Triage System provides good reliability in an Australian emergency department. Emergency medicine journal : EMJ. 2009;26(7):484-6.

9) Jimenez JG, Murray MJ, Beveridge R, Pons JP, Cortes EA, Garrigos JB, et al. Implementation of the Canadian Emergency Department Triage and Acuity Scale (CTAS) in the Principality of Andorra: Can triage parameters serve as emergency department quality indicators? CJEM. 2003;5(5):315-22.

10) Lake R, Georgiou A, Li J, Li L, Byrne M, Robinson M, et al. The quality, safety and governance of telephone triage and advice services - an overview of evidence from systematic reviews. BMC health services research. 2017;17(1):614.

11) Blank L, Coster J, O'Cathain A, Knowles E, Tosh J, Turner J, et al. The appropriateness of, and compliance with, telephone triage decisions: a systematic review and narrative synthesis. J Adv Nurs. 2012;68(12):2610-21.

12) Jansen $T$, de Hoon $S$, Hek K, Verheij R. Developments at the out-of-hours services in primary care. Changes in care demand and health care issues in 2013-2015. [Ontwikkelingen op de huisartsenpost. Veranderingen in zorgvraag en gezondheidsproblemen in 2013-2015.]. NIVEL, 2017.

13) Keizer E, Maassen I, Smits M, Wensing M, Giesen P. Reducing the use of out-of-hours primary care services: A survey among Dutch general practitioners. The European journal of general practice. 2016;22(3):189-95.

14) O'Cathain A, Munro J, Armstrong I, O'Donnell C, Heaney D. The effect of attitude to risk on decisions made by nurses using computerised decision support software in telephone clinical assessment: an observational study. BMC Med Inform Decis Mak. 2007;7:39.

15) O'Cathain A, Nicholl J, Sampson F, Walters S, McDonnell A, Munro J. Do different types of nurses give different triage decisions in NHS Direct? A mixed methods study. J Health Serv Res Policy. 2004;9(4):226-33. 
16) Dutch Health and Youth Care Inspectorate, IGJ. Learning from incident reports in openness. Learn and improve, working together on further improvement of quality of care. [In openheid leren van meldingen. Leren en verbeteren, samen werken aan verdere verbetering van kwaliteit van zorg.]. Dutch Ministry of Health, Welfare and Sport; 2016.

17) Smits $M$, Verheij R. Changes in urgency of contacts with the out-of-hours services in primary care 2013-2016. [Veranderingen in de urgentie van contacten met de huisartsenpost 20132016.]. NIVEL, 2017.

18) Plat FM, Peters YAS, Loots FJ, de Groot CJA, Eckhardt T, Keizer E, et al. Ambulance dispatch versus general practitioner home visit for highly urgent out-of-hours primary care. Family practice. 2017(Dec 20).

19) Hoorweg BB, Willemsen RT, Cleef LE, Boogaerts T, Buntinx F, Glatz JF, et al. Frequency of chest pain in primary care, diagnostic tests performed and final diagnoses. Heart. 2017;103(21):1727-32.

20) Wibring K, Herlitz J, Christensson L, Lingman M, Bang A. Prehospital factors associated with an acute life-threatening condition in non-traumatic chest pain patients - A systematic review. International journal of cardiology. 2016;219:373-9.

21) Rawshani A, Larsson A, Gelang C, Lindqvist J, Gellerstedt M, Bang A, et al. Characteristics and outcome among patients who dial for the EMS due to chest pain. International journal of cardiology. 2014;176(3):859-65.

22) Bosner S, Haasenritter J, Becker A, Karatolios K, Vaucher P, Gencer B, et al. Ruling out coronary artery disease in primary care: development and validation of a simple prediction rule. CMAJ : Canadian Medical Association journal = journal de l'Association medicale canadienne. 2010;182(12):1295-300.

23) Berglund A, von Euler M, Schenck-Gustafsson K, Castren M, Bohm K. Identification of stroke during the emergency call: a descriptive study of callers' presentation of stroke. BMJ open. 2015;5(4):e007661.

24) Leathley MJ, Jones SP, Gibson JM, Ford GA, McAdam JJ, Quinn T, et al. "Can you send an ambulance please?": a comparison of callers' requests for emergency medical dispatch in non-stroke and stroke calls. Emergency medicine journal : EMJ. 2014;31(e1):e25-8.

25) Coster JE, Turner JK, Bradbury D, Cantrell A. Why Do People Choose Emergency and Urgent Care Services? A Rapid Review Utilizing a Systematic Literature Search and Narrative Synthesis. Acad Emerg Med. 2017;24(9):1137-49.

26) Ernesater A, Winblad U, Engstrom M, Holmstrom IK. Malpractice claims regarding calls to Swedish telephone advice nursing: what went wrong and why? J Telemed Telecare. 2012;18(7):379-83.

27) Roing M, Holmstrom IK. Malpractice claims in Swedish telenursing: lessons learned from interviews with telenurses and managers. Nurs Res. 2015;64(1):35-43.

28) Katz HP, Kaltsounis $D$, Halloran L, Mondor M. Patient safety and telephone medicine : some lessons from closed claim case review. J Gen Intern Med. 2008;23(5):517-22.

29) The Dutch College of General Practitioners, NHG. The International Classification of Primary Care (ICPC). Version 6 (Dutch translation derived from ICPC-1 by the WONCA International Classification Committee). 2018. Available from: https://www.nhg.org/themas/artikelen/ icpc.

30) Zwaanswijk M, Hek K. ICPC coding at the out-of-hours service in primary care [ICPC-codering op de huisartsenpost]. Huisarts Wet. 2013;56(11). 
31) Rosendal M, Carlsen A, Rask M, Moth G. Symptoms as the main problem in primary care: A cross-sectional study of frequency and characteristics. Scandinavian journal of primary health care. 2015;33(2):91-9.

32) Efron BT, R. An introduction to the bootstrap. Monographs on statistics and applied probability. New York: Chapman \& Hall; 1993.

33) Harrell FE, Jr., Lee KL, Califf RM, Pryor DB, Rosati RA. Regression modelling strategies for improved prognostic prediction. Stat Med. 1984;3(2):143-52.

34) Healthcare Quality, Complaints and Disputes Act (WKKGZ), 2016.

35) Rutten MH, Kant J, Giesen P. What can we learn from calamities at out-of-hours services in primary care? [Wat kunnen we leren van calamiteiten op de huisartsenpost?]. Huisarts Wet. 2018;6(61).

36) Henriksen K, Kaplan H. Hindsight bias, outcome knowledge and adaptive learning. Qual Saf Health Care. 2003;12 Suppl 2:ii46-50.

37) Zwaan L, Monteiro S, Sherbino J, Ilgen J, Howey B, Norman G. Is bias in the eye of the beholder? A vignette study to assess recognition of cognitive biases in clinical case workups. BMJ Qual Saf. 2017;26(2):104-10.

38) Jefferson G. A technique for inviting laughter and its subsequent acceptance/declination. . In: Psathas G, editor. Everyday language: Studies in ethnomethodology. New York, London: Irvington; 1979. p. 79-96.

39) Jefferson G. On a failed hypothesis: conjunctionals as overlap-vulnerable. In: Brabant KU, editor. Tilburg papers in language and literature. Tilburg1983. p. 1-33.

40) Jefferson G. Notes on a possible metric which provides for a 'standard maximum' silence of approximately one second in conversation. In: Brabant KU, editor. Tilburg papers in language and literature. Tilburg1983. p. 1-83.

41) Dempsey N. Stimulated recall interviews in ethnography. Qualitative sociology. 2010;33(3):349-67.

42) Kolb SM. Grounded theory and the constant comparative method: valid research strategies for educators. Journal of Emerging Trends in Educational Research and Policy Studies. 2012;3:83-6.

43) Huibers L, Smits M, Renaud V, Giesen P, Wensing M. Safety of telephone triage in out-ofhours care: a systematic review. Scandinavian journal of primary health care. 2011;29(4):198209.

44) Annual reports of 2014 and 2015. [Jaarverslagen 2014 en 2015.]. Utrecht, The Netherlands: Foundation Primair out-of-hours services in primary care [Stichting Primair Huisartsenposten]

45) Holmstrom I. Decision aid software programs in telenursing: not used as intended? Experiences of Swedish telenurses. Nurs Health Sci. 2007;9(1):23-8.

46) Pettinari CJ, Jessopp L. "Your ears become your eyes": managing the absence of visibility in NHS Direct. J Adv Nurs. 2001;36(5):668-75.

47) Roing $M$, Rosenqvist $U$, Holmstrom IK. Threats to patient safety in telenursing as revealed in Swedish telenurses' reflections on their dialogues. Scand J Caring Sci. 2013;27(4):969-76.

48) Smits M, Keizer E, Ram P, Giesen P. Development and testing of the KERNset: an instrument to assess the quality of telephone triage in out-of-hours primary care services. BMC health services research. 2017;17(1):798.

49) Murdoch J, Barnes R, Pooler J, Lattimer V, Fletcher E, Campbell JL. The impact of using computer decision-support software in primary care nurse-led telephone triage: interactional dilemmas and conversational consequences. Soc Sci Med. 2015;126:36-47. 


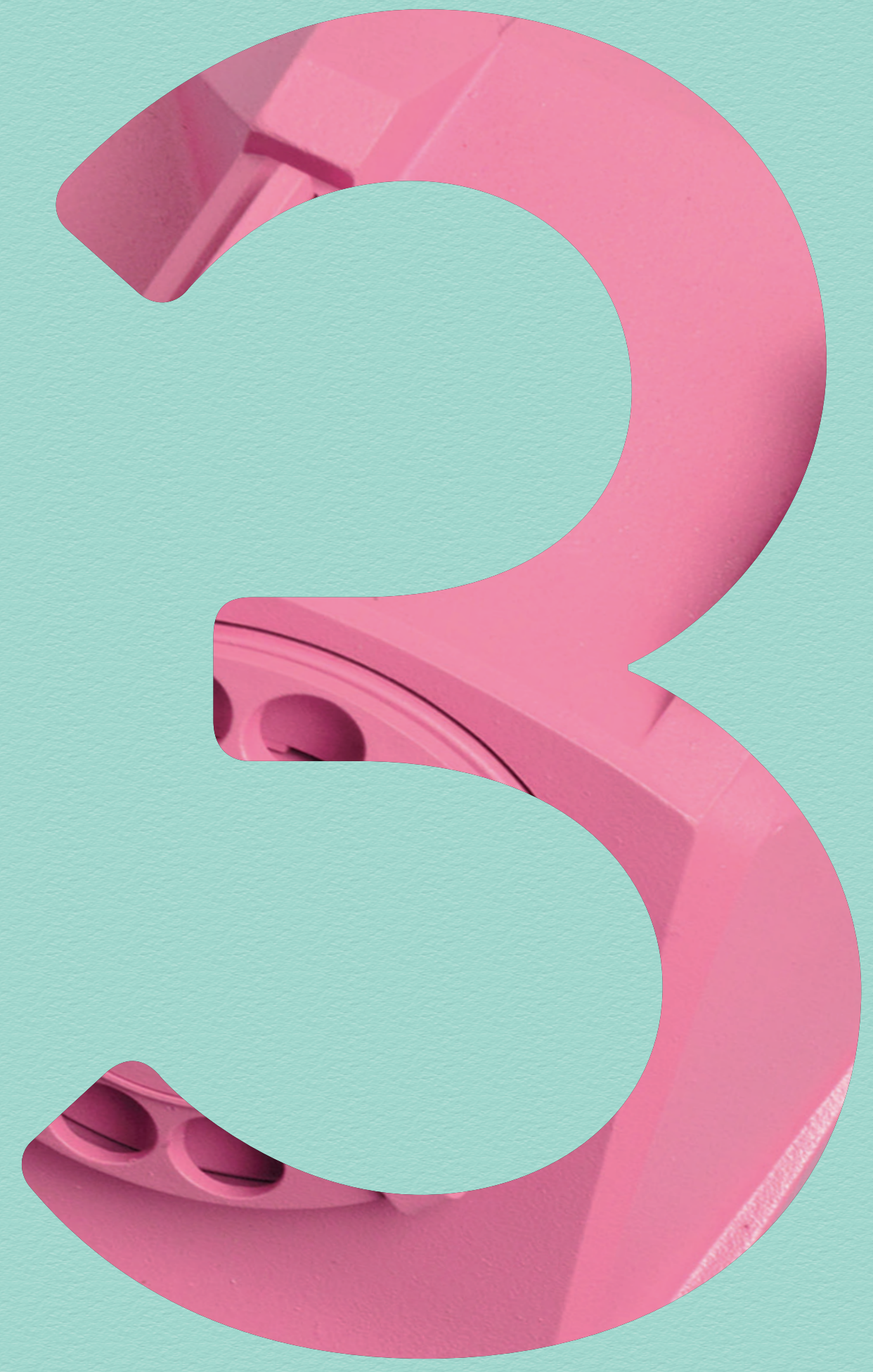


Accuracy of telephone triage in suspected transient ischaemic

attack or stroke: A cross-sectional study

D.C. Erkelens

F.H. Rutten

L.T. Wouters

L.S. Dolmans

E. de Groot

R.A. Damoiseaux

D.L. Zwart

Submitted 


\section{Abstract}

Background: The Netherlands Triage Standard (NTS) is a widely used decision support tool for telephone triage at Dutch out-of-hours primary care services (OHS-PC), which, however, has never been validated against clinical outcomes. We aimed to determine the accuracy of the NTS urgency allocation for patients with neurological symptoms suggestive of a transient ischaemic attack (TIA) or stroke, with the clinical outcomes TIA, stroke, and other (neurologic) life-threatening events (LTES) as the reference.

Methods: A cross-sectional study of telephone triage recordings of patients with neurological symptoms calling the OHS-PC between 2014 and 2016.The allocated NTS urgencies were derived from the electronic medical records of the OHS-PC. The clinical outcomes were retrieved from the electronic medical records of the patients' own general practitioners. The accuracy of a high NTS urgency allocation (medical help within three hours) was calculated in terms of sensitivity, specificity, positive and negative predictive values (PPV and NPV) with the clinical outcomes TIA/stroke/other LTEs as the reference.

Results: Of 1,269 patients, 635 (50.0\%) received the diagnosis TIA/stroke (34.2\% TIA/ minor stroke, $15.8 \%$ major ischaemic or haemorrhagic stroke), and $4.8 \%$ other LTEs. For TIA/stroke/other LTEs, the sensitivity and specificity of the NTS urgency allocation were $0.72(95 \% \mathrm{Cl} 0.68-0.75)$ and $0.48(95 \% \mathrm{Cl} 0.43-0.52)$, and the PPV and NPV were 0.62 (95\% Cl 0.60-0.64) and $0.58(95 \% \mathrm{Cl} 0.54-0.62)$.

Conclusions: The NTS decision support tool used in Dutch OHS-PC performed poor to moderately regarding safety (sensitivity) and efficiency (specificity) in allocating adequate urgencies to patients with and without TIA/stroke/other LTES. 


\section{Introduction}

Prompt recognition of patients with a transient ischaemic attack (TIA) or ischaemic stroke is crucial for timely initiation of therapeutic interventions to minimise the risk of (permanent) brain injury and recurrent stroke.(1-6) Previous studies showed that urgent diagnostic assessment of TIA and minor stroke patients followed by a timely start of stroke preventive treatment resulted in a tremendous decrease of the early stroke risk $(1,5,7)$ with a reduction of recurrent stroke up to $80 \%$ within three months. (1) However, the detection of TIA, and to a lesser extent stroke, may be challenging because multiple other diseases like migraine with aura, seizures or syncope can mimic TIA or stroke.(8-10) Moreover, symptoms may be non-specific in TIA or stroke, notably vertebrobasilar insufficiency, and in the case of TIA, symptoms are often short lasting and already resolved by the time a patient seeks medical help. $(8,11)$

Patients with symptoms suggestive of TIA or stroke often contact the general practitioner (GP) first.(12-15) During evenings, nights and weekends such care is provided by the out-of-hours services in primary care (OHS-PC). At the OHS-PC, the initial contact is by telephone, and nurses perform triage while supervised by GPs.(16) The goal of telephone triage is to assess the severity of patients' complaints and to link this to an adequate urgency allocation with corresponding response time to medical care. Telephone triage in the Netherlands is supported by a semi-automatic decision support tool called the 'Netherlands Triage Standard' (NTS). The NTS is a five-level triage tool, which was developed by an expert panel and derived from existing Dutch national telephone guidelines for primary care office hours, and the Manchester Triage System (MTS).(17, 18) Based on the annual incidence of $0.006 \%$ of serious adverse events (SAEs) in the Dutch OHS-PC setting, the NTS is considered to be safe (19). However, questions have been raised about the efficiency.(16) There was a clear increase in high urgency allocations since the implementation of the NTS in 2011 onwards, suggesting a low efficiency.(20) This was supported by the results of a national survey among GPs in 2016, showing that the vast majority believed telephone triage with the NTS resulted in unnecessary consultations and home visits.(16, 21)

Most previous studies assessed the overall accuracy of triage decision support tools in emergency department (ED) settings, and to a lesser extent at the OHS-PC. $(22,23)$ Few studies focused on specific domains of patients (e.g. chest pain), some of which included clinical outcomes as the reference (e.g. acute coronary syndrome), yet, only in ED settings.(24-31) Comparable accuracy studies in primary care settings are limited; one study that assessed the overall accuracy of a telephone triage tool in primary care used a 'surrogate' reference created by the researchers themselves (e.g. hospital referrals or costs).(18, 22, 32-34) The NTS urgency allocation, or the urgency allocation of other decision support tools for telephone triage in primary care settings, were never evaluated against the final clinical outcomes of patients as the reference. 
We aimed to determine the accuracy of the NTS urgency allocation in patients calling the OHS-PC with symptoms suggestive of TIA or stroke, with presence or absence of the final clinical outcomes TIA, stroke and other (neurologic) life-threatening events (LTES) as the reference.

\section{Methods}

\section{Design and setting}

We conducted a cross-sectional study in which we analysed real-life telephone triage recordings of nine OHS-PC locations in the vicinity of Utrecht, the Netherlands between 2014-2016. These OHS-PCs provide out-of-hours primary care for approximately 1,5 million people, handling 400,000 triage calls per year.

\section{Data collection}

We evaluated patients with symptoms suggestive of TIA or stroke. The accuracy of NTS urgency allocation was assessed with the final clinical outcomes as the reference, that is, TIA, stroke and other (neurologic) life-threatening events (LTEs), e.g. subarachnoid haemorrhage. The triage recordings were selected in a two-step inclusion procedure, i.e. (i) selection based on the International Classification of Primary Care (ICPC) codes that are linked to the call and reflected our study domain (i.e. K89, K90, N17, N18, N19, N29, N89, N91), and (ii) keywords in the OHS-PC electronic medical records suggesting TIA/stroke (e.g. neurological deficit, arm or leg weakness, face drooping, communication problem, visual problems, sensory disturbances and common synonyms).(35) A detailed description of the ICPC codes, medical keywords, inclusion and exclusion criteria has been published elsewhere.(36) We selected and re-listened a random sample of 2,209 calls. Patient and call characteristics, and assigned NTS urgencies were collected. From the patients' own GPs we retrieved the final diagnosis, which was based on the discharge letter from the neurologist or the ED if the patient was referred for additional investigations. For patients who were not referred to the hospital we used follow-up data from the electronic medical records of GPs for up to one month to capture possible recurrence of TIA/stroke.

\section{NTS urgency allocation in day-to-day practice}

Telephone triage with the NTS starts with a mandatory 'ABCD' check (i.e. airway, breathing, circulation, disability). In case of direct life-threatening situations, an ambulance will be sent immediately.(37) If there is no life-threatening situation, the triage nurse continues by choosing one out of the 56 main complaints within the NTS. Every main complaint consists of an algorithm composed of hierarchically ordered questions. (18). One of these 56 main complaints is 'neurological deficit'. After filling out the patient's responses, the NTS will automatically generate an urgency level ranging from U0 to U5 which is linked to the response time within which a patient should receive medical help 
(see Table 1).(18, 38) The NTS urgency may be scaled up or down by the triage nurse, often after first consulting the supervising GP.(21) The reason for overruling should be registered, but this is not a mandatory step to complete the NTS triage process.

Table 1. NTS levels of urgency

\begin{tabular}{|c|c|c|c|}
\hline NTS Urgency level & Definition & Response time & Medical help \\
\hline UO - Resuscitation & Loss of vital functions & Immediately & Ambulance \\
\hline U1 - Life threatening & $\begin{array}{l}\text { Unstable vital } \\
\text { functions }\end{array}$ & $\begin{array}{l}\text { As soon as possible, } \\
\text { within } 15 \text { minutes }\end{array}$ & Ambulance \\
\hline U2 - Emergent & $\begin{array}{l}\text { Vital functions in } \\
\text { danger or organ } \\
\text { damage }\end{array}$ & Within 1 hour & $\begin{array}{l}\text { Home visit by GP } \\
\text { or appointment at } \\
\text { OHS-PC }\end{array}$ \\
\hline U3 - Urgent & $\begin{array}{l}\text { Possible risk of } \\
\text { damage, human } \\
\text { reasons }\end{array}$ & Within 3 hours & $\begin{array}{l}\text { Home visit by GP } \\
\text { or appointment at } \\
\text { OHS-PC }\end{array}$ \\
\hline U4-Non-urgent & $\begin{array}{l}\text { Marginal risk of } \\
\text { damage }\end{array}$ & Within 24 hours & $\begin{array}{l}\text { Appointment at } \\
\text { OHS-PC or telephone } \\
\text { advice }\end{array}$ \\
\hline U5-Advice & No risk of damage & $\begin{array}{l}\text { Advice, not time } \\
\text { related }\end{array}$ & Telephone advice \\
\hline
\end{tabular}

\section{Difference between NTS urgency and final urgency}

Besides the NTS urgency, which is automatically generated, we also evaluated the final urgency, which was defined as either the NTS urgency (if not changed) or the overruled NTS urgency. In around $20 \%$ of all triage calls, the final urgency was unclear after relistening the recordings in which it was evident that the triage nurse overruled the NTS urgency. This because the triage nurse did not notify the actual allocated urgency after overruling the NTS; e.g. the NTS urgency was U3, but in the audio recording the triage nurse tells the caller "I will sent an ambulance immediately" (U1)). Nevertheless, the urgency in the NTS system remained U3. A panel of three experienced GPs assessed calls in which the final urgency was unclear, blinded to the final diagnosis, and determined the final urgency (unanimously, or majority of votes after group discussion).

\section{Data analyses}

The patients were dichotomised into a high (U1 and U2) and low (U3, U4 and U5) urgency group, and differences in characteristics between these groups were compared. We calculated the accuracy in terms of sensitivity, specificity, positive and negative predictive values of (i) the NTS urgency allocation and (ii) the final urgency allocation (including overruled NTS urgencies), with the clinical outcomes TIA/stroke/LTEs as the reference. For the accuracy calculations we considered for TIA/minor stroke case the urgencies U1, $\mathrm{U} 2$ and U3 as adequate, and for major stroke and other LTEs the urgencies U1 and U2. Finally, we compared the baseline characteristics of patients in whom we could retrieve 
the final diagnosis with those in whom we could not, to assess potential selection bias. Statistical analyses were performed using SPSS version 25.0 (IBM Corp., Armonk, NY, USA).

\section{Results}

\section{Group characteristics}

We included 1,269 patients of whom a final diagnosis could be obtained (see Figure 1). The median age was 72.0 (IQR 57.0-83.0) years, and $56.9 \%$ were female. The NTS allocation of high (U1 and U2) and low (U3, U4 and U5) urgencies was equally distributed between men and women (see Table 2). The characteristics of patients with a known final diagnosis were comparable with those for whom the GP did not provide the final diagnosis (see Supplementary Data Table S1).

\section{Final diagnoses}

In 434 (34.2\%) patients the final diagnosis was a TIA or minor stroke, and in 201 (15.8\%) a major stroke. Sixty-one (4.8\%) patients had other LTEs, i.e. intracerebral haemorrhage or subarachnoid haemorrhage. The remaining 573 patients (45.2\%) were diagnosed with other neurological disorders (e.g. migraine, epilepsy) or other disorders (e.g. peripheral vestibular syndromes or psychogenic syndromes). See Table 3 for a complete overview of final diagnoses.

\section{Final urgency allocation}

Of all 1,269 patients, 770 (60.7\%) received a high NTS urgency (U1 or U2) and 499 (39.3\%) a low NTS urgency (U3, U4 or U5). In 728 (57.4\%) patients the NTS urgency was equal to the final urgency. In the remaining 541 (42.6\%) patients the NTS urgency was overruled, of which in 364 (67.3\%) patients the NTS urgency was scaled up by the triage nurse, and in 177 (32.7\%) patients it was scaled down (see Figure 2 and for details Supplementary Data Tables S2-S5). 


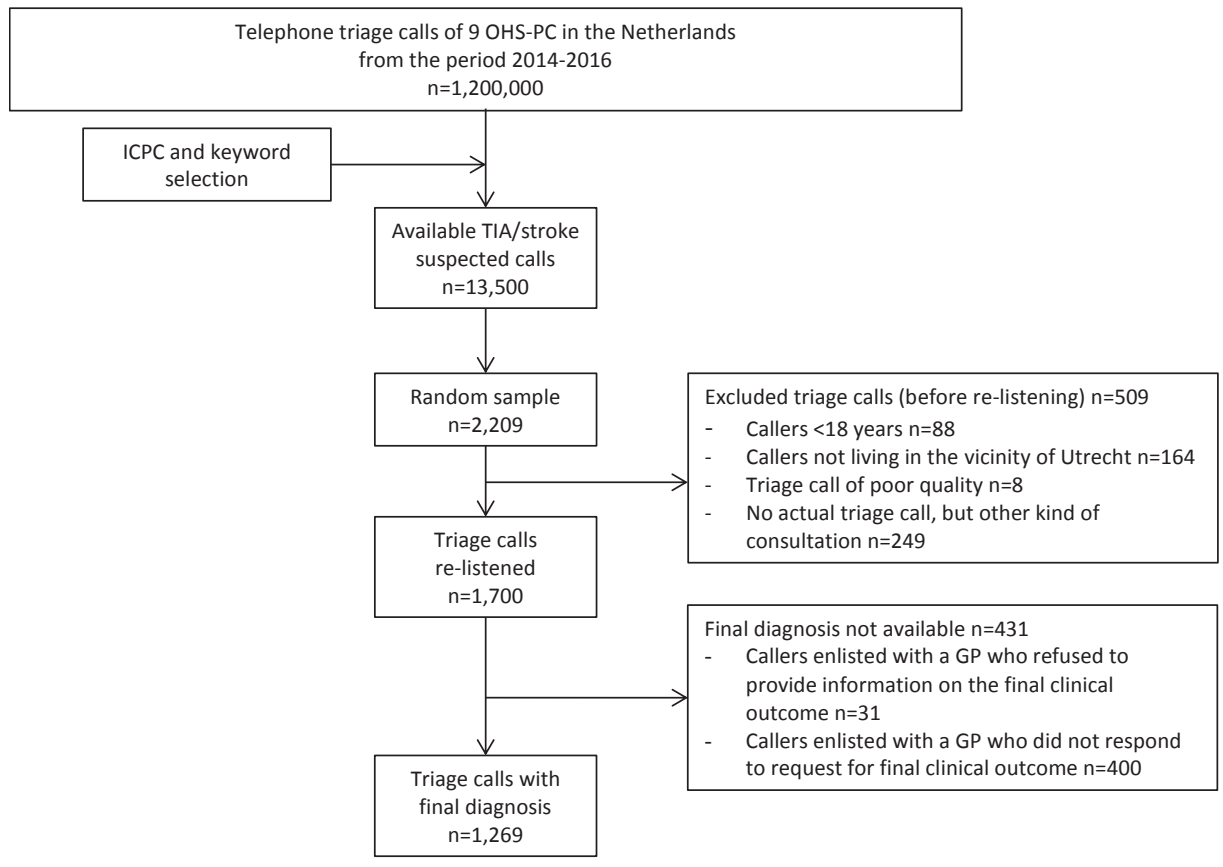

Figure 1. Flowchart study population

Compared to the low NTS urgency group, patients in the high NTS urgency group were older (73.5 vs. 69.0 years, $p<0.001)$. Also, the call duration of patients in the high urgency group was shorter (06:32 min vs. 07:59 min, $p<0.001)$, and more often someone else called on behalf of the patient $(80.6 \% \mathrm{vs} .68 .5 \%, \mathrm{p}<0.001)$ in comparison to the low NTS urgency group. In nearly all calls concern about the symptoms was expressed $(90.3 \%$ vs $96.1 \%, p=0.006)$, and in the vast majority, symptoms were still present at the time of calling (93.4\% vs. 89.9\%, $p=0.030)$. Patients classified as high urgent more often had face drooping ( $54.3 \%$ vs. $39.1 \%$, $p<0.001$ ), arm weakness ( $51.0 \%$ vs. $28.1 \%$, $p<0.001$ ), leg weakness $(49.0 \%$ vs. $35 \%, p<0.001)$, and communication problems in general $(80.8 \%$ vs. $72.5 \%, p=0.008)$, whereas patients classified as low urgent more often reported sweating (36.7\% vs. $56.3 \%, p=0.006)$. 
Table 2. Characteristics of 1,269 patients with symptoms suggestive of TIA or stroke calling the OHS-PC

\begin{tabular}{|c|c|c|c|}
\hline & $\begin{array}{l}\text { High NTS urgency } \\
\mathrm{n}=770(60.7 \%)\end{array}$ & $\begin{array}{l}\text { Low NTS urgency } \\
\mathrm{n}=499(39.3 \%)\end{array}$ & P-value \\
\hline \multicolumn{4}{|l|}{ Patient characteristics } \\
\hline Median age in years (IQR) & $73.5(59.0-84.0)$ & $69.0(55.0-82.0)$ & $<0.001$ \\
\hline Female sex & $441(57.3)$ & $281(56.3)$ & 0.736 \\
\hline Family history of CVD $(n=36)$ & $14(82.4)$ & $13(68.4)$ & $0.451^{\&}$ \\
\hline \multicolumn{4}{|l|}{ Medical history } \\
\hline Cardiovascular disease $(n=882)$ & $421(79.1)$ & $259(74.0)$ & 0.076 \\
\hline TIA $(n=637)$ & $116(29.7)$ & $60(24.4)$ & 0.147 \\
\hline Stroke $(n=637)$ & $113(28.9)$ & $60(24.4)$ & 0.213 \\
\hline Coronary artery disease $(n=303)$ & $36(20.6)$ & $18(14.1)$ & 0.144 \\
\hline Arrhythmia $(n=292)$ & $32(19.5)$ & $25(19.5)$ & 0.997 \\
\hline Valvular heart disease $(n=260)$ & $16(10.9)$ & $9(8.0)$ & 0.429 \\
\hline Heart failure $(n=263)$ & $14(9.5)$ & $10(8.7)$ & 0.831 \\
\hline Epilepsy $(n=233)$ & $15(11.6)$ & $9(8.7)$ & 0.458 \\
\hline Migraine $(n=102)$ & $17(27.0)$ & $14(35.9)$ & 0.342 \\
\hline Cardiovascular risk factors & $14(9.5)$ & $10(8.7)$ & 0.831 \\
\hline Hypertension $(n=421)$ & $121(50.2)$ & $85(47.2)$ & 0.544 \\
\hline $\begin{array}{l}\text { Hypercholesterolemia or use of statins } \\
(n=395)\end{array}$ & $95(43.0)$ & $75(43.1)$ & 0.981 \\
\hline Diabetes mellitus $(n=417)$ & $87(36.7)$ & $63(35.0)$ & 0.719 \\
\hline \multicolumn{4}{|l|}{ Cardiovascular medication } \\
\hline Antithrombotics ( $n=939)$ & $290(48.7)$ & $149(43.4)$ & 0.123 \\
\hline $\begin{array}{l}\text { Other cardiovascular medication } \\
(\mathrm{n}=764)\end{array}$ & $253(57.55)$ & $178(54.9)$ & 0.480 \\
\hline
\end{tabular}

\section{Call characteristics}

\begin{tabular}{|c|c|c|c|}
\hline Median call duration in min:sec (IQR) & $06: 32(04: 43-08: 54)$ & 07:59 (05:54-10:50) & $<0.001$ \\
\hline $\begin{array}{l}\text { Median time for caller's introduction in } \\
\text { min:sec (IQR) }\end{array}$ & $\begin{array}{l}00: 19 \\
(00: 12-00: 27)\end{array}$ & $\begin{array}{l}00: 20 \\
(00: 13-00: 29)\end{array}$ & 0.189 \\
\hline $\begin{array}{l}\text { Initial call by someone else than the } \\
\text { patient }\end{array}$ & $621(80.6)$ & $342(68.5)$ & $<0.001$ \\
\hline $\begin{array}{l}\text { Triage nurse consulted the general } \\
\text { practitioner }\end{array}$ & $449(58.3)$ & $305(61.1)$ & 0.319 \\
\hline
\end{tabular}

\section{Main NTS complaint chosen by triage nurse}

\begin{tabular}{llll}
\hline Neurological deficit & $587(76.2)$ & $220(44.1)$ & $<0.001$ \\
\hline Dizziness & $21(2.7)$ & $87(17.4)$ & $<0.001$ \\
\hline Headache & $23(3.0)$ & $28(5.6)$ & 0.020 \\
\hline Odd behavior & $21(2.7)$ & $18(3.6)$ & 0.375 \\
\hline Syncope & $20(2.6)$ & $9(1.8)$ & 0.355 \\
\hline Vision problem & $2(0.3)$ & $25(5.0)$ & $<0.001^{\&}$ \\
\hline Leg or arm problem & $11(1.4)$ & $34(6.8)$ & $<0.001$
\end{tabular}


Table 2. Continued.

\begin{tabular}{|c|c|c|c|}
\hline & $\begin{array}{l}\text { High NTS urgency } \\
n=770(60.7 \%)\end{array}$ & $\begin{array}{l}\text { Low NTS urgency } \\
n=499(39.3 \%)\end{array}$ & P-value \\
\hline Other ${ }^{\wedge}$ & $85(11.0)$ & $78(15.6)$ & 0.017 \\
\hline \multicolumn{4}{|l|}{ Symptoms mentioned during the call } \\
\hline $\begin{array}{l}\text { Decreased or loss of consciousness } \\
(n=1103)\end{array}$ & $49(7.4)$ & $21(4.8)$ & 0.081 \\
\hline Face drooping $(n=713)$ & $258(54.3)$ & $93(39.1)$ & $<0.001$ \\
\hline Arm weakness $(n=772)$ & $254(51.0)$ & $77(28.1)$ & $<0.001$ \\
\hline Leg weakness $(n=653)$ & $201(49.0)$ & $85(35.0)$ & $<0.001$ \\
\hline Sensory disturbances $(n=375)$ & $192(89.7)$ & $150(93.2)$ & 0.243 \\
\hline $\begin{array}{l}\text { Communication problem in general } \\
(n=769)\end{array}$ & $413(80.8)$ & $187(72.5)$ & 0.008 \\
\hline Dysarthria $(n=416)$ & $181(65.1)$ & $76(55.1)$ & 0.047 \\
\hline Dysphasia $(n=419)$ & $163(59.1)$ & $72(50.3)$ & 0.089 \\
\hline Vision problem in general $(n=184)$ & $68(78.2)$ & $82(84.5)$ & 0.266 \\
\hline Blurry vision $(n=74)$ & $27(77.1)$ & $27(69.2)$ & 0.444 \\
\hline Diplopia $(n=74)$ & $14(63.6)$ & $23(44.2)$ & 0.127 \\
\hline Reduced vision $(n=62)$ & $15(53.6)$ & $22(64.7)$ & 0.374 \\
\hline Headache $(n=497)$ & $147(57.0)$ & $140(58.6)$ & 0.718 \\
\hline $\begin{array}{l}\text { Loss of balance/motor coordination } \\
\text { (ataxia) }(n=236)\end{array}$ & $130(86.1)$ & $66(77.6)$ & 0.097 \\
\hline Dizziness ( $n=312)$ & $120(82.2)$ & $143(86.1)$ & 0.338 \\
\hline Seizure $(n=11)$ & $4(66.7)$ & $3(60.0)$ & $0.819^{\&}$ \\
\hline Short term memory loss ( $n=68)$ & $33(76.7)$ & $21(84.0)$ & 0.476 \\
\hline Shortness of breath $(n=403)$ & $62(24.4)$ & $25(16.8)$ & 0.072 \\
\hline \multicolumn{4}{|c|}{ Autonomic nervous system associated symptoms } \\
\hline Sweating $(n=208)$ & $47(36.7)$ & $45(56.3)$ & 0.006 \\
\hline Nausea or vomiting $(n=311)$ & $84(61.8)$ & $94(53.7)$ & 0.155 \\
\hline Pallor $(n=255)$ & $54(32.7)$ & $27(30.0)$ & 0.655 \\
\hline Ashen skin ( $n=198)$ & $18(14.1)$ & $12(17.1)$ & 0.563 \\
\hline (Feeling of nearly) fainting ( $n=1103$ ) & $57(8.6)$ & $41(9.3)$ & 0.680 \\
\hline \multicolumn{4}{|l|}{ Course of symptoms } \\
\hline \multicolumn{4}{|l|}{ Onset of symptoms: } \\
\hline Per acute (seconds) $(n=211)$ & $52(44.1)$ & $56(60.2)$ & 0.020 \\
\hline Acute (minutes) $(n=211)$ & $46(39.0)$ & $23(24.7)$ & 0.028 \\
\hline Gradually (hours) (n=211) & $20(16.9)$ & $14(15.1)$ & 0.710 \\
\hline $\begin{array}{l}\text { Duration of symptoms } \leq 4.5 \text { hours } \\
(n=986)\end{array}$ & $381(61.4)$ & $203(55.6)$ & 0.077 \\
\hline $\begin{array}{l}\text { Symptoms still present at time of } \\
\text { calling }(n=1254)\end{array}$ & $716(93.4)$ & $438(89.9)$ & 0.030 \\
\hline \multicolumn{4}{|l|}{ Other characteristics } \\
\hline Caller expresses concern $(n=628)$ & $334(90.3)$ & $248(96.1)$ & 0.006 \\
\hline
\end{tabular}


Table 2. Continued.

\begin{tabular}{llll} 
& $\begin{array}{l}\text { High NTS urgency } \\
\mathbf{n}=\mathbf{7 7 0}(\mathbf{6 0 . 7 \% )}\end{array}$ & $\begin{array}{l}\text { Low NTS urgency } \\
\mathbf{n = 4 9 9}(\mathbf{3 9 . 3} \%)\end{array}$ & P-value $^{\#}$ \\
\hline $\begin{array}{l}\text { Patient never experienced similar } \\
\text { symptoms before }(\mathrm{n}=368)\end{array}$ & $104(49.8)$ & $68(42.8)$ & 0.183 \\
\hline Recognition of symptoms: & & & \\
\hline TIA $(\mathrm{n}=368)$ & $40(19.1)$ & $26(16.4)$ & 0.490 \\
\hline Stroke $(\mathrm{n}=368)$ & $25(12.0)$ & $16(10.1)$ & 0.566 \\
\hline
\end{tabular}

Legend: NTS: Netherlands Triage Standard; IQR: interquartile range; CVD: cardiovascular disease; TIA: transient ischaemic attack. ${ }^{*}$ Concerns all cardiovascular medication with the exception of antithrombotics; "Pearson Chi Square Test for categorical variables and Mann-Whitney U Test for not normally distributed continuous variables; ' Fisher's Exact Test for categorical variables; 'Amongst others: vomiting, dyspnea, neck symptoms, insult, disability problems ('D from $\left.A B C D^{\prime}\right)$.

Table 3. Final diagnoses of 1,269 patients who called the OHS-PC for symptoms suggestive of TIA/stroke

\begin{tabular}{llll} 
& $\begin{array}{l}\text { High NTS urgency } \\
\mathbf{n = 7 7 0}(\mathbf{6 0 . 7 \% )}\end{array}$ & $\begin{array}{l}\text { Low NTS urgency } \\
\mathbf{n = 4 9 9}(\mathbf{3 9 . 3} \%)\end{array}$ & P-value \\
\hline TIA/minor stroke & $276(35.8)$ & $158(31.7)$ & 0.125 \\
\hline Major stroke* & $149(10.4)$ & $52(19.4)$ & $<0.001$ \\
\hline Other life threatening events (LTEs)** & $45(5.8)$ & $16(3.2)$ & 0.032 \\
Intracerebral haemorrhage & $17(37.8)$ & $5(31.3)$ & 0.640 \\
Subarachnoid haemorrhage & $0(0.0)$ & $2(12.5)$ & $0.066^{\wedge}$ \\
\hline Migraine & $21(2.7)$ & $21(4.2)$ & 0.150 \\
With aura & $9(42.9)$ & $7(33.3)$ & 0.525 \\
\hline Epilepsy & $17(2.2)$ & $6(1.2)$ & 0.190 \\
\hline Syncope & $18(2.3)$ & $12(2.4)$ & 0.939 \\
\hline Brain tumor & $13(1.7)$ & $2(0.4)$ & $0.059^{\wedge}$ \\
\hline Peripheral vestibular syndromes & $22(2.9)$ & $42(8.4)$ & $<0.001$ \\
Benign paroxysmal positional vertigo & $10(45.5)$ & $11(26.2)$ & 0.119 \\
Meniere disease & $1(4.5)$ & $1(2.4)$ & $0.999^{\wedge}$ \\
Vestibular neuritis & $0(0.0)$ & $5(11.9)$ & $0.155^{\wedge}$ \\
\hline Peripheral nerve problem & $75(9.7)$ & $47(9.4)$ & 0.850 \\
Bell's palsy & $22(29.3)$ & $13(27.7)$ & 0.842 \\
Facial nerve palsy other than Bell's palsy & $53(70.7)$ & $34(72.3)$ & 0.842 \\
\hline Psychogenic syndromes & $27(3.5)$ & $26(5.2)$ & 0.138 \\
\hline Other non-urgent diagnoses*** & $107(13.9)$ & $117(23.4)$ & $<0.001$ \\
\hline
\end{tabular}

Legend: *Including lacunar infarction and stroke not otherwise specified; **Amongst others sepsis, acute coronary syndrome, meningitis, herpes encephalitis, coma, severe anemia due to gastrointestinal bleeding, hypoglycaemia, acute pulmonary embolism; *** Amongst others guillain barre, multiple sclerosis, alcohol intoxication; ^Fisher's Exact Test. 


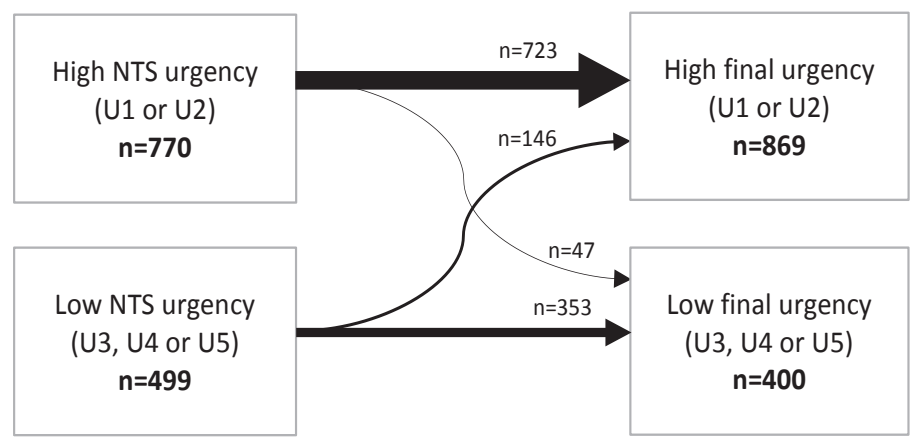

Figure 2. NTS urgency adjustments of 1,269 patients with symptoms suggestive of TIA/minor stroke.

Legend: This Figure does not show differences within the high and low urgency groups, for the differences within all urgency groups (U1-U5) see Supplementary Data Table S2.

\section{Accuracy of the NTS urgency and TIA/stroke, or TIA/stroke/other LTEs as the reference}

The sensitivity of the NTS for allocating a high urgency to patients with TIA/stroke was 0.71 (95\% Cl 0.68-0.75), and for patients with TIA/stroke/other LTEs 0.72 (0.68-0.75). The specificity was $0.46(0.42-0.50)$ and $0.48(0.43-0.52)$, respectively. The positive and negative predictive values were $0.41(0.38-0.43)$ and $0.75(0.72-0.78)$ for TIA/stroke, and 0.62 (0.60-0.64) and 0.58 (0.54-0.62) for TIA/stroke/other LTEs, respectively.

\section{Accuracy of the final urgency (including overruling) and TIA/stroke, or TIA/stroke/other LTEs as the reference}

The sensitivity of the final urgency allocation for allocating a high urgency to patients with TIA/stroke was 0.86 (0.84-0.89), and for TIA/stroke/other LTEs 0.86 (0.83-0.89). The specificity was $0.38(0.34-0.42)$ and $0.40(0.36-0.44)$, respectively. The positive and negative predictive values for TIA/stroke were $0.42(0.40-0.44)$ and 0.84 (0.810.87), respectively, and for TIA/stroke/other LTEs 0.63 (0.62-0.65) and 0.70 (0.66-0.74), respectively. See also Table 4. 
Table 4. Accuracy of adequate NTS urgency and final urgency allocation for detecting TIA/stroke/ other LTEs

\begin{tabular}{|c|c|c|c|}
\hline & & $\begin{array}{l}\text { Adequate } \\
\text { NTS urgency } \\
\text { allocation*** } \\
\text { Value }(95 \% \mathrm{Cl})\end{array}$ & $\begin{array}{l}\text { Adequate } \\
\text { final urgency } \\
\text { allocation*** } \\
\text { Value }(95 \% \mathrm{Cl})\end{array}$ \\
\hline \multirow[t]{4}{*}{ TIA/stroke* } & Sensitivity & $0.71(0.68-0.75)$ & $0.86(0.84-0.89)$ \\
\hline & Specificity & $0.46(0.42-0.50)$ & $0.38(0.34-0.42)$ \\
\hline & Positive predictive value & $0.41(0.38-0.43)$ & $0.42(0.40-0.44)$ \\
\hline & Negative predictive value & $0.75(0.72-0.78)$ & $0.84(0.81-0.87)$ \\
\hline \multirow[t]{4}{*}{ Other LTEs** } & Sensitivity & $0.74(0.61-0.84)$ & $0.82(0.70-0.91)$ \\
\hline & Specificity & $0.40(0.37-0.43)$ & $0.32(0.30-0.35)$ \\
\hline & Positive predictive value & $0.06(0.05-0.07)$ & $0.06(0.05-0.06)$ \\
\hline & Negative predictive value & $0.97(0.95-0.98)$ & $0.97(0.95-0.98)$ \\
\hline \multirow[t]{4}{*}{ TIA/stroke and other LTEs } & Sensitivity & $0.72(0.68-0.75)$ & $0.86(0.83-0.89)$ \\
\hline & Specificity & $0.48(0.43-0.52)$ & $0.40(0.36-0.44)$ \\
\hline & Positive predictive value & $0.62(0.60-0.64)$ & $0.63(0.62-0.65)$ \\
\hline & Negative predictive value & $0.58(0.54-0.62)$ & $0.70(0.66-0.74)$ \\
\hline
\end{tabular}

Legend: *Prevalence TIA/minor stroke $34.2 \%$ and prevalence major stroke 15.8\%; **Prevalence other LTEs 4.8\%; ***For TIA/minor stroke urgencies U1, U2 and U3 were all considered adequate, for major stroke and other LTEs urgencies U1 and U2 were considered adequate.

\section{Discussion}

\section{Summary}

Of 1,269 patients suspected of TIA/stroke, 635 (50.0\%) showed to have a TIA or stroke; 434 (34.2\%) had a TIA or minor stroke, 201 (15.8\%) a major ischaemic or haemorrhagic stroke. In addition, 61 (4.8\%) patients had other (neurologic) LTEs. The urgency allocation of the NTS tool was poor to moderate regarding sensitivity and specificity with TIA/ stroke/other LTES as the reference. In $42.6 \%$ the NTS urgency was overruled by the triage nurse. The final urgency allocation (including overruled NTS urgencies) showed modestly improved sensitivity (safety) whereas the specificity remained equally poor (efficiency). The positive predictive value did not change after overruling of the NTS, but the negative predictive value increased. This suggests that overruling by the triage nurses leads to safer telephone triage without compromising efficiency (i.e. overlapping confidence intervals of the NTS and final urgencies' specificities).

\section{Strengths and limitations}

This is the first study to report accuracy findings of the NTS tool for telephone triage at the OHS-PC with clinical outcomes as the reference. Because researchers were blinded 
to the final clinical outcome during data collection, the effect of hindsight bias was limited.

A limitation was missing data on the final clinical outcome (25\% of all re-listened recordings). However, a detailed comparison in patient characteristics between those with a final outcome and those without showed that these groups were comparable (no indication of selection bias). Therefore, we believe our results are generalizable to similar OHS-PC settings.

\section{Comparison with existing literature}

As described previously, many studies assessed the accuracy of other triage systems (22), and some of these also used clinical outcomes as the reference.(24-31) One study assessed the Manchester Triage System (MTS) in the domain of patients suspected for neurological disease seen at the ED.(32) The accuracy of a high urgency allocation was calculated with neurological disease (not otherwise specified) as the reference; a c-statistic of 0.73 was reported. High MTS urgency allocation was significantly associated with neurological disease (odds ratio 3.0, 95\%Cl 2.4-3.8, p<0.001).(32) Unfortunately, sensitivity or specificity was not calculated. Comparison to our study is also hampered, because in the primary care setting the prevalence of emergent cerebrovascular events is lower, and on average includes less severe cases. This may be reflected in less evident clinical presentations.

In our study, we considered different urgency levels as adequate; for TIA/minor stroke U1-U3, and for major stroke/other LTEs U1-U2. The rationale for high urgency allocations in suspected stroke patients is mainly because of available treatment options, and not because TIA/stroke may result in ABCD instability (i.e. airway, breathing, circulation, disability). Assigning high urgency levels to patients with acute stroke enables early initiation of (invasive) prognostically beneficial treatment.(39-41) In patients with TIA/ minor stroke early initiation of antiplatelets for secondary stroke prevention is key, given the substantial risk of major stroke in the first hours to days after a TIA $(5,6,42)$. Current treatment guidelines on TIA/stroke recommend that patients suspected of TIA should be seen within 24 hours after symptom onset at a TIA outpatient clinic for a neurological assessment, while secondary stroke prevention should be started as soon as possible after a confirmed diagnosis of TIA/minor stroke $(43,44)$ or directly if the patient cannot be assessed by a neurologist the same day.(45) Therefore, we considered U3 (patient seen within three hours) as sufficient in patients who finally showed to have had a TIA/ minor stroke.

\section{Implications for research and/or practice}

Our study indicated that the accuracy of the NTS was poor to moderate, yet safety improved after overruling by the triage nurse. Apparently, triage nurses and/or their GP supervisors capture some vital patient information that is not yet incorporated in the 
NTS. Further improvement of safety, as well as improving efficiency of telephone triage in the domain of patients calling with neurological symptoms is necessary. Improving the accuracy of already existing triage systems such as the NTS should be the first step. In order to do so, prediction models are needed based on multivariable analyses to provide an evidence-based basis for which triage questions are helpful, and which are not.

\section{Conclusions}

The NTS decision support tool used in Dutch OHS-PC performed poor to moderately regarding safety (sensitivity) and efficiency (specificity) in allocating adequate urgencies to patients with and without TIA/stroke/other LTEs. There are indications that overruling the NTS by triage nurses improves safety, without compromising efficiency.

\section{List of abbreviations}

GP: General Practitioner; LTE: Life-Threatening Events; NTS: Netherlands Triage Standard; OHS-PC: Out-Of-Hours Services in Primary Care; TIA: Transient Ischaemic Attack.

\section{Declarations}

\section{Ethics approval and consent to participate}

The Medical Ethics Review Committee Utrecht, the Netherlands approved this study (National Trial Register identification number: NTR7331, reference number WAG/ $\mathrm{mb} / 16 / 003208)$. In addition, a waiver of informed consent was granted as our study involved minimal risk to subjects and this study would not have been practicable without the waiver. All personal and research data were handled and stored according to the European General Data Protection Regulation.

\section{Consent for publication}

Not applicable as all personal and research data were made unidentifiable 


\section{Competing interests}

The authors declare that they have no competing interests.

\section{Funding}

This work was supported by (i) the department of general practice of the University Medical Center Utrecht, (ii) Associate Professorship-promotion grant of D.L. Zwart, MD, PhD, (iii) the foundation 'Netherlands Triage Standard' and (iv) the 'Stoffels-Hornstra' foundation. The views expressed are those of the authors and not necessarily those of the foundations. This research was conducted without direct involvement from both funding foundations.

\section{Authors' contributions}

DLZ and FHR conceived the idea for the study and gained funding. All authors designed the study. DCE and LTW collected the data, and DCE analysed the data. DCE prepared the manuscript and wrote the first draft, supervised by DLZ. All authors provided intellectual input, critically reviewed the manuscript and read and approved the final manuscript.

\section{Acknowledgements}

The authors thank the OHS-PC foundation 'Primair Huisartsenposten' and all employees of the participating locations for their cooperation in this study, notably for providing data and technical support. 


\section{References}

1) Rothwell PM, Giles MF, Chandratheva A, et al. Effect of urgent treatment of transient ischaemic attack and minor stroke on early recurrent stroke (EXPRESS study): a prospective population-based sequential comparison. Lancet. 2007;370(9596):1432-42.

2) Kidwell CS, Warach $S$. Acute ischemic cerebrovascular syndrome: diagnostic criteria. Stroke. 2003;34(12):2995-8.

3) Coull AJ, Lovett JK, Rothwell PM, Oxford Vascular S. Population based study of early risk of stroke after transient ischaemic attack or minor stroke: implications for public education and organisation of services. BMJ. 2004;328(7435):326.

4) Johnston SC, Gress DR, Browner WS, Sidney S. Short-term prognosis after emergency department diagnosis of TIA. Jama. 2000;284(22):2901-6.

5) Rothwell PM, Algra A, Chen Z, et al. Effects of aspirin on risk and severity of early recurrent stroke after transient ischaemic attack and ischaemic stroke: time-course analysis of randomised trials. Lancet. 2016;388(10042):365-75.

6) Wu CM, McLaughlin K, Lorenzetti DL, et al. Early risk of stroke after transient ischemic attack: a systematic review and meta-analysis. Archives of internal medicine. 2007;167(22):2417-22.

7) Lavallee $P C$, Meseguer $E, A b b o u d ~ H$, et al. A transient ischaemic attack clinic with roundthe-clock access (SOS-TIA): feasibility and effects. Lancet Neurol. 2007;6(11):953-60.

8) Nadarajan V, Perry RJ, Johnson J, Werring DJ. Transient ischaemic attacks: mimics and chameleons. Pract Neurol. 2014;14(1):23-31.

9) Hand PJ, Kwan J, Lindley RI, et al. Distinguishing between stroke and mimic at the bedside: the brain attack study. Stroke. 2006;37(3):769-75.

10) Ay H, Buonanno FS, Rordorf G, et al. Normal diffusion-weighted MRI during stroke-like deficits. Neurology. 1999;52(9):1784-92.

11) Sheehan OC, Merwick A, Kelly LA, et al. Diagnostic usefulness of the ABCD2 score to distinguish transient ischemic attack and minor ischemic stroke from noncerebrovascular events: the North Dublin TIA Study. Stroke. 2009;40(11):3449-54.

12) Doggen $C J$, Zwerink M, Droste HM, et al. Prehospital paths and hospital arrival time of patients with acute coronary syndrome or stroke, a prospective observational study. BMC Emerg Med. 2016;16:3.

13) Manawadu D, Shuaib A, Collas DM. Emergency department or general practitioner following transient ischaemic attack? A comparison of patient behaviour and speed of assessment in England and Canada. Emergency medicine journal : EMJ. 2010;27(5):364-7.

14) Giles MF, Flossman E, Rothwell PM. Patient behavior immediately after transient ischemic attack according to clinical characteristics, perception of the event, and predicted risk of stroke. Stroke. 2006;37(5):1254-60.

15) Lasserson DS, Chandratheva A, Giles MF, et al. Influence of general practice opening hours on delay in seeking medical attention after transient ischaemic attack (TIA) and minor stroke: prospective population based study. BMJ. 2008;337:a1569.

16) Smits $M$, Rutten $M$, Keizer E, et al. The Development and Performance of After-Hours Primary Care in the Netherlands: A Narrative Review. Annals of internal medicine. 2017;166(10):73742.

17) National guidelines for telephone triage and advice in Family Practice [cited 2018 June 22]. Available from: https://www.nhg.org/winkel/producten/nhg-triagewijzer-versie-2016. 
18) van lerland $Y$, van Veen $M$, Huibers $L$, et al. Validity of telephone and physical triage in emergency care: the Netherlands Triage System. Family practice. 2011;28(3):334-41.

19) Rutten $\mathrm{MH}$, Kant J, Giesen P. What can we learn from calamities at out-of-hours services in primary care? [Wat kunnen we leren van calamiteiten op de huisartsenpost?]. Huisarts Wet. 2018;6(61).

20) Jansen $T$, de Hoon $S$, Hek K, Verheij R. Developments at the out-of-hours services in primary care. Changes in care demand and health care issues in 2013-2015. [Ontwikkelingen op de huisartsenpost. Veranderingen in zorgvraag en gezondheidsproblemen in 2013-2015.]. NIVEL, 2017.

21) Keizer E, Maassen I, Smits M, et al. Reducing the use of out-of-hours primary care services: A survey among Dutch general practitioners. The European journal of general practice. 2016;22(3):189-95.

22) Kuriyama A, Urushidani $S$, Nakayama T. Five-level emergency triage systems: variation in assessment of validity. Emergency medicine journal : EMJ. 2017;34(11):703-10.

23) Zachariasse JM, van der Hagen $V$, Seiger $N$, et al. Performance of triage systems in emergency care: a systematic review and meta-analysis. BMJ open. 2019;9(5):e026471.

24) Nishi F, de Oliveira Motta Maia F, de Souza Santos I, de Almeida Lopes Monteiro da Cruz D. Assessing sensitivity and specificity of the Manchester Triage System in the evaluation of acute coronary syndrome in adult patients in emergency care: a systematic review. JBI Database of Systematic Reviews and Implementation Reports. 2017;15(6):1747-61.

25) Pinto D, Lunet N, Azevedo A. Sensitivity and specificity of the Manchester Triage System for patients with acute coronary syndrome. Rev Port Cardiol. 2010;29(6):961-87.

26) Leite L, Baptista R, Leitao J, et al. Chest pain in the emergency department: risk stratification with Manchester triage system and HEART score. BMC cardiovascular disorders. 2015;15:48.

27) Trigo J, Gago P, Mimoso J, et al. In-hospital delay in ST-segment-elevation myocardial infarction after Manchester Triage. Rev Port Cardiol. 2008;27(10):1251-9.

28) Matias $C$, Oliveira $R$, Duarte $R$, et al. The Manchester Triage System in acute coronary syndromes. Rev Port Cardiol. 2008;27(2):205-16.

29) Providencia R, Gomes PL, Barra S, et al. Importance of Manchester Triage in acute myocardial infarction: impact on prognosis. Emergency medicine journal : EMJ. 2011;28(3):212-6.

30) Gouvea VET, Reis MAM, Gouvea GM, et al. Evaluation the Manchester Triage System in the acute coronary syndrome. Int J Cardiovasc Sci. 2015;28(2):107-13.

31) Nishi FA, Polak C, Cruz D. Sensitivity and specificity of the Manchester Triage System in risk prioritization of patients with acute myocardial infarction who present with chest pain. Eur J Cardiovasc Nurs. 2018;17(7):660-6.

32) Steiner D, Renetseder F, Kutz A, et al. Performance of the Manchester Triage System in Adult Medical Emergency Patients: A Prospective Cohort Study. J Emerg Med. 2016;50(4):678-89.

33) Grouse Al, Bishop RO, Bannon AM. The Manchester Triage System provides good reliability in an Australian emergency department. Emergency medicine journal : EMJ. 2009;26(7):484-6.

34) Lake R, Georgiou A, Li J, et al. The quality, safety and governance of telephone triage and advice services - an overview of evidence from systematic reviews. BMC health services research. 2017;17(1):614.

35) The Dutch College of General Practitioners, NHG. The International Classification of Primary Care (ICPC). Version 6 (Dutch translation derived from ICPC-1 by the WONCA International Classification Committee). 2018. Available from: https://www.nhg.org/themas/artikelen/ icpc. 
36) Erkelens DC, Wouters $L T$, Zwart DL, et al. Optimisation of telephone triage of callers with symptoms suggestive of acute cardiovascular disease in out-of-hours primary care: observational design of the Safety First study. BMJ open. 2019;9(7):e027477.

37) Thim T, Krarup NH, Grove EL, et al. Initial assessment and treatment with the Airway, Breathing, Circulation, Disability, Exposure (ABCDE) approach. Int J Gen Med. 2012;5:117-21.

38) Netherlands Triage Standard [Nederlandse Triage Standaard], 2019. Accessed at www. de-nts.nl on 7 October 2019.

39) Prabhakaran $S$, Ruff I, Bernstein RA. Acute stroke intervention: a systematic review. Jama. 2015;313(14):1451-62.

40) Leng T, Xiong ZG. Treatment for ischemic stroke: From thrombolysis to thrombectomy and remaining challenges. Brain Circ. 2019;5(1):8-11.

41) Powers WJ, Rabinstein AA, Ackerson T, et al. Guidelines for the Early Management of Patients With Acute Ischemic Stroke: 2019 Update to the 2018 Guidelines for the Early Management of Acute Ischemic Stroke: A Guideline for Healthcare Professionals From the American Heart Association/American Stroke Association. Stroke. 2019;50(12):e344-e418.

42) Hankey GJ. Secondary stroke prevention. Lancet Neurol. 2014;13(2):178-94.

43) Kernan WN, Ovbiagele B, Black HR, et al. Guidelines for the prevention of stroke in patients with stroke and transient ischemic attack: a guideline for healthcare professionals from the American Heart Association/American Stroke Association. Stroke. 2014;45(7):2160-236.

44) Stroke and transient ischaemic attack in over 16s: diagnosis and initial management. National Institute for Health and Care Excellence: Clinical Guidelines. London2019.

45) Verburg AF, Tjon ATMR, Verstappen WH, et al. Summary of the 'Stroke' guideline of the Dutch College of General Practitioners [Samenvatting van de NHG-Standaard Beroerte]. Ned Tijdschr Geneeskd. 2014;158(1):A7022. 


\section{Supplementary Data}

Table S1. Characteristics of 1,700 patients with symptoms suggestive of TIA/stroke.

\begin{tabular}{|c|c|c|c|}
\hline & $\begin{array}{l}\text { Final diagnosis } \\
\text { available } \\
n=1269(74.6 \%)\end{array}$ & $\begin{array}{l}\text { Final diagnosis not } \\
\text { available } \\
n=431(25.4 \%)\end{array}$ & P-value \\
\hline \multicolumn{4}{|l|}{ Patient characteristics } \\
\hline Median age in years (IQR) & $72.0(57.0-83.0)$ & $73.0(58.0-84.0)$ & 0.495 \\
\hline Female sex & $722(56.9)$ & $239(55.5)$ & 0.602 \\
\hline Family history of CVD $(n=41)$ & $27(75.0)$ & $3(60.0)$ & $0.478^{\&}$ \\
\hline \multicolumn{4}{|l|}{ Medical history } \\
\hline Cardiovascular disease $(n=1181)$ & $680(77.1)$ & $253(84.6)$ & 0.006 \\
\hline $\mathrm{TIA}(\mathrm{n}=853)$ & $176(27.6)$ & $65(30.1)$ & 0.483 \\
\hline Stroke $(n=853)$ & $173(27.2)$ & $73(33.8)$ & 0.063 \\
\hline Coronary artery disease $(n=394)$ & $54(17.8)$ & $28(30.8)$ & 0.008 \\
\hline Arrhythmia $(n=375)$ & $57(19.5)$ & $21(25.3)$ & 0.252 \\
\hline Valvular heart disease $(n=331)$ & $25(9.6)$ & $9(12.7)$ & 0.452 \\
\hline Heart failure $(n=336)$ & $24(9.1)$ & $10(13.7)$ & 0.252 \\
\hline Epilepsy $(n=294)$ & $24(10.3)$ & $8(13.1)$ & 0.530 \\
\hline Migraine $(n=134)$ & $31(30.4)$ & $10(31.3)$ & 0.927 \\
\hline \multicolumn{4}{|l|}{ Cardiovascular risk factors } \\
\hline Hypertension $(n=559)$ & $206(48.9)$ & $79(57.2)$ & 0.090 \\
\hline $\begin{array}{l}\text { Hypercholesterolemia or use of statins } \\
(n=497)\end{array}$ & $170(43.0)$ & $46(45.1)$ & 0.708 \\
\hline Diabetes mellitus ( $n=538)$ & $150(36.0)$ & $58(47.9)$ & 0.017 \\
\hline \multicolumn{4}{|l|}{ Cardiovascular medication } \\
\hline Antithrombotics use $(n=1259)$ & $439(46.8)$ & $165(51.6)$ & 0.137 \\
\hline $\begin{array}{l}\text { Other cardiovascular medication } \\
(\mathrm{n}=1019)\end{array}$ & $431(56.4)$ & $161(63.1)$ & 0.060 \\
\hline \multicolumn{4}{|l|}{ Call characteristics } \\
\hline Median call duration in min:sec (IQR) & $\begin{array}{l}07: 08 \\
(05: 07-09: 37)\end{array}$ & $\begin{array}{l}07: 26 \\
(05: 10-09: 42)\end{array}$ & 0.350 \\
\hline $\begin{array}{l}\text { Median time for caller's introduction in } \\
\text { min:sec (IQR) }\end{array}$ & $\begin{array}{l}00: 20 \\
(00: 13-00: 28)\end{array}$ & $\begin{array}{l}00: 19 \\
(00: 12-00: 27)\end{array}$ & 0.744 \\
\hline $\begin{array}{l}\text { Initial call by someone else than the } \\
\text { patient }\end{array}$ & $963(75.9)$ & $324(75.2)$ & 0.766 \\
\hline $\begin{array}{l}\text { Triage nurse consulted the general } \\
\text { practitioner }\end{array}$ & $754(59.4)$ & $259(60.1)$ & 0.805 \\
\hline \multicolumn{4}{|l|}{ Main NTS complaint chosen by triage nurse } \\
\hline Neurological deficit & $807(63.6)$ & $292(67.7)$ & 0.119 \\
\hline Dizziness & $108(8.5)$ & $23(5.3)$ & 0.033 \\
\hline Headache & $51(4.0)$ & $13(3.0)$ & 0.345 \\
\hline Odd behavior & $39(3.1)$ & $14(3.2)$ & 0.857 \\
\hline
\end{tabular}


Table S1. Continued.

\begin{tabular}{|c|c|c|c|}
\hline & $\begin{array}{l}\text { Final diagnosis } \\
\text { available } \\
n=1269(74.6 \%)\end{array}$ & $\begin{array}{l}\text { Final diagnosis not } \\
\text { available } \\
n=431(25.4 \%)\end{array}$ & P-value \\
\hline Syncope & $29(2.3)$ & $6(1.4)$ & 0.259 \\
\hline Vision problem & $27(2.1)$ & $13(3.0)$ & 0.293 \\
\hline Leg or arm problem & $45(3.5)$ & $18(4.2)$ & 0.550 \\
\hline Other & $163(12.8)$ & $52(12.1)$ & 0.674 \\
\hline \multicolumn{4}{|l|}{ Symptoms mentioned during the call } \\
\hline $\begin{array}{l}\text { Decreased or loss of consciousness } \\
(n=1467)\end{array}$ & $70(6.3)$ & $19(5.2)$ & 0.435 \\
\hline Face drooping $(n=959)$ & $351(49.2)$ & $112(45.5)$ & 0.317 \\
\hline Arm weakness ( $n=1060)$ & $331(42.9)$ & $123(42.7)$ & 0.961 \\
\hline Leg weakness ( $n=890)$ & $286(43.8)$ & $105(44.3)$ & 0.893 \\
\hline Sensory disturbances $(n=496)$ & $342(91.2)$ & $109(90.1)$ & 0.710 \\
\hline $\begin{array}{l}\text { Communication problem in general } \\
(n=1033)\end{array}$ & $600(78.0)$ & $211(79.9)$ & 0.517 \\
\hline Dysarthria $(n=554)$ & $257(61.8)$ & $78(56.5)$ & 0.274 \\
\hline Dysphasia $(n=559)$ & $235(56.1)$ & $74(52.9)$ & 0.506 \\
\hline Vision problem in general $(n=250)$ & $150(81.5)$ & $50(75.8)$ & 0.315 \\
\hline Blurry vision $(n=96)$ & $54(73.0)$ & $11(50.0)$ & 0.043 \\
\hline Diplopia $(n=93)$ & $37(50.0)$ & $9(47.4)$ & 0.838 \\
\hline Vision loss $(n=82)$ & $37(59.7)$ & $14(70.0)$ & 0.408 \\
\hline Headache $(n=644)$ & $287(57.7)$ & $93(63.3)$ & 0.232 \\
\hline $\begin{array}{l}\text { Loss of balance/motor coordination } \\
\text { (ataxia) }(n=298)\end{array}$ & $196(83.1)$ & $55(88.7)$ & 0.277 \\
\hline Dizziness ( $n=396)$ & $263(84.3)$ & $64(76.2)$ & 0.082 \\
\hline Seizure $(n=15)$ & $7(63.6)$ & $2(50.0)$ & $0.999^{\&}$ \\
\hline Short term memory loss $(n=90)$ & $54(79.4)$ & $14(63.6)$ & 0.135 \\
\hline Shortness of breath $(n=535)$ & $87(21.6)$ & $25(18.9)$ & 0.516 \\
\hline \multicolumn{4}{|c|}{ Autonomic nervous system associated symptoms } \\
\hline Sweating $(n=278)$ & $92(44.2)$ & $29(41.4)$ & 0.683 \\
\hline Nausea or vomiting $(n=399)$ & $178(57.2)$ & $40(45.5)$ & 0.050 \\
\hline Pallor ( $n=343)$ & $81(31.8)$ & $26(29.5)$ & 0.698 \\
\hline Ashen skin $(n=271)$ & $30(15.2)$ & $11(15.1)$ & 0.986 \\
\hline (Feeling of nearly) fainting ( $n=1467$ ) & $98(8.9)$ & $31(8.5)$ & 0.830 \\
\hline \multicolumn{4}{|l|}{ Course of symptoms } \\
\hline \multicolumn{4}{|l|}{ Onset of symptoms: } \\
\hline Per acute (seconds) $(n=272)$ & $108(51.2)$ & $31(50.8)$ & 0.960 \\
\hline Acute (minutes) $(n=272)$ & $69(32.7)$ & $23(37.7)$ & 0.467 \\
\hline Gradually (hours) $(n=272)$ & $34(16.1)$ & $7(11.5)$ & 0.373 \\
\hline $\begin{array}{l}\text { Duration of symptoms } \leq 4.5 \text { hours } \\
(n=1317)\end{array}$ & $584(59.2)$ & $215(65.0)$ & 0.065 \\
\hline
\end{tabular}


Table S1. Continued.

\begin{tabular}{|c|c|c|c|}
\hline & $\begin{array}{l}\text { Final diagnosis } \\
\text { available } \\
n=1269(74.6 \%)\end{array}$ & $\begin{array}{l}\text { Final diagnosis not } \\
\text { available } \\
n=431(25.4 \%)\end{array}$ & P-value \\
\hline $\begin{array}{l}\text { Symptoms still present at time of calling } \\
(n=1676)\end{array}$ & $962(93.5)$ & $585(90.4)$ & 0.022 \\
\hline \multicolumn{4}{|l|}{ Other characteristics } \\
\hline Caller expresses concern $(n=818)$ & $582(92.7)$ & $179(94.2)$ & 0.466 \\
\hline $\begin{array}{l}\text { Patient never experienced similar } \\
\text { symptoms before }(n=501)\end{array}$ & $172(46.7)$ & $59(44.4)$ & 0.637 \\
\hline \multicolumn{4}{|l|}{ Recognition of symptoms: } \\
\hline $\operatorname{TIA}(n=501)$ & 66 (17.9) & $24(18.0)$ & 0.977 \\
\hline Stroke $(n=501)$ & 41 (11.1) & $22(16.5)$ & 0.107 \\
\hline
\end{tabular}

Legend: NTS: Netherlands Triage Standard; IQR: interquartile range; CVD: cardiovascular disease; TIA: transient ischaemic attack. *Concerns all cardiovascular medication with the exception of antithrombotics; "Pearson Chi Square Test for categorical variables and Mann-Whitney U Test for not normally distributed continuous variables; ${ }^{\circledR}$ Fisher's Exact Test for categorical variables; 'Amongst others: vomiting, dyspnea, neck symptoms, insult, disability problems ('D from $\left.A B C D^{\prime}\right)$.

Table S2. NTS urgency and final urgency allocation of 1,269 patients with symptoms suggestive of TIA/minor stroke

\begin{tabular}{lllllll} 
& Final U1 & Final U2 & Final U3 & Final U4 & Final U5 & Total \\
\hline NTS U1 & 229 & 115 & 8 & 1 & 7 & 360 \\
\hline NTS U2 & 27 & 352 & 11 & 10 & 10 & 410 \\
\hline NTS U3 & 1 & 14 & 92 & 7 & 7 & 121 \\
\hline NTS U4 & 0 & 7 & 9 & 15 & 1 & 32 \\
\hline NTS U5 & 41 & 83 & 123 & 59 & 40 & 346 \\
\hline Total & 298 & 571 & 243 & 92 & 65 & 1269 \\
\hline
\end{tabular}

Table S3. NTS urgency and final urgency allocation of 434 patients with TIA/minor stroke

\begin{tabular}{lllllll} 
& Final U1 & Final U2 & Final U3 & Final U4 & Final U5 & Total \\
\hline NTS U1 & 71 & 45 & 3 & 1 & 3 & 123 \\
\hline NTS U2 & 10 & 131 & 3 & 3 & 6 & 153 \\
\hline NTS U3 & 1 & 1 & 24 & 2 & 0 & 28 \\
\hline NTS U4 & 0 & 1 & 3 & 0 & 0 & 4 \\
\hline NTS U5 & 18 & 35 & 41 & 20 & 12 & 126 \\
\hline Total & 100 & 213 & 74 & 26 & 21 & 434 \\
\hline
\end{tabular}


Table S4. NTS urgency and final urgency allocation of 201 patients with major stroke

\begin{tabular}{lllllll} 
& Final U1 & Final U2 & Final U3 & Final U4 & Final U5 & Total \\
\hline NTS U1 & 58 & 25 & 2 & 0 & 1 & 86 \\
\hline NTS U2 & 8 & 49 & 3 & 1 & 2 & 63 \\
\hline NTS U3 & 0 & 1 & 11 & 0 & 0 & 12 \\
\hline NTS U4 & 0 & 0 & 0 & 2 & 0 & 2 \\
\hline NTS U5 & 6 & 15 & 11 & 5 & 1 & 38 \\
\hline Total & 72 & 90 & 27 & 8 & 4 & 201 \\
\hline
\end{tabular}

Table S5. NTS urgency and final urgency allocation of 61 patients with other LTES

\begin{tabular}{lllllll} 
& Final U1 & Final U2 & Final U3 & Final U4 & Final U5 & Total \\
\hline NTS U1 & 23 & 7 & 0 & 0 & 0 & 30 \\
\hline NTS U2 & 2 & 13 & 0 & 0 & 0 & 15 \\
\hline NTS U3 & 0 & 0 & 2 & 0 & 0 & 2 \\
\hline NTS U4 & 0 & 0 & 1 & 2 & 0 & 3 \\
\hline NTS U5 & 3 & 2 & 5 & 1 & 0 & 11 \\
\hline Total & 28 & 22 & 8 & 3 & 0 & 61 \\
\hline
\end{tabular}




$$
4
$$




\section{Is the time of calling helpful for}

differentiating transient ischaemic attack and stroke from mimics in primary care out-of-hours services? A cross-sectional study

D.C. Erkelens

D.L. Zwart

G.H. van der Meer

L.T. Wouters

E. de Groot

R.A. Damoiseaux

A.W. Hoes

F.H. Rutten

Submitted 


\section{Abstract}

Background: Telephone triage of patients suspected of transient ischaemic attack (TIA) or stroke is challenging. As TIA or stroke more likely occur during daytime, with a peak in the morning hours, the time of calling might be a helpful determinant during telephone triage. We assessed the time of calling in patients with stroke-like symptoms who called the out-of-hours services in primary care (OHS-PC), and evaluated whether the time of calling differed between patients with TIA or stroke compared to those with mimics.

Methods: Cross-sectional study of 1,269 telephone triage recordings of patients calling the OHS-PC because of stroke-like symptoms. We collected information on patient characteristics, symptoms, time of calling and urgency allocation. The final diagnosis related to each triage call was based on letters from the neurologist (retrieved from the patient's general practitioner). We assessed the time of calling hourly and 4-hourly, calculated risks of TIA or stroke per hour and the risk ratio of TIA or stroke in the morning (8am-noon) vs. other hours.

Results: Mean age was 68.6 (SD \pm 18.5 ) years, $56.9 \%$ were women, and $50.0 \%$ had a TIA or stroke. The risk ratio of TIA or stroke among people calling with stroke-like symptoms between 8am-noon vs. other hours was $1.13(95 \% \mathrm{Cl} 1.00-1.28, \mathrm{p}=0.070)$. After correction for age and sex the adjusted risk ratio was $0.94(95 \% \mathrm{Cl} 0.80-1.10, \mathrm{p}=0.434)$.

Conclusions: In patients who called the OHS-PC because of stroke-like symptoms the time of calling did not differ between patients with TIA or stroke and patients with mimics.

\section{Strengths and limitations of this study:}

- This is the first study that examined the time of calling as a possible predictor of TIA or stroke at out-of-hours services in primary care.

- $\quad$ All people with stroke-like symptoms were included, and not only patients with established TIA or stroke.

- The researchers were blinded to the final diagnosis at the time of data collection, which limited the influence of hindsight bias.

- As the exact time of onset was often unknown, we used the time of calling. 


\section{Introduction}

Early recognition and timely diagnosis of patients with a transient ischaemic attack (TIA) or stroke is of vital importance in order to initiate interventions that can reduce the risk of (permanent) brain injury and recurrent stroke.(1-4) The risk of subsequent ischaemic stroke after TIA is highest in the first few days and gradually decreases in the following weeks.(5, 6) Previous studies on the early risk of subsequent ischaemic stroke after TIA reported reduction rates of such stroke ranging from $60 \%$ within six weeks to $80 \%$ within three months after early start of antiplatelet therapy, and oral anticoagulation in those with atrial fibrillation. $(1,6-8)$ In order to achieve early treatment, neurological symptoms must be interpreted adequately, which can be rather challenging. Other diseases can mimic the signs and symptoms of TIA or stroke. Moreover, symptoms can be non-specific, and in the case of TIA short-lasting and thus resolved by the time a patient calls for medical help.(9-12)

In The Netherlands, as in other European countries, a large number of suspected TIA or stroke patients first contact the general practitioner (GP). During out of office hours (i.e. evenings, nights, weekends and holidays) patients can contact the out-of-hours services in primary care (OHS-PC).(13) At the OHS-PC trained nurses perform telephone triage, and they are supported by a semi-automatic decision support tool called the Netherlands Triage Standard (NTS).(14) The NTS is based on the hospital-based Manchester Triage System.(14-16) The aim of the NTS is to allocate adequate urgencies based on an algorithm that helps the triage nurse to assess patient complaints. These automatically generated urgencies are linked to a certain time period within which a general practitioner (GP) or ambulance should examine the patient. Since the implementation of the NTS at Dutch OHS-PCs in 2011, an increase in higher urgency allocations was seen, (17) without an increase of clinically critical disorders, suggesting the NTS results in a more defensive triage process than a less structured history taking applied by triage nurses. Also, the care demand and workload at Dutch OHS-PC increased over time $(18,19)$, underlining the urgent need for determinants that could optimize telephone triage.

Previous studies already showed that, comparable to other acute cardiovascular diseases, stroke more often occurs during daytime than at night, with a peak incidence in the morning hours between 6am and noon (20-24), and a less prominent peak in the (early) evening.(25-30) This circadian rhythm applies to both ischaemic and haemorrhagic stroke (22-25, 31), and also to TIA.(23) A similar circadian pattern was found in telephone calls for acute neurological events at the emergency department (ED).(32) Whether the time of calling helps to triage calls for neurological events in out-of-hours primary care settings is unknown. This would be the case, if during certain time periods the incidence of TIA or stroke is higher than that of mimics as compared to other time periods (i.e. a higher risk ratio of TIA or stroke). 
To date, studies concerning the time of calling and the circadian rhythm in TIA or stroke have been executed in secondary care settings, and only evaluated those with established TIA or stroke.(22) We aimed to assess whether urgency allocation in telephone triage at the OHS-PC could be improved if the time of calling was considered in patients with stroke-like symptoms, that is, whether the incidence of TIA or stroke was different from that of mimics (i.e. a difference in risk ratio) over 24 hours.

\section{Methods}

\section{Study design and data collection}

This cross-sectional study is part of a larger research project called Safety First (The Netherlands National Trial Register identifier: NTR 7331).(33)

Telephone triage recordings of patients with stroke-like symptoms who called the OHS-PC between 2014 and 2016 were evaluated. Data was collected from six OHS-PC locations in the vicinity of Utrecht, The Netherlands, covering rural and urban areas.(34)

The triage recordings were selected based on (i) keywords in the OHS-PC electronic health records suggesting stroke-like symptoms (e.g. neurological deficit, arm or leg weakness, face drooping, speech or visual problems, sensory disturbances and common synonyms) and on (ii) International Classification of Primary Care (ICPC) codes linked to the calls which reflected our study domain (i.e. K89, K90, N17, N18, N19, N29, N89, N91).(35) Both patients with ongoing and already faded symptoms were included. After the aforementioned selection, we re-listened a random sample of $>1,000$ recordings and collected information about symptom presentation, and in addition, other patient characteristics, and urgency allocation. The time of calling was considered as the time of first medical contact. The final diagnosis of each patient that has contacted the OHS-PC was retrieved from the electronic health record of the patient's own GP. Thus, for all patients referred to the hospital, the final diagnosis of TIA or stroke was based on discharge letters from the neurologist (or the emergency department). We defined a final diagnosis of TIA or stroke as (i) a TIA, (ii) a minor ischaemic or (iii) major ischaemic stroke. TIA or stroke mimics were defined as stroke-like symptoms, but with a diagnosis other than TIA or stroke. For patients who were not referred to the hospital we used follow-up data up to one month on possible recurrence of TIA or stroke from the GP's electronic health record.

\section{Data analyses}

The occurrence of TIA or stroke was first analyzed hourly. We calculated per time period the absolute number of patients with a final diagnosis of TIA or stroke and the whole population of those calling with stroke-like symptoms. By dividing the absolute number of TIA or stroke patients by the total number of callers with stroke-like symptoms, the risk ratio of TIA or stroke per hour was calculated. Furthermore, we calculated the risk ratios of TIA or stroke for several time periods in order to identify time period(s) in which 
the risk ratio of TIA or stroke was highest. Also, we calculated adjusted risk ratios for TIA or stroke after correction for age and gender.

Patient characteristics, symptoms, medical history and urgency allocation were compared between the time period in which the risk of TIA or stroke was highest to other time periods. We used the Chi-squared test or Fischer's exact test for categorical variables and the independent-samples t test for continuous variables in order to compare callers with and without established TIA or stroke. The duration of symptoms was dichotomized in $<4.5$ and $\geq 4$.5hours, in line with the recommendation of the prevailing Dutch GP national guidelines in 2014.(36) At that time, ischaemic stroke patients were considered eligible for thrombolysis if symptoms lasted $<4.5$ hours.(37-39) Urgency levels were dichotomized in high (U1-U2) and low (U3-U5) according to the NTS hierarchy of urgencies (U1; medical help within 15 minutes (by ambulance)); U2; patient must be seen by a GP <1 hour; U3; patient must be seen <3 hours; U4; patient must be seen <24 hours; U5; telephone advice is considered adequate).(33) Data analyses were performed using SPSS version 25.0 (IBM Corp., Armonk, NY, USA).

\section{Ethical approval}

The Medical Ethics Review Committee Utrecht approved this study (National Trial Register identification number: NTR7331).

\section{Patient and Public Involvement}

No patients were involved in setting the research question or the outcome measures, or in developing plans for design, however, they were involved in the implementation of the study. In addition, they were asked to advise on interpretation and writing up of results. Results will be shared and discussed with the national patient community of cardiovascular diseases.

\section{Results}

Our study population consisted of 1,269 patients of whom we could obtain a final diagnosis. A flowchart of the inclusion and exclusion criteria, and number of eligible patients and final included study population is displayed in Figure 1.

The mean age was 68.6 (SD) \pm 18.5 ) years, and 722 (56.9\%) were women. In total, 291 (22.9\%) patients were diagnosed with TIA, 143 (11.3\%) with minor stroke, 201 (15.8\%) with major ischaemic stroke, and 61 (4.8\%) with other (neurological) life-threatening events (LTE), including haemorrhagic stroke. The remaining 573 (45.2\%) patients were diagnosed with non-urgent disease (e.g. migraine with aura, syncope, peripheral vestibular disorder). Men had somewhat more often a TIA or minor stroke than women (37.3\% vs. 31.9\%, p=0.043) and women had more often a major ischaemic stroke than men $(14.4 \%$ vs. $16.9 \%, p=0.236)$. 


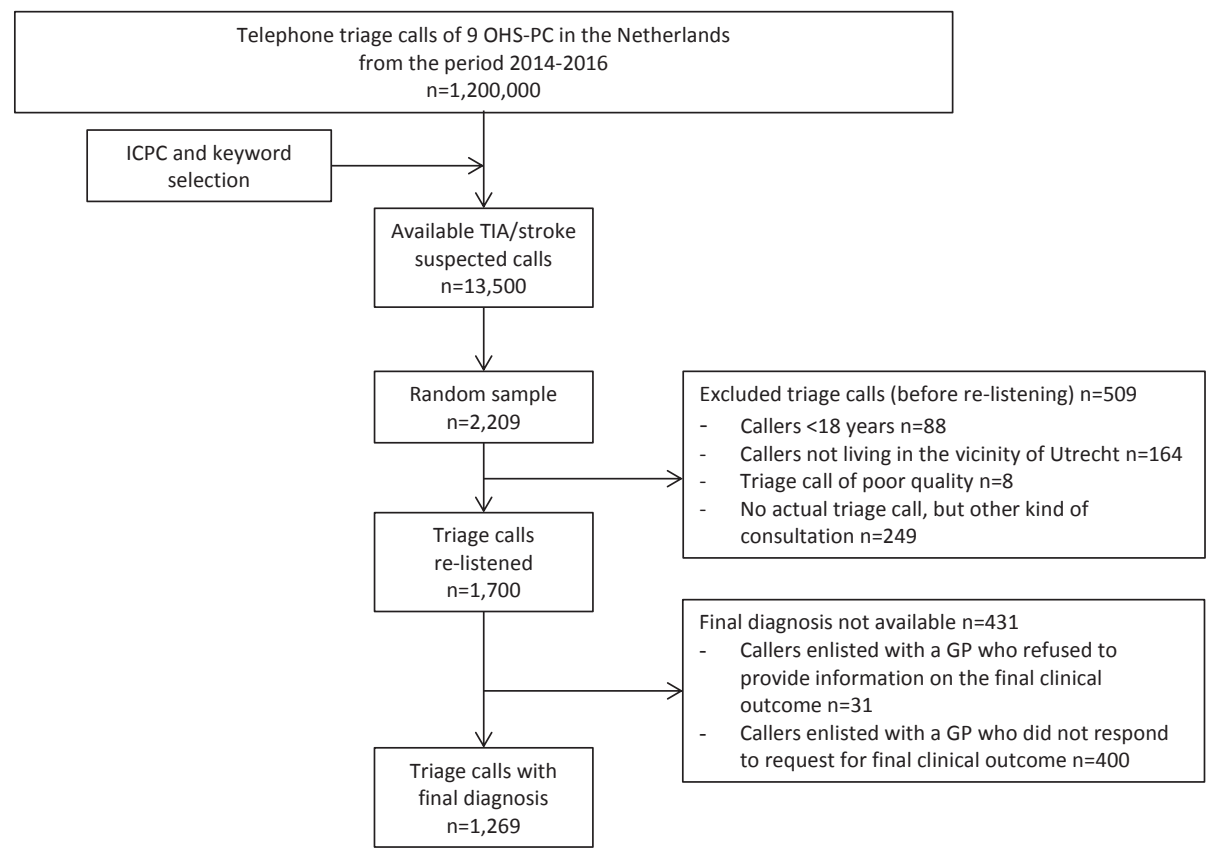

Figure 1. Flowchart

In Figure 2 the absolute numbers per hour are shown of patients with and without TIA or stroke. Most patients with TIA or stroke called during daytime with a peak incidence between 8-12am; 140 (22.0\%) and a peak between 2-6pm; 125 (19.7\%). The lowest incidence of TIA or stroke was between 1-5am (18; 2.8\%). The distribution in time of patients calling with mimics of TIA or stroke was similar to those with TIA or stroke.

The overall risk of TIA or stroke was 50.0\% (51.7\% in men, and $48.9 \%$ in women). In Figure 3 the distribution of the risk of TIA or stroke per hour divided into men and women is plotted. The risk distribution of TIA or stroke per hour was comparable for men and women. A sensitivity analysis for TIA or minor stroke and major stroke separately showed similar results as for the combination of TIA or stroke. 


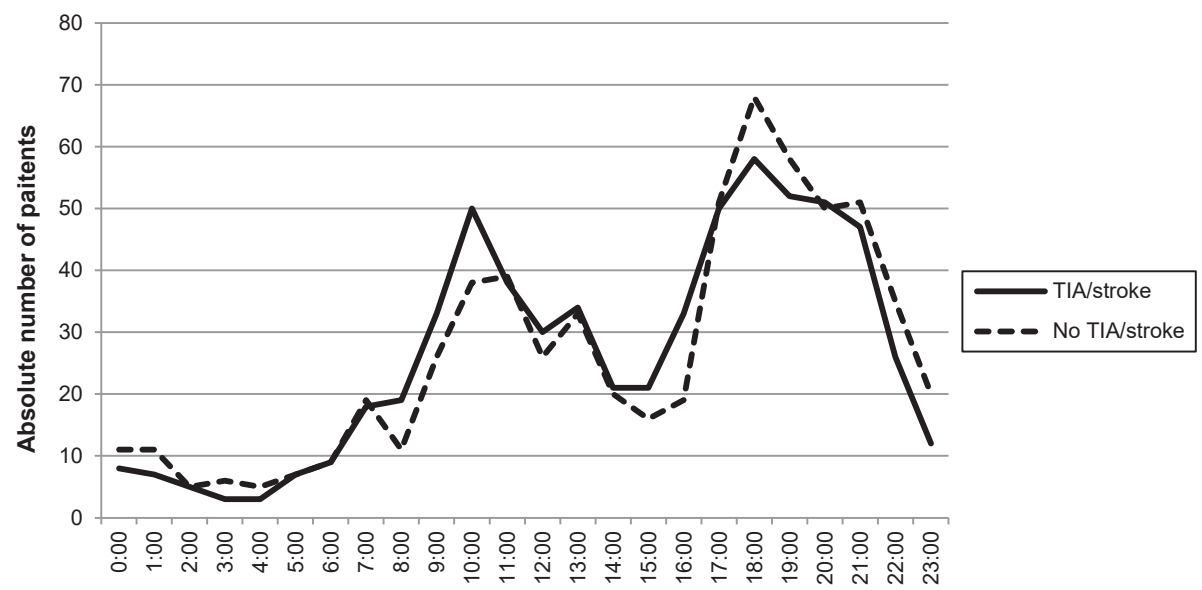

Time of calling (per hour, e.g. 0:00 = 0:00-0:59)

Figure 2. Time of calling of 1269 patients with neurological symptoms suggestive of $\mathrm{TIA} / \mathrm{stroke}$ calling the OHS-PC, divided in patients with and without TIA/stroke

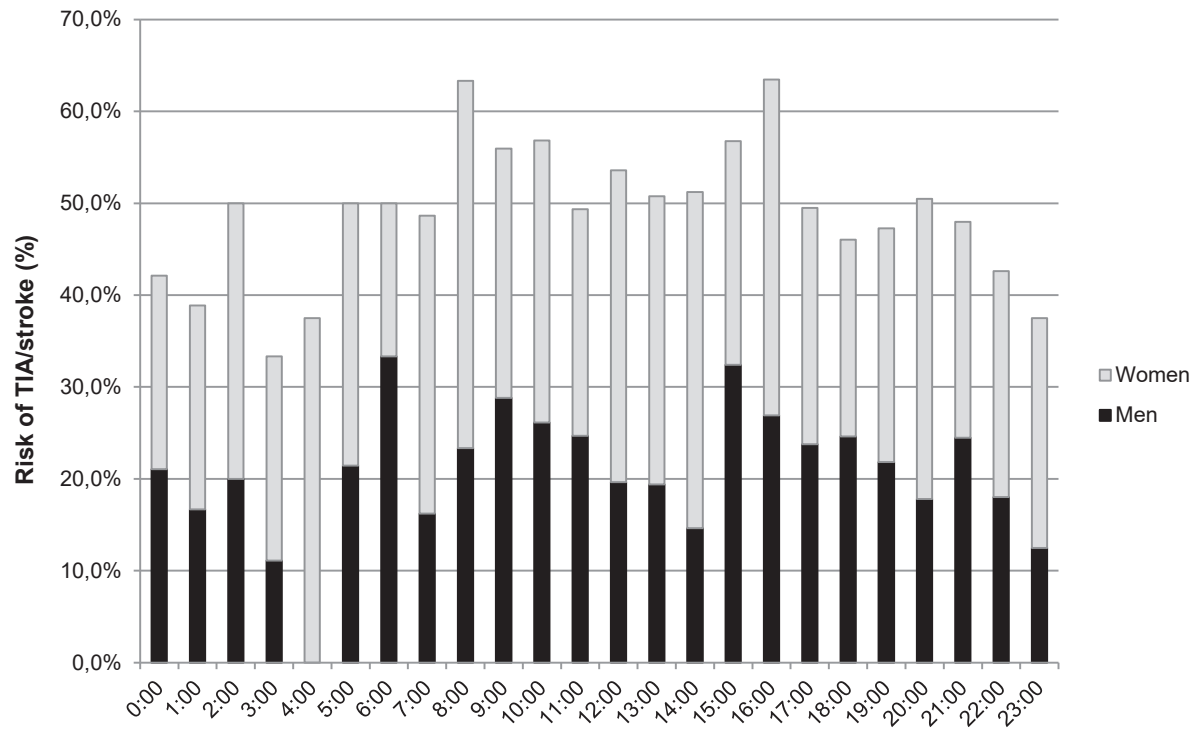

Time of calling (per hour, e.g. 0:00 = 0:00-0:59)

Figure 3. Risk of TIA/stroke per hour of 1269 patients with neurological symptoms suggestive of TIA/stroke calling the OHS-PC, divided in men and women 
Based on the 4-hourly analysis (see Figure 4), most patients with stroke-like symptoms called between 4-8pm (30.7\%). Only 4.4\% called at night between 0-4am, and $6.1 \%$ between 4-8am. Of those who received a final diagnosis of TIA or stroke $30.4 \%$ called between $4-8 \mathrm{pm}$, and $3.6 \%$ called during the night between $0-4 \mathrm{am}$. The risk of TIA or stroke during the day ranged from $46.6 \%(8-12 \mathrm{pm})$ to $55.1 \%$ (8-12am) during the day, while this was $41.1 \%$ at night from $0-4 a m$.

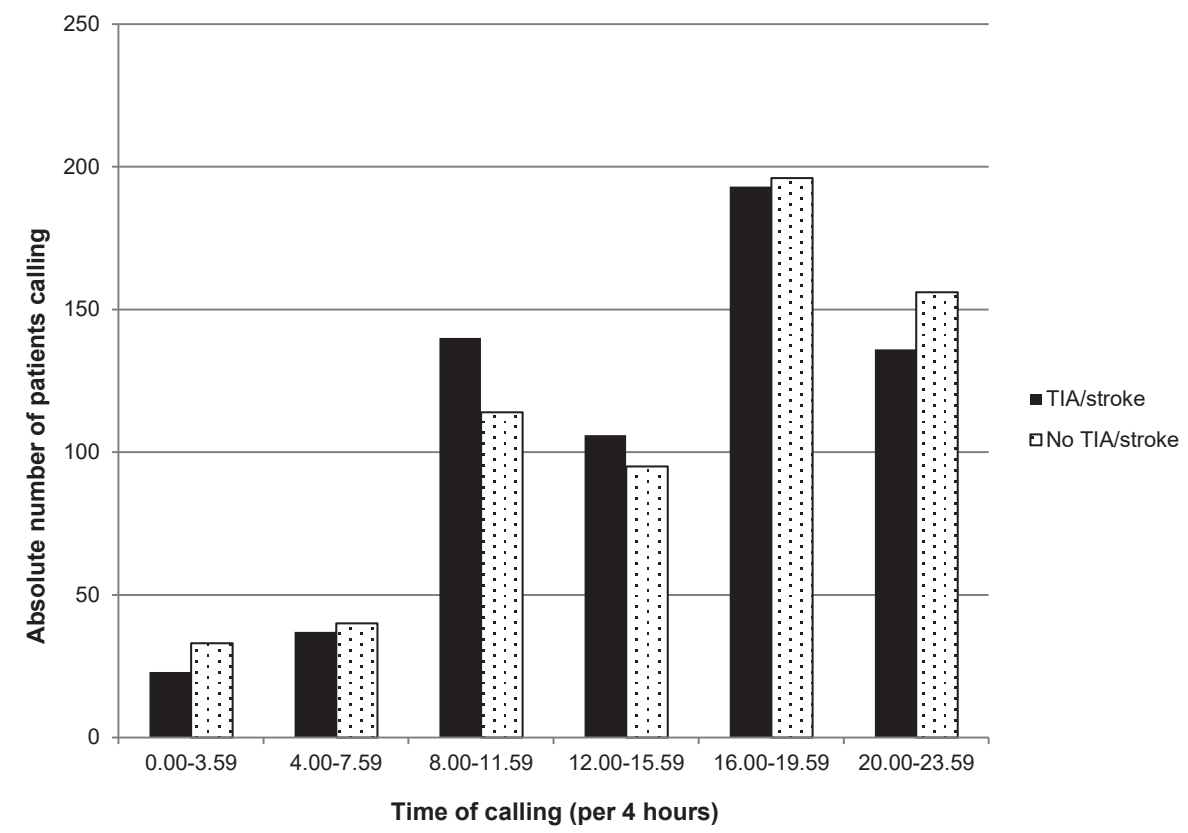

Figure 4. Time of calling (per 4 hours) of 1269 patients with neurological symptoms suggestive of TIA/stroke calling the OHS-PC, divided in patients with and without TIA/stroke

The risk ratio of TIA or stroke from 8am-noon compared to others hours was 1.13 (95\%confidence interval $(95 \% \mathrm{Cl}) 1.00-1.28, \mathrm{p}=0.070) ; 1.25(95 \% \mathrm{Cl} 1.05-1.49, \mathrm{p}=0.022)$ for men, and $1.04(95 \% \mathrm{Cl} 0.87-1.25, \mathrm{p}=0.666)$ for women, respectively. After correction for age and gender, the adjusted risk ratio for TIA or stroke from 8am-noon compare to other hours was 0.94 (95\% $\mathrm{Cl} 0.80-1.10, \mathrm{p}=0.434)$.

The baseline characteristics of patients calling during the time period with the highest risk of TIA or stroke (i.e. between 8am-noon) and those who called during other hours are shown in Table 1. Patients calling between 8am-noon were significantly older (76.0 years vs. 71.0 years, $p=0.003)$, more often experienced arm weakness $(51.3 \%$ vs. $40.8 \%, p=0.19$ ), and more often had patient delay (i.e. more often called $\geq 4.5$ hours after the start of symptoms, $54.0 \%$ vs. $37.4 \%, p<0.001$ ) than those calling during other hours $(50.0 \%$ vs. $35.6 \%, p=0.005)$. Also, patients calling in the morning had less speech problems $(71.7 \%$ vs. $79.5 \%, p=0.042)$ and (near) fainting $(5.4 \%$ vs. $9.8 \%, p=0.041)$. Both 
groups were comparable with respect to medical history, cardiovascular medication use, cardiovascular risk factors and call characteristics. The majority of patients calling for stroke-like symptoms received a high urgency allocation: $65.4 \%$ in the 8 am-noon group and $59.5 \%$ in the group calling other hours $(p=0.088)$. Patients calling between 8 am and noon were significantly more often diagnosed with TIA or minor stroke than those calling during other hours ( $39.8 \%$ vs. $32.8 \%, p=0.037$ ), whereas the proportion of major ischaemic stroke and other LTEs (e.g. haemorrhagic stroke, subarachnoid haemorrhage, sepsis, meningitis) as final diagnoses were comparable in both groups.

Table 1. Baseline characteristics of 1,269 patients who called the OHS-PC for symptoms suggestive of TIA or stroke, divided in those calling 8am-noon and other hours

\begin{tabular}{|c|c|c|c|}
\hline & $\begin{array}{l}\text { 8am-noon } \\
n=254(20.0 \%)\end{array}$ & $\begin{array}{l}\text { Other hours } \\
n=1015(80.0 \%)\end{array}$ & P-value* \\
\hline \multicolumn{4}{|l|}{ Patient characteristics } \\
\hline Mean age in years (SD) & 71.9 (16.7) & $67.7(18.9)$ & 0.001 \\
\hline Female sex & $147(57.9)$ & $575(56.7)$ & 0.725 \\
\hline \multicolumn{4}{|l|}{ Medical history and cardiovascular medication } \\
\hline Cardiovascular disease $(n=882)$ & $126(74.6)$ & $554(77.7)$ & 0.382 \\
\hline TIA $(n=637)$ & $36(29.0)$ & $140(27.3)$ & 0.697 \\
\hline Stroke $(n=637)$ & $26(21.0)$ & $147(28.7)$ & 0.084 \\
\hline Coronary artery disease $(n=303)$ & $15(23.8)$ & $39(16.3)$ & 0.163 \\
\hline Arrhythmia $(n=292)$ & $9(16.4)$ & $48(20.3)$ & 0.512 \\
\hline Antithrombotics use $(n=939)$ & $78(41.3)$ & $361(48.1)$ & 0.091 \\
\hline \multicolumn{4}{|l|}{ Cardiovascular risk factors } \\
\hline Hypertension $(n=421)$ & $38(45.2)$ & $168(49.9)$ & 0.449 \\
\hline Hypercholesterolemia $(n=395)$ & $32(40.5)$ & $138(43.7)$ & 0.611 \\
\hline Diabetes mellitus $(n=417)$ & $23(29.1)$ & $127(37.6)$ & 0.158 \\
\hline \multicolumn{4}{|l|}{ Call characteristics } \\
\hline Mean call duration in min:sec (SD) & $07: 26(03: 31)$ & $07: 49(03: 47)$ & 0.154 \\
\hline Initial call by someone else than the patient & $194(76.4)$ & $769(75.8)$ & 0.838 \\
\hline $\begin{array}{l}\text { Triage nurse consulted the general } \\
\text { practitioner }\end{array}$ & $142(55.9)$ & $612(60.3)$ & 0.203 \\
\hline \multicolumn{4}{|l|}{ Symptoms mentioned during the call } \\
\hline Face drooping $(n=713)$ & $75(52.4)$ & $276(48.4)$ & 0.389 \\
\hline Arm weakness ( $n=772)$ & $78(51.3)$ & $253(40.8)$ & 0.019 \\
\hline Leg weakness $(n=653)$ & $68(51.1)$ & $218(41.9)$ & 0.056 \\
\hline Sensory disturbances $(n=375)$ & $72(90.0)$ & $270(91.5)$ & 0.669 \\
\hline Speech problems $(n=769)$ & $104(71.7)$ & $496(79.5)$ & 0.042 \\
\hline Vision problems $(n=184)$ & $23(85.2)$ & $127(80.9)$ & 0.595 \\
\hline Headache $(n=497)$ & $56(55.4)$ & $231(58.3)$ & 0.600 \\
\hline Ataxia $(n=236)$ & $52(91.2)$ & $144(80.4)$ & 0.059 \\
\hline Dizziness $(n=312)$ & $60(82.2)$ & $203(84.9)$ & 0.573 \\
\hline
\end{tabular}


Table 1. Continued.

\begin{tabular}{|c|c|c|c|}
\hline & $\begin{array}{l}\text { 8am-noon } \\
n=254(20.0 \%)\end{array}$ & $\begin{array}{l}\text { Other hours } \\
n=1015(80.0 \%)\end{array}$ & P-value* \\
\hline \multicolumn{4}{|l|}{ ANS-associated symptoms } \\
\hline Sweating $(n=208)$ & $17(45.9)$ & $75(43.9)$ & 0.817 \\
\hline Nausea or vomiting $(n=311)$ & $39(59.1)$ & $139(56.7)$ & 0.731 \\
\hline Pallor $(n=255)$ & $15(30.0)$ & $66(32.2)$ & 0.765 \\
\hline Ashen skin $(n=198)$ & $5(12.8)$ & $25(15.7)$ & 0.651 \\
\hline (Feeling of nearly) fainting ( $n=1103)$ & $12(5.4)$ & $86(9.8)$ & 0.041 \\
\hline \multicolumn{4}{|l|}{ Course of symptoms } \\
\hline Per acute onset (within seconds) $(n=211)$ & $15(53.6)$ & $93(50.8)$ & 0.786 \\
\hline Duration of symptoms $\leq 4.5$ hours $(n=986)$ & $92(46.0)$ & $492(62.6)$ & $<0.001$ \\
\hline $\begin{array}{l}\text { Symptoms still present at time of calling } \\
(\mathrm{n}=1254)\end{array}$ & $237(94.4)$ & $917(91.4)$ & 0.117 \\
\hline \multicolumn{4}{|l|}{ NTS urgency } \\
\hline High (U1 or U2) & $166(65.4)$ & $604(59.5)$ & $0.088 * *$ \\
\hline Low (U3, U4 or U5) & $88(34.6)$ & $411(40.5)$ & \\
\hline \multicolumn{4}{|l|}{ Final diagnosis } \\
\hline TIA/minor stroke & $101(39.8)$ & $333(32.8)$ & 0.037 \\
\hline Major stroke*** & $39(15.4)$ & $162(16.0)$ & 0.813 \\
\hline Life threatening events (LTEs) $* * * *$ & $9(3.5)$ & $52(5.1)$ & 0.292 \\
\hline Intracerebral hemorrhage & $3(33.3)$ & $19(36.5)$ & 0.585 \\
\hline Other non-urgent diseases $* * * * *$ & $105(41.3)$ & $468(46.1)$ & 0.172 \\
\hline
\end{tabular}

Legend: ANS=Autonomic Nervous System; NTS=Netherlands Triage Standard; *Pearson Chi Square Test for categorical variables, Fisher's Exact Test for categorical variables if cell counts $<5$, and Mann-Whitney $U$ Test for not normally distributed continuous variables; **P-value for high vs. low NTS urgency; ***Including lacunar infarction and stroke not otherwise specified; ****Amongst others sepsis, acute coronary syndrome, meningitis, herpes encephalitis; ${ }^{* * * * *}$ Amongst others migraine (with aura), syncope, peripheral vestibular disorder, Bell's palsy.

\section{Discussion}

Patients with stroke-like symptoms most often called during daytime with a peak in the morning between 8-noon and a peak between 2-6pm. There was no time period in which the relative risk of TIA or stroke among callers with stroke-like symptoms was substantially higher than in other time blocks.

This is the first study in which the time of calling among patients with stroke-like symptoms is assessed in the OHS-PC setting and in which data on the ratio between TIA or stroke and all people calling for stroke-like symptoms are presented. Previous studies included patients with established TIA or stroke only, were performed in emergency 
department settings, and showed that TIA or stroke occurred more frequently during daytime than during nighttime, and, in particular, more frequently during the morning (6am-noon) than during the afternoon.(22-25, 31) Pathophysiologic mechanisms like an increase of heart rate, blood pressure, and peaks in clotting factors, cortisol and epinephrine levels start in the early morning, and have been shown to be underlying mechanisms of the occurrence of cardiovascular events (e.g. acute coronary syndrome or rupture of aortic aneurysms). $(22,25,40)$ TIA and stroke probably share, at least in part, these pathophysiologic mechanisms with cardiovascular events.(30, 32) Nevertheless, some studies also reported a second peak in the early evening between 4-8pm.(27, 28)

Analyzed hourly and 4-hourly, we could reproduce the morning peak as well as a peak in the afternoon among TIA or stroke patients, and the lowest number of TIA or stroke during the night, similar to previous literature.(23) In a meta-analysis of 31 publications including more than 11,000 strokes, based on the time of onset of symptoms, a crude odds ratio for stroke of $1.79(95 \% \mathrm{Cl} 1.72-1.87)$ between 6am-noon was found compared to other hours.(23) In our study, based on the time of contacting the OHS-PC, the crude risk ratio was $1.13(95 \% \mathrm{Cl} 1.00-1.28, \mathrm{p}=0.070)$ for $8 \mathrm{am}$-noon compared to other hours. The results of the meta-analyses and our study may also be affected by difference in settings (ED vs. OHS-PC), and thus case-mix with differences in prevalence of TIA or stroke. While other studies suggested to organize care processes (e.g. quality and quantity of staff in the emergency department) based on the demand during the TIA or stroke peak hours (32), our study shows that this seems not to be worthwhile in the OHS-PC setting because the risk ratio of TIA or stroke did not substantially differ over time.

An important strength of our study is that we considered all people with stroke-like symptoms, and not only patients with established TIA or stroke. Also, there was a low susceptibility to hindsight or recall bias, because the researchers were blinded to the final diagnosis at the time of data collection.

A limitation is that we could not use the time of symptom onset, because in the vast majority of patients the exact time of onset was unknown and patients could only indicate whether symptoms existed less than or more than 4.5 hours. Furthermore, we had missing values on several symptoms, a phenomenon inextricably linked to research with routine care data. However, these missing values did not affect our primary outcome (the final diagnosis of TIA or stroke), making multiple imputation unnecessary in order to perform multivariable analysis. Finally, patient delay could have created 'a shift to later hours' in our study, because we used the time of contacting the OHS-PC, while previous studies used the time of onset of symptoms for evaluating the incidence over 24 hours. 


\section{Conclusion}

In patients who called the OHS-PC because of stroke-like symptoms the time of calling did not differ between patients with TIA or stroke and patients with mimics.

\section{Declarations}

\section{Ethics approval and consent to participate}

The Medical Ethics Review Committee Utrecht, the Netherlands approved this study (National Trial Register identification number: NTR7331, reference number WAG/ $\mathrm{mb} / 16 / 003208)$. In addition, a waiver of informed consent was granted as our study involved minimal risk to subjects and this study would not have been practicable without the waiver. All personal and research data were handled and stored according to the European General Data Protection Regulation.

\section{Consent for publication}

Not applicable as all personal and research data were made unidentifiable

\section{Competing interests}

The authors declare that they have no competing interests.

\section{Funding}

This work was supported by (i) the department of general practice of the University Medical Center Utrecht, (ii) Associate Professorship-promotion grant of D.L. Zwart, MD, PhD, (iii) the foundation 'Netherlands Triage Standard' and (iv) the 'Stoffels-Hornstra' foundation. The views expressed are those of the authors and not necessarily those of the foundations. This research was conducted without direct involvement from both funding foundations. 


\section{Authors' contributions}

DLZ and FHR conceived the idea for the study and gained funding. All authors designed the study. DCE and GHM collected and analysed the data. DCE prepared the manuscript and wrote the first draft, supervised by FHR. All authors provided intellectual input, critically reviewed the manuscript and read and approved the final manuscript.

\section{Acknowledgements}

We would like to thank the primary care out-of-hours foundation 'Primair Huisartsenposten' in Utrecht, Professor L.J. Kappelle and Nienke van Veelen for their participation. 


\section{References}

1) Rothwell PM, Giles MF, Chandratheva A, Marquardt L, Geraghty O, Redgrave JN, et al. Effect of urgent treatment of transient ischaemic attack and minor stroke on early recurrent stroke (EXPRESS study): a prospective population-based sequential comparison. Lancet. 2007;370(9596):1432-42.

2) Kidwell CS, Warach $S$. Acute ischemic cerebrovascular syndrome: diagnostic criteria. Stroke. 2003;34(12):2995-8.

3) Coull AJ, Lovett JK, Rothwell PM, Oxford Vascular S. Population based study of early risk of stroke after transient ischaemic attack or minor stroke: implications for public education and organisation of services. BMJ. 2004;328(7435):326.

4) Johnston SC, Gress DR, Browner WS, Sidney S. Short-term prognosis after emergency department diagnosis of TIA. Jama. 2000;284(22):2901-6.

5) Wu CM, McLaughlin K, Lorenzetti DL, Hill MD, Manns BJ, Ghali WA. Early risk of stroke after transient ischemic attack: a systematic review and meta-analysis. Archives of internal medicine. 2007;167(22):2417-22.

6) Rothwell PM, Algra A, Chen Z, Diener HC, Norrving B, Mehta Z. Effects of aspirin on risk and severity of early recurrent stroke after transient ischaemic attack and ischaemic stroke: time-course analysis of randomised trials. Lancet. 2016;388(10042):365-75.

7) Hart RG, Pearce LA, Koudstaal PJ. Transient ischemic attacks in patients with atrial fibrillation: implications for secondary prevention: the European Atrial Fibrillation Trial and Stroke Prevention in Atrial Fibrillation III trial. Stroke. 2004;35(4):948-51.

8) Kirchhof P, Benussi S, Kotecha D, Ahlsson A, Atar D, Casadei B, et al. 2016 ESC Guidelines for the management of atrial fibrillation developed in collaboration with EACTS. European heart journal. 2016;37(38):2893-962.

9) Nadarajan V, Perry RJ, Johnson J, Werring DJ. Transient ischaemic attacks: mimics and chameleons. Pract Neurol. 2014;14(1):23-31.

10) Hand PJ, Kwan J, Lindley RI, Dennis MS, Wardlaw JM. Distinguishing between stroke and mimic at the bedside: the brain attack study. Stroke. 2006;37(3):769-75.

11) Ay H, Buonanno FS, Rordorf G, Schaefer PW, Schwamm LH, Wu O, et al. Normal diffusionweighted MRI during stroke-like deficits. Neurology. 1999;52(9):1784-92.

12) Sheehan OC, Merwick A, Kelly LA, Hannon N, Marnane M, Kyne L, et al. Diagnostic usefulness of the $A B C D 2$ score to distinguish transient ischemic attack and minor ischemic stroke from noncerebrovascular events: the North Dublin TIA Study. Stroke. 2009;40(11):3449-54.

13) Smits $M$, Rutten $M$, Keizer $E$, Wensing $M$, Westert $G$, Giesen P. The Development and Performance of After-Hours Primary Care in the Netherlands: A Narrative Review. Annals of internal medicine. 2017;166(10):737-42.

14) van lerland $Y$, van Veen $M$, Huibers $L$, Giesen $P$, Moll HA. Validity of telephone and physical triage in emergency care: the Netherlands Triage System. Family practice. 2011;28(3):33441.

15) Storm-Versloot MN, Ubbink DT, Kappelhof J, Luitse JS. Comparison of an informally structured triage system, the emergency severity index, and the manchester triage system to distinguish patient priority in the emergency department. Acad Emerg Med. 2011;18(8):822-9.

16) Cooke MW, Jinks S. Does the Manchester triage system detect the critically ill? J Accid Emerg Med. 1999;16(3):179-81. 
17) Jansen $T$, de Hoon $S$, Hek K, Verheij R. Developments at the out-of-hours services in primary care. Changes in care demand and health care issues in 2013-2015. [Ontwikkelingen op de huisartsenpost. Veranderingen in zorgvraag en gezondheidsproblemen in 2013-2015.]. NIVEL, 2017.

18) Smits M, Keizer E, Huibers L, Giesen P. GPs' experiences with out-of-hours GP cooperatives: a survey study from the Netherlands. The European journal of general practice. 2014;20(3):196-201.

19) InEen. Benchmark Out-of-Hours Services in Primary Care 2018. [Ineen. Benchmark Huisartsenposten 2018]. Utrecht.

20) Argentino $C$, Toni $D$, Rasura $M$, Violi F, Sacchetti ML, Allegretta A, et al. Circadian variation in the frequency of ischemic stroke. Stroke. 1990;21(3):387-9.

21) Muller JE. Circadian variation in cardiovascular events. Am J Hypertens. 1999;12(2 Pt 2):35S42S.

22) Ripamonti L, Riva R, Maioli F, Zenesini C, Procaccianti G. Daily Variation in the Occurrence of Different Subtypes of Stroke. Stroke Res Treat. 2017;2017:9091250.

23) Elliott WJ. Circadian variation in the timing of stroke onset: a meta-analysis. Stroke. 1998;29(5):992-6.

24) Chaturvedi S, Adams HP, Jr., Woolson RF. Circadian variation in ischemic stroke subtypes. Stroke. 1999;30(9):1792-5.

25) Manfredini R, Boari B, Smolensky MH, Salmi R, la Cecilia O, Maria Malagoni A, et al. Circadian variation in stroke onset: identical temporal pattern in ischemic and hemorrhagic events. Chronobiol Int. 2005;22(3):417-53.

26) Feng J, Zhang JH, Qin X. Timing pattern of onset in hypertensive intracerebral hemorrhage patients. Acta Neurochir Suppl. 2011;111:327-31.

27) Omama S, Yoshida Y, Ogawa A, Onoda T, Okayama A. Differences in circadian variation of cerebral infarction, intracerebral haemorrhage and subarachnoid haemorrhage by situation at onset. J Neurol Neurosurg Psychiatry. 2006;77(12):1345-9.

28) Butt MU, Zakaria M, Hussain HM. Circadian pattern of onset of ischaemic and haemorrhagic strokes, and their relation to sleep/wake cycle. J Pak Med Assoc. 2009;59(3):129-32.

29) Sloan MA, Price TR, Foulkes MA, Marler JR, Mohr JP, Hier DB, et al. Circadian rhythmicity of stroke onset. Intracerebral and subarachnoid hemorrhage. Stroke. 1992;23(10):1420-6.

30) Manfredini R, Gallerani M, Portaluppi F, Salmi R, Fersini C. Chronobiological patterns of onset of acute cerebrovascular diseases. Thromb Res. 1997;88(6):451-63.

31) Elliott WJ. Cyclic and circadian variations in cardiovascular events. Am J Hypertens. 2001;14((9 Pt 2)):291S-5S.

32) Manfredini R, La Cecilia O, Boari B, Steliu J, Michelinidagger V, Carlidagger $P$, et al. Circadian pattern of emergency calls: implications for ED organization. Am J Emerg Med. 2002;20(4):282-6.

33) Erkelens DC, Wouters LT, Zwart DL, Damoiseaux RA, De Groot E, Hoes AW, et al. Optimisation of telephone triage of callers with symptoms suggestive of acute cardiovascular disease in out-of-hours primary care: observational design of the Safety First study. BMJ open. 2019;9(7):e027477.

34) Annual reports of 2014-2017. [Jaarverslagen 2014-2017.] Utrecht, The Netherlands: Foundation Primair out-of-hours services in primary care [Stichting Primair Huisartsenposten] 
35) The Dutch College of General Practitioners, NHG. The International Classification of Primary Care (ICPC). Version 6 (Dutch translation derived from ICPC-1 by the WONCA International Classification Committee). 2018. Available from: https://www.nhg.org/themas/artikelen/ icpc.

36) Verburg AF, Tjon ATMR, Verstappen WH, Beusmans GH, Wiersma T, Burgers JS. [Summary of the 'Stroke' guideline of the Dutch College of General Practitioners' (NHG)]. Nederlands tijdschrift voor geneeskunde. 2014;158(1):A7022.

37) Hacke W, Kaste M, Bluhmki E, Brozman M, Davalos A, Guidetti D, et al. Thrombolysis with alteplase 3 to 4.5 hours after acute ischemic stroke. N Engl J Med. 2008;359(13):1317-29.

38) Emberson J, Lees KR, Lyden P, Blackwell L, Albers G, Bluhmki E, et al. Effect of treatment delay, age, and stroke severity on the effects of intravenous thrombolysis with alteplase for acute ischaemic stroke: a meta-analysis of individual patient data from randomised trials. Lancet. 2014;384(9958):1929-35.

39) Jauch EC, Saver JL, Adams HP, Jr., Bruno A, Connors JJ, Demaerschalk BM, et al. Guidelines for the early management of patients with acute ischemic stroke: a guideline for healthcare professionals from the American Heart Association/American Stroke Association. Stroke. 2013;44(3):870-947.

40) Chen L, Yang G. Recent advances in circadian rhythms in cardiovascular system. Front Pharmacol. 2015;6:71. 


$$
5
$$




\section{Development of a diagnostic prediction model for detecting}

transient ischaemic attack and stroke in out-of-hours primary care: A cross-sectional study

D.C. Erkelens

D.L. Zwart

L.T. Wouters

M. van Smeden

S. van Doorn

E. de Groot

R.A. Damoiseaux

F.H. Rutten

Manuscript in preparation 


\section{Abstract}

Background: Accurate diagnosis of transient ischaemic attack (TIA) and stroke during telephone triage at out-of-hours services in primary care (OHS-PC) is crucial for improving the prognosis. Yet, this is challenging due to the availability of verbal information only on symptom presentation. Several diagnostic prediction models exist for triage in the hospital setting, but notably are lacking for the OHS-PC setting during telephone triage.

Aim: To develop a diagnostic prediction model for telephone triage of patients presenting with symptoms suggestive of TIA or stroke who call the OHS-PC.

Design and Setting: Cross-sectional study at nine OHS-PC locations in the Netherlands between 2014 and 2017.

Methods: We included triage recordings of OHS-PC callers with neurological deficit or other symptoms suggestive of TIA or stroke. We collected information about symptoms and medical history by listening to the triage recordings, and we gathered patient and call characteristics from the electronic health records (EHR) at the OHS-PC. The primary outcome - whether or not having a final diagnosis of TIA or stroke - was retrieved from the EHR of the patients' own general practitioner and included information from hospital discharge letters. We used multivariable logistic regression models to predict TIA or stroke, and calculated c-statistics to quantify the discriminative ability of the models. We applied bootstrapping for internal validation.

Results: Of 1,381 patients (mean age 68.9 years (SD 18.4), 56.6\% women) who called with symptoms suggestive of TIA or stroke, 703 (50.9\%) received the diagnosis TIA/ stroke (34.5\% TIA/minor stroke, $16.4 \%$ major ischaemic or haemorrhagic stroke). The final prediction model for TIA/stroke included five predictors (age, female sex, face drooping, arm weakness, and speech problems) and had a discriminative ability (c-statistic) of 0.73 (95\% Cl 0.70-0.75).

Conclusions: Our diagnostic prediction model for TIA and stroke has good discriminative ability and could be applied at the OHS-PC to improve telephone triage of patients calling with neurological symptoms after future external validation.

How this fits in: Existing hospital-based diagnostic prediction models for TIA or stroke lack generalizability to the out-of-hours service in primary care (OHS-PC) setting. A new model based on symptom presentation assessed by telephone at the OHS-PC could improve timely diagnosis and thus impacts on time of initiation of treatment and prognosis. 


\section{Introduction}

Early recognition of patients with a transient ischaemic attack (TIA) or ischaemic stroke is crucial for rapid initiation of stroke prevention that may result in a tremendous decrease of stroke risk.(1-3) A reduction of recurrent stroke of up to $80 \%$ after swift evaluation and treatment within three months has been reported.(1) In patients with major ischaemic stroke, timely initiation of therapeutic interventions focused on revascularisation reduces the risk of (permanent) brain injury and recurrent stroke.(1, 3-7) Still, recognition of TIA, and to a lesser extent stroke, is challenging, because of the high rate of 'mimics'.(8-10) In addition, symptoms may be non-specific, short lasting or have already resolved by the time the patient requests medical help. $(8,11)$

In the Netherlands, patients with neurological symptoms or other symptoms suggestive of TIA or stroke often first contact the general practitioner (GP).(12-15) Outside the GP's office hours primary care is delivered in large services (i.e. out-of-hours services in primary care, $\mathrm{OHS}-\mathrm{PC}$ ), with a nurse performing triage based on the initial telephone contact while supervised by the GP.(16) The aim of telephone triage is to classify patients according to the supposed urgency of their symptoms. Triage nurses at most Dutch OHSPCs use a five-level, semi-automatic decision support tool called the 'Netherlands Triage Standard' (NTS), which is partly derived from the physically oriented Manchester Triage System.(17) After the initial ABCD (airway, breathing, circulation, disability) check (18), triage nurses have to choose the most appropriate of 56 'main complaints' based on the patient's initial symptom presentation in order to start with the underlying algorithm of the NTS. After completing a few key questions, and filling out the patient's answers in the NTS, an urgency level is automatically generated which is linked to the maximum response time by which medical help should be provided. $(17,19)$ These urgency levels are: U1 (ambulance dispatch within 15 minutes), U2 (GP consultation within one hour), U3 (GP consultation within three hours), U4 (GP consultation within 24 hours), and U5 (telephone advice).(17, 20) GP consultation consists of either a home visit or an appointment at the OHS-PC. The NTS urgency may be scaled up or down by the triage nurse, which is often only done after first consulting the supervising GP.(21)

Every 'main complaint' in the NTS consists of a decision algorithm that could be considered as a diagnostic prediction model on its own, but these have never been validated for triaging nor specifically been developed or validated for TIA or stroke. Existing prediction models for TIA or stroke do exist, for instance: (i) the Dawson score, (ii) Diagnosis Of TIA (DOT) score, (iii) the (modified) Explicit Diagnostic Criteria for TIA (EDCT), (iv) Face Arm Speech Time (FAST) test, (v) the Recognition Of Stroke In the Emergency Room (ROSIER) scale, (vi) the Cincinnati Prehospital Stroke Scale (CPSS), (vii) the Los Angeles Prehospital Stroke Screen (LAPSS), (viii) the Melbourne Ambulance Stroke Scale (MASS), (ix) the Ontario Prehospital Stroke Screening (OPSS) tool, (x) the Medic Prehospital Assessment for Code Stroke (MedPACS), (xi) the PreHospital Ambulance 
Stroke Test (PreHAST), and (xii) the ABCD2.(22-34) However, all these prediction models were developed in the hospital setting, where the prevalence of TIA and stroke is higher than in primary care, and in general concern more severe cases. Clearly, both these aspects affect the diagnostic accuracy of the model through the predictor effects and intercept. It is therefore vital to not naively apply the aforementioned hospital based models in general practice. In addition, most of these models were developed in populations with confirmed TIA or stroke after physical examination, that is, with objectification of signs and symptoms. Thus, implementation of these models at the OHS-PC is seriously hampered. $(35,36)$

In this study, we aimed to develop a diagnostic prediction model for telephone triage of $\mathrm{TIA} /$ stroke at the OHS-PC that could be applied in patients with symptoms suggestive of TIA or stroke.

\section{Methods}

\section{Data collection}

We used data from a cross-sectional study in which we analysed telephone triage recordings of patients who called the OHS-PC with neurological symptoms or other symptoms suggestive of TIA or stroke between 2014 and 2017. The recordings were obtained from nine OHS-PC locations in the central region of the Netherlands that serve a total population of 1.5 million people, with on average 300,000 calls per year. The triage recordings were selected in a two-step inclusion procedure based on (i) the International Classification of Primary Care (ICPC) codes linked to the call, and (ii) medical keywords in the OHS-PC electronic health records (EHR).(37) We sampled a broad variety of ICPC codes and keywords to capture our entire study domain of patients suspected of TIA or stroke (see Figure 1). After selecting a random sample of 2,500 calls, we applied the following exclusion criteria: age below 18 years, callers not living in the vicinity of the OHS-PC (i.e. final diagnosis not retrievable), poor quality of the recording or the call was no actual triage call (i.e. other kind of conversation, e.g. between GP and neurologist). A detailed description of the study design, and inclusion and exclusion criteria has been published elsewhere.(38)

\section{Candidate predictors}

For data collection we used two sources: the triage recording and the EHR of the OHS-PC. Two researchers (DCE, LTW) and 15 medical students listened to the triage recordings while blinded to the final outcome, and collected data on signs and symptoms, medical history, and assigned urgencies. Patient and call characteristics were retrieved from the EHR of the OHS-PC. As candidate predictors we included age, gender, face drooping, arm weakness, speech problems, leg weakness, history of TIA, history of acute cardiovascular disease, hypertension, diabetes, acute onset of symptom(s) (i.e. within seconds to 1-2 
minutes). Selection of these candidate predictors was based on previous literature on diagnostic prediction models for TIA or stroke in hospital settings (22-34), NTS triage criteria, and other commonly discussed items during telephone triage of patients with symptoms suggestive of TIA or stroke (see Table 1).

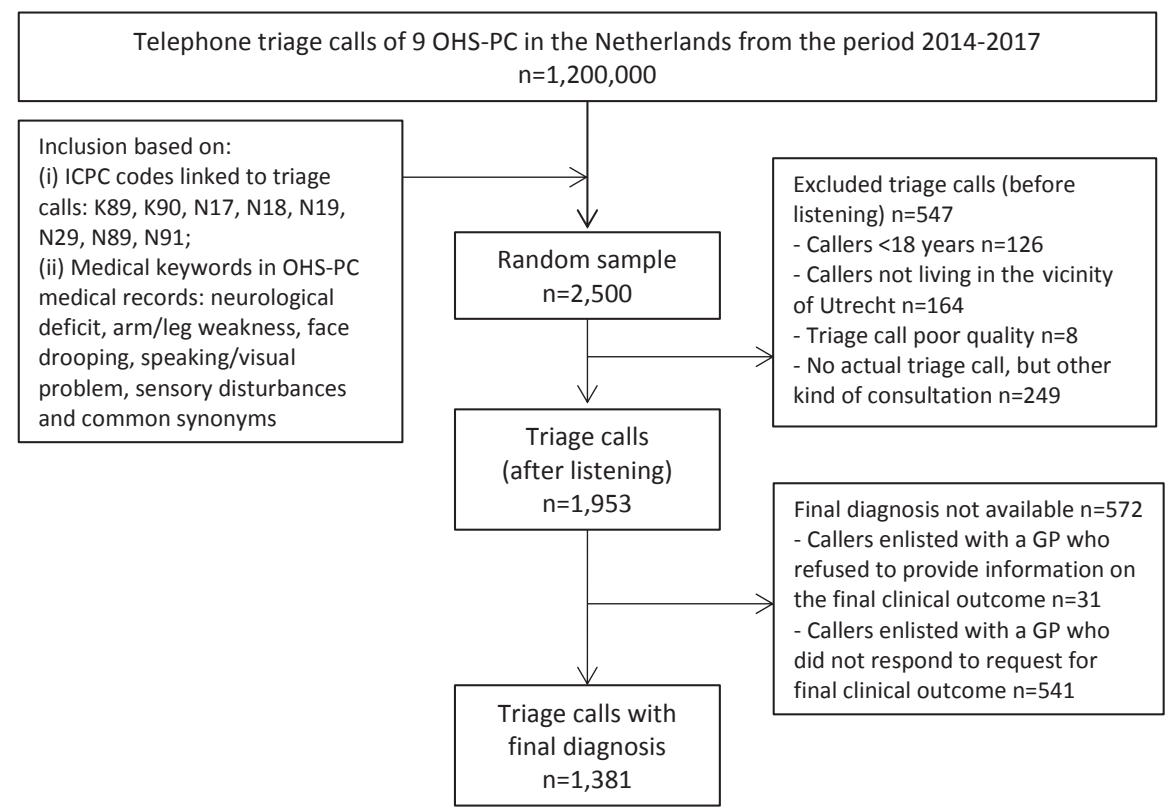

Figure 1. Flowchart

\section{Primary outcome}

The primary outcome was a final diagnosis of TIA or stroke. The final diagnosis of every patient was retrieved from the patient's own GP. If the patient was referred to the hospital for additional investigations, the final diagnosis was based on the discharge letter from the neurologist. For patients who were not referred we used follow-up information from the EHR of the GPS, up to one month after the OHS-PC contact to also capture possible recurrence of TIA or stroke.

\section{Sample size calculation}

We calculated the minimal sample size required for developing a prediction model using the 'pmsampsize' package in R.(39-41) Within the domain of patients suspected of TIA or stroke in OHS-PC settings we assumed a prevalence of TIA/stroke of around $50 \%$ based on existing literature.(11, 22, 42-48) In the absence of information on performance of existing models for telephone triage of TIA or stroke in OHS-PC settings, we used an $\mathrm{R}^{2}$ of 0.15 as suggested by Riley et al. and maximum expected shrinkage of 0.95.(39) The calculated minimum sample size to consider 11 candidate predictors was 1,281 patients, including 653 with a final diagnosis of TIA or stroke. 







\section{Data analyses}

First, we compared patients with and without a final diagnosis (i.e. due to non-response of some GPs to deliver the final clinical diagnosis related to the OHS-PC contact) to assess potential differences in characteristics, and thus selection (see Supplementary Data Table S1).

Secondly, we developed a diagnostic prediction model while following the 'Transparent Reporting of a multivariable prediction model for Individual Prognosis Or Diagnosis' (TRIPOD) criteria.(49) We used multivariable logistic regression analyses to test 11 candidate predictors, and compare four pre-defined models with increasing complexity to predict TIA/stroke. Because automated predictor selection in multivariable modelling may yield over-fitted and optimistic models (49-53), we decided to use pre-defined models. The candidate predictors of the pre-defined were selected because they were included in previous diagnostic prediction models for TIA or stroke (see Table 1), included in the NTS triage criteria or commonly discussed during telephone triage, and thus considered clinically relevant.(22-34) The first pre-defined model was the base model and included age and female sex. For the second model we added face drooping, arm weakness and speech problems to the base model. For the third model we added three candidate predictors with less than $50 \%$ missing data, namely leg weakness, history of TIA and a history of cardiovascular disease. For the fourth model we added three other candidate predictors with more than $50 \%$ missing data: hypertension, diabetes and acute onset of symptom(s).(54)

For missing data of candidate predictors (see Supplementary Data Table S2) we applied the multiple imputation method using the 'Multivariate Imputation via Chained Equation' (MICE) package in $\mathrm{R}$ with 70 imputation rounds and 50 iterations.(55) The results were pooled following Rubin's rules.(56) We assessed the internal validity of the models through bootstrapping, by using the 'Regression Modelling Strategies (rms)' package in R, with replications of the analyses on 200 different samples in each of the 70 imputed data sets.(57) The results of the regression coefficients estimates were pooled, i.e. apparent and internally validated c-statistics from each of the 70 imputed sets following Rubin's rules.(56) In addition, we calculated the calibration slope of each model. In the absence of other studies on diagnostic prediction models for telephone triage of patients suspected of TIA or stroke at the OHS-PC, external validation of our prediction model could not be performed. Analyses of descriptive statistics were performed with SPSS version 25.0.0.2 and multiple imputation, model development, and performance testing were done with R Studio version 1.2.5042.

\section{Ethical approval}

This study (National Trial Register identification number: NTR7331) was approved by the Medical Ethics Review Committee Utrecht, the Netherlands (reference number WAG/ $\mathrm{mb} / 16 / 003208$ ) and complied with the Declaration of Helsinki. In addition, a waiver of informed consent was granted as our study involved minimal risk to subjects and could 
not have been carried out otherwise. All personal and research data were handled and stored according to the European General Data Protection Regulation.

\section{Results}

Of the 1,381 patients with symptoms suggestive of TIA/stroke in whom a final diagnosis was established, 703 (50.9\%) had a TIA/stroke. The mean age of the entire study population was 68.9 (standard deviation (SD) 18.4) years, and 56.6\% were women. Patients with a TIA/stroke as the final diagnosis were significantly older (75.5 vs. 62.0 years, $p<0.001)$, had shorter calls (06:54 min vs. 07:30 min, $p=0.018)$, more often someone else called on behalf of the patient ( $84.5 \%$ vs. $68.1 \%, p<0.001)$, and the triage nurse consulted the GP more often for supervision (62.9\% vs. 55.8\%, $p=0.007$ ) than in calls of patients with other diagnoses. Almost all patients (92.0\%) still had symptoms at the time of calling, and about half of all patients (52.9\%) had a history of cardiovascular disease. The majority of patients (69.5\%) were allocated a high urgency (seen within one hour; U1 or U2), and in patients with a final diagnosis of TIA/stroke this was $75.8 \%$. The flowchart of the study population and a complete overview of all characteristics (patient and call characteristics, symptoms, and medical history) are displayed in Figure 1 and Table 2, respectively.

There were no clinically meaningful differences in patient or call characteristics and symptoms between the 1,381 patients with and the 572 patients without a final diagnosis (see Supplementary Data Table S1). 
Table 2. Characteristics of 1,381 patients who called the OHS-PC with symptoms suggestive of TIA/stroke between 2014 and 2017

\begin{tabular}{|c|c|c|c|}
\hline & $\begin{array}{l}\text { TIA/stroke } \\
\mathrm{n}=703(50.9 \%)\end{array}$ & $\begin{array}{l}\text { No TIA/stroke } \\
n=678(49.1 \%)\end{array}$ & P-value \\
\hline \multicolumn{4}{|l|}{ Patient characteristics } \\
\hline Mean age in years (SD) & 75.5 (13.9) & $62.0(19.8)$ & $<0.001$ \\
\hline Female sex & $388(55.2)$ & $393(58.0)$ & 0.299 \\
\hline \multicolumn{4}{|l|}{ Medical history } \\
\hline Cardiovascular disease $(n=953)$ & $427(84.4)$ & $304(68.0)$ & $<0.001$ \\
\hline TIA $(n=699)$ & $125(33.1)$ & $65(20.2)$ & $<0.001$ \\
\hline Stroke $(n=699)$ & $102(27.0)$ & $86(26.8)$ & 0.954 \\
\hline Coronary artery disease $(n=333)$ & $29(20.3)$ & $27(14.2)$ & 0.143 \\
\hline Arrhythmia $(n=325)$ & $40(28.4)$ & $24(13.0)$ & 0.001 \\
\hline \multicolumn{4}{|l|}{ Cardiovascular risk factors } \\
\hline Hypertension $(n=465)$ & $133(60.5)$ & $94(38.4)$ & $<0.001$ \\
\hline $\begin{array}{l}\text { Hypercholesterolemia or use of statins } \\
(n=428)\end{array}$ & $107(51.7)$ & $69(31.2)$ & $<0.001$ \\
\hline Diabetes $(n=459)$ & $94(44.3)$ & $69(27.9)$ & $<0.001$ \\
\hline \multicolumn{4}{|l|}{ Cardiovascular medication } \\
\hline Antiplatelets ( $n=1025)$ & $170(30.4)$ & $94(20.2)$ & $<0.001$ \\
\hline $\begin{array}{l}\text { Anticoagulants (new oral anticoagulant } \\
\text { or vitamin K) ( } n=1025)\end{array}$ & 59 (10.6) & $36(7.7)$ & 0.120 \\
\hline \multicolumn{4}{|l|}{ Call characteristics } \\
\hline Median call duration in min:sec (IQR) & 06:54 (05:01-09:21) & 07:30 (05:15-09:58) & $0.018^{*}$ \\
\hline $\begin{array}{l}\text { Median time for caller's introduction in } \\
\text { min:sec (IQR) }\end{array}$ & $00: 20(00: 13-00: 30)$ & $00: 19(00: 12-00: 26)$ & $0.009^{*}$ \\
\hline $\begin{array}{l}\text { Someone else called first on behalf of } \\
\text { the patient }\end{array}$ & $594(84.5)$ & $462(68.1)$ & $<0.001$ \\
\hline $\begin{array}{l}\text { Triage nurse consulted the general } \\
\text { practitioner }\end{array}$ & $442(62.9)$ & $378(55.8)$ & 0.007 \\
\hline Caller expresses concern $(n=670)$ & $306(92.7)$ & $315(92.6)$ & 0.968 \\
\hline \multicolumn{4}{|l|}{ Symptoms mentioned during the call } \\
\hline Face drooping $(n=783)$ & $187(44.0)$ & $190(53.1)$ & 0.011 \\
\hline Arm weakness $(n=856)$ & $248(51.1)$ & $119(32.1)$ & $<0.001$ \\
\hline Leg weakness $(n=721)$ & $196(49.6)$ & $118(36.2)$ & $<0.001$ \\
\hline Sensory disturbances $(n=402)$ & $176(92.6)$ & $190(89.6)$ & 0.292 \\
\hline Speech problems $(n=845)$ & $416(81.7)$ & $240(71.4)$ & $<0.001$ \\
\hline Dysarthria $(n=454)$ & $184(65.5)$ & $91(52.6)$ & 0.006 \\
\hline Dysphasia $(n=470)$ & $177(60.6)$ & $87(48.9)$ & 0.013 \\
\hline Vision problem $(n=206)$ & $73(79.3)$ & $91(79.8)$ & 0.933 \\
\hline Headache $(n=532)$ & $112(49.1)$ & $190(62.5)$ & 0.002 \\
\hline Ataxia $(n=256)$ & $141(84.4)$ & $73(82.0)$ & 0.620 \\
\hline Dizziness $(n=334)$ & $121(80.7)$ & $159(86.4)$ & 0.156 \\
\hline
\end{tabular}


Table 2. Continued.

$\begin{array}{lll}\text { TIA/stroke } & \text { No TIA/stroke } & \text { P-value } \\ n=703(50.9 \%) & n=678(49.1 \%) & \end{array}$

Autonomic nervous system associated symptoms

\begin{tabular}{|c|c|c|c|}
\hline Sweating $(n=227)$ & $36(34.3)$ & $65(53.3)$ & 0.004 \\
\hline Nausea or vomiting $(n=336)$ & $50(40.7)$ & $136(63.8)$ & $<0.001$ \\
\hline Pallor or ashen skin $(n=286)$ & $57(38.3)$ & $55(40.1)$ & 0.743 \\
\hline (Feeling of nearly) fainting ( $n=1206)$ & $39(6.4)$ & $63(10.6)$ & 0.007 \\
\hline \multicolumn{4}{|l|}{ Course of symptoms } \\
\hline Acute onset of symptom(s) $(n=233)$ & $96(89.7)$ & $100(79.4)$ & 0.031 \\
\hline $\begin{array}{l}\text { Duration of symptoms } \leq 4.5 \text { hours } \\
(n=1054)\end{array}$ & $356(65.2)$ & $277(54.4)$ & $<0.001$ \\
\hline Symptoms still present at time of calling & $640(91.0)$ & $630(92.9)$ & 0.198 \\
\hline \multicolumn{4}{|l|}{ Other characteristics } \\
\hline $\begin{array}{l}\text { Recognition of symptoms from } \\
\text { previous TIA ( } n=395)\end{array}$ & $46(23.7)$ & $25(12.4)$ & 0.004 \\
\hline $\begin{array}{l}\text { Estimation of TIA/stroke risk according } \\
\text { to researcher: median presentiment } \\
\text { researcher (range } 0-100, I Q R \text { ) }\end{array}$ & $80.0(60.0-80.0)$ & $50.0(20.0-70.0)$ & $<0.001^{*}$ \\
\hline \multicolumn{4}{|l|}{ Urgency allocation } \\
\hline High urgency (U1 or U2) & $533(75.8)$ & $427(63.0)$ & \multirow[t]{4}{*}{$<0.001$} \\
\hline U1 & $193(27.5)$ & $137(20.2)$ & \\
\hline U2 & $340(48.4)$ & $290(42.8)$ & \\
\hline Low urgency (U3, U4 or U5) & $170(24.2)$ & $251(37.0)$ & \\
\hline
\end{tabular}

Legend: Abbreviations: CVD: cardiovascular disease; IQR: interquartile range; OHS-PC: out of hours services in primary care; SD: standard deviation; TIA: transient ischaemic attack. For differences of continuous variables we used the independent sample t-test or Mann-Whitney $U$ test $\left({ }^{*}\right)$, and for categorical variables we used the Chi ${ }^{2}$ test.

\section{Final diagnosis}

Of the 1,381 patients, 703 had a final diagnosis of TIA/stroke; $67.7 \%$ had a TIA or minor stroke and $32.3 \%$ had an ischaemic or haemorrhagic stroke (Table 3). The majority (82.6\%) of TIA/stroke patients was diagnosed by the treating neurologist upon referral, while the remainder was diagnosed by the GP (at the OHS-PC or the patient's own GP). Sixty-eight (4.9\%) patients had (neurological) life-threatening events other than stroke like subarachnoid haemorrhage, sepsis, meningitis, severe hypoglycaemia, herpes encephalitis. The remaining final (groups of) diagnoses were (i.e. 'mimics'): peripheral nerve problem (9.1\%), peripheral vestibular syndromes (4.9\%), psychogenic syndromes (3.9\%), migraine (3.4\%), syncope (2.3\%), epilepsy (1.8\%), brain tumour $(1.2 \%)$ and other non-urgent diagnoses (17.6\%). 
Table 3. Final diagnoses of 1,381 patients who called the OHS-PC with symptoms suggestive of TIA/stroke between 2014 and 2017

\begin{tabular}{ll} 
Diagnosis & $\begin{array}{l}\text { Total } \\
\mathbf{n}=\mathbf{1 3 8 1}\end{array}$ \\
\hline TIA/minor stroke & $476(34.5)$ \\
\hline Major stroke $^{*}$ & $227(16.4)$ \\
\hline Other life threatening events** $^{* *}$ & $68(4.9)$ \\
Subarachnoid haemorrhage & $2(2.9)$ \\
\hline Migraine & $47(3.4)$ \\
With aura & $17(37.8)$ \\
\hline Epilepsy & $25(1.8)$ \\
\hline Syncope & $31(2.3)$ \\
\hline Brain tumor & $17(1.2)$ \\
\hline Peripheral vestibular syndromes & $68(4.9)$ \\
Benign paroxysmal positional vertigo & $22(32.4)$ \\
Meniere disease & $2(2.9)$ \\
Vestibular neuritis & $5(7.4)$ \\
\hline Peripheral nerve problem & $125(9.1)$ \\
Bell's palsy & $36(28.8)$ \\
Facial nerve palsy other than Bell's palsy & $89(71.2)$ \\
\hline Psychogenic syndromes & $54(3.9)$ \\
\hline Other non-urgent diagnoses & $243(17.6)$ \\
\hline
\end{tabular}

Legend: Abbreviations: OHS-PC: out of hours services in primary care; TIA: transient ischaemic attack. *Including lacunar infarction and stroke not otherwise specified; **Amongst others sepsis, acute coronary syndrome, meningitis, herpes encephalitis, coma, severe anemia due to gastrointestinal bleeding, hypoglycaemia, acute pulmonary embolism; ${ }^{* * *}$ Amongst others guillain barre, multiple sclerosis, alcohol intoxication.

\section{Prediction models}

We used a multivariable logistic regression analysis considering 11 candidate predictors, and compare four pre-defined models to predict TIA/stroke. The regression coefficients and odds ratios of the predictors, and the (apparent and optimism corrected) c-statistics and calibration slope of each of the models are displayed in Tables 4-7. The first predefined model (base model with age and female sex as predictors) had an optimism corrected c-statistic (after bootstrapping) of 0.70 (0.68-0.73). The second model (i.e. addition of face drooping, arm weakness and speech problems to the base model) had an optimism corrected c-statistic of 0.73 (0.70-0.75). The third model (i.e. addition of leg weakness, history of TIA and a history of cardiovascular disease to the second model) had an optimism corrected c-statistic 0.73 (0.70-0.75). Finally, the fourth model (i.e. addition of hypertension, diabetes and acute onset of symptom(s) to the third model) had an optimism corrected c-statistic of 0.73 (0.71-0.76). 
Table 4. Pre-defined model 1

\begin{tabular}{llll} 
Predictors & Beta (SE) & Odds ratio & P-value \\
\hline Intercept & $-3.096(0.265)$ & 0.045 & $<0.001$ \\
\hline Age in years & $0.047(0.004)$ & 1.048 & $<0.001$ \\
\hline Female sex & $-0.269(0.118)$ & 0.764 & 0.023 \\
\hline Performance measures & & \\
\hline Apparent c-statistic $(95 \% \mathrm{Cl})$ & $0.706(0.678-0.733)$ & \\
\hline Optimism corrected c-statistic $(95 \% \mathrm{Cl})$ & $0.704(0.676-0.731)$ & \\
\hline Calibration slope & 0.993 & \\
\hline
\end{tabular}

Legend: Abbreviation: SE: standard error.

Table 5. Pre-defined model 2

\begin{tabular}{llll} 
Predictors & Beta (SE) & Odds ratio & P-value \\
\hline Intercept & $-3.517(0.298)$ & 0.030 & $<0.001$ \\
\hline Age in years & $0.044(0.004)$ & 1.045 & $<0.001$ \\
\hline Female sex & $-0.312(0.122)$ & 0.732 & 0.010 \\
\hline Face drooping & $-0.024(0.157)$ & 0.976 & 0.880 \\
\hline Arm weakness & $0.550(0.147)$ & 1.734 & $<0.001$ \\
\hline Speech problems & $0.651(0.163)$ & 1.917 & $<0.001$ \\
\hline Performance measures & & \\
\hline Apparent c-statistic $(95 \% \mathrm{Cl})$ & $0.730(0.702-0.758)$ & \\
\hline Optimism corrected c-statistic (95\% Cl) & $0.726(0.699-0.754)$ & \\
\hline Calibration slope & 0.982 & \\
\hline
\end{tabular}

Legend: Abbreviation: SE: standard error.

Table 6. Pre-defined model 3

\begin{tabular}{llll} 
Predictors & Beta (SE) & Odds ratio & P-value \\
\hline Intercept & $-3.504(0.302)$ & 0.030 & $<0.001$ \\
\hline Age in years & $0.044(0.004)$ & 1.045 & $<0.001$ \\
\hline Female sex & $-0.306(0.123)$ & 0.737 & 0.013 \\
\hline Face drooping & $-0.028(0.160)$ & 0.972 & 0.859 \\
\hline Arm weakness & $0.526(0.185)$ & 1.692 & 0.005 \\
\hline Speech problems & $0.656(0.166)$ & 1.927 & $<0.001$ \\
\hline Leg weakness & $0.049(0.184)$ & 1.051 & 0.788 \\
\hline History of TIA & $0.223(0.197)$ & 1.250 & 0.258 \\
\hline History of cardiovascular disease & $-0.083(0.197)$ & 0.920 & 0.675 \\
\hline Performance measures & & & \\
\hline Apparent c-statistic (95\% CI) & $0.732(0.704-0.760)$ & \\
\hline Optimism corrected c-statistic $(95 \% \mathrm{CI})$ & $0.726(0.698-0.754)$ & \\
\hline Calibration slope & 0.967 &
\end{tabular}

Legend: Abbreviation: SE: standard error. 
Table 7. Pre-defined model 4

\begin{tabular}{llll} 
Predictors & Beta (SE) & Odds ratio & P-value \\
\hline Intercept & $-3.834(0.352)$ & 0.022 & $<0.001$ \\
\hline Age in years & $0.043(0.004)$ & 1.044 & $<0.001$ \\
\hline Female sex & $-0.339(0.129)$ & 0.712 & 0.009 \\
\hline Face drooping & $0.020(0.165)$ & 1.020 & 0.904 \\
\hline Arm weakness & $0.503(0.196)$ & 1.654 & 0.0106 \\
\hline Speech problems & $0.640(0.173)$ & 1.896 & $<0.001$ \\
\hline Leg weakness & $0.055(0.193)$ & 1.056 & 0.776 \\
\hline History of TIA & $0.192(0.201)$ & 1.212 & 0.340 \\
\hline History of cardiovascular disease & $-0.250(0.335)$ & 0.779 & 0.456 \\
\hline Hypertension & $-0.075(0.341)$ & 0.928 & 0.827 \\
\hline Diabetes & $0.334(0.259)$ & 1.397 & 0.200 \\
\hline Acute onset of symptom(s) & $0.523(0.238)$ & 1.688 & 0.030 \\
\hline Performance measures & & \\
\hline Apparent c-statistic $(95 \% \mathrm{CI})$ & $0.743(0.713-0.772)$ & \\
\hline Optimism corrected c-statistic $(95 \% \mathrm{CI})$ & $0.734(0.705-0.763)$ & \\
\hline Calibration slope & 0.955 &
\end{tabular}

Legend: Abbreviation: SE: standard error.

\section{Discussion}

\section{Main findings}

This is the first study to develop a diagnostic prediction model specifically for the use during telephone triage of patients presenting with symptoms suggestive of TIA or stroke who call the OHS-PC. The most comprehensive model included 11 predictors, and had an optimism corrected c-statistic of 0.73 (95\% Cl 0.71-0.76). Yet, the final model that seems most appropriate for the OHS-PC is a more simplified model with only five predictors (i.e. age, female sex and the three items of the FAST test; face drooping, arm weakness, and speech problems), which had a similar optimism corrected c-statistic of 0.73 (0.70-0.75) and a higher calibration slope (0.98 vs. 0.96).

\section{Strengths and limitations}

An important strength was that we used two data sources and therefore, the original telephone triage conversations could be analysed blinded to the final medical outcome that was retrieved afterwards (i.e. without hindsight bias). Another strength was that for the reporting of our diagnostic prediction model we adhered to the TRIPOD criteria.(49) Finally, we included nine OHS-PC locations covering both urban and rural areas of the Netherlands which makes our findings generalizable to the whole of the Netherlands, but also to other countries with a similar healthcare system with a strong primary care that is 
organized in large scale out-of-hours primary care centers, e.g. Scandinavian countries, Germany, Belgium and the UK.(58)

A limitation of our study was a relatively large portion of missing data on some of the candidate predictors. Because complete case analysis may lead to biased results, we applied multiple imputation for missing data. $(55,59)$ We had also missing outcome data, but fortunately, we could compare rather detailed patient characteristics of those in whom the GP delivered the final diagnosis and those in whom the GP did not. This comparison showed no substantial differences, and therefore missing outcome data unlikely resulted in selection bias by only using the data of patients in whom the final diagnosis was known. Another limitation was the lack of external validation of the proposed final model. To the best of our knowledge, there are no other studies available as validation sample; there are no other diagnostic prediction models for telephone triage (without assessment of symptoms and signs with physical examination). However, we performed internal validation of the final model, of which the results are hopeful considering the relatively simple model that would be easy to implement in practice. In addition, there are no prediction models specifically developed for the combined outcome of TIA and stroke. We explicitly chose for this combined outcome because the vast majority of patients (92\%) still had symptoms at the time of calling, and thus could be suspected of both TIA and stroke.

\section{Comparison with other studies}

Several TIA and stroke diagnostic prediction models exist, however, nearly all are developed and considered applicable for the emergency department where physicians may evaluate the patient, including physical examination. $(36,60)$ Triage nurses at the OHS-PC are not trained in diagnostic reasoning, and are unable to objectify the verbally presented signs and symptoms (e.g. asking for face drooping or arm weakness can result in unclear answers of callers, whereas objectification of these signs entails less risk of wrong interpretation of these symptoms). A few studies evaluated diagnostic prediction models for TIA or stroke in daytime general practice. $(25,48)$ The Dawson score performed good for diagnosing TIA when validated in UK general practice, with c-statistic of 0.70 (95\% Cl 0.66-0.75).(48) Overlapping with our final model are the predictors age, and the three items from the FAST test (i.e. face drooping, arm weakness and speech problems), although, the Dawson score combined arm with leg weakness into a single predictor. Also, the mean age (68.5 vs. 68.9 years) and the proportion women $(55.2 \%$ vs. $56.6 \%$ ) was similar to our study. The relation between female sex and stroke seems to be largely dependent on age, possibly because of a longer life expectancy of women compared to men. $(61,62)$ Although, overall stroke occurs more in women than men, at young age, the risk of stroke in women is similar to men, yet, at older ages the relative risk is slightly higher in men.(63) Thus, in a population with a higher absolute number of older women than men, the overall risk of stroke in women is somewhat higher than for men. 
The original and modified EDCT criteria performed very good in daytime general practice with TIA/minor stroke as the reference, with c-statistics for the EDCT of 0.80 ( $95 \% \mathrm{Cl} 0.73$ 0.87 ) and for the modified EDCT 0.86 (95\% Cl 0.80-0.92), respectively.(25) Importantly, however, the EDCT criteria were developed and validated in patients who had no longer symptoms. One of the criteria that needed to be fulfilled is full reversibility of symptoms. As a comparison, in our study $92 \%$ still had symptoms at the time of calling. Interestingly, in the validation study of the EDCT criteria the diagnosis was based on the consensus of three experienced neurologists using all available diagnostic information, including brain imaging in all patients, and in $38.8 \%$ they considered TIA/minor stroke absent while the treating neurologist considered TIA/minor stroke present (in $1.6 \%$ it was the other way around). Finally, another important EDCT criterion is that there should be no evidence of acute infarction on brain imaging, as seen with major stroke. All the aforementioned aspects create the opportunity for a good accuracy with the EDCT, and when appreciating these findings, one should realize that the domain of the validation study did not include a difficult to diagnose population, while it was in ours; patients suspected of any type of stroke, including a lacunar infarction or with a stroke in the vertebrobasilar circulation (see also Table 3).

\section{Implications for clinical practice and future research}

Our final prediction model (i.e. three items from the FAST test plus age and female sex) is explicitly useful for the OHS-PC setting, when the assessment is based on a telephone conversation under time pressure, where on average patient delay is low (in our study $60.1 \%$ of the patients contacted the OHS-PC within less than 4.5 hours after onset of symptoms), most patients still have symptoms at the time of calling, and when the composite endpoint TIA/stroke is the most appropriate. Furthermore, the three items from the FAST test were used in awareness campaigns for lay people (64, 65); it is therefore possible that these items are better known to the general public and thus sufficiently understandable during a triage conversation. The modified EDCT seems useful for daytime general practice, in patients in whom symptoms have resolved, and the diagnostic dilemma is condensed to discriminating TIA from a 'mimic'. Our final model included three items from the FAST test that are already incorporated in the NTS decision algorithms, namely face drooping, speech problems and arm weakness. Based on our findings, we recommend to also include age and female sex in the algorithm. Furthermore, our final diagnostic prediction model should preferably be externally validated in another OHS-PC setting.

\section{Conclusion}

Our diagnostic prediction model for TIA and stroke has good discriminative ability, and could be applied at the OHS-PC to improve telephone triage of patients calling with neurological symptoms after future external validation. 


\section{Declarations}

\section{Competing interests}

The authors declare that they have no competing interests.

\section{Funding}

This work was supported by (i) the department of general practice of the University Medical Center Utrecht, (ii) Associate Professorship-promotion grant of D.L. Zwart, MD, PhD, (iii) the foundation 'Netherlands Triage Standard' and (iv) the 'Stoffels-Hornstra' foundation. The views expressed are those of the authors and not necessarily those of the foundations. This research was conducted without direct involvement from both funding foundations.

\section{Authors' contributions}

DLZ and FHR conceived the idea for the study and gained funding. All authors designed the study. DCE and LTW collected the data. Data analysis was carried out by DCE and MVS. DCE prepared the manuscript and wrote the first draft, supervised by FHR. All authors provided intellectual input, critically reviewed the manuscript and read and approved the final manuscript.

\section{Acknowledgements}

The authors thank the OHS-PC foundation 'Primair Huisartsenposten' and all employees of the participating locations for their cooperation in this study, notably for providing data and technical support. 


\section{References}

1) Rothwell PM, Giles MF, Chandratheva A, Marquardt L, Geraghty O, Redgrave JN, et al. Effect of urgent treatment of transient ischaemic attack and minor stroke on early recurrent stroke (EXPRESS study): a prospective population-based sequential comparison. Lancet. 2007;370(9596):1432-42.

2) Lavallee PC, Meseguer E, Abboud H, Cabrejo L, Olivot JM, Simon O, et al. A transient ischaemic attack clinic with round-the-clock access (SOS-TIA): feasibility and effects. Lancet Neurol. 2007;6(11):953-60.

3) Rothwell PM, Algra A, Chen Z, Diener HC, Norrving B, Mehta Z. Effects of aspirin on risk and severity of early recurrent stroke after transient ischaemic attack and ischaemic stroke: time-course analysis of randomised trials. Lancet. 2016;388(10042):365-75.

4) Kidwell CS, Warach $S$. Acute ischemic cerebrovascular syndrome: diagnostic criteria. Stroke. 2003;34(12):2995-8.

5) Coull AJ, Lovett JK, Rothwell PM, Oxford Vascular S. Population based study of early risk of stroke after transient ischaemic attack or minor stroke: implications for public education and organisation of services. BMJ. 2004;328(7435):326.

6) Johnston SC, Gress DR, Browner WS, Sidney S. Short-term prognosis after emergency department diagnosis of TIA. Jama. 2000;284(22):2901-6.

7) Wu CM, McLaughlin K, Lorenzetti DL, Hill MD, Manns BJ, Ghali WA. Early risk of stroke after transient ischemic attack: a systematic review and meta-analysis. Archives of internal medicine. 2007;167(22):2417-22.

8) Nadarajan V, Perry RJ, Johnson J, Werring DJ. Transient ischaemic attacks: mimics and chameleons. Pract Neurol. 2014;14(1):23-31.

9) Hand PJ, Kwan J, Lindley RI, Dennis MS, Wardlaw JM. Distinguishing between stroke and mimic at the bedside: the brain attack study. Stroke. 2006;37(3):769-75.

10) Ay H, Buonanno FS, Rordorf G, Schaefer PW, Schwamm LH, Wu O, et al. Normal diffusionweighted MRI during stroke-like deficits. Neurology. 1999;52(9):1784-92.

11) Sheehan OC, Merwick A, Kelly LA, Hannon N, Marnane M, Kyne L, et al. Diagnostic usefulness of the $A B C D 2$ score to distinguish transient ischemic attack and minor ischemic stroke from noncerebrovascular events: the North Dublin TIA Study. Stroke. 2009;40(11):3449-54.

12) Doggen $C J$, Zwerink M, Droste HM, Brouwers PJ, van Houwelingen GK, van Eenennaam FL, et al. Prehospital paths and hospital arrival time of patients with acute coronary syndrome or stroke, a prospective observational study. BMC Emerg Med. 2016;16:3.

13) Manawadu D, Shuaib A, Collas DM. Emergency department or general practitioner following transient ischaemic attack? A comparison of patient behaviour and speed of assessment in England and Canada. Emergency medicine journal : EMJ. 2010;27(5):364-7.

14) Giles MF, Flossman E, Rothwell PM. Patient behavior immediately after transient ischemic attack according to clinical characteristics, perception of the event, and predicted risk of stroke. Stroke. 2006;37(5):1254-60.

15) Lasserson DS, Chandratheva A, Giles MF, Mant D, Rothwell PM. Influence of general practice opening hours on delay in seeking medical attention after transient ischaemic attack (TIA) and minor stroke: prospective population based study. BMJ. 2008;337:a1569.

16) Smits M, Rutten M, Keizer E, Wensing M, Westert G, Giesen P. The Development and Performance of After-Hours Primary Care in the Netherlands: A Narrative Review. Annals of internal medicine. 2017;166(10):737-42. 
17) van lerland $Y$, van Veen $M$, Huibers $L$, Giesen $P$, Moll HA. Validity of telephone and physical triage in emergency care: the Netherlands Triage System. Family practice. 2011;28(3):33441.

18) Thim $T$, Krarup NH, Grove EL, Rohde CV, Lofgren B. Initial assessment and treatment with the Airway, Breathing, Circulation, Disability, Exposure (ABCDE) approach. Int J Gen Med. 2012;5:117-21.

19) Blank L, Coster J, O'Cathain A, Knowles E, Tosh J, Turner J, et al. The appropriateness of, and compliance with, telephone triage decisions: a systematic review and narrative synthesis. J Adv Nurs. 2012;68(12):2610-21.

20) Bureau NTS. Nederlandse Triage Standaard (NTS) - Homepage 2020 [cited 2020 July 1]. Available from: https://de-nts.nl/.

21) Keizer E, Maassen I, Smits M, Wensing M, Giesen P. Reducing the use of out-of-hours primary care services: A survey among Dutch general practitioners. The European journal of general practice. 2016;22(3):189-95.

22) Dawson J, Lamb KE, Quinn TJ, Lees KR, Horvers M, Verrijth MJ, et al. A recognition tool for transient ischaemic attack. QJM : monthly journal of the Association of Physicians. 2009;102(1):43-9.

23) Dutta D. Diagnosis of TIA (DOT) score--design and validation of a new clinical diagnostic tool for transient ischaemic attack. BMC Neurol. 2016;16:20.

24) Lebedeva ER, Gurary NM, Gilev DV, Christensen AF, Olesen J. Explicit diagnostic criteria for transient ischemic attacks to differentiate it from migraine with aura. Cephalalgia. 2018;38(8):1463-70.

25) Dolmans LS, Lebedeva ER, Veluponnar D, van Dijk EJ, Nederkoorn PJ, Hoes AW, et al. Diagnostic Accuracy of the Explicit Diagnostic Criteria for Transient Ischemic Attack: A Validation Study. Stroke. 2019;50(8):2080-5.

26) Harbison J, Hossain O, Jenkinson D, Davis J, Louw SJ, Ford GA. Diagnostic accuracy of stroke referrals from primary care, emergency room physicians, and ambulance staff using the face arm speech test. Stroke. 2003;34(1):71-6.

27) Nor AM, Davis J, Sen B, Shipsey D, Louw SJ, Dyker AG, et al. The Recognition of Stroke in the Emergency Room (ROSIER) scale: development and validation of a stroke recognition instrument. Lancet Neurol. 2005;4(11):727-34.

28) Kothari RU, Pancioli A, Liu T, Brott T, Broderick J. Cincinnati Prehospital Stroke Scale: reproducibility and validity. Ann Emerg Med. 1999;33(4):373-8.

29) Kidwell CS, Starkman S, Eckstein M, Weems K, Saver JL. Identifying stroke in the field. Prospective validation of the Los Angeles prehospital stroke screen (LAPSS). Stroke. 2000;31(1):71-6.

30) Bray JE, Martin J, Cooper G, Barger B, Bernard S, Bladin C. Paramedic identification of stroke: community validation of the melbourne ambulance stroke screen. Cerebrovasc Dis. 2005;20(1):28-33.

31) Chenkin J, Gladstone DJ, Verbeek PR, Lindsay P, Fang J, Black SE, et al. Predictive value of the Ontario prehospital stroke screening tool for the identification of patients with acute stroke. Prehosp Emerg Care. 2009;13(2):153-9.

32) Studnek JR, Asimos A, Dodds J, Swanson D. Assessing the validity of the Cincinnati prehospital stroke scale and the medic prehospital assessment for code stroke in an urban emergency medical services agency. Prehosp Emerg Care. 2013;17(3):348-53. 
33) Andsberg G, Esbjornsson M, Olofsson A, Lindgren A, Norrving B, von Euler M. PreHospital Ambulance Stroke Test - pilot study of a novel stroke test. Scand J Trauma Resusc Emerg Med. 2017;25(1):37.

34) Johnston SC, Rothwell PM, Nguyen-Huynh MN, Giles MF, Elkins JS, Bernstein AL, et al. Validation and refinement of scores to predict very early stroke risk after transient ischaemic attack. Lancet. 2007;369(9558):283-92.

35) Leeflang MM, Rutjes AW, Reitsma JB, Hooft L, Bossuyt PM. Variation of a test's sensitivity and specificity with disease prevalence. CMAJ : Canadian Medical Association journal = journal de l'Association medicale canadienne. 2013;185(11):E537-44.

36) Justice AC, Covinsky KE, Berlin JA. Assessing the generalizability of prognostic information. Annals of internal medicine. 1999;130(6):515-24.

37) The Dutch College of General Practitioners, NHG. The International Classification of Primary Care (ICPC). Version 6 (Dutch translation derived from ICPC-1 by the WONCA International Classification Committee). 2018. Available from: https://www.nhg.org/themas/artikelen/ icpc.

38) Erkelens DC, Wouters LT, Zwart DL, Damoiseaux RA, De Groot E, Hoes AW, et al. Optimisation of telephone triage of callers with symptoms suggestive of acute cardiovascular disease in out-of-hours primary care: observational design of the Safety First study. BMJ open. 2019;9(7):e027477.

39) Riley RD, Ensor J, Snell KIE, Harrell FE, Jr., Martin GP, Reitsma JB, et al. Calculating the sample size required for developing a clinical prediction model. BMJ. 2020;368:m441.

40) Riley RD, Snell KI, Ensor J, Burke DL, Harrell FE, Jr., Moons KG, et al. Minimum sample size for developing a multivariable prediction model: PART II - binary and time-to-event outcomes. Stat Med. 2019;38(7):1276-96.

41) van Smeden M, Moons KG, de Groot JA, Collins GS, Altman DG, Eijkemans MJ, et al. Sample size for binary logistic prediction models: Beyond events per variable criteria. Stat Methods Med Res. 2019;28(8):2455-74.

42) Cameron AC, Dawson J, Quinn TJ, Walters MR, Mclnnes GT, Morrison D, et al. Longterm outcome following attendance at a transient ischemic attack clinic. Int J Stroke. 2011;6(4):306-11.

43) Murray S, Bashir K, Lees KR, Muir K, MacAlpine $C$, Roberts $M$, et al. Epidemiological aspects of referral to TIA clinics in Glasgow. Scott Med J. 2007;52(1):4-8.

44) Gibbs RG, Newson R, Lawrenson R, Greenhalgh RM, Davies AH. Diagnosis and initial management of stroke and transient ischemic attack across UK health regions from 1992 to 1996: experience of a national primary care database. Stroke. 2001;32(5):1085-90.

45) Clarey J, Lasserson D, Levi C, Parsons M, Dewey H, Barber PA, et al. Absolute cardiovascular risk and GP decision making in TIA and minor stroke. Family practice. 2014;31(6):664-9.

46) Magin P, Lasserson D, Parsons M, Spratt N, Evans M, Russell M, et al. Referral and triage of patients with transient ischemic attacks to an acute access clinic: risk stratification in an Australian setting. Int J Stroke. 2013;8 Suppl A100:81-9.

47) McNeill A. How accurate are primary care referral letters for presumed acute stroke? Scott Med J. 2008;53(4):11-2.

48) Lasserson DS, Mant D, Hobbs FD, Rothwell PM. Validation of a TIA recognition tool in primary and secondary care: implications for generalizability. Int J Stroke. 2015;10(5):692-6.

49) Moons KG, Altman DG, Reitsma JB, loannidis JP, Macaskill P, Steyerberg EW, et al. Transparent Reporting of a multivariable prediction model for Individual Prognosis or Diagnosis (TRIPOD): explanation and elaboration. Annals of internal medicine. 2015;162(1):W1-73. 
50) Steyerberg EW, Harrell FE, Jr., Borsboom GJ, Eijkemans MJ, Vergouwe Y, Habbema JD. Internal validation of predictive models: efficiency of some procedures for logistic regression analysis. Journal of clinical epidemiology. 2001;54(8):774-81.

51) Steyerberg EW, Eijkemans MJ, Harrell FE, Jr., Habbema JD. Prognostic modeling with logistic regression analysis: in search of a sensible strategy in small data sets. Med Decis Making. 2001;21(1):45-56.

52) Steyerberg EW, Eijkemans MJ, Harrell FE, Jr., Habbema JD. Prognostic modelling with logistic regression analysis: a comparison of selection and estimation methods in small data sets. Stat Med. 2000;19(8):1059-79.

53) Van Houwelingen HC, Sauerbrei W. Cross-validation, shrinkage and variable selection in linear regression revisited. Open J Statist. 2013;3:79-102.

54) Steyerberg E. Clinical Prediction Models. A Practical Approach to Development, Validation, and Updating. 2 ed: Springer International Publishing; 2019. 558 p.

55) Jolani S, Debray TP, Koffijberg H, van Buuren S, Moons KG. Imputation of systematically missing predictors in an individual participant data meta-analysis: a generalized approach using MICE. Stat Med. 2015;34(11):1841-63.

56) Rubin DB. Multiple imputation for non response in surveys. John Wiley \& Sons, Hoboken, NJ. 1987.

57) Harrell FE, Jr. Regression Modeling Strategies: With Applications to Linear Models, Logistic and Ordinal Regression, and Survival Analysis. . Second edition ed. Cham, Switzerland: Springer International; 2015.

58) Steeman L, Uijen M, Plat E, Huibers L, Smits M, Giesen P. Out-of-hours primary care in 26 European countries: an overview of organizational models. Family practice. 2020.

59) Janssen KJ, Donders AR, Harrell FE, Jr., Vergouwe Y, Chen Q, Grobbee DE, et al. Missing covariate data in medical research: to impute is better than to ignore. Journal of clinical epidemiology. 2010;63(7):721-7.

60) Zhelev Z, Walker G, Henschke N, Fridhandler J, Yip S. Prehospital stroke scales as screening tools for early identification of stroke and transient ischemic attack. The Cochrane database of systematic reviews. 2019;4:CD011427.

61) Reeves MJ, Fonarow GC, Zhao X, Smith EE, Schwamm LH, Get With The Guidelines-Stroke Steering $C$, et al. Quality of care in women with ischemic stroke in the GWTG program. Stroke. 2009;40(4):1127-33.

62) Roger VL, Go AS, Lloyd-Jones DM, Benjamin EJ, Berry JD, Borden WB, et al. Heart disease and stroke statistics--2012 update: a report from the American Heart Association. Circulation. 2012;125(1):e2-e220.

63) Kapral MK, Fang J, Hill MD, Silver F, Richards J, Jaigobin C, et al. Sex differences in stroke care and outcomes: results from the Registry of the Canadian Stroke Network. Stroke. 2005;36(4):809-14.

64) Dombrowski SU, Mackintosh JE, Sniehotta FF, Araujo-Soares V, Rodgers H, Thomson RG, et al. The impact of the UK 'Act FAST' stroke awareness campaign: content analysis of patients, witness and primary care clinicians' perceptions. BMC public health. 2013;13:915.

65) Flynn D, Ford GA, Rodgers H, Price C, Steen N, Thomson RG. A time series evaluation of the FAST National Stroke Awareness Campaign in England. PloS one. 2014;9(8):e104289. 


\section{Supplementary Data}

Table S1. Characteristics of 1,953 patients calling the OHS-PC with symptoms suggestive of $\mathrm{TIA} /$ stroke, comparing patients with and without follow-up information on the final diagnosis

\begin{tabular}{|c|c|c|c|}
\hline & $\begin{array}{l}\text { Follow-up } \\
\mathrm{n}=1381(70.7 \%)\end{array}$ & $\begin{array}{l}\text { No follow-up } \\
n=572(29.3 \%)\end{array}$ & P-value \\
\hline \multicolumn{4}{|l|}{ Patient characteristics } \\
\hline Mean age in years (SD) & $68.9(18.4)$ & $69.1(18.4)$ & 0.738 \\
\hline Female sex & $781(56.6)$ & $306(53.5)$ & 0.216 \\
\hline \multicolumn{4}{|l|}{ Medical history } \\
\hline Cardiovascular disease $(n=1348)$ & $731(76.7)$ & $327(82.8)$ & 0.013 \\
\hline TIA (n=996) & $190(27.1)$ & $83(28.0)$ & 0.772 \\
\hline Stroke $(n=996)$ & $188(26.9)$ & $106(35.8)$ & 0.005 \\
\hline Coronary artery disease $(n=459)$ & $57(17.1)$ & $34(27.2)$ & 0.015 \\
\hline Arrhythmia $(n=446)$ & $64(19.7)$ & $30(24.8)$ & 0.240 \\
\hline \multicolumn{4}{|l|}{ Cardiovascular risk factors } \\
\hline Hypertension $(n=647)$ & $227(48.8)$ & $101(55.5)$ & 0.127 \\
\hline Hypercholesterolemia or use of statins $(n=565)$ & $176(41.1)$ & $58(42.3)$ & 0.802 \\
\hline Diabetes $(n=626)$ & $163(35.5)$ & $78(46.7)$ & 0.011 \\
\hline \multicolumn{4}{|l|}{ Cardiovascular medication } \\
\hline Antiplatelets $(n=1450)$ & $264(25.8)$ & $117(27.5)$ & 0.485 \\
\hline $\begin{array}{l}\text { Anticoagulants (new oral anticoagulant or } \\
\text { vitamin } K)(n=1450)\end{array}$ & $95(9.3)$ & $56(13.2)$ & 0.027 \\
\hline \multicolumn{4}{|l|}{ Call characteristics } \\
\hline Median call duration in min:sec (IQR) & $\begin{array}{l}07: 09 \\
(05: 10-09: 39)\end{array}$ & $\begin{array}{l}07: 24 \\
(05: 12-09: 49)\end{array}$ & $0.265^{*}$ \\
\hline $\begin{array}{l}\text { Median time for caller's introduction in min:sec } \\
\text { (IQR) }\end{array}$ & $\begin{array}{l}00: 20 \\
(00: 13-00: 28)\end{array}$ & $\begin{array}{l}00: 19 \\
(00: 12-00: 28)\end{array}$ & $0.867^{*}$ \\
\hline $\begin{array}{l}\text { Someone else called first on behalf of the } \\
\text { patient }\end{array}$ & $1056(76.5)$ & $430(75.2)$ & 0.543 \\
\hline Triage nurse consulted the general practitioner & $820(59.4)$ & $328(57.3)$ & 0.406 \\
\hline Caller expresses concern $(n=917)$ & $621(92.7)$ & $232(93.9)$ & 0.513 \\
\hline \multicolumn{4}{|l|}{ Symptoms mentioned during the call } \\
\hline Face drooping $(n=1119)$ & $378(48.2)$ & $150(44.8)$ & 0.291 \\
\hline Arm weakness ( $n=1233$ ) & $367(42.9)$ & $155(41.1)$ & 0.564 \\
\hline Leg weakness ( $n=1038)$ & $314(43.5)$ & $137(43.4)$ & 0.968 \\
\hline Sensory disturbances $(n=553)$ & $367(91.1)$ & $134(89.3)$ & 0.535 \\
\hline Speech problems $(\mathrm{n}=1181)$ & $656(77.6)$ & $273(81.3)$ & 0.171 \\
\hline Dysarthria $(n=628)$ & $275(60.6)$ & $95(54.6)$ & 0.173 \\
\hline Dysphasia $(n=644)$ & $264(56.2)$ & $98(56.3)$ & 0.973 \\
\hline Vision problem $(n=293)$ & $164(79.6)$ & $66(75.9)$ & 0.475 \\
\hline Headache $(n=728)$ & $303(56.8)$ & $120(61.5)$ & 0.256 \\
\hline Ataxia $(n=358)$ & $214(83.6)$ & $81(79.4)$ & 0.348 \\
\hline
\end{tabular}


Table S1. Continued.

\begin{tabular}{|c|c|c|c|}
\hline & $\begin{array}{l}\text { Follow-up } \\
n=1381(70.7 \%)\end{array}$ & $\begin{array}{l}\text { No follow-up } \\
n=572(29.3 \%)\end{array}$ & P-value \\
\hline Dizziness ( $n=457)$ & $280(83.8)$ & $94(76.4)$ & 0.068 \\
\hline \multicolumn{4}{|l|}{ Autonomic nervous system associated symptoms } \\
\hline Sweating $(n=327)$ & $101(44.5)$ & $40(40.0)$ & 0.450 \\
\hline Nausea or vomiting $(n=455)$ & $186(55.4)$ & $55(46.2)$ & 0.086 \\
\hline Pallor or ashen skin $(n=420)$ & $112(39.2)$ & $55(41.0)$ & 0.713 \\
\hline (Feeling of nearly) fainting ( $n=1697$ ) & $102(8.5)$ & $35(7.1)$ & 0.370 \\
\hline \multicolumn{4}{|l|}{ Course of symptoms } \\
\hline Acute onset of symptom(s) $(n=338)$ & $196(84.1)$ & $91(86.7)$ & 0.545 \\
\hline Duration of symptoms $\leq 4.5$ hours $(n=1487)$ & $637(60.0)$ & $270(63.4)$ & 0.232 \\
\hline $\begin{array}{l}\text { Symptoms still present at time of calling } \\
(n=1941)\end{array}$ & $1270(92.0)$ & $523(93.4)$ & 0.282 \\
\hline \multicolumn{4}{|l|}{ Other characteristics } \\
\hline $\begin{array}{l}\text { Recognition of symptoms from previous TIA } \\
(n=559)\end{array}$ & $71(18.0)$ & $30(18.3)$ & 0.929 \\
\hline $\begin{array}{l}\text { Estimation of TIA/stroke risk according to } \\
\text { researcher: median presentiment researcher } \\
\text { (range } 0-100, I Q R)\end{array}$ & $\begin{array}{l}60.0 \\
(40.0-80.0)\end{array}$ & $\begin{array}{l}60.0 \\
(40.0-80.0)\end{array}$ & $0.821^{*}$ \\
\hline \multicolumn{4}{|l|}{ Urgency allocation } \\
\hline High urgency (U1 or U2) & $960(69.5)$ & $401(70.1)$ & 0.796 \\
\hline U1 & $330(23.9)$ & $142(24.8)$ & \\
\hline U2 & $630(45.6)$ & $259(45.3)$ & \\
\hline Low urgency (U3, U4 or U5) & $421(30.5)$ & $171(29.9)$ & \\
\hline
\end{tabular}

Legend: Abbreviations: CVD: cardiovascular disease; IQR: interquartile range; OHS-PC: out of hours services in primary care; SD: standard deviation; TIA: transient ischaemic attack. For differences of continuous variables we used the independent sample t-test or Mann-Whitney $U$ test ( $\left.{ }^{*}\right)$, and for categorical variables we used the Chi ${ }^{2}$ test. 
Table S2. Overview of the percentages missing data of candidate predictors for patients with and without TIA/stroke

\begin{tabular}{|c|c|c|}
\hline & $\begin{array}{l}\text { TIA/stroke }(n=703) \\
\text { Missing (\%) }\end{array}$ & $\begin{array}{l}\text { No TIA/stroke }(n=678) \\
\text { Missing }(\%)\end{array}$ \\
\hline \multicolumn{3}{|l|}{ Patient characteristics } \\
\hline Age in years & 0 & 0 \\
\hline Female sex & 0 & 0 \\
\hline \multicolumn{3}{|l|}{ Medical history } \\
\hline Cardiovascular disease & 28.0 & 34.1 \\
\hline TIA & 46.2 & 52.7 \\
\hline Stroke & 46.2 & 52.7 \\
\hline Coronary artery disease & 79.7 & 72.0 \\
\hline Arrhythmia & 79.9 & 72.9 \\
\hline \multicolumn{3}{|l|}{ Cardiovascular risk factors } \\
\hline Hypertension & 68.7 & 63.9 \\
\hline Hypercholesterolemia or use of statins & 70.6 & 67.4 \\
\hline Diabetes & 69.8 & 63.6 \\
\hline \multicolumn{3}{|l|}{ Cardiovascular medication } \\
\hline Antiplatelets & 20.5 & 31.3 \\
\hline Anticoagulation & 20.5 & 31.3 \\
\hline \multicolumn{3}{|l|}{ Call characteristics } \\
\hline Median call duration in min:sec & 0 & 0 \\
\hline $\begin{array}{l}\text { Median time for caller's introduction in } \\
\text { min:sec }\end{array}$ & 0 & 0 \\
\hline $\begin{array}{l}\text { Someone else called first on behalf of the } \\
\text { patient }\end{array}$ & 0 & 0 \\
\hline $\begin{array}{l}\text { Triage nurse consulted the general } \\
\text { practitioner }\end{array}$ & 0 & 0 \\
\hline Caller expresses concern & 53.1 & 49.9 \\
\hline \multicolumn{3}{|l|}{ Symptoms mentioned during the call } \\
\hline Face drooping & 39.5 & 47.2 \\
\hline Arm weakness & 31.0 & 45.3 \\
\hline Leg weakness & 43.8 & 51.9 \\
\hline Sensory disturbances & 73.0 & 68.7 \\
\hline Speech problems & 27.6 & 50.4 \\
\hline Dysarthria & 60.0 & 74.5 \\
\hline Dysphasia & 58.5 & 73.7 \\
\hline Vision problem & 86.9 & 83.2 \\
\hline Headache & 67.6 & 55.2 \\
\hline Ataxia & 76.2 & 86.9 \\
\hline Dizziness & 78.7 & 72.9 \\
\hline
\end{tabular}

Autonomic nervous system associated symptoms

Sweating 85.1 82.0 
Table S2. Continued.

\begin{tabular}{|c|c|c|}
\hline & $\begin{array}{l}\text { TIA/stroke }(n=703) \\
\text { Missing }(\%)\end{array}$ & $\begin{array}{l}\text { No TIA/stroke }(n=678) \\
\text { Missing (\%) }\end{array}$ \\
\hline Nausea or vomiting & 82.5 & 68.6 \\
\hline Pallor or ashen skin & 78.8 & 79.8 \\
\hline (Feeling of nearly) fainting ${ }^{*}$ & 12.7 & 12.7 \\
\hline \multicolumn{3}{|l|}{ Course of symptoms } \\
\hline Acute onset of symptom(s) & 84.8 & 81.4 \\
\hline Duration of symptoms $\leq 4.5$ hours & 22.3 & 25.1 \\
\hline Symptoms still present at time of calling & 0 & 0 \\
\hline \multicolumn{3}{|l|}{ Other characteristics } \\
\hline Recognition of symptoms from previous TIA & 72.4 & 70.4 \\
\hline $\begin{array}{l}\text { Estimation of TIA/stroke risk according to } \\
\text { researcher: median presentiment researcher } \\
\text { (range } 0-100, I Q R \text { ) }\end{array}$ & 0 & 0 \\
\hline \multicolumn{3}{|l|}{ Urgency allocation } \\
\hline High urgency (U1 or U2) & 0 & 0 \\
\hline U1 & 0 & 0 \\
\hline U2 & 0 & 0 \\
\hline Low urgency (U3, U4 or U5) & 0 & 0 \\
\hline
\end{tabular}

Legend: Abbreviations: CVD: cardiovascular disease; OHS-PC: out of hours services in primary care; TIA: transient ischaemic attack. 


$$
6
$$




\section{Missed acute coronary syndrome during telephone triage at out-of- hours primary care: Lessons from a case-control study}

D.C. Erkelens

F.H. Rutten

L.T. Wouters

H.G. Kirkels

J.M. Poldervaart

E. de Groot

R.A. Damoiseaux
A.W. Hoes
D.L. Zwart

Submitted 


\section{Abstract}

Background: Serious adverse events at out-of-hours services in primary care (OHSPC) are rare, and most often concern missed acute coronary syndrome (ACS). Previous studies on serious adverse events mainly concern root cause analyses, which highlighted errors in the telephone triage process, but are hampered by hindsight bias. This study aims to compare recorded triage calls of patients with chest discomfort contacting the OHS-PC in whom an ACS was missed (cases), with triage calls involving matched controls with chest discomfort but without a missed ACS (controls), with the aim to assess predictors of missed ACS.

Methods: A case-control study with data from 2013-2017 of nine OHS-PC in the Netherlands. The cases were matched 1:8 with controls based on age and gender. Clinical, patient and call characteristics were univariably assessed and general practitioner experts evaluated the triage, while blinded to the final diagnosis or the case/control status.

Results: Fifteen missed ACS calls and 120 matched control calls were included. Cases used less cardiovascular medication (38.5\% vs. 64.1\%, $\mathrm{p}=0.05$ ) and more often experienced pain other than retrosternal chest pain $(63.3 \%$ vs. $24.7 \%, p=0.02)$ than controls. Consultation of the supervising general practitioner ( $86.7 \%$ vs. $49.2 \%, p=0.02$ ) occurred more often in cases than controls. Experts rated the triage of cases more often as 'poor' (33.3\% vs. $10.9 \%, p=0.001)$, and 'unsafe' (73.3\% vs. $22.5 \%, p<0.001)$ compared to controls.

Conclusions: We could not identify characteristics of missed ACS that during triage are likely to be helpful to prevent future adverse outcomes in patients with chest discomfort. 


\section{Introduction}

Ensuring patient safety throughout the care process at out-of-hours services in primary care (OHS-PC) is a challenging task. Telephone triage, the starting point of care at OHS-PC, is considered the most complex and vulnerable part of the out-of-hours care process.(1) During this initial telephone conversation with patients, adequate collection of information is crucial to determine the urgency of the patient's complaints, which further dictates the next steps in the care process (e.g. diagnosis, treatment).

Similar to other European countries, telephone triage at OHS-PC in the Netherlands is performed by triage nurses, who are supervised by general practitioners (GPs).(2) To support the quality and safety of triage and subsequent decision making, almost all OHS-PC use a decision support tool called the 'Netherlands Triage Standard' (NTS).(3)

Inevitably and despite such decision support, however, errors in telephone triage occur, potentially leading to serious adverse events (SAEs). A SAE is defined by the Dutch Healthcare Quality, Complaints and Disputes Act as: "an unintended or unexpected event related to the quality of care and resulting in death or a severe harmful event for the patient".(4) Such SAEs are rare, given the occurrence of just $0.006 \%$ of all OHS-PC contacts per year, but have a major impact on both patients and families, and on the professionals involved.(5-7) Almost half (46.2\%) of the 240 SAEs at Dutch OHS-PC are related to missed acute cardiovascular disease: $30.4 \%$ concerned acute myocardial infarction/acute cardiac death, $7.9 \%$ stroke and $7.9 \%$ ruptured abdominal aortic aneurysm.(5)

To publicly account for and learn from these medical catastrophes Dutch law requires instant reporting and an elaborate root cause analysis for each SAE. Root cause analysis is aimed at determining how and why the particular SAE could occur based on causal reasoning. Yet, a known pitfall is hindsight bias as the assessors know the outcome of the case. $(8,9)$ Hindsight bias is the "tendency to exaggerate the extent to which an event can be predicted beforehand if the outcome is known", which fuels investigators' expectations that those involved in the SAE could have known what was actually learned by hindsight. $(8,10,11)$ After root cause analysis, recommendations are given to prevent similar future events.(12-14) It is often insufficiently realized that such, mainly defensive measures also may cause harm by burdening the health care system, cause overdiagnosis, and increase the risk of iatrogenic damage. $(14,15)$ Altogether, the effectiveness of this safety management approach based on root cause analysis can be questioned.

For improving the learning from SAEs, it is key to know whether SAEs actually contain clues representing structural flaws in triage or just display regular clinical variance in out-of-hours primary care. For that, SAEs need to be analysed in comparison to similar cases where no SAE occurred. Therefore, in this study we compared triage calls of missed acute coronary syndrome (ACS) in patients with chest discomfort to matched controls 
with chest discomfort, but in whom no SAE occurred, with the aim to identify predictors of missed ACS. Furthermore, we hypothesized that experienced GPS might be able to differentiate SAEs from controls based on the safety and quality of performed triage. Hence, expert GPs were asked to appraise the overall quality and safety of the triage calls.

\section{Methods}

\section{Design and setting}

We conducted a retrospective, matched case-control study among patients who called the OHS-PC with symptoms suggestive of ACS. This study is part of a larger research project on telephone triage at the OHS-PC, of which the design has been published elsewhere.(16) For this case-control study we used data from a collaboration of nine OHS-PC locations in the Netherlands providing care to approximately 1.5 million people. These OHS-PC cover both rural and suburban areas, and are representative of OHS-PC in the Netherlands. All triage calls with the OHS-PC were routinely recorded and archived for training, quality control, and research purposes.

\section{Patient selection}

Identification of cases

We retrieved all registered SAEs concerning a missed diagnosis of ACS between 2013 and 2017 from the OHS-PC database. This database includes information on the triage process and urgency allocation. The corresponding triage call recordings were retrieved.

\section{Identification of controls}

We defined controls as triage calls of patients with chest discomfort or other symptoms suggestive of an ACS, and that did not end in SAE. Eight controls per case were matched based on age and gender.(17) The triage recordings of matched controls were collected from an existing database.(16) We retrieved follow-up data on the final diagnosis from the patients' own GP electronic health records (EHR). For patients who were referred to the hospital, the final diagnosis of ACS was derived from letters from the emergency or cardiology departments. For more detailed information on the inclusion and exclusion criteria of this larger research project, we refer to our design paper.(16)

\section{Data collection}

Two researchers blinded to the final diagnosis and case/control status re-listened to the archived triage calls and retrieved information from the EHR of the OHS-PC using a standardised case record form. Information such as clinical characteristics (i.e. age, gender, symptoms, medical history and use of medication), call characteristics (i.e. time of calling, call duration, first person calling, triage nurse's consultation of a GP), and 
urgency allocation was extracted. Within the NTS six urgency levels with corresponding response time to medical care can be distinguished (see Table 1). The urgency levels UO to U2 were defined as high, because we considered presence of a GP or ambulance on site within an hour as highly urgent care, and U3 to U5 as low. Items that were not discussed during telephone triage were considered missing.

Table 1. NTS levels of urgency

\begin{tabular}{|c|c|c|c|}
\hline NTS Urgency level & Definition & Response time & Medical help \\
\hline U0 - Resuscitation & Loss of vital functions & Immediately & Ambulance \\
\hline U1 - Life threatening & $\begin{array}{l}\text { Unstable vital } \\
\text { functions }\end{array}$ & $\begin{array}{l}\text { As soon as possible, } \\
\text { within } 15 \text { minutes }\end{array}$ & Ambulance \\
\hline U2 - Emergent & $\begin{array}{l}\text { Vital functions in } \\
\text { danger or organ } \\
\text { damage }\end{array}$ & Within 1 hour & $\begin{array}{l}\text { Home visit by GP } \\
\text { or appointment at } \\
\text { OHS-PC }\end{array}$ \\
\hline U3 - Urgent & $\begin{array}{l}\text { Possible risk of } \\
\text { damage, human } \\
\text { reasons }\end{array}$ & Within 3 hours & $\begin{array}{l}\text { Home visit by GP } \\
\text { or appointment at } \\
\text { OHS-PC }\end{array}$ \\
\hline U4-Non-urgent & $\begin{array}{l}\text { Marginal risk of } \\
\text { damage }\end{array}$ & Within 24 hours & $\begin{array}{l}\text { Appointment at } \\
\text { OHS-PC or telephone } \\
\text { advice }\end{array}$ \\
\hline U5 - Advice & No risk of damage & $\begin{array}{l}\text { Advice, not time } \\
\text { related }\end{array}$ & Telephone advice \\
\hline
\end{tabular}

\section{Experts' assessment of safety and quality}

Fifteen expert GPS assessed the triage calls. Every expert listened individually, and blinded to the case/control status of the patient, to a randomly allocated subset of around twenty triage recordings, and thus the total set of 135 recordings was re-listened to twice. We asked the experts to give an overall appraisal of the triage quality (on a scale of zero to ten), and whether the telephone triage process was done safely (yes or no). For quality we considered a score of five or lower as 'poor'.

\section{Data analyses}

For univariable analysis of differences in characteristics between cases and controls we used conditional logistic regression analysis, which is standard procedure in matched case-control studies to control for matching factors. $(18,19)$ A p-value $<0.05$ was considered to be statistically significant for all analyses. Statistical analyses were performed using SPSS version 25.0 and SAS version 9.4.

\section{Ethical approval}

The Medical Ethics Review Committee Utrecht, the Netherlands approved this study (National Trial Register identification number: NTR7331, reference number WAG/ $\mathrm{mb} / 16 / 003208)$. In addition, a waiver of informed consent was granted as our study 
involved minimal risk to subjects and this study would not have been practicable without the waiver. All personal and research data were handled and stored according to the European General Data Protection Regulation.

\section{Results}

\section{Clinical characteristics}

The flowchart of the study population is displayed in Figure 1. We included 15 missed ACS cases; 5 missed acute myocardial infarctions and 10 acute cardiac deaths. Of the 120 matched controls, $17.5 \%$ had an ACS, $21.7 \%$ non-urgent cardiovascular diseases (e.g. stable angina pectoris, stable heart failure, arrhythmias, hypertension), $19.2 \%$ a musculoskeletal disease, $17.5 \%$ non-cardiac chest pain which was not further specified (cardiac pathology eliminated after diagnostic work-up), 4.2\% gastrointestinal, $4.2 \%$ psychiatric, 3.3 respiratory, and $4.2 \%$ other diagnosis.

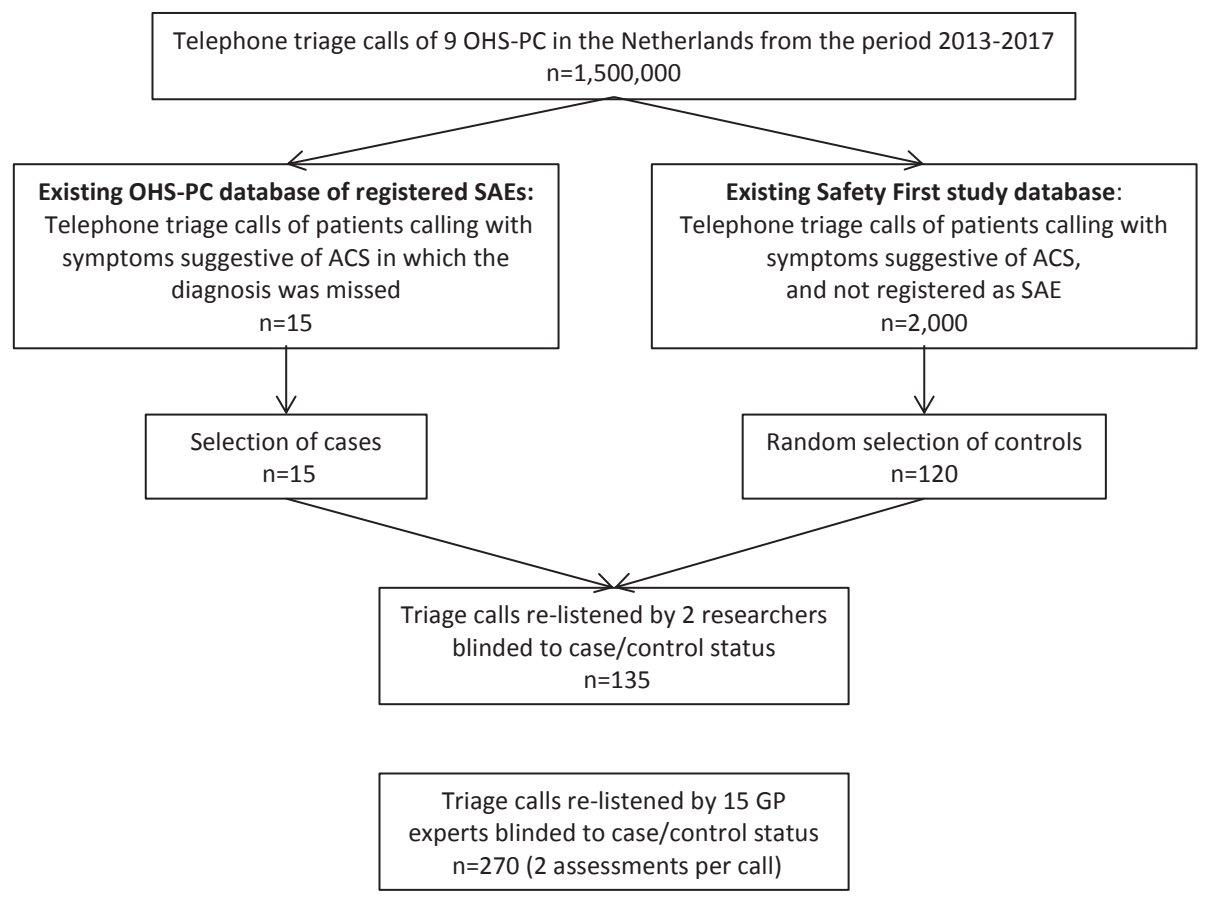

Figure 1. Flowchart

Legend: Flowchart of inclusion of the study population. Abbreviations: Acute Coronary Syndrome (ACS); Out-of-Hours Services in Primary Care (OHS-PC); Serious Adverse Event (SAE). 
Table 2 shows the clinical characteristics of our study population. The median age was 62.0 years (interquartile range 18.0, range $32-90$ years), and $46.7 \%$ were men. Cases less often used cardiovascular medication ( $38.5 \%$ vs. $64.1 \%, p=0.05$ ) and significantly more often reported pain other than retrosternal pain (e.g. epigastric region, upper back or shoulder pain) than controls (63.6\% vs. $24.7 \%, p=0.02$ ).

Table 2. Clinical characteristics of patients with symptoms suggestive of ACS who called the $\mathrm{OHS}-\mathrm{PC}$, divided into cases and controls

\begin{tabular}{|c|c|c|c|}
\hline & $\begin{array}{l}\text { Cases } \\
\mathrm{n}=15\end{array}$ & $\begin{array}{l}\text { Controls } \\
n=120\end{array}$ & P-value \\
\hline \multicolumn{4}{|l|}{ Patient characteristics } \\
\hline Median age in years (interquartile range) & $63.0(18.0)$ & $61.5(18.0)$ & 0.53 \\
\hline Male sex & $7(46.7)$ & $56(46.7)$ & 0.99 \\
\hline Cardiovascular history $(\mathrm{n}=103)$ & $4(36.4)$ & $51(55.4)$ & 0.10 \\
\hline Diabetes Mellitus ( $n=71$ ) & $4(44.4)$ & $8(12.9)$ & 0.08 \\
\hline Hypertension $(n=57)$ & $1(16.7)$ & $22(43.1)$ & 0.32 \\
\hline Hypercholesterolemia $(n=73)$ & $2(25.0)$ & $20(30.8)$ & 0.68 \\
\hline Cardiovascular medication use $(n=105)$ & $5(38.5)$ & $59(64.1)$ & 0.05 \\
\hline Positive family history of cardiovascular disease $(n=25)$ & $2(40.0)$ & $14(70.0)$ & 0.44 \\
\hline Caller expresses concern ${ }^{*}(n=117)$ & $9(90.0)$ & $64(59.8)$ & 0.11 \\
\hline \multicolumn{4}{|l|}{ Symptoms } \\
\hline Shortness of breath $(n=98)$ & $6(46.2)$ & $57(67.1)$ & 0.13 \\
\hline Chest discomfort $(n=131)$ & $11(84.6)$ & $111(94.1)$ & 0.11 \\
\hline Character: oppressive or heavy feeling $(n=107)$ & $6(60.0)$ & $68(70.1)$ & 0.64 \\
\hline $\begin{array}{l}\text { Located: retrosternal or left anterior thoracic region } \\
(n=100)\end{array}$ & $4(36.4)$ & $67(75.3)$ & 0.02 \\
\hline Pain onset $<12$ hours $(n=127)$ & $10(71.4)$ & $96(85.0)$ & 0.20 \\
\hline Pain duration $>15$ minutes $(n=128)$ & $13(100)$ & $111(96.5)$ & 0.65 \\
\hline Radiation of pain $(n=115)$ & $9(90)$ & $67(63.8)$ & 0.16 \\
\hline Pain scored as severe $(\text { VAS }>7)^{* *}(n=76)$ & $3(42.9)$ & $26(37.7)$ & 0.85 \\
\hline $\begin{array}{l}\text { Autonomic nervous system associated symptoms }{ }^{* * *} \\
(n=133)\end{array}$ & $11(78.6)$ & $63(52.9)$ & 0.09 \\
\hline Symptoms similar to a previous cardiac event $(n=65)$ & $0(0)$ & $15(25.0)$ & 0.35 \\
\hline Never experienced similar symptoms before $(n=65)$ & $4(80.0)$ & $28(46.7)$ & 0.07 \\
\hline
\end{tabular}

Legend: $(n=x)$ : Missing data; ${ }^{*}$ Concerns as expressed verbally by the caller (i.e. the patient, a family member or caregiver); ${ }^{* *}$ Visual Analogue Scale (VAS); ${ }^{* *}$ Occurrence of one or more of the following symptoms: nausea, vomiting, sweating, pallor, ashen skin, and (near) fainting.

Abbreviations: ACS: Acute Coronary Syndrome; OHS-PC: Out-Of-Hours Services in Primary Care; SAE: Serious Adverse Event. 


\section{Call characteristics}

Most calls were in the evening in both groups ( $46.7 \%$ vs. $31.7 \%, p=0.27$ ), and there was no significant difference in median call duration (see Table 3). In SAE cases, consultation of the supervising GP and a GP taking over the triage call were more common than in controls; $86.7 \%$ vs. $49.2 \%, p=0.02$ and $40.0 \%$ vs. $10.0 \%, p=0.004$, respectively. Cases received less often a high urgency (U1 or U2) than controls (33.3\% vs. $75.0 \%, p=0.003$ ).

Table 3. Call characteristics and expert assessments of patients with symptoms suggestive of ACS who called the OHS-PC, divided into cases and controls

\begin{tabular}{|c|c|c|c|}
\hline & $\begin{array}{l}\text { Cases } \\
\mathrm{n}=15\end{array}$ & $\begin{array}{l}\text { Controls } \\
n=120\end{array}$ & P-value \\
\hline \multicolumn{4}{|l|}{ General call characteristics } \\
\hline \multicolumn{4}{|l|}{ Time of calling: } \\
\hline Morning (06.00-12.00 hours) & $2(13.3)$ & $29(24.2)$ & 0.36 \\
\hline Afternoon (12.00-18.00 hours) & $2(13.3)$ & $27(22.5)$ & 0.42 \\
\hline Evening (18.00-00.00 hours) & $7(46.7)$ & $38(31.7)$ & 0.27 \\
\hline Night (00.00 - 06.00 hours) & $4(26.7)$ & $26(21.7)$ & 0.65 \\
\hline $\begin{array}{l}\text { Median call duration in minutes:seconds } \\
\text { (interquartile range) }\end{array}$ & 07:28 (03:02) & $06: 23(03: 32)$ & 0.39 \\
\hline $\begin{array}{l}\text { Initial call by someone else than the patient } \\
(n=135)\end{array}$ & $10(66.7)$ & $56(46.7)$ & 0.14 \\
\hline $\begin{array}{l}\text { Consultation of the supervising GP by the triage } \\
\text { nurse }\end{array}$ & $13(86.7)$ & $59(49.2)$ & 0.02 \\
\hline Supervising GP takes over the call & $6(40.0)$ & $12(10.0)$ & 0.004 \\
\hline \multicolumn{4}{|l|}{ Urgency } \\
\hline \multirow[t]{3}{*}{ High urgency allocation (U1 or U2) } & $5(33.3)$ & $90(75.0)$ & 0.003 \\
\hline & Cases & Controls & P-value \\
\hline & $\begin{array}{l}n=30 \\
\text { assessments } \\
\text { of } n=15 \text { cases }\end{array}$ & $\begin{array}{l}n=240 \\
\text { assessments of } \\
n=120 \text { controls }\end{array}$ & \\
\hline \multicolumn{4}{|l|}{ Experts } \\
\hline $\begin{array}{l}\text { Mean triage quality (scale 1-10) (standard } \\
\text { deviation) }\end{array}$ & $5.8(2.0)$ & $7.2(1.5)$ & 0.001 \\
\hline Triage quality considered 'poor' (score $\leq 5)^{*}$ & $10(33.3)$ & $26(10.9)$ & 0.001 \\
\hline Triage considered as 'unsafe' & $22(73.3)$ & $54(22.5)$ & $<0.001$ \\
\hline
\end{tabular}

Legend: "Experts assessed the triage quality on a scale from one (worst quality possible) to ten (excellent), scores of five or lower were considered 'poor' triage quality. Abbreviations: ACS: Acute Coronary Syndrome; GP: General Practitioner; OHS-PC: Out-Of-Hours Services in Primary Care; SAE: Serious Adverse Event. 


\section{Experts' assessment of safety and quality}

All 135 calls were re-listened to twice by a panel of 15 GP experts between August and October 2018, with as a result 270 assessments ( $2 \times 15$ cases and $2 \times 120$ controls). The mean triage quality of cases was 5.8 (standard deviation (SD) 2.01) compared to 7.2 (SD 1.5) for controls $(p<0.001)$. Experts considered the triage quality more often 'poor' (score $\leq 5)(33.3 \%$ vs. $10.9 \%, p=0.001)$, and 'unsafe' $(73.3 \%$ vs. $22.5 \%, p<0.001)$ in cases than in controls. The reasons most often cited by the experts for considering triage quality 'poor' were: too slow pace of triage and insufficient additional questioning when symptoms are still unclear. For 'unsafe' triage, the reasons most often mentioned were insufficient safety check of 'ABCD' (i.e. airway, breathing, circulation, disability) and lack of a 'safety net' instruction (e.g. "call back if...").

\section{Discussion}

\section{Summary}

In this study we compared recorded triage calls of 15 patients with chest discomfort contacting the OHS-PC in whom an ACS was missed, with 120 triage calls involving matched controls with chest discomfort but without a missed ACS. Cases used less cardiovascular medication (38.5\% vs. 64.1\%) and more often experienced nonretrosternal chest pain (63.3\% vs. $24.7 \%$ ) than controls. Consultation of the supervising GP (86.7\% vs. $49.2 \%)$ occurred more often in cases than controls. Experts blinded to the case/control status rated the triage of SAE cases more often as 'unsafe' (73.3\% vs. 22.5\%) and of 'poor' quality (33.3\% vs. 10.9\%) than the calls of the controls.

\section{Comparison with existing literature}

This is the first study that assessed cardiac SAEs at the OHS-PC with matched controls in detail. One previous study analysed all SAE reports in Dutch OHS-PC settings considering all domains including missed acute cardiovascular diseases.(5) They found that being male, age of 45 to 74 years, recent previous contact with the own GP for the same symptom(s), multiple contacts with the OHS-PC in a short time frame, and contacts during the night were univariably related to SAEs. However, this study was hampered by a lack of controls from the same domain. Another study compared malpractice claims (in which a SAE occurred) of a national telephone triage system in Sweden to matched controls. Yet, this study focused specifically on communication patterns and the assessors knew the case/control status of the patients, of which the latter may have biased the results. The researchers reported that triage nurses more often used closed-ended questions in malpractice claimed calls which resulted in less information about the caller's symptom presentation, and may be considered as a surrogate of poor triage quality.(20) 
Our study highlighted a few differences between SAE cases and controls, however, these differences seem to be of limited relevance for daily practice. Compared to controls, the use of cardiovascular medication was reported less in triage calls of cases. With prescription rates of Dutch GPs varying between $12.0 \%$ and $27.0 \%(21)$, the remaining majority of the population does not use cardiovascular medication. Thus, considering all patients presenting with chest discomfort and without cardiovascular medication as possible SAE is rather inefficient. Furthermore, non-retrosternal chest pain was more often reported in cases. It is already well-known that among patients with nonretrosternal chest pain a non-cardiac cause is more likely $(22,23)$, and as a result the diagnosis of ACS may be missed more often. Also, in SAE cases the GP was involved more often, which mainly suggests that these calls were more troublesome for triage nurses.

Although we did not find differences in characteristics between cases and controls helpful to prevent future adverse outcomes within the domain of patients with chest discomfort, the experts have picked up aspects in the triage calls of cases that led them to score lower on quality and safety. This could be attributable to disturbing factors in the conversation which we did not score in our study, such as the previously mentioned communication patterns (e.g. open or closed-ended questions, language barrier) or emotional expressions (e.g. audible anxiety of irritation).(24, 25) Furthermore, the difference in setting between an experts re-listening and a triage nurse actually performing the triage call possibly has played a role in our findings concerning quality and safety of the calls. It is conceivable that a triage nurse registers information ('in the heat of the moment') in a different way than an expert who does not perform the triage and only re-listens it without direct responsibility. Cognitive overload of triage nurses may easily occur in real practice because they need to multitask under time pressure. $(26,27)$ Also, disturbing factors such as a hectic work environment, shiftwork, fatigue, stress or understaffing might contribute to a difference in information registration.(24, $25,28,29)$ Still, apart from these considerations, it also remains unclear whether the poorer quality and safety in triage calls of cases is either cause or consequence in the chain of events up to the SAE.

\section{Implications for research and/or practice}

Our findings challenge the assumption that SAEs in the domain of cardiovascular disease in OHS-PC are preventable. Yet, it remains unclear whether structural faults in the triage of this domain exist, that were not included in our study. Searching for true systemic rather than incidental discrepancies between 'work processes as imagined' and 'work processes as done' (i.e. actual daily practice) more likely will contribute to improving current practice. $(30,31)$ Therefore, to facilitate learning from SAEs in the future these should be bundled and carefully assessed without hindsight bias within the context of 'normal' clinical practice. In addition, further research into disturbing factors and the potential consequences during telephone triage is needed. 


\section{Strengths and limitations}

An important strength of our study is the case-control design, which is well suited if outcomes like SAEs are rare.(19) Another strength is the blinding of both the researchers and the experts to the final diagnosis and the case/control status when assessing the calls, which minimised the risk of hindsight bias. A third strength is that re-listening to triage recordings enabled us to gather more detailed information about the clinical and call characteristics than would be available with only considering the information about a patient notified in the EHR of the OHS-PC. An important limitation is the relatively small number of SAEs. Despite using all available data of one of the largest OHS-PC collaborations in the Netherlands and including a study period of five years (around 50,000 contacts for chest discomfort), we could only include 15 cardiac SAEs (0.03\%). (32) Still, the limitation of our sample size should also be seen in the context of SAEs in OHS-PC settings; with an incidence of $0.006 \%$, it is impossible to conduct a study on SAEs with cohort-like sample sizes. Another limitation is missing data on some determinants, a common problem in research with routine care data. Lastly, we focused on telephone triage, but SAEs may also occur in later steps of the out-of-hours care process as well. Unfortunately, we had no information about these later steps.

\section{Conclusion}

It is difficult to differentiate calls at the OHS-PC that result in missed ACS from others with chest discomfort that did not turn out to be SAEs. In the domain of patients with symptoms suggestive of ACS the use of cardiovascular medication, pain other than retrosternal chest pain, and consultation of the supervising GP are not helpful to prevent future adverse outcomes.

\section{Declarations}

\section{Competing interests}

The authors declare that they have no competing interests.

\section{Funding}

This work was supported by (i) the foundation 'Nederlandse Triage Standaard' and (ii) the foundation 'Stoffels-Hornstra'. The views expressed are those of the authors and not necessarily those of the foundations. This research was conducted without direct involvement from both funding foundations. 


\section{Authors' contributions}

DLZ and FHR conceived the idea for the study and gained funding. DLZ, FHR, DCE and AWH designed the study. DCE, HGK and JMP performed data collection, DCE and HGK performed data analysis, and DCE wrote the first draft of the manuscript under the supervision of FHR. DLZ, FHR, LTW, RAD, JMP, EDG and AWH provided intellectual input and critically reviewed the manuscript. All authors read and approved the final manuscript.

\section{Acknowledgements}

The authors thank the out-of-hours primary care foundation 'Primair Huisartsenposten', the participating general practitioner experts, and medical student Eline Groenland for their participation. 


\section{References}

1) Giesen $P$, Smits $M$, Huibers $L$, Grol R, Wensing M. Quality of after-hours primary care in the Netherlands: a narrative review. Annals of internal medicine. 2011;155(2):108-13.

2) Giesen P, Ferwerda R, Tijssen R, Mokkink H, Drijver R, van den Bosch W, et al. Safety of telephone triage in general practitioner cooperatives: do triage nurses correctly estimate urgency? Qual Saf Health Care. 2007;16(3):181-4.

3) Smits M, Rutten M, Keizer E, Wensing M, Westert G, Giesen P. The Development and Performance of After-Hours Primary Care in the Netherlands: A Narrative Review. Annals of internal medicine. 2017;166(10):737-42.

4) Healthcare Quality, Complaints and Disputes Act (WKKGZ), 2016.

5) Rutten MH, Kant J, Giesen P. What can we learn from calamities at out-of-hours services in primary care? [Wat kunnen we leren van calamiteiten op de huisartsenpost?]. Huisarts Wet. 2018;6(61).

6) Vanhaecht K, Seys D, Schouten L, Bruyneel L, Coeckelberghs E, Panella M, et al. Duration of second victim symptoms in the aftermath of a patient safety incident and association with the level of patient harm: a cross-sectional study in the Netherlands. BMJ open. 2019;9(7):e029923.

7) Wu AW, Shapiro J, Harrison R, Scott SD, Connors C, Kenney L, et al. The Impact of Adverse Events on Clinicians: What's in a Name? J Patient Saf. 2017.

8) Henriksen K, Kaplan H. Hindsight bias, outcome knowledge and adaptive learning. Qual Saf Health Care. 2003;12 Suppl 2:ii46-50.

9) Zwaan L, Monteiro S, Sherbino J, Ilgen J, Howey B, Norman G. Is bias in the eye of the beholder? A vignette study to assess recognition of cognitive biases in clinical case workups. BMJ Qual Saf. 2017;26(2):104-10.

10) Wears RL, Nemeth CP. Replacing hindsight with insight: toward better understanding of diagnostic failures. Ann Emerg Med. 2007;49(2):206-9.

11) Fischhoff B. Hindsight not equal to foresight: the effect of outcome knowledge on judgment under uncertainty. 1975. Qual Saf Health Care. 2003;12(4):304-11; discussion 11-2.

12) Reason J. Human error. Cambridge University Press, 1990.

13) Vincent C, Taylor-Adams S, Stanhope N. Framework for analysing risk and safety in clinical medicine. BMJ. 1998;316(7138):1154-7.

14) Peerally MF, Carr S, Waring J, Dixon-Woods M. The problem with root cause analysis. BMJ Qual Saf. 2017;26(5):417-22.

15) Kellogg KM, Hettinger $Z$, Shah $M$, Wears RL, Sellers $C R$, Squires $M$, et al. Our current approach to root cause analysis: is it contributing to our failure to improve patient safety? BMJ Qual Saf. 2017;26(5):381-7.

16) Erkelens DC, Wouters LT, Zwart DL, Damoiseaux RA, De Groot E, Hoes AW, et al. Optimisation of telephone triage of callers with symptoms suggestive of acute cardiovascular disease in out-of-hours primary care: observational design of the Safety First study. BMJ open. 2019;9(7):e027477.

17) Hennessy S, Bilker WB, Berlin JA, Strom BL. Factors influencing the optimal control-to-case ratio in matched case-control studies. Am J Epidemiol. 1999;149(2):195-7.

18) Pearce N. Analysis of matched case-control studies. BMJ. 2016;352:1969. 
19) Grobbee DE, Hoes AW. Clinical Epidemiology: Principles, Methods, and Applications for Clinical Research. Second ed: Jones \& Bartlett Learning; 2015. Chapter 9: Case-Control Studies; p. 255-301.

20) Ernesater A, Engstrom M, Winblad U, Holmstrom IK. A comparison of calls subjected to a malpractice claim versus 'normal calls' within the Swedish healthcare direct: a case-control study. BMJ open. 2014;4(10):e005961.

21) de Bekker-Grob EW, van Dulmen S, van den Berg M, Verheij RA, Slobbe LC. Primary prevention of cardiovascular diseases: a cost study in family practices. BMC family practice. 2011;12:69.

22) Eslick GD. Usefulness of chest pain character and location as diagnostic indicators of an acute coronary syndrome. The American journal of cardiology. 2005;95(10):1228-31.

23) Bennett KR. Atypical chest pain--it's time to be rid of it. Am J Med. 2013;126(3):191.

24) Roing $M$, Holmstrom IK. Malpractice claims in Swedish telenursing: lessons learned from interviews with telenurses and managers. Nurs Res. 2015;64(1):35-43.

25) Ernesater A, Winblad U, Engstrom M, Holmstrom IK. Malpractice claims regarding calls to Swedish telephone advice nursing: what went wrong and why? J Telemed Telecare. 2012;18(7):379-83.

26) Sweller J. Cognitive load during problem solving: Effects on learning. Cognitive Science. 1988;12(2):257-85.

27) Dekker S. Patient safety: A human factors approach. Boca Raton, FL: Taylor \& Francis; 2011. Chapter 3: Cognitive Factors of Healthcare Work; p. 65-83.

28) Johannessen LEF. How triage nurses use discretion: a literature review. Professions and professionalism. 2016;6 (1):1446.

29) Farquharson $B$, Allan J, Johnston $D$, Johnston $M$, Choudhary $C$, Jones $M$. Stress amongst nurses working in a healthcare telephone-advice service: relationship with job satisfaction, intention to leave, sickness absence, and performance. J Adv Nurs. 2012;68(7):1624-35.

30) De Vos MS, den Dijker L, Hamming JF. How we can learn better and safely from serious adverse events [Hoe we beter en veilig kunnen leren van calamiteiten]. Nederlands tijdschrift voor geneeskunde. 2017;161(D1090).

31) Hollnagel E, Wears RL, Braithwaite J. From Safety-I to Safety-II: A White Paper. The Resilient Health Care Net: Published simultaneously by the University of Southern Denmark, University of Florida, USA, and Macquarie University, Australia. 2015.

32) Annual reports of 2014-2017. [Jaarverslagen 2014-2017.] Utrecht, The Netherlands: Foundation Primair out-of-hours services in primary care [Stichting Primair Huisartsenposten] 


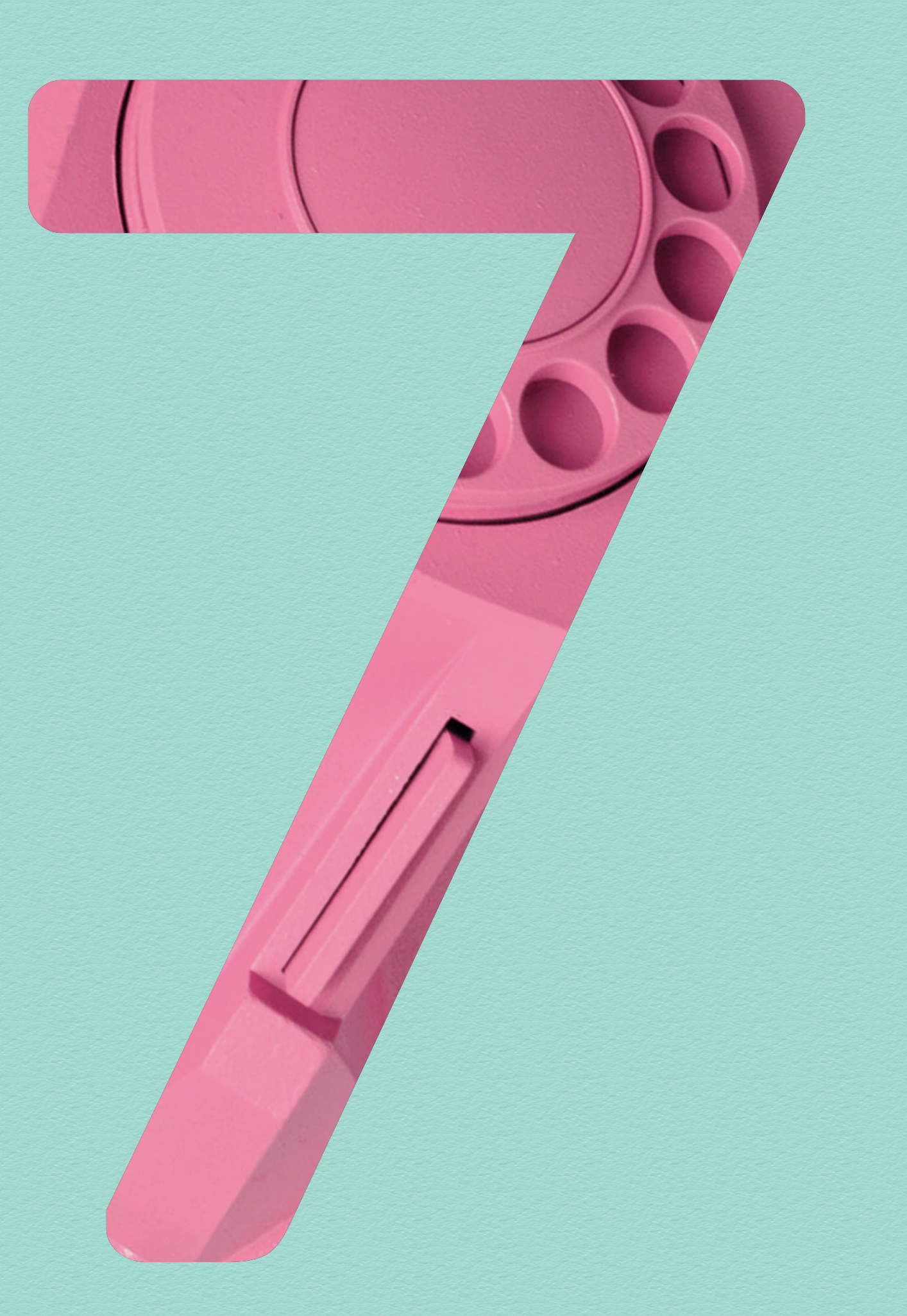




\section{Limited reliability of experts' assessment of telephone triage in primary care patients with chest discomfort}

D.C. Erkelens

F.H. Rutten

L.T. Wouters

E. de Groot

R.A. Damoiseaux

A.W. Hoes

D.L. Zwart

Published: Journal of Clinical Epidemiology 2020 


\section{Abstract}

Background: Root cause analyses of serious adverse events (SAE) in out-of-hours primary care (OHS-PC) often point to errors in telephone triage. Such analyses are, however, hampered by hindsight bias. We assessed whether experts, blinded to the outcome, recognize (un)safety of triage of patients with chest discomfort, and we quantified interrater reliability.

Methods: A case-control study with triage recordings from 2013-2017 at OHS-PC. Cases were missed acute coronary syndromes (ACS, considered as SAE). These cases were age- and gender-matched 1:8 with controls, sampled from the remainder of people calling for chest discomfort. Fifteen experts listened to the recordings and rated the safety of triage. We calculated sensitivity and specificity of recognizing an ACS and the intra-class correlation.

Results: In total 135 calls (15 SAE, 120 matched controls) were re-listened. The experts identified ACS with a sensitivity of $0.86(95 \% \mathrm{Cl} 0.71-0.95)$ and a specificity of $0.51(95 \% \mathrm{Cl}$ $0.43-0.58)$. Cases were rated significantly more often as unsafe than controls $(73.3 \%$ vs. $22.5 \%, p<0.001)$. The inter-rater reliability for safety was poor: ICC $0.16(95 \% \mathrm{Cl} 0.00$ $0.32)$.

Conclusions: Blinded experts rated calls of missed ACS more often as unsafe than matched control calls, but with a low level of agreement among the experts.

\section{What is new?}

- $\quad$ This is the first study in which multiple expert assessments were combined to compare serious adverse events (SAE) evaluations.

\section{Key findings}

- Blinded experts rate SAE calls more often as unsafe than matched control calls.

- There is a low level of agreement among experts on the safety of OHS-PC telephone triage.

\section{What is the implication and what should change now?}

- Learning from SAEs should not be based on single-case analysis only but also on a comparison with controls.

- Expert assessment of triage calls should be cautiously interpreted due to low interrater agreement. 


\section{Introduction}

For people with chest discomfort calling the out-of-hours services in primary care (OHSPC) adequate telephone triage is vital.(1, 2) Telephone triage should help to differentiate acute coronary syndrome (ACS) from non-life-threatening conditions, to allow for timely intervention and to improve prognosis.(3) Similar to other European countries, Australia and New-Zealand, telephone triage at Dutch OHS-PC is performed by triage nurses, who use a decision support tool called the 'Netherlands Triage Standard'.(4-11) During telephone triage, information on the patient's symptoms is collected and interpreted into an appropriate urgency level. Each level is linked with a corresponding type of care (e.g. ambulance, home visit, consultation at OHS-PC or telephone advice, Supplementary Data Table S1). It is, however, challenging to differentiate ACS from other conditions based on patient's complaints only. $(1,12,13)$ Therefore, assigning a too low urgency level to callers with chest discomfort may occur and can result in a missed ACS, i.e. a serious adverse event (SAE).

In the Netherlands, a SAE is defined by the Healthcare Quality, Complaints and Disputes Act as "an unintended or unexpected event related to the quality of care and resulting in death or a severe harmful event for the patient".(14) In Dutch OHS-PC settings almost half (46.2\%) of all 240 SAEs in 2012 concerned missed acute cardiovascular disease, of which the majority were missed ACS (i.e. acute myocardial infarction, acute cardiac death). (15) With a legally required root cause analysis investigation each SAE is scrutinized for factors contributing to the emergence of the SAE, intending to prevent similar events from occurring in the future. $(16,17)$ Root cause analyses at the OHS-PC often pointed to triage-related errors: too low urgency allocations or assigning the incorrect type of care frequently played a role.(15) Importantly, however, investigators doing a root cause analysis are often hampered by hindsight bias, believing that what they learned during the assessment of the events, influenced by outcome knowledge, could have been known in foresight by the professionals involved in the process which led to SAEs.(18, 19) As a result, investigators tend to judge harshly about the decision process of triage nurses, and may draw false conclusions leading to inadequate improvement measures for future triage.

The substantial risk of hindsight bias in root cause analysis of SAEs is acknowledged by the Dutch Health and Youth Care Inspectorate, part of the Ministry of Health, Welfare and Sport. $(20,21)$ In scientific literature numerous measures are proposed to decrease the influence of hindsight bias and to improve the quality of root cause analysis $(17,20)$, for example the use of an independent expert from another institution (20,22), using a group of multiple experts to obtain adequate coverage of the range of opinions with a weighted average as endpoint (23) and involving one or more experts with extensive knowledge of the subject in question.(24-26) Yet, the use of experts as a measure to decrease hindsight bias seems to be at least partly based on the assumption that experts 
are less sensitive to hindsight bias. From earlier research it is, however, known that experts also fall prey to hindsight bias.(27-29) In order to gain more insight into the effect of hindsight bias when using experts to evaluate safety and quality in root cause analysis of SAEs, a study is needed in which both SAEs and non-SAEs are included and experts are blinded to the final outcome while assessing the triage calls.

We assessed whether experts, unaware of the outcome, assess triage calls of patients calling the OHS-PC with chest discomfort in whom an ACS was missed (SAE) differently than triage calls of others calls with chest discomfort, but in whom the call did not end in a SAE. In addition, their inter-rater reliability was assessed.

\section{Methods}

\section{Study design and setting}

We conducted a retrospective, matched nested case-control study. The calls were part of a larger research project on telephone triage among callers with symptoms suggestive of acute cardiovascular disease in OHS-PC settings, of which the design is published elsewhere.(30) This case-control study included telephone triage recordings from all registered SAEs concerning missed ACS in the period 2013-2017 from a collaboration of six OHS-PC in the Netherlands. We matched SAEs with controls (1:8) based on age and gender from an existing database, which is part of the aforementioned larger research project and included telephone triage recordings of callers presenting with chest discomfort and other symptoms more or less suggestive of ACS.(30) Follow-up data on the final diagnoses of the controls were retrieved from the patients' own general practitioner's (GPs) electronic medical files.

\section{Expert panel and data collection}

A convenience sample of 15 GPs with ample triage consultation experience at the OHS-PC was approached by email and telephone to participate in the study. We defined triage experience as at least 5 years of experience with (telephone) triage in the OHS-PC setting, preferably in combination with additional training in cardiovascular disease or emergency medicine or with experience in the field of patient safety. The expert panel evaluated the quality and safety of the performed triage while being blinded to the final outcome (case/ control status). Panel members received a description of the study domain (patients with symptoms suggestive of ACS who called the OHS-PC). Members were informed that there were SAEs within the sample but did not receive further information (e.g. number of SAEs, final diagnoses). We randomly allocated the triage calls to the GPS in such a way that every triage call was listened to by 2 different experts, thus with two expert assessments per triage call. For every call, we determined the exact time moment just before the triage nurse said anything that revealed the urgency or the assigned type of medical help. Panel members were obliged to stop the recordings at 
these pre-defined time moments. They received an overview of the pre-defined time moments for all the triage calls they had to assess. At this pre-defined time moment, the experts had to determine what they considered the most proper urgency allocation for that specific call (ranging from U1 to U5, see Supplementary Data Table S1) $(5,31)$ and whether or not they considered ACS present, without being influenced by the urgency assignment of the triage nurse. The experts continued listening to the remaining part of the tape (including new information about the triage nurse's final urgency allocation). At the end of the call, experts were asked to assess whether the triage nurse handled the telephone contact safely and to give an overall appraisal of the triage quality (visual analogue scale ranging from zero to ten). Experts could not reconsider and change their response after completion of a question. An overview of the complete questionnaire is available in Figure 1.

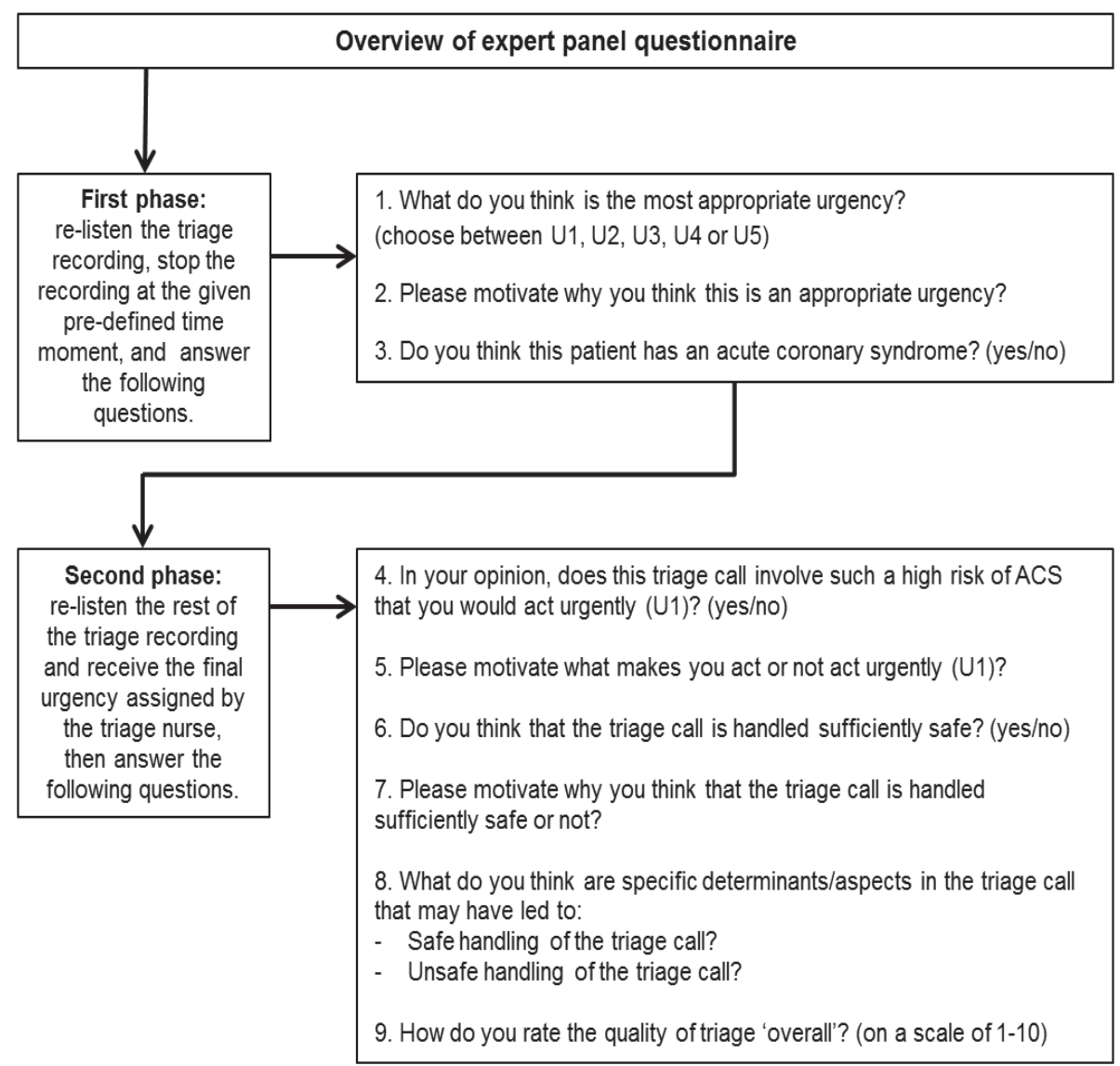

Figure 1. Expert panel questionnaire 


\section{Data analysis}

We dichotomised the experts' appraisal of triage quality and defined poor triage quality as five or less on a scale from zero to ten. For differences in experts' assessments of urgency, quality and safety of triage we used conditional logistic regression analysis.(32, 33) Also, we calculated the sensitivity and specificity (with corresponding 95\% confidence intervals) of ACS identification by the triage nurses and experts within the control group. For the triage nurses' urgencies we used an U1 urgency allocation as an expression of ACS identification, whereas for the experts we used their answers to question number 4 from the questionnaire (see Figure 1): "Does this triage call involve such a high risk of ACS that you would act urgently (U1)?"

In order to quantify inter-rater reliability of the expert assessments (that is two assessments per triage recording with different experts, and not every recording was listened to by the same two experts), we calculated intraclass correlation coefficients (ICC) as an approximation of weighted Kappa's. $(34,35)$ As suggested in previous literature on the interpretation of ICC, we considered values less than 0.40 indicative of poor interrater reliability, values between 0.40 to 0.75 indicative of fair to good reliability, and values greater than 0.75 indicative of excellent reliability. $(34,36-38)$ A p-value $<0.05$ was considered statistically significant for all analyses. Statistical analyses were performed using both SPSS version 25.0 and SAS version 9.4.

\section{Results}

\section{Characteristics of the expert panel}

Of the 15 GPs nine were male (60\%) and work experience as a GP ranged from 5 to 36 years with a median work experience of 23 years (interquartile range 6-27 years). The areas of expertise varied: four GPs completed additional training in cardiovascular disease, five in emergency medicine and five GPs had experience in the field of patient safety (e.g. member of incident/SAE board, patient safety researcher or advisor).

\section{Experts' assessments}

Each triage call was assessed twice by different experts, resulting in a total amount of 270 assessments ( $2 \times 15$ SAE-cases and $2 \times 120$ controls). Five cases concerned a missed myocardial infarction and ten were acute cardiac deaths. Of the controls, $17.5 \%$ had an ACS, 75\% had a diagnosis other than ACS of non-life-threatening origin (e.g. musculoskeletal, respiratory or gastro-intestinal disease), and in $7.5 \%$ the exact final diagnosis was missing.

In Table 1, both the actual assigned urgencies by triage nurses and the experts' blinded assessments on the most appropriate urgency allocation are displayed. Considering the highest urgency level (U1) appropriate in suspected ACS, experts correctly allocated a high urgency in $55.2 \%$ of all calls vs. $51.1 \%$ by the triage nurses. In SAE calls, triage nurses 
under-triaged 28 cases (93.3\% U2-U5), whereas experts would have under-triaged 13 cases (43.3\% U2-U5). If we would also consider U2 as adequate, experts would have correctly allocated a U1 or U2 urgency in $85.2 \%$ of all calls vs. $84.4 \%$ by the triage nurse. In SAE calls, triage nurses under-triaged 14 cases (46.7\% U3-U5) whereas experts would have under-triaged 2 cases (6.6\% U3-U5).

Table 1. Urgencies allocated by triage nurses and experts

\begin{tabular}{|c|c|c|c|}
\hline & $\begin{array}{l}\text { Cases } \\
\text { ( } n=30 \text { assessments } \\
\text { in } n=15 \text { cases) }\end{array}$ & $\begin{array}{l}\text { Controls } \\
\text { ( } n=240 \text { assessments } \\
\text { in } n=120 \text { controls) }\end{array}$ & $\begin{array}{l}\text { Total } \\
\text { ( } n=270 \\
\text { assessments) }\end{array}$ \\
\hline \multirow{5}{*}{$\begin{array}{l}\text { Actual urgency allocation by } \\
\text { triage nurses }(n(\%))\end{array}$} & U1: 2 (6.7) & U1: 136 (56.7) & U1: 138 (51.1) \\
\hline & U2: 14 (46.6) & U2: 76 (31.7) & U2: 90 (33.3) \\
\hline & U3: 10 (33.3) & U3: 22 (9.1) & U3: 32 (11.9) \\
\hline & U4: 2 (6.7) & U4: $0(0)$ & U4: $2(0.7)$ \\
\hline & U5: 2 (6.7) & U5: 6 (2.5) & U5: 8 (3.0) \\
\hline \multirow{5}{*}{$\begin{array}{l}\text { Urgency allocation by } \\
\text { experts (after hearing the } \\
\text { first part of the triage call), } \\
\text { and blinded to the actual } \\
\text { triage nurses' allocation } \\
(\mathrm{n}(\%))\end{array}$} & U1: 17 (56.7) & U1: 132 (55.0) & U1: 149 (55.2) \\
\hline & U2: 11 (36.7) & U2: 70 (29.2) & U2: 81 (30.0) \\
\hline & U3: 1 (3.3) & U3: 30 (12.5) & U3: 31 (11.5) \\
\hline & U4: 1 (3.3) & U4: 6 (2.5) & U4: 7 (2.6) \\
\hline & U5: 0 (0.0) & U5: 2 (0.8) & U5: 2 (0.7) \\
\hline
\end{tabular}

Table 2 shows the results of the experts' assessments. We compared assigned urgencies by triage nurses and experts (dichotomized into high or low). In cases the difference between a high assigned urgency category by experts and a low assigned urgency by triage nurses was significantly more often present: $50.0 \%$ vs. 9.6\%, p<0.001 (U1 vs. U2-U5) and $43.4 \%$ vs. $5.4 \%, p<0.001$ (U1-U2 vs. U3-U5). Experts considered, after listening to the first part of the triage call, ACS the most likely diagnosis in 18 out of 30 case assessments, which was quite comparable to controls ( $60.0 \%$ vs. $56.7 \%, p=0.73$ ).

We compared the experts' assessments that urgent acting was required due to a high risk of ACS (question 4, see Figure 1) with the actual final diagnosis ACS, and found that this relation was significantly more often present for the cases (63.3\% vs. $16.2 \%, p<0.001)$. A poor triage quality ( $\leq 5$ on a scale of $0-10$ ) was significantly more given by experts to calls of cases than calls of controls ( $33.3 \%$ vs. $10.9 \%, p=0.004)$. Also, experts considered the handling of calls of cases more often unsafe than calls of controls ( $73.3 \%$ vs. $22.5 \%$, $p<0.001)$.

Within the controls, we calculated sensitivity and specificity of ACS identification by the triage nurses and experts. For the triage nurses we compared a U1 urgency allocation (as an expression of ACS within the domain of patients calling with chest discomfort) to the other urgencies for patients with and without a final diagnosis of ACS. In 36 out of 42 
ACS calls, the triage nurses allocated an U1 urgency; sensitivity 0.86 (95\% Cl 0.71-0.95). Also, in 88 out of 180 non-ACS calls, the triage nurse correctly allocated an urgency level lower than $\mathrm{U} 1$; specificity of 0.49 ( $95 \% \mathrm{Cl} 0.41-0.56)$.

For the experts, we compared whether urgent acting was required due to a high risk of ACS or not (question 4, see Figure 1) for patients with and without a final diagnosis of ACS. Comparable to the triage nurses, 36 out of 42 ACS calls were identified by the experts as at high risk of ACS for which an U1 urgency was required; sensitivity of 0.86 (95\% Cl 0.71-0.95). In addition, 91 out of 180 non-ACS calls were correctly assessed as non-ACS by the experts; specificity of 0.51 (95\% Cl 0.43-0.58).

Table 2. Results of experts' assessments of urgency, quality and safety of triage

\begin{tabular}{|c|c|c|c|}
\hline & $\begin{array}{l}\text { Cases } \\
\text { ( } n=30 \\
\text { assessments } \\
\text { in } n=15 \text { cases) }\end{array}$ & $\begin{array}{l}\text { Controls } \\
\text { ( } n=240 \\
\text { assessments } \\
\text { in } n=120 \\
\text { controls) }\end{array}$ & P-value \\
\hline \multirow{5}{*}{$\begin{array}{l}\text { Urgency allocation by experts, blinded to the } \\
\text { actual triage nurses' allocation }\end{array}$} & U1: 17 (56.7) & U1: $132(55.0)$ & \multirow[t]{5}{*}{0.47} \\
\hline & U2: $11(36.7)$ & U2: $70(29.2)$ & \\
\hline & U3: 1 (3.3) & U3: 30 (12.5) & \\
\hline & U4: 1 (3.3) & U4: $6(2.5)$ & \\
\hline & U5: $0(0.0)$ & U5: $2(0.8)$ & \\
\hline $\begin{array}{l}\text { Highest urgency allocation (U1) by experts, } \\
\text { blinded to the actual triage nurses' allocation }\end{array}$ & $17(56.7)$ & $132(55.0)$ & 0.87 \\
\hline $\begin{array}{l}\text { High urgency allocation (U1-U2) by experts, } \\
\text { blinded to the actual triage nurses' allocation }\end{array}$ & $28(93.3)$ & $202(84.2)$ & 0.21 \\
\hline \multicolumn{4}{|l|}{ Assigned urgency by experts vs. triage nurse differs: } \\
\hline Expert high (U1) vs. triage nurse low (U2-U5) & $15(50.0)$ & $23(9.6)$ & $<0.001$ \\
\hline Expert low (U2-U5) vs. triage nurse high (U1) & $0(0.0)$ & $27(11.3)$ & 0.23 \\
\hline Expert high (U1-U2) vs. triage nurse low (U3-U5) & $13(43.4)$ & $13(5.4)$ & $<0.001$ \\
\hline Expert low (U3-U5) vs. triage nurse high (U1-U2) & $1(3.3)$ & $23(9.6)$ & 0.30 \\
\hline ACS considered likely & $18(60.0)$ & $136(56.7)$ & 0.73 \\
\hline $\begin{array}{l}\text { Poor triage quality on a scale of } 0-10 \\
\text { ( } \leq 5 \text { is considered 'poor') }\end{array}$ & $10(33.3)$ & $26(10.9)$ & 0.004 \\
\hline Urgent acting required because of high risk of ACS & $19(63.3)$ & $135(56.3)$ & 0.47 \\
\hline $\begin{array}{l}\text { Urgent acting required because considered high } \\
\text { risk of ACS and final outcome indeed ACS }\end{array}$ & $19(63.3)$ & $36(16.2)$ & $<0.001$ \\
\hline Contact safely handled & $8(26.7)$ & $186(77.5)$ & $<0.001$ \\
\hline $\begin{array}{l}\text { Contact both safely handled and sufficient triage } \\
\text { quality on a scale of } 0-10 \text { ( } 6 \geq \text { is considered } \\
\text { sufficient) }\end{array}$ & $8(26.7)$ & $179(74.6)$ & $<0.001$ \\
\hline
\end{tabular}




\section{Inter-rater reliability}

Table 3 shows the overall inter-rater reliability for the experts' assessments of the presence of ACS, urgency levels, urgently acting, safety and quality of triage and for the cases and controls separately. The overall inter-rater reliability of the presence of ACS after pausing the triage call at the given time was poor (ICC=0.34), as well as for the controls (ICC=0.32), while inter-rater reliability was fair for the cases (ICC $=0.44)$. The interrater reliability on urgency level was fair for cases (ICC $=0.48)$, controls (ICC $=0.53$ ) and overall (0.53). Yet, overall agreement on urgently acting due to high risk of ACS (ICC=0.37) and agreement for cases (ICC $=0.28$ ) and controls (ICC=0.37) apart were poor. Agreement on the safety of the triage was lower than previous assessments, with poor inter-rater reliability for controls $(I C C=0.09)$ and overall $(I C C=0.16)$. Among the cases agreement was the lowest $(I C C=0.00)$. Similarly, the inter-rater reliability for poor triage quality (defined as $\leq 6$ on a scale of $1-10$ ) overall (ICC $=0.17$ ) and for controls only (ICC $=0.05)$ was slight. However, agreement on poor triage quality among cases was fair (ICC=0.40).

Table 3. Inter-rater reliability of experts' assessments

\begin{tabular}{|c|c|c|c|}
\hline & $\begin{array}{l}\text { Cases } \\
\text { ICC }(95 \% \mathrm{CI})\end{array}$ & $\begin{array}{l}\text { Controls } \\
\text { ICC }(95 \% \mathrm{CI})\end{array}$ & $\begin{array}{l}\text { Overall } \\
\text { ICC }(95 \% \mathrm{CI})\end{array}$ \\
\hline \multicolumn{4}{|c|}{ After listening to triage call recording until given stop time: } \\
\hline Presence of ACS & $0.44(0.00-0.89)$ & $0.32(0.16-0.48)$ & $0.34(0.18-0.49)$ \\
\hline \multicolumn{4}{|c|}{ After listening to whole triage call recording: } \\
\hline Urgency level (U1-U5) & $0.48(0.06-0.91)$ & $0.53(0.40-0.66)$ & $0.53(0.40-0.65)$ \\
\hline $\begin{array}{l}\text { Urgently acting required } \\
\text { because of high risk of ACS }\end{array}$ & $0.28(0.00-0.79)$ & $0.37(0.22-0.53)$ & $0.37(0.22-0.51)$ \\
\hline Safely handled triage call & $0.00(0.00-0.66)$ & $0.09(0.00-0.27)$ & $0.16(0.00-0.32)$ \\
\hline Poor triage quality & $0.40(0.00-0.87)$ & $0.05(0.00-0.23)$ & $0.17(0.00-0.33)$ \\
\hline
\end{tabular}

\section{Discussion}

Fifteen GP experts assessed the urgency, safety and quality of telephone triage calls in recordings of patients with symptoms suggestive of ACS, while blinded to the final outcome. We found that in SAE calls with missed ACS cases, triage nurses under-triaged 14 cases (46.7\% U3-U5) whereas experts would have under-triaged 2 cases (6.6\% U3-U5) when considering both $\mathrm{U} 1$ and $\mathrm{U} 2$ adequate. Our analysis of control calls suggests that experts are reasonably capable of identifying ACS with a sensitivity of 0.86 , but less able to rule out ACS with a specificity of 0.51 . We calculated sensitivity and specificity only for the control calls, because we believe that population was a more realistic reflection of our study domain of suspected ACS, and the prevalence of ACS within this control group (17.5\%) approximates the prevalence of ACS within our study domain (10\%-12\%). (39-42) Sensitivity and specificity of ACS identification should be interpreted carefully for triage nurses because they worked under the stress of real life decision, while the 
experts interpreted the calls, however, without having direct responsibility. Cases were rated significantly more often as unsafe and of lower triage quality than controls, which might suggest that experts recognize unsafety in triage of patients with chest discomfort without knowing the final outcome. However, the poor inter-rater reliability remains striking.

Many international studies have been performed on the reliability of triage systems (35, 43-45), also for triage of chest pain (46-49), yet, studies on the reliability of blinded experts' assessments on recordings of triage of missed ACS have never been carried out.(50) In a previous retrospective study from New-Zealand an expert panel of GPs did examine emergency department discharges with the aim to identify cases that could have been managed in primary care. Between 37\%-50\% of all cases were considered 'primary care appropriate' by the experts, who were not blinded to the final diagnosis. Nevertheless, similar to our study there was poor to fair agreement (Kappa 0.35-0.45) between panel members about which cases were appropriate. Also, in $15 \%$ of all cases, GPs gave a different response to the same individual case on different occasions, illustrating the variability of clinicians' assessments, even while knowing the final diagnosis.(51)

In our study experts may have recognized unsafe triage without outcome knowledge, illustrated by the observations that they allocated higher urgencies to cases and rated them more often as unsafe. In contrast, the experts' assessments showed poor interrater reliability, which implies 'one expert is no expert'. The value of a single expert assessment such as in root cause analysis, therefore, seems questionable.(52) We believe that, contrary to the individual case oriented approach of root cause analysis (17), a blinded assessment of multiple SAEs by experts, preferably in a case-control manner provides a more realistic view on safety and quality of telephone triage in the context of daily practice. Furthermore, a substantial proportion of the triage calls from the control group were considered as unsafe (22.5\%), of poor triage quality (10.9\%) or both (7.9\%). This suggests room for improvement of OHS-PC telephone triage of patients with symptoms suggestive of ACS, irrespective of an adverse outcome. Similarly, in $26.7 \%$ of the SAE triage calls the safety and quality were considered sufficient. On the other hand, aforementioned finding and the poor inter-rater reliability among experts may reflect the inherent complexity of handling triage calls concerning chest discomfort. One could argue that telephone triage is such a complex task that a certain complication rate is inevitable, in line with a recent publication on the risks of striving for 'zero harm'. $(53-56)$

A strength and key feature in our study design was the blinding of the expert panel to the final outcome (case/control status), which limited the influence of hindsight bias. However, it is conceivable that experts' knowledge that SAEs were present in the study might have raised their awareness for potential SAEs. Our study is limited by missing 
values on the final diagnosis of some of the controls. It is possible that this $7.5 \%$ of callers could have had a 'silent' ACS, but the possibility of a SAE as the final outcome is virtually ruled out as these control calls were not registered as SAEs in the OHS-PC database nor reported in an incident reporting system. Therefore, there were no missing values on the final outcome. Another limitation is the relatively small sample size of our study, which is mainly problematic for the reported absolute numbers and percentages in Table 2, but not for the ICC. Yet, our study is unique in blinded assessments of multiple SAEs of missed ACS, and it provides an alternative to solely a qualitative root cause analysis of a single $S A E$.

\section{Conclusion}

Blinded experts rated telephone triage calls of SAEs in which ACS was missed more often as unsafe and of lower triage quality than matched control calls. However, there is such a low level of agreement among the experts that the value of a single expert assessment is questionable.

\section{Declarations}

\section{Ethics approval}

The Medical Ethics Review Committee, Utrecht, the Netherlands.

\section{Competing interests}

All authors declared no competing interests.

\section{Funding}

This work was supported by the department of general practice of the University Medical Center Utrecht, Associate Professorship-promotion grant of D.L. Zwart, MD, PhD, the foundation 'Netherlands Triage Standard' and the foundation 'Stoffels-Hornstra'. The views expressed are those of the authors and not necessarily those of the foundations. The funding foundations had no role in study design, data collection and analysis, preparation of the article, or decision to publish. 


\section{Authors' contributions (CRediT roles)}

D.C. Erkelens: Conceptualization, Data curation, Formal analysis, Methodology, Project administration, Roles/Writing - original draft. F.H. Rutten: Conceptualization, Funding acquisition, Methodology, Supervision, Writing - review \& editing. L.T. Wouters: Writing - review \& editing. E. de Groot: Writing - review \& editing. R.A. Damoiseaux: Writing review \& editing. A.W. Hoes: Writing - review \& editing. D.L. Zwart: Conceptualization, Funding acquisition, Methodology, Supervision, Writing - review \& editing.

\section{Acknowledgements}

The authors thank the out-of-hours primary care foundation 'Primair Huisartsenposten' and the participating general practitioners of the expert panel. The authors also thank Harmke Kirkels for her help with the data collection and Paul Westers and Peter Zuithoff for their help with the data analysis. 


\section{References}

1) International Working Group on Chest Pain in Primary $C$, Aerts $M$, Minalu G, Bosner $S$, Buntinx F, Burnand B, et al. Pooled individual patient data from five countries were used to derive a clinical prediction rule for coronary artery disease in primary care. Journal of clinical epidemiology. 2017;81:120-8.

2) Mol KA, Smoczynska A, Rahel BM, Meeder JG, Janssen L, Doevendans PA, et al. Non-cardiac chest pain: prognosis and secondary healthcare utilisation. Open Heart. 2018;5(2):e000859.

3) Bosner S, Haasenritter J, Becker A, Karatolios K, Vaucher P, Gencer B, et al. Ruling out coronary artery disease in primary care: development and validation of a simple prediction rule. CMAJ : Canadian Medical Association journal = journal de l'Association medicale canadienne. 2010;182(12):1295-300.

4) Smits $M$, Rutten $M$, Keizer E, Wensing M, Westert G, Giesen P. The Development and Performance of After-Hours Primary Care in the Netherlands: A Narrative Review. Annals of internal medicine. 2017;166(10):737-42.

5) Netherlands Triage Standard [Nederlandse Triage Standaard], 2019. Accessed at www. de-nts.nl on 7 October 2019.

6) Berchet C, Nader C. The Organisation of Out-of-Hours Primary Care in OECD Countries. OECD Health Working Papers no. 89. Paris: OECD Pub: 2016.

7) Schoen C, Osborn R, Squires D, Doty M, Rasmussen P, Pierson R, et al. A survey of primary care doctors in ten countries shows progress in use of health information technology, less in other areas. Health Aff (Millwood). 2012;31(12):2805-16.

8) Hansen $\mathrm{EH}$, Hunskaar $\mathrm{S}$. Telephone triage by nurses in primary care out-of-hours services in Norway: an evaluation study based on written case scenarios. BMJ Qual Saf. 2011;20(5):3906.

9) Leibowitz R, Day S, Dunt D. A systematic review of the effect of different models of afterhours primary medical care services on clinical outcome, medical workload, and patient and GP satisfaction. Family practice. 2003;20(3):311-7.

10) Dunt D, Day SE, Kelaher M, Montalto M. Impact of standalone and embedded telephone triage systems on after hours primary medical care service utilisation and mix in Australia. Aust New Zealand Health Policy. 2005;2:30.

11) St George I, Cullen M, Gardiner L, Karabatsos G. Universal telenursing triage in Australia and New Zealand - a new primary health service. Aust Fam Physician. 2008;37(6):476-9.

12) Burman RA, Zakariassen E, Hunskaar S. Management of chest pain: a prospective study from Norwegian out-of-hours primary care. BMC family practice. 2014;15:51.

13) Rawshani N, Rawshani A, Gelang C, Herlitz J, Bang A, Andersson JO, et al. Could ten questions asked by the dispatch center predict the outcome for patients with chest discomfort? International journal of cardiology. 2016;209:223-5.

14) Healthcare Quality, Complaints and Disputes Act (WKKGZ), 2016.

15) Rutten $\mathrm{MH}$, Kant J, Giesen P. What can we learn from calamities at out-of-hours services in primary care? [Wat kunnen we leren van calamiteiten op de huisartsenpost?]. Huisarts Wet. 2018;6(61).

16) Reason J. Human error. Cambridge University Press, 1990.

17) Peerally MF, Carr S, Waring J, Dixon-Woods M. The problem with root cause analysis. BMJ Qual Saf. 2017;26(5):417-22. 
18) Henriksen $\mathrm{K}$, Kaplan $\mathrm{H}$. Hindsight bias, outcome knowledge and adaptive learning. Qual Saf Health Care. 2003;12 Suppl 2:ii46-50.

19) Fischhoff B. Hindsight not equal to foresight: the effect of outcome knowledge on judgment under uncertainty. 1975. Qual Saf Health Care. 2003;12(4):304-11; discussion 11-2.

20) Eeuwijk J, van den Bosch J, van der Wal G, Robben PBM. With the wisdom afterwards. Hindsight and outcome bias in supervision. [Met de wijsheid achteraf. Hindsight en outcome bias in het toezicht.]. Tijdschrift voor Toezicht. 2015;6(3):6-20.

21) Robben PBM, Vedder A, Braams N, Mannée Y. Learning from five years of research, Knowledge Report, Academic Workshop Supervision. [Leren van vijf jaar onderzoek, Kenniscahier, Academische Werkplaats Toezicht]. Utrecht: Health and Youth Care Inspectorate, Ministry of Health, Welfare and Sport, March 2017.

22) Nicolini D, Waring J, Mengis J. Policy and practice in the use of root cause analysis to investigate clinical adverse events: mind the gap. Soc Sci Med. 2011;73(2):217-25.

23) Morgan MG. Use (and abuse) of expert elicitation in support of decision making for public policy. Proc Natl Acad Sci U S A. 2014;111(20):7176-84.

24) Pham JC, Kim GR, Natterman JP, Cover RM, Goeschel CA, Wu AW, et al. ReCASTing the RCA: an improved model for performing root cause analyses. Am J Med Qual. 2010;25(3):186-91.

25) Christensenszalanski JJJ, Willham CF. The Hindsight Bias - a Metaanalysis. Organ Behav Hum Dec. 1991;48(1):147-68.

26) Woloshynowych $M$, Rogers $S$, Taylor-Adams $S$, Vincent $C$. The investigation and analysis of critical incidents and adverse events in healthcare. Health Technol Assess. 2005;9(19):1-143, iii.

27) Arkes HR, Wortmann RL, Saville PD, Harkness AR. Hindsight bias among physicians weighing the likelihood of diagnoses. J Appl Psychol. 1981;66(2):252-4.

28) Dawson NV, Arkes HR, Siciliano C, Blinkhorn R, Lakshmanan M, Petrelli M. Hindsight bias: an impediment to accurate probability estimation in clinicopathologic conferences. Med Decis Making. 1988;8(4):259-64.

29) Marks Knoll MAZ. The Effects of Expertise on the Hindsight Bias [dissertation from the internet]. Ohio: The Ohio State University; 2009. Available from: https://etd.ohiolink. edu/!etd.send_file?accession=osu1242920562\&disposition=inline.

30) Erkelens DC, Wouters LT, Zwart DL, Damoiseaux RA, De Groot E, Hoes AW, et al. Optimisation of telephone triage of callers with symptoms suggestive of acute cardiovascular disease in out-of-hours primary care: observational design of the Safety First study. BMJ open. 2019;9(7):e027477.

31) van lerland $Y$, van Veen $M$, Huibers $L$, Giesen $P$, Moll HA. Validity of telephone and physical triage in emergency care: the Netherlands Triage System. Family practice. 2011;28(3):33441.

32) Pearce N. Analysis of matched case-control studies. BMJ. 2016;352:1969.

33) Grobbee DE, Hoes AW. Clinical Epidemiology: Principles, Methods, and Applications for Clinical Research. Second ed: Jones \& Bartlett Learning; 2015. Chapter 9: Case-Control Studies; p. 255-301.

34) Fleiss J, Levin B, Paik M. Statistical Methods for Rates and Proportions. Third Edition ed: John Wiley \& Sons Inc; 2003. p. 598-626.

35) van der Wulp I, van Stel HF. Adjusting weighted kappa for severity of mistriage decreases reported reliability of emergency department triage systems: a comparative study. Journal of clinical epidemiology. 2009;62(11):1196-201. 
36) Shrout PE, Fleiss JL. Intraclass correlations: uses in assessing rater reliability. Psychol Bull. 1979;86(2):420-8.

37) Fleiss J. Design and analysis of clinical experiments. New York: Wiley Classics Library; 1999.

38) Landis JR, Koch GG. Measurement of Observer Agreement for Categorical Data. Biometrics. 1977;33(1):159-74.

39) Rawshani A, Larsson A, Gelang C, Lindqvist J, Gellerstedt M, Bang A, et al. Characteristics and outcome among patients who dial for the EMS due to chest pain. International journal of cardiology. 2014;176(3):859-65.

40) Hoorweg BB, Willemsen RT, Cleef LE, Boogaerts T, Buntinx F, Glatz JF, et al. Frequency of chest pain in primary care, diagnostic tests performed and final diagnoses. Heart. 2017;103(21):1727-32.

41) Frese T, Mahlmeister J, Heitzer M, Sandholzer H. Chest pain in general practice: Frequency, management, and results of encounter. J Family Med Prim Care. 2016;5(1):61-6.

42) Plat FM, Peters YAS, Loots FJ, de Groot CJA, Eckhardt T, Keizer E, et al. Ambulance dispatch versus general practitioner home visit for highly urgent out-of-hours primary care. Family practice. 2017(Dec 20).

43) Rutschmann OT, Kossovsky M, Geissbuhler A, Perneger TV, Vermeulen B, Simon J, et al. Interactive triage simulator revealed important variability in both process and outcome of emergency triage. Journal of clinical epidemiology. 2006;59(6):615-21.

44) van der Wulp I, van Stel HF. Calculating kappas from adjusted data improved the comparability of the reliability of triage systems: a comparative study. Journal of clinical epidemiology. 2010;63(11):1256-63.

45) Kuriyama A, Urushidani S, Nakayama T. Five-level emergency triage systems: variation in assessment of validity. Emergency medicine journal : EMJ. 2017;34(11):703-10.

46) Nishi F, de Oliveira Motta Maia F, de Souza Santos I, de Almeida Lopes Monteiro da Cruz D. Assessing sensitivity and specificity of the Manchester Triage System in the evaluation of acute coronary syndrome in adult patients in emergency care: a systematic review. JBI Database of Systematic Reviews and Implementation Reports. 2017;15(6):1747-61.

47) Leite L, Baptista R, Leitao J, Cochicho J, Breda F, Elvas L, et al. Chest pain in the emergency department: risk stratification with Manchester triage system and HEART score. BMC cardiovascular disorders. 2015;15:48

48) Nishi FA, Polak C, Cruz D. Sensitivity and specificity of the Manchester Triage System in risk prioritization of patients with acute myocardial infarction who present with chest pain. Eur J Cardiovasc Nurs. 2018;17(7):660-6.

49) Matias C, Oliveira R, Duarte R, Bico P, Mendonca C, Nuno L, et al. The Manchester Triage System in acute coronary syndromes. Rev Port Cardiol. 2008;27(2):205-16.

50) Bertens LC, Broekhuizen BD, Naaktgeboren CA, Rutten FH, Hoes AW, van Mourik Y, et al. Use of expert panels to define the reference standard in diagnostic research: a systematic review of published methods and reporting. PLoS medicine. 2013;10(10):e1001531.

51) Elley CR, Randall PJ, Bratt D, Freeman P. Can primary care patients be identified within an emergency department workload? N Z Med J. 2007;120(1256):U2583.

52) van Houten $C B$, Naaktgeboren $C A$, Ashkenazi-Hoffnung L, Ashkenazi S, Avis W, Chistyakov I, et al. Expert panel diagnosis demonstrated high reproducibility as reference standard in infectious diseases. Journal of clinical epidemiology. 2019;112:20-7.

53) Thomas EJ. The harms of promoting 'Zero Harm'. BMJ Qual Saf. 2020;29(1):4-6.

54) Amalberti $R$, Vincent $C$. Managing risk in hazardous conditions: improvisation is not enough. BMJ Qual Saf. 2020;29(1):60-3. 
55) Carthey J, de Leval MR, Reason JT. Institutional resilience in healthcare systems. Qual Health Care. 2001;10(1):29-32.

56) Welsh D, Bush J, Thiel C, Bonner J. Reconceptualizing goal setting's dark side: The ethical consequences of learning versus outcome goals. Organ Behav Hum Dec. 2019;150:14-27. 


\section{Supplementary Data}

Table S1. NTS levels of urgency

\begin{tabular}{|c|c|c|c|}
\hline NTS Urgency level & Definition & Response time & Medical help \\
\hline U0 - Resuscitation & Loss of vital functions & Immediately & Ambulance \\
\hline U1 - Life threatening & $\begin{array}{l}\text { Unstable vital } \\
\text { functions }\end{array}$ & $\begin{array}{l}\text { As soon as possible, } \\
\text { within } 15 \text { minutes }\end{array}$ & Ambulance \\
\hline U2 - Emergent & $\begin{array}{l}\text { Vital functions in } \\
\text { danger or organ } \\
\text { damage }\end{array}$ & Within 1 hour & $\begin{array}{l}\text { Home visit by GP } \\
\text { or appointment at } \\
\text { OHS-PC }\end{array}$ \\
\hline U3-Urgent & $\begin{array}{l}\text { Possible risk of } \\
\text { damage, human } \\
\text { reasons }\end{array}$ & Within 3 hours & $\begin{array}{l}\text { Home visit by GP } \\
\text { or appointment at } \\
\text { OHS-PC }\end{array}$ \\
\hline U4 - Non-urgent & $\begin{array}{l}\text { Marginal risk of } \\
\text { damage }\end{array}$ & Within 24 hours & $\begin{array}{l}\text { Appointment at } \\
\text { OHS-PC or telephone } \\
\text { advice }\end{array}$ \\
\hline U5-Advice & No risk of damage & $\begin{array}{l}\text { Advice, not time } \\
\text { related }\end{array}$ & Telephone advice \\
\hline
\end{tabular}




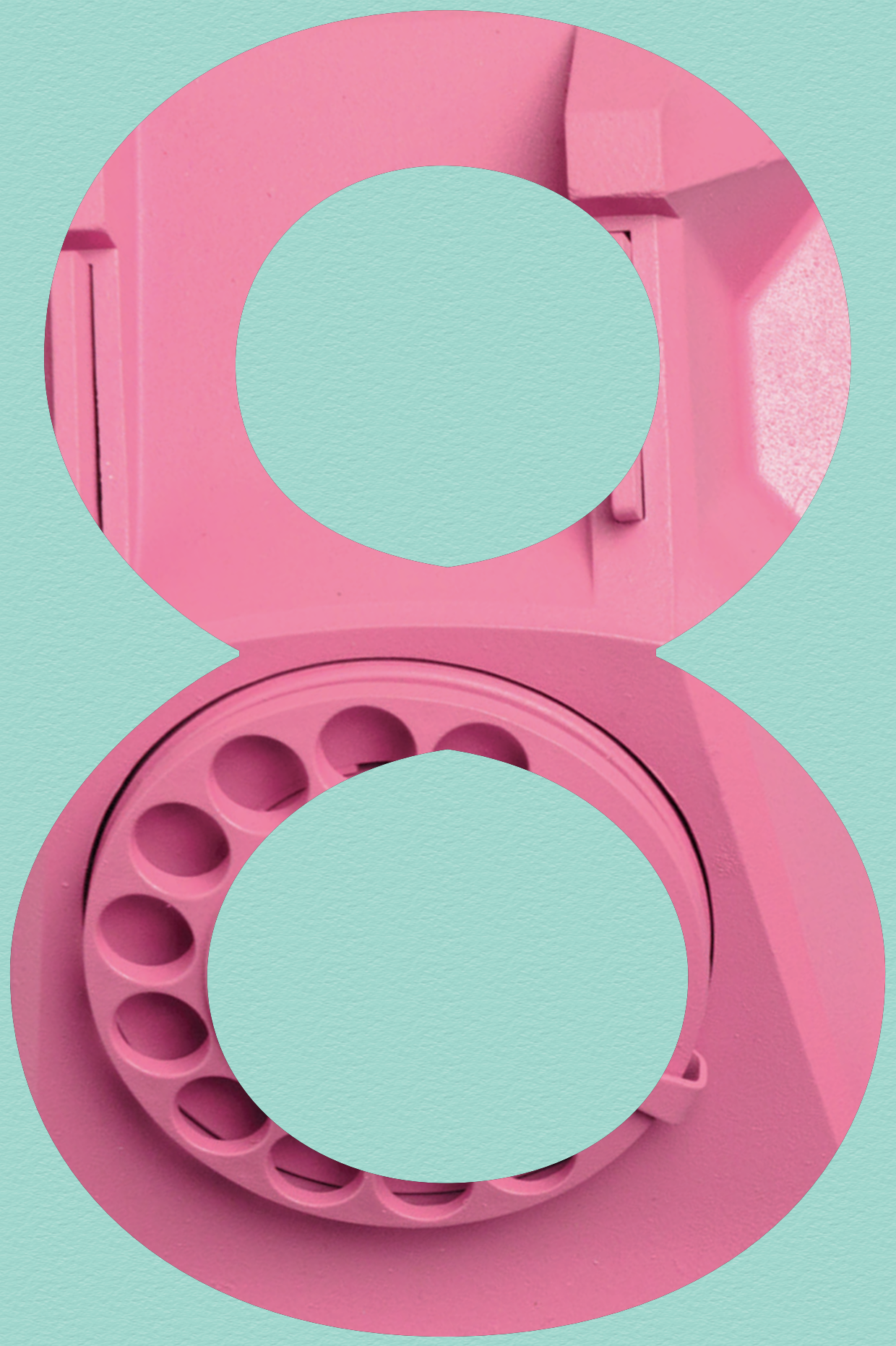




\section{Interactional implications of either/ or-questions during telephone}

triage of callers with chest discomfort in out-of-hours primary care: A conversation analysis

D.C. Erkelens

T.C. van Charldorp

V.V. Vinck

L.T. Wouters

R.A. Damoiseaux

F.H. Rutten

D.L. Zwart

E. de Groot

Published: Patient Education and Counseling 2020 


\section{Abstract}

Objective: To explore the interactional implications of either/or-questions on the interaction between people who call out-of-hours services in primary care (OHS-PC) and triage nurses who use a decision support tool called the 'Netherlands Triage Standard' (NTS) during telephone triage.

Methods: A qualitative study of 68 triage conversations at six Dutch OHS-PC. Patients called the OHS-PC with symptoms, e.g. chest discomfort, suggestive of acute coronary syndrome. Using conversation analysis, we identified two categories of multiple-choice either/or-questions that indicated interactional difficulties, shown in hesitation markers within callers' responses.

Results: Our analysis shows that interactional difficulties mainly arise when (i) questions are poorly designed by the triage nurse; or (ii) when the caller's complaints are ambiguously presented reflecting patient's difficulties to verbalize them (e.g. "not feeling well").

Conclusions: The way NTS displays key diagnostic options encourages triage nurses to use multiple-choice either/or-questions. More awareness among triage nurses is needed on undesirable implications of either/or-questions on the interaction.

Practice implications: We recommend changing the NTS display of diagnostic options and to use questions with fewer options in order to decrease the chance of formulating ambiguous questions soliciting unclear responses. Furthermore, asking content questions when complaints are ambiguously formulated may specify the presentation of complaints. 


\section{Introduction}

During telephone triage conversations at out-of-hours services in primary care (OHS-PC) in the Netherlands patients call to share their concerns and ask for medical help outside the office hours of their own general practice.(1) Triage nurses perform telephone triage under supervision of a general practitioner (GP).(1) The key goal of telephone triage is to identify callers with the most urgent need for care by allocating adequate urgency levels.(2) In order to assign an adequate urgency level, triage nurses in the Netherlands use a computer decision support system called the 'Netherlands Triage System' (NTS). (3) The NTS consists of mandatory medical topics on which the triage nurses have to ask questions. The mandatory topics are hierarchically ordered (1); questions about the most critical symptoms and circumstances requiring immediate action are asked first, followed by less critical questions.(4) Besides the mandatory topics, triage nurses may ask optional questions throughout the conversation. Triage nurses fill out the callers' responses in the NTS, which then automatically generates an urgency level linked to a maximum response time by which medical help must be provided.(2)

Telephone triage conversations concern a challenging type of interaction, because triage nurses can only use verbal information. $(4,5)$ There is a substantial body of literature on medical institutional interaction (6), the structure of doctor-patient interaction (7-9), and more specifically on primary care encounters between GPs and patients.(10) Yet, studies focusing on triage nurse-caller interaction in OHS-PC settings are scarce. Previous analyses from an interactional perspective showed that most medical consultations follow a standard structure consisting of recognizable phases $(11,12)$, however, these are mostly based on doctor-patient interaction where the main goal is to establish a diagnosis. In triage conversations the main institutional goal is urgency allocation. Based on previous international literature on the phase structure of calls to a medical helpline $(13,14)$ and emergency service $(15)$, and a preliminary bottom-up analysis of our data of triage calls between triage nurses and callers, we identified seven phases of telephone triage conversations at the OHS-PC (see Figure 1). 


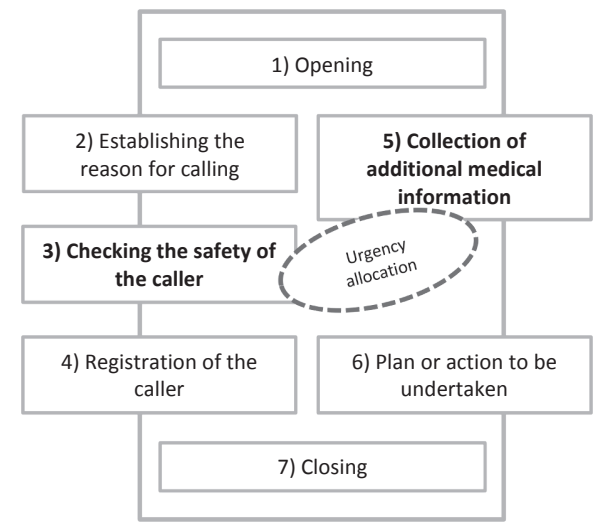

Figure 1. Phases of telephone triage conversation at the out-of-hours service in primary care (OHS-PC)

The process of urgency allocation is mainly shaped by phase three and five, which contain medically relevant questions. As mentioned before, triage nurses have to follow the structure of the NTS, formulate questions, interpret responses, and enter the responses in the NTS, with in the meantime coordinating the conversation. Obviously, this is a difficult interactional challenge.(14) An additional complicating factor for this type of institutional interaction is time; telephone triage should be fast, in order to limit delay of treatment aimed at improving prognosis. Especially for callers with symptoms suggestive of an acute coronary syndrome this is crucial, yet requires great effort as callers can present a wide variety of symptoms, and physical signs are lacking.(16-18)

The NTS is set up in such a way that the triage nurse needs to choose between multiple options, with one option leading to a higher urgency than the other(s). During a telephone triage conversation, the NTS proposes possible diagnostic 'main complaints' based on word recognition software; when the triage nurse types information from the caller into a free text field, the NTS responds with possible 'main complaints' from which the triage nurse can choose. By choosing a 'main complaint' a new screen is activated within the NTS, showing the rest of the mandatory triage topics related to that specific 'main complaint'. The topics are listed vertically as keywords (e.g. sweating, nausea, clammy) and have an additional information button. The triage nurse has the possibility to click on this button, after which a short explanation on the topic and a pre-formulated sample question appear (e.g. "Do you feel sweaty or nauseous or clammy?"). In this unique context of telephone triage with the NTS, triage nurses use questions with one or more options. Questions in general can differ in lexical, morphological, syntactic and intonational characteristics.(19) Across cultures and languages these characteristics also differ.(20,21) For the Dutch language there is a categorization of questions focusing on the types of responses questions require: polar questions, content questions and either/ or-questions.(20) We adapted this categorization for triage conversations, displayed in Figure 2.(20-25) 
Interactional implications of either/or-questions during telephone triage

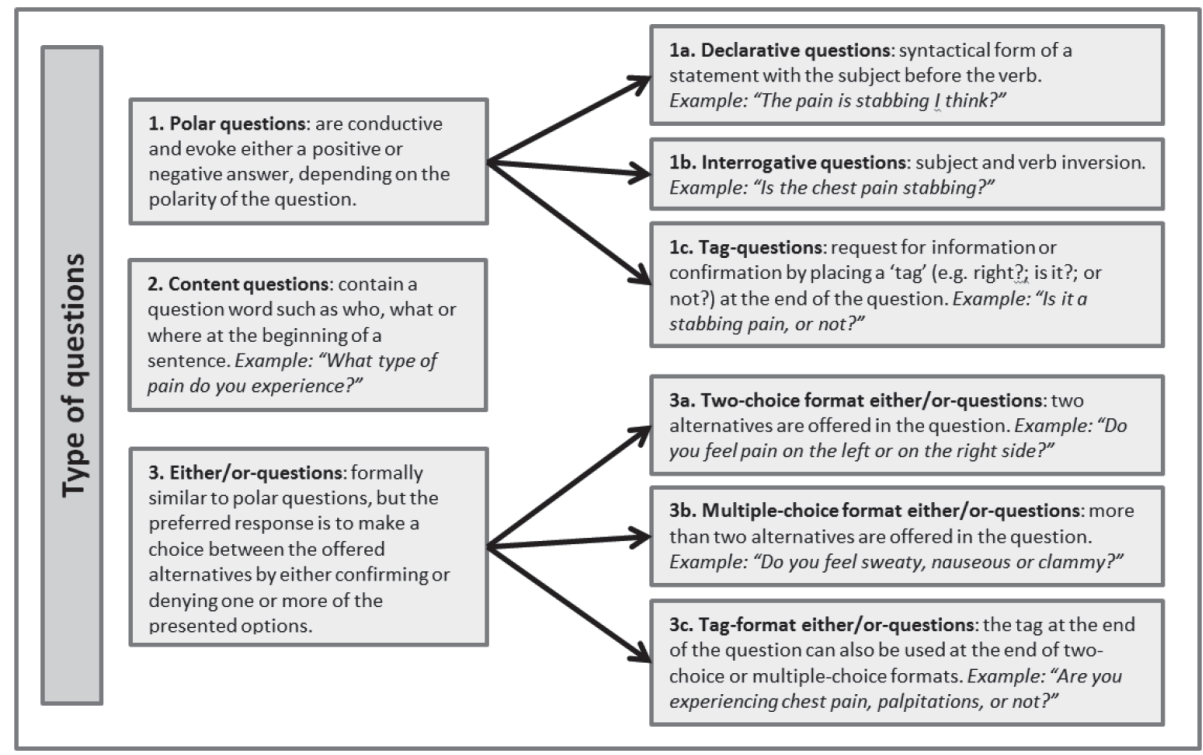

Figure 2. Type of questions in Dutch and corresponding examples (20-25)

A first look at our data revealed that triage nurses often use either/or-questions, which come in different formats: two choice, multiple-choice and tag-format. We noticed friction within the multiple-choice format of 'either/or-questions', category $3 \mathrm{~b}$ in Figure 2. On the one hand, multiple-choice questions are easy and fast, because they require an unambiguous response and make a certain type of interactionally 'preferred' response relevant.(26) According to the general principle of preference organisation in interaction, preferred responses (e.g. accepting an invitation) are shown by a quick and direct turn shape, whereas non-preferred responses (e.g. rejecting an invitation) are produced with delay components, such as hesitation makers. $(26,27)$ In case of multiple-choice formatted questions, the preferred response is repeating one of the offered options.(20) A previous conversation analytic study of emergency calls reported that multiple-choice questions were more effective than content questions, as multiple-choice questions helped to align callers to the communicative task of the triage nurse in this interactional context.(28) On the other hand, we observed a lot of hesitation markers such as pauses, filled pauses (e.g. "eh" or "ehm"), reformulations and repairs in response to multiplechoice questions. Hesitation markers are indications of non-preferred responses that take more time (29), which is especially suboptimal in an emergent setting such as telephone triage conversations of people calling with chest discomfort suggestive of acute coronary syndrome. Also, non-preferred responses suggest that the questions were problematic for the caller.(26) Thus, the aim of our study was to explore the implications of multiplechoice either/or-questions on the interaction between people who called the OHS-PC and triage nurses who used the NTS during the calls for triage. 


\section{Methods}

This study is part of a larger project called 'Safety First' paying attention to triage and diagnosis of callers with symptoms suggestive of acute cardiovascular disease in the OHS-PC setting. Details of the design were published elsewhere.(30)

We used a random sample of 68 telephone triage conversations of over 2,000 recordings of conversations between callers with chest discomfort and triage nurses at Dutch OHSPCs between 2014 and 2016. Such conversations are routinely recorded and archived for training, quality control, and research purposes. The triage recordings were anonymized in accordance with ethical guidelines and all researchers involved in the data collection and analysis signed a confidentiality agreement. The triage recordings were transcribed verbatim and coded by the authors for the phases and categories of either/or-questions (see Figure 2). Subsequently, for all transcripts containing either/or-questions we used Jeffersonian conventions for transcription, which makes phonetic information and pacing visible (see Supplementary Data Table S1).(31) Conversation analysis enabled us to systematically study the interaction between callers and triage nurses by focusing on the various types of either/or-questions and what types of responses they yield.(27, 32) Within our dataset of triage calls, we could collect 250 either/or-questions among 68 callers with chest discomfort (see Figure 1 and Table 1). The frequency and distribution of the different formats within our dataset are displayed in Table 1.

Table 1. Distribution of either/or-questions per phase of OHS-PC telephone triage conversations among 68 callers with chest discomfort (See also Figure 1)

\begin{tabular}{lllllllll} 
& Phase & Phase & Phase & Phase & Phase & Phase & Unclear & Total \\
& $\mathbf{1}$ & $\mathbf{2}$ & $\mathbf{3}$ & $\mathbf{4}$ & $\mathbf{5}$ & $\mathbf{6}$ & & \\
\hline Two-choice format & 0 & 2 & 29 & 4 & 119 & 5 & 1 & 160 \\
\hline $\begin{array}{l}\text { Multiple-choice } \\
\text { format }\end{array}$ & 0 & 0 & 15 & 0 & 47 & 1 & 0 & 63 \\
\hline Tag-questions* & 0 & 0 & 4 & 3 & 18 & 2 & 0 & 27 \\
\hline
\end{tabular}

Previously, we have shown what kind of response two-choice format questions, multiplechoice format questions and tag-questions elicit in triage conversations and when they are utilized effectively.(33) In this study, we focus on multiple-choice either/or-questions and the responses they elicit in phase three and five because of their high importance in the urgency allocation process, and because the frequent use of either/or-questions in these phases (see Table 1). 


\section{Results}

The multiple-choice format of either/or-questions in our data and the hesitation markers in the responses show the callers' difficulties in responding to this type of questions. Our analysis showed that such difficulties mainly arise when a) questions are poorly designed; or b) when callers' complaints are ambiguously presented (i.e. callers are looking for words to describe the sensations experienced). These two categories will be further illustrated below.

\section{Poorly designed multiple-choice either/or-questions}

Callers often responded to questions with hesitation markers such as "eh", "ehm", pauses or restarts. Sometimes, the triage nurse had to repeat (part of) the question, in the absence of a clear response to all the options within the question. These hesitant responses led us to further investigate the (problematic) questions that preceded these responses. The data shows that problematic questions occurred when response options have an unclear relation to each other. The use of the conjunction 'or' provides alternative response options. These options can exclude each other, i.e.: "on the left or on the right?" or they can offer options that fall within the same category, i.e.: "Is the pain stinging or pressing?".(34) Sometimes, the offered values have an unclear relationship or they do not exclude each other risking interactional difficulties. Examples of problematic question designs are displayed in Table 2.

Table 2. Examples of poorly designed multiple-choice either/or-questions

\begin{tabular}{lll}
\hline CC014 & T: & $\begin{array}{l}\text { () And uh/ Because you've had these /t/ symptoms for three whole weeks? } \\
\text { Really every <day>? Or uh is it fa[ding] too: or not? }\end{array}$ \\
\hline CC018 & T: $\begin{array}{l}\text { Hmhm. And do you also feel } \downarrow \text { sweaty or } \downarrow \text { clammy or do you feel a pain } \\
\text { anywhere else? }\end{array}$ \\
\hline CC019 & T: $\begin{array}{l}\text { O个kay and are you eh really aware of your heartbeat or are you saying well I } \\
\text { 个really do have this pressing PAIN on my chest or (.) I am brea:thless e:hm (.) } \\
\text { What's the } \downarrow \text { most im } \downarrow \text { portant mis } \downarrow \text { ter (.)? }\end{array}$ \\
\hline
\end{tabular}

Not all problematic questions could be found by looking at problematic responses. In Table 3 we see a relatively straightforward response given by the caller in line 8 . Here, the caller provides a confirmation ("yeah") and chooses one of the options provided by the question in lines 4-7: "it just stays the same all the time". 
Table 3. Transcript of CC041

\begin{tabular}{|c|c|c|}
\hline 1 & C: & $\begin{array}{l}\text { Het is een pijn dat ik nog wel kan ver } \downarrow \text { dragen. } \\
\text { It's a pain I can still tol } \downarrow \text { erate. }\end{array}$ \\
\hline 2 & $\mathrm{~T}:$ & $\begin{array}{l}\text { 个Ja wat voor cijfer is dat? } \\
\text { 个Yes what number is it? }\end{array}$ \\
\hline 3 & C: & $\begin{array}{l}\mathrm{Hm}: 4 \text { of } \uparrow 5 . \\
\mathrm{Hm}: 4 \text { or } \uparrow 5 .\end{array}$ \\
\hline 4 & $\mathrm{~T}: \rightarrow$ & $\begin{array}{l}\text { Ok: En: e/ehm hoe is het >verder met die pijn<? Zit ie vast aan } \\
\text { Okay: And: u/uhm what >about this pain<? Is it connected to }\end{array}$ \\
\hline 5 & & $\begin{array}{l}\text { de <ademhaling > of als u een bepaalde <bewe:gingen maakt }>\text { of } \\
\text { your <breathing > or when you make a certain <move:ment> or }\end{array}$ \\
\hline 6 & & $\begin{array}{l}\text { als u wat gaat do:en is hij dan } \uparrow \text { erger of blijft ie } \uparrow \text { al die } \\
\text { when you're ab:out to do something does it get } \uparrow \text { worse or stay }\end{array}$ \\
\hline 7 & & $\begin{array}{l}\downarrow \text { tijd hetzelfde? } \\
\text { the same } \uparrow \text { all the } \downarrow \text { time? }\end{array}$ \\
\hline 8 & C: & $\begin{array}{l}\downarrow \text { Ja het blijft gewoon al die tijd het } \downarrow \text { zelfde }(0.3) \\
\downarrow \text { Yeah it just stays the } \downarrow \text { same all the time (0.3) }\end{array}$ \\
\hline 9 & $\mathrm{~T}:$ & $\begin{array}{l}\text { Eh/ gebruikt u nog andere medicijnen? } \\
\text { Uh/do you use any other medication? }\end{array}$ \\
\hline
\end{tabular}

Taking a closer look at the question, the presented options (lines 4-7) concern breathing, movement and the course of the pain. These options are presented as multiple-choice alternatives using 'or' to mark the various options. However, the relationship between these three options is imprecise and unclear. The options do not fall within the same category, nor do they exclude each other. In fact, the options cover three separate topics. The first two topics (respiration and movement) are polar (interrogative) questions (meaning that a yes or no response would be relevant) and the third option (course of pain) is a two-choice either/or-question "when you're about to do something does it get worse or stay the same?". Yet, these three topics and question formats are combined into one multiple-choice either/or-question with three options. Following the principle of interactional contiguity (35), the caller only responds to the last part of the question by choosing one of the two options. Whether the pain is connected to the respiration or movement is not mentioned and cannot be excluded with certainty. This example shows that by combining options with different content and/or combining different questions formats to form a multiple-choice either/or-question, the triage nurse risks missing out on important information. These poorly designed questions not only cost extra (unnecessary) time to respond to, but also possibly hinder safe triage.

\section{Ambiguous presentation of complaints}

In the dataset, some multiple-choice either/or-questions frequently lead to wordy and ambiguously formulated responses. On closer inspection, these types of ambiguous responses often concern complaints that are difficult to put into words by the caller. In 
these cases, either/or-questions did not help in eliciting a concrete response (see Table 4).(6)

Table 4. Transcript of CCO17

\begin{tabular}{|c|c|c|}
\hline 1 & $\mathrm{~T}:$ & $\begin{array}{l}\text { En u voelt zich niet } \downarrow \text { lekker } \\
\text { And you're not feeling } \downarrow \text { well }\end{array}$ \\
\hline 2 & C: & $\begin{array}{l}\downarrow \text { Nee al e: } h \text { ja al een paar dagen } \downarrow \text { niet gewoon echt pijn } \downarrow \text { echt } \\
\downarrow \text { No not u: } h \text { yeah for a couple of days } \downarrow \text { just not real pain } \downarrow \text { really }\end{array}$ \\
\hline 3 & $\mathrm{~T}: \rightarrow$ & $\begin{array}{l}\downarrow \text { Ok. Maar het straalt } \uparrow \text { niet uit naar uw }<\text { arm }>\text { of uw }<\text { ka:ken }> \\
\downarrow \text { Okay. But } \uparrow \text { doesn't it spread down your }<\text { arm }>\text { or to your }<j a: w>\end{array}$ \\
\hline 4 & & $\begin{array}{l}\text { of rug? } \\
\text { or back? }\end{array}$ \\
\hline 5 & C: & $\begin{array}{l}\text { E:h ik/ik/ik/ik/ ik weet het } \downarrow \text { echt niet. Ik weet het } \downarrow \text { echt niet. } \\
\text { U:h I/I/I/I/I } \downarrow \text { really don't know. I } \downarrow \text { really don't know. }\end{array}$ \\
\hline 6 & & $\begin{array}{l}{[\text { Maar ik/] }} \\
{[\text { But I/] }}\end{array}$ \\
\hline 7 & $\mathrm{~T}: \rightarrow$ & $\begin{array}{l}\text { [Maar u kan zeggen of uw daar ook }<\text { pijn }>\text { heeft aan uw }<\uparrow a r m>\text { of uw } \\
\text { [But can you say if you have }<\text { pain }>\text { in your }<\uparrow \text { arm }>\text { or your }\end{array}$ \\
\hline 8 & & $\begin{array}{l}<\uparrow k a a k>\text { of/ Of u daar } \uparrow \text { pijn heeft? } \\
<\uparrow j a w>\text { or/ Whether you have } \uparrow \text { pain there? }\end{array}$ \\
\hline 9 & C: & $\begin{array}{l}\text { Dat heb ik niet in de } \downarrow \text { gaten eerlijk gezegd. } \\
\text { I'm not } \downarrow \text { aware of it honestly. }\end{array}$ \\
\hline 10 & $\mathrm{~T}:$ & $\begin{array}{l}\text { En u bent daar bij misselijk bij? Bent u ook aan het zweten? } \\
\text { And do you feel nauseous with it? Does it make you sweat too? }\end{array}$ \\
\hline 11 & C: & $\begin{array}{l}\text { Ja ik voel mij gewoon niet/ Nee niet zweterig maar ik voel mij } \\
\text { Yeah I just don't feel/ No not sweaty but I just don't feel }\end{array}$ \\
\hline 12 & & $\begin{array}{l}\text { gewoon niet lekker. Ja. } \\
\text { well. Yeah. }\end{array}$ \\
\hline
\end{tabular}

During the call, the patient indicated that he was not feeling well with an unpleasant sensation on the his "left side", and he is afraid that it is related to his heart. After the caller was registered in the triage system, the triage nurse returns to the complaint of "not feeling well". If we analyse the interaction line-by-line, the either/or-question in lines 3-4 receives multiple hesitations, restarts and an ambiguous response. The phase of collecting additional medical information (phase five, Figure 1) is opened in line 1 with "And you're not feeling well". By using this negatively formulated declarative, the triage nurse gives the caller little space to formulate his problem. Although the negative formulation is confirmed by the turn-initial "No" (line 2), the caller also briefly adds the elapsed period of time, a technique often used when problems are difficult to put in words (6), and follows up with an extreme case formulation: "real pain" with an additional "really". This extreme case formulation legitimates his complaints about the suffering endured.(36) By doing so, the caller stresses the severity of the problem and underlines that these sensations are more severe than "not feeling well" - as proposed by the triage nurse. Conveying that symptoms 
are worthy of a doctor's time and attention, is a phenomenon called doctorability, referring to patients' orientation towards legitimizing their request for the doctor's help.(37, 38) Previous literature on doctorability described practices that patients use in contexts where justification of medical help seemed to be at stake. One of these is making 'troubles resistant' claims, e.g. about the length of time a patient waited before seeking medical help (37), which is also been done by the caller in line 2. This legitimization of the caller's problem is not responded to by the triage nurse with an acknowledgment, but rather with a transition in topic. By using "Okay. But ..." (line 3) - a discourse marker followed by a contrastive discourse marker - the triage nurse indicates that she hasn't received the information she was looking for.(39) This then explains the concrete, declarative multiplechoice question in lines 3-4 giving three options concerning the location of radiating pain. However, the negative formulation within the question ("doesn't it...") expects a negative response ("no, it doesn't"), making the caller's problem less doctorable. It is therefore not surprising that the caller's response (lines 5-6), shows multiple hesitation markers and restarts followed by a non-preferred response - rather than confirming that his problem is indeed not doctorable, the caller responds with "I really don't know". The triage nurse does not accept this 'unknowing' response (line 7) by using the contrastive discourse marker "but" and repeating the question in lines 7-8. Again, the caller is unable to respond to the question. This time, the triage nurse starts a new sequence with "and" offering two new topics (line 10), presumably in order to fill out the NTS. While confirming that he is not sweaty - and therefore making his own problem less doctorable, the caller still emphasizes that he doesn't feel well, a repetition of what the triage nurse stated in line 1.

This excerpt shows that the triage nurse has to interactionally work hard to find out what the caller is suffering from while the caller is continuously presenting his problem as doctorable. Offering all the options to the caller doesn't provide the triage nurse with the information she is looking for and costs valuable time. The caller's responses include hesitation markers, re-starts, unknowing responses and repetitions, while the nurse continues to offer concrete symptom options in order to fill out the NTS.

In Table 5 the caller has an "unpleasant feeling" on his chest and has difficulties describing his complaints. First, the triage nurse checks the caller's safety (phase three, Figure 1) and registers the caller in the triage system (phase four, Figure 1). Then the triage nurse comes back to the opening question in line 1 . The caller struggles to describe the unfamiliar sensations as "a bit of a dash" (line 6), "a little stabbing" (lines 21-22), "unpleasant feeling" (lines 26) and "it stabs a bit" (line 26) and mentions that he has difficulties in determining whether these symptoms are actual symptoms that he is experiencing (lines 6-7 and 9). The triage nurse uses contrastive discourse markers showing that she is looking for other information: "Yeah but/ you say" (line 10), "But as far as I'm concerned," (line 28) showing that she hasn't got the information she needs and is still looking for a concrete response to be able to proceed to the next mandatory question within the NTS. That the triage nurse needs an unambiguous response in order to be able to fill out the NTS 
is even more evident from the utterance: "I just want a yes or a no" (lines 29-30). By creating this polarity there is no space given for narratives and ambiguously formulated complaints, like an "unpleasant feeling" or "it stabs a bit".

Remarkable is that the caller's response in line 31 ends with a minimal pause and an adverb of frequency "sometimes", downgrading the preferred unambiguous response "Yes. In my back".(40) This also shows that the interactionally preferred option 'yes' doesn't cover the symptoms experienced. The confirmation of the triage nurse "I'll tick that" without repeating "sometimes" also implies that there is no attention given to the nuance that the word "sometimes" provides. "I'll tick that" shows that the triage nurse needs to tick one of the NTS boxes to be able to proceed. This displays the friction that occurs during the translation from conversational interaction to the NTS system.

Table 5. Transcript of CCO13

\begin{tabular}{lll}
\hline 1 & T: & $\begin{array}{l}\text { Ok. Even kijken hoe ik u kan helpen hoor. Vertel nog eens, } \\
\text { Okay. Let's see how I can help you, aye? Tell me again, }\end{array}$ \\
\hline 2 & $\begin{array}{l}\text { sinds wanneer heeft u nou dat akelige gevoel op de borst? } \\
\text { when did you begin having that unpleasant feeling in your chest? }\end{array}$ \\
\hline $3 \quad$ C: $\quad \begin{array}{l}\text { Ja nou goed. Ik eh/ War het voor mijn gevol enigszins mee begonnen is, } \\
\text { Yeah, okay, I eh/ I think it started a bit }\end{array}$ \\
\hline 4 & $\begin{array}{l}\text { is ik had ziekteverschijnselen. Beetje spierpijn in de } \\
\text { when I began getting symptoms. A bit of a muscle pain in the }\end{array}$ \\
\hline 5 & $\begin{array}{l}\text { nek zeg maar. } \\
\text { neck, so to speak. }\end{array}$
\end{tabular}

(Time past: 01:42 minutes. Conversation about the course of the symptoms and use of medication.)

\begin{tabular}{|c|c|c|}
\hline 5 & C: & $\begin{array}{l}\text { Nee het is/ het is ook geen echte } \downarrow \text { pijn. Ja het lijk wel of nu of } \\
\text { No it's/it's not proper } \downarrow \text { pain either. Yeah it's like now and }\end{array}$ \\
\hline 6 & & $\begin{array}{l}\text { ik af en toe een scheutje voel zeg } \downarrow \text { maar. Maar dan vraag ik me af } \\
\text { then I feel a bit of a dash you } \downarrow k n o w \text {. But then I wonder }\end{array}$ \\
\hline 7 & & $\begin{array}{l}\text { of dat in mn hoofd [((is die] dat } \\
\text { if it's all in my head [((is it] }\end{array}$ \\
\hline 8 & $\mathrm{~T}:$ & $\begin{array}{l}{[\mathrm{ja}]} \\
\text { [yes] }\end{array}$ \\
\hline 9 & C: & $\begin{array}{l}\text { zegt)) ((lacht)) of mijn lichaam zeg } \downarrow \text { maar } \\
\text { saying that?)) ((laughs)) or in my body you } \downarrow \text { know }\end{array}$ \\
\hline 10 & $\mathrm{~T}: \rightarrow$ & $\begin{array}{l}\text { Ja maar/ en }((\mathrm{ik})) \text { ben niet benauwd zeg je. Geen benauwd ge } \downarrow \text { voel. } \\
\text { Yeah but/ you say }((I)) \text { I'm not short of breath. No short } \downarrow \text { iness of }\end{array}$ \\
\hline 11 & & $\begin{array}{l}\text { Je gaat op de fiets naar je } \downarrow \text { werk. Ik STEL even gewoon wat/ } \\
\text { breath? You ride your bike to your } \downarrow \text { work. I'm just ASKING a few/ }\end{array}$ \\
\hline 12 & & $\begin{array}{l}\text { wat eh eh vra: } \downarrow \text { gen IS er ergens ANDers } \angle \text { PIJN:> beHA:Ive } \\
\text { few uh uh ques: } \downarrow \text { tions IS there } \angle \text { PAIN: }>\text { somewhere ELse beSI:des }\end{array}$ \\
\hline
\end{tabular}


Table 5. Continued

\begin{tabular}{|c|c|c|}
\hline 13 & & $\begin{array}{l}\text { dat }>\text { beklemmende gevoel op de borst }<\text { ? [Bijvoorbeeld] } \\
\text { that }>\text { oppressive feeling in the chest }<\text { ? [For example] }\end{array}$ \\
\hline 14 & C: & $\begin{array}{l}{[\mathrm{Ja}()]} \\
{[\text { Yes ( )] }}\end{array}$ \\
\hline 15 & $\mathrm{~T}:$ & $\begin{array}{l}\text { in de <bu:ik> of de <be:nen>, <linkera:rm> of de <ka:ken>? } \\
\text { in your <tum:my> or your <le:gs>, <left a:rm > or <ja:w>? }\end{array}$ \\
\hline 16 & C: & $\begin{array}{l}\text { Ja. Ja. Nou goed eh/ } \downarrow \text { Linkerarm inderdaad daar eh ga je ook meteen } \\
\text { Yeah. Yeah. All right uh/ } \downarrow \text { left arm indeed uh you'd feel that }\end{array}$ \\
\hline 17 & & $\begin{array}{l}\text { aan voelen. Daar heb ik niet het idee dat ik daar iets [echt voel]. } \\
\text { right away. I don't think I [really feel] something there. }\end{array}$ \\
\hline 18 & $\mathrm{~T}:$ & $\begin{array}{l}{[\text { Nee. }]} \\
{[\text { No. }]}\end{array}$ \\
\hline 19 & & $\begin{array}{l}\text { Nee. } \\
\text { No. }\end{array}$ \\
\hline 20 & C: & $\begin{array}{l}\text { Behalve dat ik er altijd op loop te drukken aan die linkerkant } \\
\text { Except I'm always feeling a tightness on my left side, }\end{array}$ \\
\hline 21 & & $\begin{array}{l}\text { de laatste dagen, dus dat gevoel af en toe. Het lijkt dat boven in } \\
\text { these past few days, that feeling, now and then. It feels like a }\end{array}$ \\
\hline 22 & & $\begin{array}{l}\text { boven in mijn rug een klein steekje zeg maar. } \\
\text { little stabbing at the top of my back so to speak. }\end{array}$ \\
\hline 24 & $\mathrm{~T}:$ & $\begin{array}{l}\text { Dus in de rug wel pijn? Boven in de rug? } \\
\text { So there's pain in your back? The upper back? }\end{array}$ \\
\hline 25 & C: & $\begin{array}{l}\text { Ja. Ja het lijkt een beetje dat ( ) dat daar soms een beetje/ ook een } \\
\text { Yes. Yes it seems like a bit () in there sometimes a bit/ of an }\end{array}$ \\
\hline 26 & & $\begin{array}{l}\text { naar gevoel. Soms een klein prikje, maar ook niet heel } \\
\text { unpleasant feeling too. Sometimes it stabs a bit, but it's not that }\end{array}$ \\
\hline 27 & & $\begin{array}{l}\text { heftig zeg maar. } \\
\text { intense you know. }\end{array}$ \\
\hline & $\mathrm{T}:$ & $\begin{array}{l}\text { Nee niet heftig. Maar het gaat mij om als iemand zegt ik heb } \\
\text { No not intense. But as far as I'm concerned, if someone says I feel }\end{array}$ \\
\hline 29 & & $\begin{array}{l}\text { een beklemmend gevoel op de borst dan wil ik gewoon een ja of een } \\
\text { feel painful pressure on my chest then I just want a yes or a }\end{array}$ \\
\hline 30 & & $\begin{array}{l}\text { nee bij, heeft u nog ergens anders pijn en waar dan? } \\
\text { no, do you have pain anywhere else and if so where? }\end{array}$ \\
\hline & $\mathrm{C}:$ & $\begin{array}{l}\text { Ok ok. Eh/ Ja. In de rug. (.) soms. } \\
\text { Okay okay. Uh/Yes. In my back. (.) sometimes }\end{array}$ \\
\hline 32 & $\mathrm{~T}:$ & $\begin{array}{l}\text { In de rug. Dan vink ik dat aan. } \\
\text { In the back. Then I'll tick that. }\end{array}$ \\
\hline 33 & C: & $\begin{array}{l}\text { Ja. } \\
\text { Okay. }\end{array}$ \\
\hline
\end{tabular}




\section{Discussion}

In triage conversations the institutional goal is to determine an adequate urgency in order to provide efficient and safe care. To support the triage nurses to reach this goal, the NTS was introduced in the Netherlands in 2011. The NTS displays key diagnostic topics in options (i.e. sweating, nausea, vomiting) to determine an urgency level. Subsequently, triage nurses formulate these options in either/or-questions ("And do you also feel $\downarrow$ sweaty or $\downarrow$ clammy or do you feel a pain anywhere else?"). Multiple-choice either/ or-questions compel the caller to choose between options, while one option would lead to a higher urgency than the other. Subsequently, the triage nurses reduce callers' complaints into symptoms that can be documented in the NTS.

Triage nurses should be more attentive to the interactional implications of either/ or-questions and further pursue patients who have difficulty verbalizing complaints through adequate question. The overriding interactional concern is how to focus the communication between triage nurse and caller on reaching the most appropriate urgency allocation, supported but not determined by a decision support system such as the NTS. Our conversation analysis reveals a deficiency of awareness amongst healthcare professionals of the influence of social technological aspects of the use of a decision support system. $(41,42)$ The way that the NTS displays key diagnostic topics provokes using either/or-questions, which can lead to communicational pitfalls.

\section{Conclusion}

During telephone triage, the Netherlands Triage Standard decision support tool influences the interaction between triage nurses and callers as it displays key diagnostic options, encouraging the triage nurse to use multiple-choice either/or-questions to check these options. Interactional difficulties mainly arise when questions are poorly designed by the triage nurse, or when the caller's complaints are ambiguously presented reflecting patient's difficulties to verbalize them. The implications are twofold: more awareness among triage nurses is needed on ineffective consequences that multiple-choice either/ or-questions evoke in the interaction, which can be done by training. Also, improvement should be sought in changing the NTS display of diagnostic options.

\section{Practice implications}

Often improvements of triage are sought in the diagnostic information within the decision support tool, giving subordinate importance to the component of interaction between caller and triage nurse. Our data give rise to opportunities for improvement different than the diagnostic information itself. The practice implications are twofold. Firstly, the 
design of the NTS can be optimised to reduce the risk of communicational pitfalls and the triage nurses should be helped to be more resilient to these pitfalls.

We recommend further ethnomethodological research, comparable to a previous study on computer-aided dispatch (43), to establish how this optimisation can be reached. This could be done by carrying out field observations and by combining audio and video recordings of telephone triage conversations_by triage nurses who use the NTS. In that way, one can analyse how computer triage tools utilised by triage nurses are embodied in the interaction and specifically in the use of either/or-questions. Secondly, awareness of the influence of the NTS on using multiple-choice either/or-questions in triage conversations should be raised among triage nurses. Our conversation analysis has led to two recommendations for daily practice:

1) Poorly designed multiple-choice either/or-questions can be avoided by utilizing questions with less options; the shorter the question the less chance of creating ambiguous questions leading to incomplete or unclear responses and missing out on important information. Also, the offered values in multiple-choice either/or-questions should be unambiguous and have a clear relationship to each other.

2) Regarding the phenomenon of using either/or-questions in case a caller has difficulties describing complaints (i.e. ambiguous presentation of complaints), we recommend making the presentation of complaints more specific through first asking content questions, and then either/or-questions, which demands a different design of the NTS. By giving more interactional space, the caller will be invited to clarify the symptoms experienced.(8) Critics might say that such invitations will incite winding narratives, however, we suggest that even in emergency conversations the advantages of narratives shouldn't be mistaken, as they permit the caller to give their own account of illness. (6) We argue that a better balance is needed between leaving space for narratives and asking either/or-questions in order to funnel complaints and to have an efficient and safe telephone triage conversation. To evoke a brief problem presentation, the triage nurse can take away callers' doubts of legitimacy by recognizing the need of the phone call. This is in line with previous literature describing doctorability and its effect of doctorability inviting physicians to offer reassurance as to the legitimacy of seeking for medical help. (37) A simple "good thing you called" during the problem presentation might reduce the chance that callers will make their problem doctorable in extended narrative styles which is suboptimal for adequate allocation of urgency and corresponding medical care. Because of the emergency context in which the calls take place, it is crucial that the triage happens fast in order to limit the delay of treatment, which is especially important for people calling with symptoms suggestive of acute coronary syndrome.(16) In order to raise awareness what either/or-questions questions do in interaction among triage nurses, and to apply the two recommendations above, it is advised to offer trainings based on research with real recordings, for example using the Conversation Analytic Role-play Method (CARM). $(44,45)$ By using real-life recordings, awareness can be created what questions really do as there is more to a question than meets the eye. 


\section{Declarations}

\section{Ethics approval}

The Medical Ethics Review Committee, Utrecht, the Netherlands.

\section{Conflict of interest}

The authors have no conflict of interest to declare.

\section{Informed consent statement}

I confirm all patient/personal identifiers have been removed or disguised so the patient/ person(s) described are not identifiable and cannot be identified through the details of the story.

\section{Funding}

This work was supported by the department of general practice of the University Medical Center Utrecht, Associate Professorship-promotion grant of D.L. Zwart, MD, PhD, the foundation 'Netherlands Triage Standard' and the foundation 'Stoffels-Hornstra'. The views expressed are those of the authors and not necessarily those of the foundations. The funding foundations had no role in study design, data collection and analysis, preparation of the article, or decision to publish.

\section{Acknowledgements}

We would like to thank the out-of-hours primary care foundation 'Primair Huisartsenposten' in Utrecht and linguistic student Celine van Laer for their participation. 


\section{References}

1) Smits $M$, Rutten $M$, Keizer $E$, Wensing $M$, Westert $G$, Giesen $P$. The Development and Performance of After-Hours Primary Care in the Netherlands: A Narrative Review. Annals of internal medicine. 2017;166(10):737-42.

2) Blank L, Coster J, O'Cathain A, Knowles E, Tosh J, Turner J, et al. The appropriateness of, and compliance with, telephone triage decisions: a systematic review and narrative synthesis. J Adv Nurs. 2012;68(12):2610-21.

3) Netherlands Triage Standard [Nederlandse Triage Standaard], 2019. Accessed at www. de-nts.nl on 7 October 2019.

4) Kuriyama A, Urushidani S, Nakayama T. Five-level emergency triage systems: variation in assessment of validity. Emergency medicine journal : EMJ. 2017;34(11):703-10.

5) Giesen P, Smits M, Huibers L, Grol R, Wensing M. Quality of after-hours primary care in the Netherlands: a narrative review. Annals of internal medicine. 2011;155(2):108-13.

6) Heritage J, Clayman S. Talk in action: interactions, identities, and institutions. Malden: WileyBlackwell; 2010.

7) Drew P, Chatwin J, Collins S. Conversation analysis: a method for research into interactions between patients and health-care professionals. Health Expect. 2001;4(1):58-70.

8) Heritage J, Robinson JD. The structure of patients' presenting concerns: physicians' opening questions. Health Commun. 2006;19(2):89-102.

9) Robinson JD. An interactional structure of medical activities during acute visits and its implications for patients' participation. Health Commun. 2003;15(1):27-57.

10) Heritage J, Maynard D. Communication in Medical Care: Interaction Between Primary Care Physicians and Patients. Cambridge: Cambridge University Press; 2006.

11) ten Have P. Sequential structures and categorical implications in doctor-patient interaction: ethnomethodology and history. Professional conference: structure and emergence of professionalized "Praxis"; J.W. Goethe-Universität September 26-28, Frankfurt, Germany2001.

12) Byrne P, Long B. Doctors Talking to Patients: A Study of the Verbal Behaviours of Doctors in the Consultation. Her Majesty's Stationary Office, London: 1976.

13) Lopriore S, LeCouteur A, Ekberg S, Ekberg K. Delivering healthcare at a distance: Exploring the organisation of calls to a health helpline. Int J Med Inform. 2017;104:45-55.

14) Pooler J. Technology and Talk in Calls to NHS Direct. Doctoral Thesis [Doctoral Thesis]. United Kingdom: The University of Loughborough; 2010.

15) Whalen J, Zimmerman DH, Whalen MR. When Words Fail - a Single Case Analysis. Soc Probl. 1988;35(4):335-62.

16) Bosner S, Haasenritter J, Becker A, Karatolios K, Vaucher P, Gencer B, et al. Ruling out coronary artery disease in primary care: development and validation of a simple prediction rule. CMAJ : Canadian Medical Association journal = journal de l'Association medicale canadienne. 2010;182(12):1295-300.

17) Burman RA, Zakariassen E, Hunskaar S. Management of chest pain: a prospective study from Norwegian out-of-hours primary care. BMC family practice. 2014;15:51.

18) Rawshani N, Rawshani A, Gelang C, Herlitz J, Bang A, Andersson JO, et al. Could ten questions asked by the dispatch center predict the outcome for patients with chest discomfort? International journal of cardiology. 2016;209:223-5. 
19) Heritage J. The limits of questioning: negative interrogatives and hostile question content. J Pragmatics. 2002;34(10-11):1427-46.

20) Englert C. Questions and responses in Dutch conversations. J Pragmatics. 2010;42(10):266684.

21) König E, Siemund P. Speech act distinctions in grammar. In: Shopen T, editor. Language Typology and Syntactic Description. Cambridge: Cambridge University Press; 2007. p. 276324.

22) Steensig J, Drew P. Introduction: questioning and affiliation/disaffiliation in interaction. Discourse Stud. 2008;10(1):5-15.

23) Tracy K, Robles J. Questions, questioning, and institutional practices: an introduction. Discourse Stud. 2009;11(2):131-52.

24) Heritage J, Raymond G. The terms of agreement: Indexing epistemic authority and subordination in talk-in-interaction. Soc Psychol Quart. 2005;68(1):15-38.

25) Mazeland HJ. Introduction in conversation analysis. [Inleiding in de conversatieanalyse]. Bussum: Coutinho; 2003.

26) Pomerantz A. Agreeing and disagreeing with assessments: some features of preferred/ dispreferred turn shaped. Structures of social action: studies in conversation analysis. Cambridge: Cambridge University Press; 1984.

27) ten Have P. Doing conversation analysis: Sage; 2007.

28) Koole T, Verberg N. Aligning caller and call-taker The opening phrase of Dutch emergency calls. Pragmat Soc. 2017;8(1):129-53.

29) Heritage J. Garfinkel and Ethnomethodology. Cambridge: Polity Press; 1984.

30) Erkelens DC, Wouters LT, Zwart DL, Damoiseaux RA, De Groot E, Hoes AW, et al. Optimisation of telephone triage of callers with symptoms suggestive of acute cardiovascular disease in out-of-hours primary care: observational design of the Safety First study. BMJ open. 2019;9(7):e027477.

31) Jefferson G. Glossary of transcript symbols with an introduction. In: Lerner GH, editor. Conversation Analysis: Studies from the First Generation. Amsterdam/Philadelphia: John Benjamins; 2004. p. 13-31.

32) Sidnell J, Stivers T. The handbook of conversation analysis. Chichester: John Wiley \& Sons; 2012.

33) Vinck VV, de Groot E, Wouters LT, Rutten FH, Damoiseaux RA, van Charldorp TC, et al. Conversation analysis of triage calls. [Een conversatieanalyse van triagegesprekken.]. Huisarts Wet. 2018;61(6).

34) Biezma M, Rawlins K. Responding to alternative and polar questions. Linguist Philos. 2012;35(5):361-406.

35) Sacks H. On the Preferences for Agreement and Contiguity in Sequences in Conversation. In: Button G, Lee J, editors. Talk and Social Organisation: Multilingual Matters, ; 1987. p. 54-69.

36) Pomerantz A. Extreme Case Formulations - a Way of Legitimizing Claims. Hum Stud. 1986;9(2-3):219-29.

37) Heritage J, Robinson J. Accounting for the visit: Giving reasons for seeking medical care. In J. Heritage \& D. Maynard (Eds.), Communication in Medical Care: Interaction between Primary Care Physicians and Patients (Studies in Interactional Sociolinguistics, pp. 48-85). Cambridge: Cambridge University Press. 2006.

38) Maynard DW, Heritage J. Conversation analysis, doctor-patient interaction and medical communication. Medical Education. 2005;39(4):428-35. 
39) Fraser B. Contrastive discourse markers in English. Pragmatics and Beyond New Series. 1998:301-26.

40) Bilmes J. The Concept of Preference in Conversation Analysis. Lang Soc. 1988;17(2):161-81.

41) Murdoch J, Barnes R, Pooler J, Lattimer V, Fletcher E, Campbell JL. The impact of using computer decision-support software in primary care nurse-led telephone triage: interactional dilemmas and conversational consequences. Soc Sci Med. 2015;126:36-47.

42) Morgan JI, Muskett T. Interactional misalignment in the UK NHS 111 healthcare telephone triage service. International Journal of Medical Informatics. 2020;134.

43) Whalen J. A technology of order production: computer-aided dispatch in public safety communication. In: Psathas G, ten Have P, editors. Situated Order: Studies in the Social Organization of Talk and Embodied Action. Washington, D.C.: University Press of America; 1995.

44) Stokoe E. The Conversation Analytic Role-play Method (CARM): A Method for Training Communication Skills as an Alternative to Simulated Role-play. Res Lang Soc Interac. 2014;47(3):255-65.

45) Sikveland RO, Stokoe E. Effective telephone triage methods. Practice Management. 2017;27(6):20-2. 


\section{Supplementary Data}

Table S1. Transcription conventions

\begin{tabular}{ll} 
Symbol & Definition \\
\hline$?$ & Strong rising phrase intonation \\
\hline$($ ) & Inaudible speech \\
\hline$(($ laughs $))$ & Unclear speech, guess by researcher \\
\hline$l$ & Verbal description of (non-verbal) actions \\
\hline$()$. & Indicates a repair or a cut-off \\
\hline$(1.0)$ & Pause or silence less than 0.2 seconds \\
\hline$>$ word $<$ & Pause or silence of one second \\
\hline$<$ word $>$ & Faster than surrounding speech \\
\hline CAPITALS & Slower than surrounding speech \\
\hline${ }^{\circ}$ word ${ }^{\circ}$ & Louder than surrounding speech \\
\hline$:$ & Softer than surrounding speech \\
\hline$\uparrow$ & Lengthening of the preceding speech \\
\hline$\downarrow$ & Marked rising shift in syllable intonation \\
\hline
\end{tabular}

Legend: The symbols listed below are based on Jefferson's glossary of transcript symbols, which are routinely used in conversation analytic research.(31) 


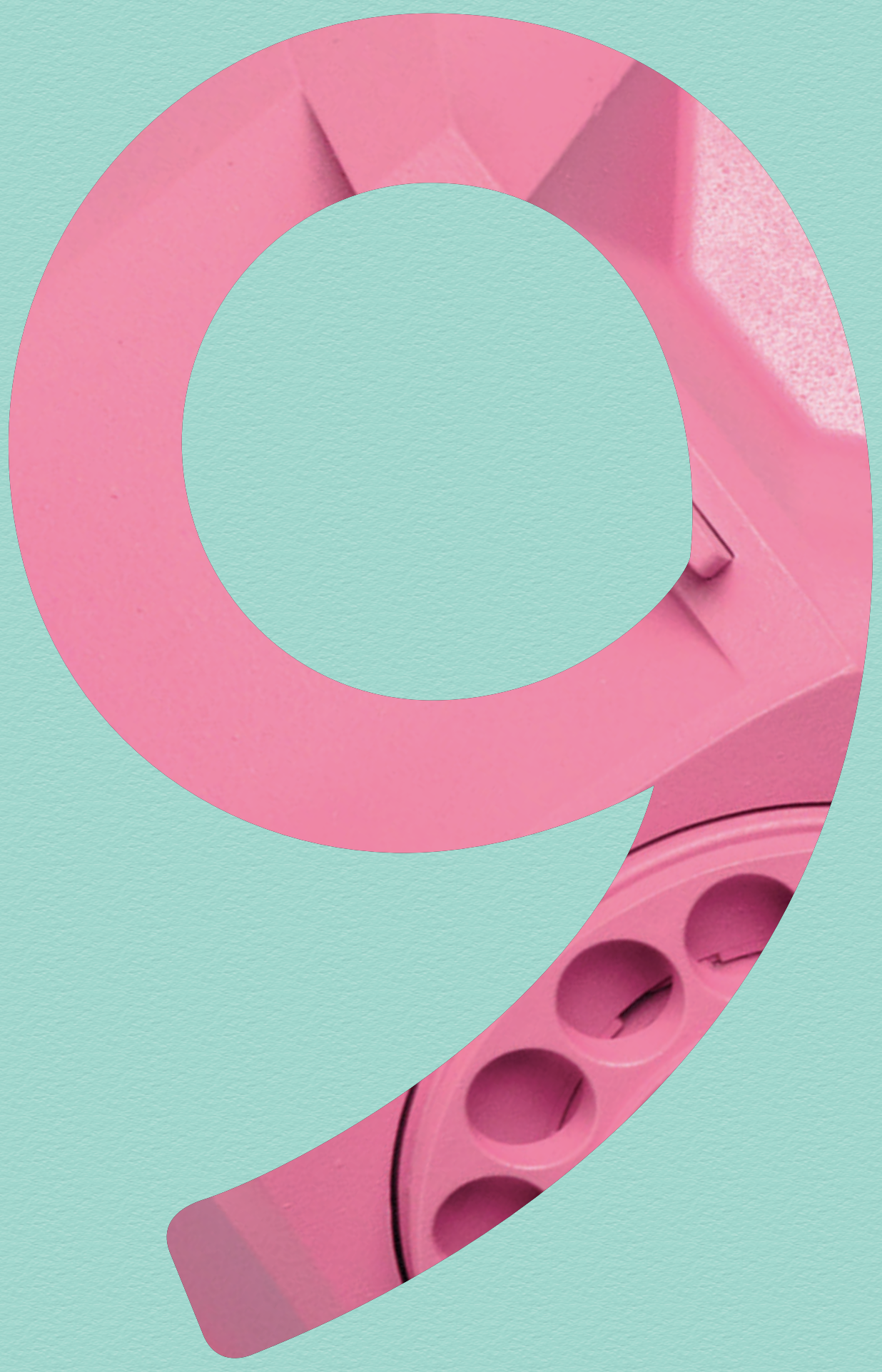




\title{
General discussion
}

\author{
D.C. Erkelens
}


This thesis focuses on the contemporary way in which telephone triage is carried out with the "Netherlands Triage Standard" (NTS) in callers with acute cardiovascular symptoms who call the out-of-hours service in primary care (OHS-PC). In this chapter, I will summarize the main findings of this thesis. Furthermore, I will provide final comments on the case of Mrs. Elders from the introduction, with additional reflections on the clinical dilemmas. Finally, I will discuss future research on telephone triage and offer some suggestions.

\section{Main findings of this thesis}

- $\quad$ The sensitivity, specificity, positive and negative predictive values of the NTS urgency allocation for TIA/stroke/other (neurologic) life-threatening events were $0.72(95 \% \mathrm{Cl}$ $0.68-0.75), 0.48$ (0.43-0.52), 0.62 (0.60-0.64) and 0.58 (0.54-0.62), respectively. In other words, the NTS decision support system was at best moderately safe in allocating high urgencies to patients who showed to have a TIA/stroke/other LTES, as still $28 \%$ received a too low urgency. The efficiency of the NTS was low; only $48 \%$ of the patients who showed to have TIA/stroke mimics (i.e. TIA/stroke-like symptoms, but with a non-urgent diagnosis other than TIA/stroke) received a low urgency. (Chapter 3)

- TIA/stroke was more common in the morning between 8am and noon and in the (early) evening between 2-6pm; however, also mimics occurred more during these hours. As a result, there was not a time period in which the risk of TIA/stroke was higher or lower than the risk of mimics among patients calling for stroke-like symptoms. Even between 8am and noon - known for an increased risk of TIA/stroke (1-12) - the risk ratio of TIA/stroke was only $1.13(95 \% \mathrm{Cl} 1.00-1.28, \mathrm{p}=0.070)$ compared to others hours. In conclusion, the time of calling was not useful for stratifying the risk of callers with TIA/ stroke-like symptoms in the OHS-PC setting. (Chapter 4)

- We developed a new diagnostic prediction model for detecting TIA/stroke during telephone triage at the OHS-PC, because existing diagnostic prediction models were all developed and intended to use in the hospital.(13-18) Of 1,381 patients (mean age 68.9 years (SD 18.4), 56.6\% women) who called with symptoms suggestive of TIA/stroke, $703(50.9 \%)$ received the diagnosis TIA/stroke (34.5\% TIA/minor stroke, $16.4 \%$ major ischaemic or haemorrhagic stroke). The final model included 11 predictors, of which the strongest predictors were age, female sex, arm weakness, and speech problems. The discriminative ability (c-statistic) of the model was $0.734(0.705-0.763)$ with a calibration slope of 0.955. (Chapter 5)

- $\quad$ By comparing, in a blinded case-control manner, 15 patients with a missed ACS (i.e. missed myocardial infarction or sudden cardiac death) (= cases) to 120 patients with comparable symptoms suggestive of ACS, but without a serious adverse event (SAE) in which an ACS was missed (= controls), we could show that cases largely overlap in patient and call characteristics and symptom presentation. Cases used less cardiovascular medication (38.5\% vs. $64.1 \%, p=0.05$ ), more often experienced non-retrosternal chest 
pain $(63.3 \%$ vs. $24.7 \%, p=0.02)$, and the triage nurse consulted the supervising GP more often $(86.7 \%$ vs. $49.2 \%, p=0.02)$ than in controls. (Chapter 6 )

- In the same case-control study, we assessed the inter-rater reliability of experts' assessments of triage safety and quality. The GP experts assessed the 135 triage calls while blinded to the outcome. Experts rated the triage of cases more often as 'unsafe' (73.3\% vs. $22.5 \%, p<0.001)$, and of 'poor' quality (33.3\% vs. $10.9 \%, p=0.001)$ than control telephone calls. However, the level of agreement among the experts was low: the intraclass correlation coefficients (ICC) of the experts' assessments on safety and quality were $0.16(95 \% \mathrm{Cl} 0.00-0.32)$ and 0.17 (0.00-0.33), respectively. (Chapter 7)

- With conversation analysis we showed that interactional difficulties arise between the caller and the triage nurse if (i) questions were poorly 'designed' by the triage nurse (e.g. multiple-choice either/or-questions such as "Is it an oppressive or stabbing or stinging pain?"), or when (ii) the caller's complaints were ambiguously presented reflecting patient's difficulties to verbalise them (e.g. "I am not feeling well", "it's an unpleasant sensation"). (Chapter 8)

\section{Reflection on the case of Mrs. Elders presented in the introduction}

In the introduction of this thesis we presented the case of Mrs. Elders. She called the OHS-PC on Sunday morning because she mispronounced some words during breakfast according to her husband, and she had experienced sudden dizziness, an unbalanced feeling, some vision problems and a tingling sensation in her left cheek on Saturday evening, which had disappeared the next morning. Along with the case of Mrs. Elders we will illustrate what we have learned in this thesis about dilemmas and misfits in the telephone triage of TIA/stroke using the NTS.

\section{Which urgency level fits?}

As described in chapter 3 , the rationale for a high urgency allocation in patients suspected of (major) stroke is primarily based on prognostically beneficial treatment options in the early hours, at a time when there is not yet complete brain necrosis due to a stroke. The high urgency is not based on the disease in itself that could easily result in $A B C D$ instability; in nearly none of the strokes such instability will occur.(19-21) Major stroke patients may be treated with intravenous thrombolysis, if the patient is seen within four and a half hours after symptom onset, and with endovascular thrombectomy, if seen within six hours or six to 24 hours in specific cases (e.g. severe neurological deficit), respectively.(22) Hence, based on the ABCD (airway, breathing, circulation, disability) approach, almost none of the (suspected) stroke patients would receive a high urgency (i.e. U1 or U2). Still, from the perspective of treatment (if indeed it is a stroke) fast transportation to the hospital is critical. Patients with TIA are not ABCD unstable and thus from an urgency perspective, even the lowest would be sufficient (only telephone advice). 
However, patients with TIA should receive secondary stroke prevention (i.e. antiplatelets) in due time to reduce the substantial risk of major stroke in the first hours to days after a TIA.(23-25) Nevertheless, because thrombolysis or endovascular thrombectomy are no treatment options in TIA, an urgency of U3 (patient seen within three hours) seems to be adequate from the perspective of initiating antiplatelet therapy in those with TIA. The Dutch primary care guidelines on TIA and stroke recommend referral to a TIA outpatient clinic of those suspected of TIA for a neurological assessment and start of secondary stroke prevention, all preferably within one working day after the onset of symptoms. If the patient cannot be seen by a neurologist the same day, it is recommended that GPS already start with a single dose of antiplatelet loading if a TIA is suspected, and symptoms have disappeared.(26)

The considerations about which urgency level is adequate in suspected TIA/stroke patients underpin our idea that, when it comes to TIA and stroke, 'thinking in urgencies', which is the current adage for triage does not hold.(27) Triage nurses and GPs have to 'think in diagnoses' in order to determine the right urgency for suspected TIA/stroke patients, so determining the urgency of the patient's clinical condition ('toestandsbeeld') is not enough. Diagnostic reasoning and assessing the risk of TIA/stroke are important to prevent patients from harm. In fact, this already is embedded in the NTS tool. A closer look at the NTS algorithm of 'neurological deficit' shows that it consists indeed of diagnostic questions.

Thus, NTS' generated urgencies are based on the prognostically relevant early treatment options, which are linked to the diagnosis. Nevertheless, many professionals, notably those who educate the triage nurses, are still convinced that what actually happens during the telephone conversation guided by the NTS is 'thinking in urgencies'.

\section{NTS in the critical care chain: one size fits all?}

Since its introduction in 2011, the NTS has been used by most OHS-PCs, and by approximately half of the ambulance dispatch centres, and an increasing number of EDs in the Netherlands.(28) In primary care settings like the OHS-PC, the prevalence of emergent diseases is lower, and on average includes less severe cases compared to the ED. Because the OHS-PC differs substantially from the ED and the ambulance dispatch centers, it is upfront unlikely to expect that a 'one size fits all' tool like the NTS is both safe and efficient in all these settings and thus will result in the best outcome for patients. An important argument, however, for using the same system within the 'critical care chain' was that it would facilitate communication during care transitions, and potentially improve transitional safety.(29) Yet, as described in chapter 3 of this thesis, the NTS tool was at best moderately safe in the domain of patients suspected of TIA/stroke, suggesting that the latter argument does not hold. Also, the large amount of overruling (42.6\%) in this domain by the triage nurse (often after consultation of the supervising GP) indicates that the NTS tool does not fit very well in the OHS-PC setting. 


\section{Choosing the best 'main complaint' and interactional workability dilemmas}

When we continue with the case of Mrs. Elders, one of the first dilemmas for the triage nurse was choosing the 'main complaint' to start within the NTS. She could choose from several possibilities, i.e. 'dizziness', 'blurred vision', or 'neurological deficit'. Mrs. Elders mentioned all of these. Although triage nurses are trained to choose the most urgent symptom as the 'main complaint', this may especially be difficult when the patient emphasises another symptom as most prominent. Importantly, however, the design of the NTS, with a restricted number of key questions for each 'main complaint', restricts further exploring of other symptoms mentioned in the initial part of a conversation. Other 'main complaints' cannot be explored simultaneously, but only sequentially, thus forcing triage nurses straight away from the start to choose one out of 56 'main complaints'. This triggers a certain fixation on that single 'main complaint', and closes other 'pathways' possibly important for the assessment of the urgency and following step of diagnosis early in the exploring phase. $(30,31)$ Also, if callers are unable to tell adequately and coherently about their symptoms, the triage nurse is forced to choose for a single 'main complaint' to start the NTS triage.(30) This pitfall of telephone triage can be interpreted as anchoring bias, which is the "tendency to fixate on specific features of a presentation too early in the diagnostic process".(32) Anchoring may lead to premature closure, which tends to stop further thinking early in the diagnostic process which obviously may jeopardise patient safety.(32) Although psychologists, economists, philosophers and medical doctors debate as to whether or not cognitive biases are, in fact, a 'good' thing, and whether or not they are easy to prevent, we at least should be careful with introducing such by means of the decision support system.(33-38)

Furthermore, the case of Mrs. Elders describes a situation in which the triage nurse has difficulties in choosing the 'main complaint' out of multiple problems mentioned by the patient; this is an example of an interactional workability dilemma. Interactional workability dilemmas arise when the computer decision support tool misaligns with the triage nurse's clinical reasoning.(39) In other words, the triage nurse has to adequately meet the needs of both the patient and the computer decision support tool in order to accomplish the 'best' fit. This has been previously described as the 'hidden labour' of telephone triage. $(31,40,41)$

\section{How to use the decision support tool?}

The dilemma of 'which main complaint to choose' is closely linked to the dilemma of 'what role the NTS should play in supporting the decision making on urgencies'.

There are multiple ways in which a decision support tool can be used, and opinions about intended use vary among triage nurses. Following the tool is the preferred way of using it, yet, this can only be done if congruence between the tool and the triage nurse exists. $(39,41)$ Several studies from the UK and Sweden have described that triage nurses do not always use the computer decision support tool as intended. $(30,42-45)$ An interview study from the UK on triage nurses' views of using a computer decision support tool indicated that as the triage nurses' knowledge of the tool increased, they became able to select 
routes through the tool in such a way that it would match their own expectations.(42) In line with this observation, a working strategy called 'tinkering' was identified in an audio stimulated recall interview study with triage nurses, which was part of the Safety First project. Triage nurses described applying this strategy when the NTS urgency allocation did not align with their own urgency 'expectation' of the patient's symptoms.(39) Rather than just following the NTS, triage nurses tinker the system in such a way that it fitted their clinical reasoning process $(39,42)$, which likely leads to safer telephone triage. This is supported by the finding of chapter 3 , in which we assessed the accuracy of the NTS urgency allocation and compared this with the final urgency allocation. In $42.6 \%$ of 1,269 patients, the NTS urgency was overruled by the triage nurse, which resulted in a modestly improved safety (increased sensitivity) and similar efficiency (unchanged specificity) that was poor. This suggests that overruling by the triage nurses tends to lead to safer telephone triage without compromising efficiency.

\section{Triage quality assessment: process evaluation vs. outcome evaluation}

Although the NTS was developed with the intention to support the triage nurse, the NTS seems to have become something the triage nurse has to obey under the assumption that obeying the protocol equals better decisions.(42) A poignant example of the latter is the root cause analysis of a serious adverse event (SAE). If a SAE occurs, a key question of the incident board investigating the SAE will be: "Did the triage nurse follow the NTS properly?"(46)

The risk of judging the quality of the decision for a large part on compliance to the protocol is that assessors fall prey to outcome bias. In chapter 6 of this thesis we described hindsight bias as a pitfall of root cause analysis.(47-49) Another pitfall is 'outcome bias', which is the "tendency to judge the quality of a decision in terms of its outcome".(50,51) As such, outcome bias implies the overweighting of outcome information in evaluations of the quality of a previous decision. $(52,53)$ For the assessment of telephone triage by triage nurses this means that the most appropriate actions can be associated with a poor outcome (and thus the quality of the decision being undervalued), whereas suboptimal actions can be associated with a good outcome (and thus quality of the decision being overvalued). Outcome bias can result in inappropriate conclusions about the relationship between action and outcome, and accordingly, information about the outcome is not a perfect tool with which to evaluate previous decisions. $(53,54)$ In order to do so, assessors should - in addition to listening back to the calls - use, as much as possible, knowledge about the information available for the triage nurses at the time decisions were taken. $(50,54,55)$

Not only root cause analysis is based on the idea that following the NTS improves decision making, but also the telephone triage training programs zoom in on teaching triage nurses to follow the NTS, and recordings of telephone triage conversations are regularly audited by OHS-PC managers focussing on the compliance with the NTS.(39) For this, auditors use an instrument called the 'KERNset' to assess the quality of telephone triage at the OHS-PC. $(56,57)$ The 'KERNset' consists of 29 'quality' indicators divided 
into four categories: ten medical items (e.g. the triage nurse selects the appropriate 'main complaint'), eleven communication items (e.g. the triage nurse structures the conversation), two items on telephone consultation of the GP (e.g. the triagist explains the reason for consultation and her question to the GP), and six reporting items (e.g. motivation for adjusting the NTS urgency allocation).(56) Without knowing the final clinical outcomes, the choice for these quality indicators for audits - which are process indicators - is understandable, but nevertheless insufficient, especially when assessment boils down to assessing compliance of the NTS.

Finally, further awareness of the complexity of judging quality is warranted because listening back to calls is not without pitfalls. As we have shown in chapter 7 of this thesis, GP experts - who were blinded to the outcome - tended to rate the quality of triage in calls that ended in a SAE more often as 'poor' than non-SAE calls, yet, the level of agreement among the experts was poor too. Thus a single expert's assessment on safety and quality - even when blinded to the outcome to prevent hindsight and outcome bias - is prone to bias in a certain, unknown direction if compared to the mean of multiple experts.

By evaluating both the process of triage (and not only checking compliance with the NTS) and its relation with the outcome of triage - preferably by multiple auditors - could substantially improve the assessment of triage quality. Such a shift in approach would align with recent developments in patient safety research, moving from Safety-I to Safety-II. Safety-I is defined as a "state where as few things as possible go wrong"; it presumes that things go wrong due to identifiable failures.(58) The safety management principle in Safety-I is to respond when something goes wrong; the focus is on causally reasoning back from the SAE. By looking back in the process the error made seems to be easily identified, and by learning from that 'root-cause' it is hoped for that a similar mistake is avoided in the future. In Safety-II the focus is on how and why "as many things as possible go right", despite the complexity of a system with varying conditions.(58) It relates to system flexibility and resilience. This Safety-II perspective is in line with the idea that both the triage process and outcome are a complex interplay that should be assessed as a whole, instead of only looking at single aspects of triage.(58)

\section{The NTS has mostly yes/no options: what to do when a symptom has partly resolved?}

Another dilemma that arises for the triage nurse in the case of Mrs Elders is whether she should consider the speaking problems as still present. The answer to this question would be 'yes' according to the husband, but 'no' according to herself. Mrs. Elders felt relieved because when calling she noticed that the dizziness, unbalanced feeling, vision problems, and tingling sensations in her face from that morning were gone. Yet, her husband noticed she still pronounced some words incorrectly, thus, according to him, not all symptoms had resolved. However, the NTS urges the triage nurse to choose between yes or no, while triage nurses and physicians more often need to think in 'more or less present'. Thus, the answer options are too restrictive, as the option of 'symptoms 
still being partly present' is not included in the NTS. This creates another interactional workability dilemma for the triage nurse.(39)

\section{Tension created by multiple-choice either/or-questions due to multiple options within the NTS}

After the triage nurse started the NTS with choosing for 'neurological deficit' as the 'main complaint', she continued - in line with the NTS - with the first key question: "Did you experience a sudden or gradual onset of face drooping or arm weakness or leg weakness or impaired sensibility?" This is an example of a multiple-choice either/orquestion (see chapter 8).(59) The NTS is set up in such a way that the triage nurse needs to choose between multiple options, with one option leading to a higher urgency than the other(s). This design indirectly encourages triage nurses to use multiple-choice either/ or-questions. Using these questions can be seen as a 'workaround'; an adaptive strategy to the constraints of using a computer decision support tool such as the NTS. $(60,61)$

Mrs. Elders hesitated for a moment, which indicated she had difficulties with responding to this question.(62) She replied with: "Uhm no, no I don't think so". Although, this seems to be an answer, it is not a thorough response to all the options embedded within the question. Taking a closer look at the question, the options are presented as multiple-choice alternatives, yet, the relationship between the options is imprecise and unclear. In fact, the options cover two separate topics. The first topic concerns the onset of symptoms, and consists of a two-choice either/or-question ("sudden or gradual onset of symptoms?"), and the second topic concerns a list of symptoms in the format of a multiple-choice either/or-question ("face drooping or arm weakness or leg weakness or impaired sensibility?"). The question of the triage nurse is an example of a poorly 'designed' multiple-choice either/or-question. By combining options with different content and/or combining different questions formats to form a multiplechoice either/or-question, the triage nurse risks missing out on important information. These poorly designed questions not only cost extra (unnecessary) time to respond, but also potentially hinder safe triage. Besides the need for more awareness among triage nurses on the interactional implications of either/or-questions, which can be done by training, we described a recommendation for daily practice in chapter 8 . Triage nurses can avoid poorly designed multiple-choice either/or-questions by utilising questions with less options; the fewer the answer options in a question, the less chance of creating ambiguous questions leading to incomplete or unclear responses and missing out on important information. Also, the offered values in multiple-choice either/or-questions should be unambiguous and have a clear relationship to each other. 


\section{The NTS does not generate questions on well-established risk factors for TIA/stroke}

Asking for risk factors might help triage nurses in their assessment of urgency of patients with symptoms suggestive of TIA/stroke. In chapter 4 of this thesis we evaluated whether the time of calling was a risk factor for TIA/stroke, and we found that it was not helpful for stratifying the risk of TIA/stroke. Furthermore, in chapter 5 of this thesis we showed that age, female sex, face drooping, arm weakness, speech problems, leg weakness, acute onset of symptoms, a medical history of TIA, cardiovascular disease, and more specifically hypertension or diabetes were useful for predicting the presence of TIA/stroke. Of the strongest predictors (i.e. age, female sex, speech problems, and arm weakness), age and female sex are not incorporated in the NTS decision algorithm of 'neurological deficit'.

In the case of Mrs. Elders, the GP who took over the call asked Mrs. Elders about her medical history, and as it turned out, Mrs. Elders had well-controlled hypertension and migraine, and a positive family history for cardiovascular disease. Given the importance of many TIA/stroke-specific risk factors, it would be useful to include these risk factors in the 'main complaint' of 'neurological deficit' of the NTS.

Risk factors for stroke are generally classified according to their potential for modification. Main non-modifiable risk factors include, amongst others age, sex, race/ethnicity, and genetic factors. $(63,64)$ Stroke is called a disease of ageing, and the incidence increases with age; it doubles each decade after the age of 55 years.(65) The relation between sex and stroke depends on age, but nevertheless, overall stroke occurs more in women than men, not only because of a longer life expectancy of women. $(65,66)$ At young age, the risk of stroke in women is similar to men, yet, at older ages the relative risk is slightly higher in men.(67) There are also considerable ethnic disparities in stroke: African Americans, Hispanic/Latin Americans have a higher risk of stroke. (68-70) Examples of genetic factors that increase the risk of stroke are a parental history or family history of stroke. $(71,72)$ Hypertension, diabetes, and smoking are among some of the well-known modifiable risk factors. $(63,64)$ The most important modifiable risk factor for stroke is hypertension. For the age groups 40-69 years, each increase of $20 \mathrm{mmHg}$ of systolic blood pressure is associated with more than a twofold higher stroke death rate. $(64,73)$ Furthermore, diabetes is an independent risk factor for stroke, with a two-fold increased risk of stroke. $(64,74)$ Current cigarette smokers have a twice as high a risk of stroke than non-smokers, and there is a strong dose-response relationship between pack-years and stroke risk. $(64,75,76)$ 


\section{Future research and learning healthcare systems}

It is evident that telephone triage of patients with symptoms suggestive of acute cardiovascular disease is complex and has many trade-offs. The trade-off between efficiency and safety, which Hollnagel refers to as the 'efficiency-thoroughness trade-off' (ETTO) principle (77), is probably one of the most challenging ones. Ideally, both safety and efficiency should be maximised at the same time. Yet, maximum safety of telephone triage will be at the expense of efficiency, because in order to ensure that no patient is assigned a too low urgency, triage nurses will have to triage defensively, with as a result more unnecessary consultations and home visits within shorter time windows. However, maximum efficiency will jeopardise safety, and thus likely result in more missed urgent cases or such a delay that adequate treatment options are missed.

Clearly, telephone triage of acute cardiovascular symptoms brings many challenges to triage nurses, GPs, and patients, but also to researchers and educators in their search for ways to improve learning from telephone triage, and ultimately improve the safety and quality of patient care. As previously mentioned, contemporary auditing is mainly based on process indicators and follows a typical Safety-I approach.(58) Optimisation of auditing and learning from telephone triage merits a Safety-II approach, in which the triage process and the final outcome are assessed as a whole, and with a focus on what goes right.

A promising organisational concept that fits in well with the Safety-II approach is that of a learning healthcare system (LHS). The Institute of Medicine defined a LHS as a system in which "science, informatics, incentives, and culture are aligned for continuous improvement and innovation, with best practices seamlessly embedded in the delivery process and new knowledge captured as an integral by-product of the delivery experience".(78) By integrating research and care, healthcare activities can be continuously studied, learned from, and improved. $(78,79)$ A recent study proposed a conceptual framework that aids the development of the successful implementation of LHS, by categorising such systems into four ordinal models with distinctive features: optimisation, comprehensive data, real-time, and full learning healthcare systems.(79) The Safety First project is actually an example of an optimisation LHS; a combination of different research methodologies (i.e. both quantitative, epidemiological research and qualitative research) led to scientific insights, of which some were translated into daily practice (e.g. conversation training for triagists), yet key ethical and legal distinctions between care and research continued to exist.(79) As the first step, we propose moving towards a comprehensive LHS for telephone triage at the OHS-PC. This type of LHS unlocks the scientific potential of routine care data because the way in which data is gathered, processed and made available for research is streamlined.(79) For future research on validating the NTS against final clinical outcomes in other common domains (e.g. patients calling with shortness of breath), collection of routine care data could be 
better streamlined by developing data linkage between electronic health records of the OHS-PC and GP day care practices.

The ideal organisational form for learning from telephone triage at the OHS-PC in the future would be a real-time LHS. The distinctive feature of such a model is that clinical decision support algorithms are to be combined with routine clinical data collection and routine care. This allows for learning from routine care data at the point of care by means of real-time feedback analysis: novel insights derived from analysis of data from previously treated patients can be directly applied into patient management and in turn this yields data that can be used to evaluate and fine-tune clinical decisions in the future. (79) Also, automated speech recognition could be used for (i) the analysis of triage calls and (ii) support of triage call reporting by triage nurses, and both would fit well in a realtime LHS. With automated speech recognition large amounts of language data can be processed and incorporated in data analyses. Furthermore, it enables the translation of triage nurse-patient interactions into data as well, e.g. documenting and incorporating the triage nurse's sense of anxiety of the patient. This can be done at a level higher than free text notes of the nurse.(80)

The overarching idea of a LHS as the organisational concept for telephone triage at the OHS-PC is that we could improve telephone triage as a whole, and not just separate links within the system (e.g. a decision rule for TIA/stroke patients, the recommendation for triage nurses to use different designed questions during triage, etc.). Therefore, the focus should be less on individual learning, and more on learning as an organisation, which requires an interdisciplinary approach. It is important to realise that learning does not happen by itself, but instead requires action. Workplace learning at the OHS-PC should be seen as an active process engaged in by triage nurses and GPs as they grasp and transform both their experience and scientific insights into learning and development through action and reflection on their own actions and thoughts.(81-83) To optimise learning from telephone triage, we should expand the current methodological approach with observational and ethnographic studies on (i) the social-technological aspects of the NTS (e.g. combination of on-screen activities within the NTS and hearable talk; "how do triage nurses and GPs really use the NTS tool in daily practice?") and (ii) inter-professional consultation at various stages of the telephone triage process (e.g. after scaling up or down the urgency; "what happens in those conversations, when triage nurses or GPs deviate from the standard?").(84) 


\section{References}

1) Argentino $C$, Toni $D$, Rasura M, Violi F, Sacchetti ML, Allegretta A, et al. Circadian variation in the frequency of ischemic stroke. Stroke. 1990;21(3):387-9.

2) Muller JE. Circadian variation in cardiovascular events. Am J Hypertens. 1999;12(2 Pt 2):35S42S.

3) Ripamonti L, Riva R, Maioli F, Zenesini C, Procaccianti G. Daily Variation in the Occurrence of Different Subtypes of Stroke. Stroke Res Treat. 2017;2017:9091250.

4) Elliott WJ. Circadian variation in the timing of stroke onset: a meta-analysis. Stroke. 1998;29(5):992-6.

5) Chaturvedi S, Adams HP, Jr., Woolson RF. Circadian variation in ischemic stroke subtypes. Stroke. 1999;30(9):1792-5.

6) Manfredini R, Boari B, Smolensky MH, Salmi R, la Cecilia O, Maria Malagoni A, et al. Circadian variation in stroke onset: identical temporal pattern in ischemic and hemorrhagic events. Chronobiol Int. 2005;22(3):417-53.

7) Feng J, Zhang JH, Qin X. Timing pattern of onset in hypertensive intracerebral hemorrhage patients. Acta Neurochir Suppl. 2011;111:327-31.

8) Omama S, Yoshida Y, Ogawa A, Onoda T, Okayama A. Differences in circadian variation of cerebral infarction, intracerebral haemorrhage and subarachnoid haemorrhage by situation at onset. J Neurol Neurosurg Psychiatry. 2006;77(12):1345-9.

9) Butt MU, Zakaria M, Hussain HM. Circadian pattern of onset of ischaemic and haemorrhagic strokes, and their relation to sleep/wake cycle. J Pak Med Assoc. 2009;59(3):129-32.

10) Sloan MA, Price TR, Foulkes MA, Marler JR, Mohr JP, Hier DB, et al. Circadian rhythmicity of stroke onset. Intracerebral and subarachnoid hemorrhage. Stroke. 1992;23(10):1420-6.

11) Manfredini R, Gallerani M, Portaluppi F, Salmi R, Fersini C. Chronobiological patterns of onset of acute cerebrovascular diseases. Thromb Res. 1997;88(6):451-63.

12) Elliott WJ. Cyclic and circadian variations in cardiovascular events. Am J Hypertens. 2001;14((9 Pt 2)):291S-5S.

13) Dawson J, Lamb KE, Quinn TJ, Lees KR, Horvers M, Verrijth MJ, et al. A recognition tool for transient ischaemic attack. QJM : monthly journal of the Association of Physicians. 2009;102(1):43-9.

14) Dutta D. Diagnosis of TIA (DOT) score--design and validation of a new clinical diagnostic tool for transient ischaemic attack. BMC Neurol. 2016;16:20.

15) Lebedeva ER, Gurary NM, Gilev DV, Christensen AF, Olesen J. Explicit diagnostic criteria for transient ischemic attacks to differentiate it from migraine with aura. Cephalalgia. 2018;38(8):1463-70.

16) Harbison J, Hossain O, Jenkinson D, Davis J, Louw SJ, Ford GA. Diagnostic accuracy of stroke referrals from primary care, emergency room physicians, and ambulance staff using the face arm speech test. Stroke. 2003;34(1):71-6.

17) Nor AM, Davis J, Sen B, Shipsey D, Louw SJ, Dyker AG, et al. The Recognition of Stroke in the Emergency Room (ROSIER) scale: development and validation of a stroke recognition instrument. Lancet Neurol. 2005;4(11):727-34.

18) Johnston SC, Rothwell PM, Nguyen-Huynh MN, Giles MF, Elkins JS, Bernstein AL, et al. Validation and refinement of scores to predict very early stroke risk after transient ischaemic attack. Lancet. 2007;369(9558):283-92. 
19) Prabhakaran $S$, Ruff I, Bernstein RA. Acute stroke intervention: a systematic review. Jama. 2015;313(14):1451-62.

20) Leng $T$, Xiong ZG. Treatment for ischemic stroke: From thrombolysis to thrombectomy and remaining challenges. Brain Circ. 2019;5(1):8-11.

21) Powers WJ, Rabinstein AA, Ackerson T, Adeoye OM, Bambakidis NC, Becker K, et al. Guidelines for the Early Management of Patients With Acute Ischemic Stroke: 2019 Update to the 2018 Guidelines for the Early Management of Acute Ischemic Stroke: A Guideline for Healthcare Professionals From the American Heart Association/American Stroke Association. Stroke. 2019;50(12):e344-e418.

22) Netherlands Society of Neurology. Guideline Ischaemic and Hemorrhagic Stroke. [Nederlandse Vereniging voor Neurologie. Richtlijn Herseninfarct en Hersenbloeding.]. 2019.

23) Hankey GJ. Secondary stroke prevention. Lancet Neurol. 2014;13(2):178-94.

24) Rothwell PM, Algra A, Chen Z, Diener HC, Norrving B, Mehta Z. Effects of aspirin on risk and severity of early recurrent stroke after transient ischaemic attack and ischaemic stroke: time-course analysis of randomised trials. Lancet. 2016;388(10042):365-75.

25) Wu CM, McLaughlin K, Lorenzetti DL, Hill MD, Manns BJ, Ghali WA. Early risk of stroke after transient ischemic attack: a systematic review and meta-analysis. Archives of internal medicine. 2007;167(22):2417-22.

26) Verburg AF, Tjon ATMR, Verstappen WH, Beusmans GH, Wiersma T, Burgers JS. Summary of the 'Stroke' guideline of the Dutch College of General Practitioners [Samenvatting van de NHG-Standaard Beroerte]. Ned Tijdschr Geneeskd. 2014;158(1):A7022.

27) van Dijk E. Telephone triage: let go of diagnostic thinking. [Telefonische triage: laat diagnostische denktrant los.]. Huisarts Wet. 2013;56(11):570-2.

28) Smits M, Rutten M, Keizer E, Wensing M, Westert G, Giesen P. The Development and Performance of After-Hours Primary Care in the Netherlands: A Narrative Review. Annals of internal medicine. 2017;166(10):737-42.

29) van lerland $Y$, van Veen $M$, Huibers $L$, Giesen $P$, Moll HA. Validity of telephone and physical triage in emergency care: the Netherlands Triage System. Family practice. 2011;28(3):33441.

30) Holmstrom I. Decision aid software programs in telenursing: not used as intended? Experiences of Swedish telenurses. Nurs Health Sci. 2007;9(1):23-8.

31) Murdoch J, Barnes R, Pooler J, Lattimer V, Fletcher E, Campbell JL. The impact of using computer decision-support software in primary care nurse-led telephone triage: interactional dilemmas and conversational consequences. Soc Sci Med. 2015;126:36-47.

32) Croskerry P. Achieving quality in clinical decision making: cognitive strategies and detection of bias. Acad Emerg Med. 2002;9(11):1184-204.

33) Polonioli A. Gigerenzer's 'external validity argument' against the heuristics and biases program: an assessment. Mind Soc. 2012;11:133-48.

34) Vranas PB. Gigerenzer's normative critique of Kahneman and Tversky. Cognition. 2000;76(3):179-93.

35) Kahneman D, Tversky A. On the reality of cognitive illusions. Psychological Review. 1996;103(3):582-91.

36) Gigerenzer G. On narrow norms and vague heuristics: A reply to Kahneman and Tversky. Psychol Rev. 1996;103(3):592-6.

37) Cohen LJ. Can Human Irrationality Be Experimentally Demonstrated. Behavioral and Brain Sciences. 1981;4(3):317-29.

38) Binmore K. Why experiment in economics? Econ J. 1999;109(453):F16-F24. 
39) Wouters LT, Zwart DL, Erkelens DC, Huijsmans M, Hoes AW, Damoiseaux RA, et al. Tinkering and overruling the computer decision support system: Working strategies of telephone triage nurses who assess the urgency of callers suspected of having an acute cardiac event. J Clin Nurs. 2020;29(7-8):1175-86.

40) Pooler J. Technology and Talk in Calls to NHS Direct. Doctoral Thesis [Doctoral Thesis]. United Kingdom: The University of Loughborough; 2010.

41) May C, Finch T, Mair F, Ballini L, Dowrick C, Eccles M, et al. Understanding the implementation of complex interventions in health care: the normalization process model. BMC health services research. 2007;7:148.

42) O'Cathain A, Sampson FC, Munro JF, Thomas KJ, Nicholl JP. Nurses' views of using computerized decision support software in NHS Direct. J Adv Nurs. 2004;45(3):280-6.

43) Ernesater A, Engstrom M, Winblad U, Holmstrom IK. A comparison of calls subjected to a malpractice claim versus 'normal calls' within the Swedish healthcare direct: a case-control study. BMJ open. 2014;4(10):e005961.

44) Dowding D, Mitchell N, Randell R, Foster R, Lattimer V, Thompson C. Nurses' use of computerised clinical decision support systems: a case site analysis. J Clin Nurs. 2009;18(8):1159-67.

45) Dowding D, Randell R, Mitchell N, Foster R, Thompson C, Lattimer V, et al. Experience and nurses use of computerised decision support systems. Stud Health Technol Inform. 2009;146:506-10.

46) Erkelens DC, Zwart DL. Authorisation at out-of-hours services in primary care. [Autoriseren op huisartsenposten]. Utrecht: 2016.

47) Henriksen K, Kaplan H. Hindsight bias, outcome knowledge and adaptive learning. Qual Saf Health Care. 2003;12 Suppl 2:ii46-50.

48) Wears RL, Nemeth CP. Replacing hindsight with insight: toward better understanding of diagnostic failures. Ann Emerg Med. 2007;49(2):206-9.

49) Fischhoff B. Hindsight not equal to foresight: the effect of outcome knowledge on judgment under uncertainty. 1975. Qual Saf Health Care. 2003;12(4):304-11; discussion 11-2.

50) Baron J, Hershey JC. Outcome Bias in Decision Evaluation. J Pers Soc Psychol. 1988;54(4):56979.

51) Croskerry P. The cognitive imperative: thinking about how we think. Acad Emerg Med. 2000;7(11):1223-31.

52) Regehr G. Self-reflection on the quality of decisions in health care. Med Educ. 2004;38(10):1025-7.

53) Sacchi $S$, Cherubini P. The effect of outcome information on doctors' evaluations of their own diagnostic decisions. Med Educ. 2004;38(10):1028-34.

54) Jones SK, Yurak TJ, Frisch D. The effect of outcome information on the evaluation and recall of individuals' own decisions. Organ Behav Hum Dec. 1997;71(1):95-120.

55) Hershey JC, Baron J. Judgment by Outcomes - When Is It Justified. Organ Behav Hum Dec. 1992;53(1):89-93.

56) Smits M, Keizer E, Ram P, Giesen P. Development and testing of the KERNset: an instrument to assess the quality of telephone triage in out-of-hours primary care services. BMC health services research. 2017;17(1):798.

57) InEen. Manual KERNset for quality monitoring telephone triage out-of-hours services in primary care. [Handleiding KERNset voor monitoren kwaliteit telefonisch triage op de huisartsenpost]. Utrecht: 2017. 
58) Hollnagel E, Wears R, Braithwaite J. From Safety-I to Safety-II: A white paper. The Resilient Health Care Net: Published simultaneously by the University of Southern Denmark, University of Florida, USA, and Macquarie University, Australia: 2015.

59) Englert C. Questions and responses in Dutch conversations. J Pragmatics. 2010;42(10):266684.

60) Debono DS, Greenfield D, Travaglia JF, Long JC, Black D, Johnson J, et al. Nurses' workarounds in acute healthcare settings: a scoping review. BMC health services research. 2013;13:175.

61) Murdoch J, Barnes R, Pooler J, Lattimer V, Fletcher E, Campbell JL. Question design in nurse-led and GP-led telephone triage for same-day appointment requests: a comparative investigation. BMJ open. 2014;4(3):e004515.

62) Gilquin G. Hesitation markers among EFL learners: Pragmatic deficiency or difference? Pragmatics and Corpus Linguistics2008. p. 119-49.

63) Goldstein LB, Adams R, Alberts MJ, Appel LJ, Brass LM, Bushnell CD, et al. Primary prevention of ischemic stroke: a guideline from the American Heart Association/American Stroke Association Stroke Council: cosponsored by the Atherosclerotic Peripheral Vascular Disease Interdisciplinary Working Group; Cardiovascular Nursing Council; Clinical Cardiology Council; Nutrition, Physical Activity, and Metabolism Council; and the Quality of Care and Outcomes Research Interdisciplinary Working Group: the American Academy of Neurology affirms the value of this guideline. Stroke. 2006;37(6):1583-633.

64) Boehme AK, Esenwa C, Elkind MS. Stroke Risk Factors, Genetics, and Prevention. Circ Res. 2017;120(3):472-95.

65) Roger VL, Go AS, Lloyd-Jones DM, Benjamin EJ, Berry JD, Borden WB, et al. Heart disease and stroke statistics--2012 update: a report from the American Heart Association. Circulation. 2012;125(1):e2-e220.

66) Reeves MJ, Fonarow GC, Zhao X, Smith EE, Schwamm LH, Get With The Guidelines-Stroke Steering C, et al. Quality of care in women with ischemic stroke in the GWTG program. Stroke. 2009;40(4):1127-33.

67) Kapral MK, Fang J, Hill MD, Silver F, Richards J, Jaigobin C, et al. Sex differences in stroke care and outcomes: results from the Registry of the Canadian Stroke Network. Stroke. 2005;36(4):809-14.

68) Cruz-Flores S, Rabinstein A, Biller J, Elkind MS, Griffith P, Gorelick PB, et al. Racial-ethnic disparities in stroke care: the American experience: a statement for healthcare professionals from the American Heart Association/American Stroke Association. Stroke. 2011;42(7):2091116.

69) Kissela B, Schneider A, Kleindorfer D, Khoury J, Miller R, Alwell K, et al. Stroke in a biracial population: the excess burden of stroke among blacks. Stroke. 2004;35(2):426-31.

70) Kleindorfer D, Broderick J, Khoury J, Flaherty M, Woo D, Alwell K, et al. The unchanging incidence and case-fatality of stroke in the 1990s: a population-based study. Stroke. 2006;37(10):2473-8.

71) Seshadri S, Beiser A, Pikula A, Himali JJ, Kelly-Hayes M, Debette S, et al. Parental occurrence of stroke and risk of stroke in their children: the Framingham study. Circulation. 2010;121(11):1304-12.

72) Schulz UG, Flossmann E, Rothwell PM. Heritability of ischemic stroke in relation to age, vascular risk factors, and subtypes of incident stroke in population-based studies. Stroke. 2004;35(4):819-24. 
73) Lewington S, Clarke R, Qizilbash N, Peto R, Collins R, Prospective Studies C. Age-specific relevance of usual blood pressure to vascular mortality: a meta-analysis of individual data for one million adults in 61 prospective studies. Lancet. 2002;360(9349):1903-13.

74) Sui X, Lavie CJ, Hooker SP, Lee DC, Colabianchi N, Lee CD, et al. A prospective study of fasting plasma glucose and risk of stroke in asymptomatic men. Mayo Clin Proc. 2011;86(11):1042-9.

75) Bhat VM, Cole JW, Sorkin JD, Wozniak MA, Malarcher AM, Giles WH, et al. Dose-response relationship between cigarette smoking and risk of ischemic stroke in young women. Stroke. 2008;39(9):2439-43.

76) Wolf PA, D’Agostino RB, Belanger AJ, Kannel WB. Probability of stroke: a risk profile from the Framingham Study. Stroke. 1991;22(3):312-8.

77) Hollnagel E. The ETTO Principle: Efficiency-Thoroughness Trade-Off. Why Things That Go Right Sometimes Go Wrong. Farnham (UK): Ashgate; 2009.

78) In: Olsen LA, Aisner D, McGinnis JM, editors. The Learning Healthcare System: Workshop Summary. The National Academies Collection: Reports funded by National Institutes of Health. Washington (DC)2007.

79) Wouters RHP, van der Graaf R, Voest EE, Bredenoord AL. Learning health care systems: Highly needed but challenging. Learn Health Sys. 2020;e10211.

80) Lee S, Mohr NM, Street WN, Nadkarni P. Machine Learning in Relation to Emergency Medicine Clinical and Operational Scenarios: An Overview. West J Emerg Med. 2019 Mar; 20(2): 219-227.

81) Kolb DA. Experiential Learning: Experience as the Source of Learning and Development. Englewood Cliffs, NJ: Prentice-Hall Inc; 1984.

82) Bransford JD, Brown AL, Cocking RR. How People Learn: Brain, Mind, Experience and School: Expanded Edition. Washington, DC: National Academy Press; 2001.

83) Schultz K, McEwen L, Griffiths J. Applying Kolb's Learning Cycle to Competency-Based Residency Education. Acad Med. 2016;91(2):284.

84) Margaryan A, Littlejohn A, Stanton NA. Research and development agenda for Learning from Incidents. Safety Sci. 2017;99:5-13. 


$$
A
$$




\section{Appendices}

Summary

Nederlandse samenvatting

Curriculum vitae

List of publications

Dankwoord

D.C. Erkelens 


\section{Summary}

People seeking medical care outside office hours of the general practitioner (GP) are urged to call the out-of-hours services in primary care (OHS-PC), where telephone triage is performed by triage nurses.(1) The aim of telephone triage is to prioritize callers based on the severity of the symptoms presented. The determined urgency level corresponds to the time within which medical help should be provided.(2) Triage nurses are supported by a semi-automatic digital support tool called the "Netherlands Triage Standard" (NTS). The NTS was developed by an expert panel and derived from the already existing (i) Dutch national telephone guidelines for office hours in primary care ('NHG-TriageWijzer'), (ii) the Dutch national standard for ambulance dispatch centers and (iii) the Manchester Triage System criteria.(3-5) The NTS comprises 56 'main complaints', each with an underlying algorithm that consists of hierarchically ordered key questions. Questions about the medically most critical symptoms should be asked first. After the triage nurse has filled out the caller's answers in the NTS, this tool automatically generates an urgency level: U0 (resuscitation for which an ambulance should immediately be sent), U1 (life-threatening situation for which an ambulance is sent that should be present within 15 minutes), U2 (emergent situation, medical help must be provided within one hour), U3 (urgent situation, medical help must be provided within three hours), U4 (non-urgent situation, medical help within 24 hours is sufficient), and U5 (no risk of damage, advice by telephone is sufficient). $(4,5)$ The automatically generated NTS urgency level can be scaled up or down ('overruled') by the triage nurse, which is usually done after consultation of the supervising GP.

The original aim of NTS was to guarantee both efficient and safe care. However, there are indications that telephone triage with the NTS is rather inefficient and that the urgency is overestimated, especially in case of suspected acute cardiovascular disease (CVD). On the one hand, most callers with symptoms suggestive of acute CVD, e.g. acute coronary syndrome (ACS), stroke, and to a lesser extent transient ischaemic attack (TIA), are generally assigned high urgency levels (6), while only a minority of them turns out to have had an acute CVD. A recent Dutch study found that approximately $70 \%$ of the people who called their GP or the OHS-PC were sent to hospital by ambulance because of chest discomfort, and only $\approx 10 \%$ actually had an ACS. $(7,8)$ In addition, during the period 2013 2016, an increase in assigned U1 urgencies (compared to other urgencies) was seen in patients who called the OHS-PC with symptoms suggestive of TIA/stroke.(6) On the other hand, it is important to realise that with adequate triage and diagnosis which is followed by a timely start of (preventive) treatment, the prognosis of patients with an ACS or TIA/ stroke can be significantly improved.(9-11) For that reason, a sufficiently high urgency level should be allocated. It is also important to realise that although serious adverse events (SAES) at the OHS-PC are rare, in almost the majority of the SAEs it concerned a missed or delayed recognition of acute CVD, notably missed myocardial infarction, missed abdominal aneurysm and late recognition of stroke.(12) 
The potential harm of both under triage and over triage of acute CVD makes telephone triage very challenging within the domain of patients suspected of having acute CVD. It is evident that the final diagnosis should be considered when assessing the quality and safety of telephone triage. Nevertheless, the NTS has only been validated against surrogate markers, i.e. against (i) hospital referrals (without considering diagnosis or treatment) and (ii) telephone self-care advice. The accuracy of the NTS has never really been weighted against clinical outcomes. This thesis therefore focuses on the process of urgency allocation with the NTS in callers with symptoms suggestive of acute CVD and the identification of determinants that improve the diagnosis with as ultimate goal to improve telephone triage of patients suspected of ACS or TIA/stroke.

\section{The Safety First project}

In chapter $\mathbf{2}$ of this thesis, we describe the aims and the design of the Safety First project. This project addressed a knowledge gap in safety and efficiency of telephone triage with the NTS of patients suspected of acute CVD who called the OHS-PC, notably those suspected of ACS or TIA/stroke. With Safety First we aimed to describe, understand and improve the diagnostic process and urgency allocation in these patients in order to improve both efficiency and safety of telephone triage. In this thesis the results of patients suspected of TIA/stroke are included, and a study on missed ACS. The other results of patients suspected of ACS are described in another thesis. Telephone triage recordings from nine OHS-PC locations in the Utrecht area from the period 20142017 were analysed. For the data collection we used (i) call characteristics, (ii) patient characteristics and (iii) symptom presentation, which were collected while listening to the triage recordings. The researchers who carried out the data collection were blinded to the final diagnosis of the patients. This final diagnosis was requested from each patient's own GP, and was based on information from specialists' discharge letters (i.e. the neurologist, cardiologist and emergency department). Furthermore, chapter 2 describes the design of three additional studies within the Safety First project: a casecontrol study on missed ACS, a conversation analysis study and an interview study with triage nurses. The results of the first two additional studies are included in this thesis and the results of the interview study are included in an other thesis.

\section{Accuracy of the NTS in patients suspected of TIA/stroke}

In chapter $\mathbf{3}$ we present the results of our study on the accuracy of the NTS urgency allocation in patients who called the OHS-PC with symptoms suggestive of TIA/stroke, using the final clinical outcomes TIA, stroke and other (neurologic) life-threatening events (LTEs) as the reference. In this cross-sectional study of 1,269 patients, 635 (50.0\%) showed to have had a TIA/stroke; 434 (34.2\%) a TIA/minor stroke, 201 (15.8\%) a major ischaemic 
or haemorrhagic stroke, and 61 (4.8\%) patients an other (neurologic) LTE. The sensitivity, specificity, and positive and negative predictive values of the NTS urgency allocation for TIA/stroke/other LTEs were 0.72 (95\% Cl 0.68-0.75), 0.48 (0.43-0.52), 0.62 (0.60-0.64), and 0.58 (0.54-0.62), respectively. In conclusion, the NTS performs moderately in terms of safety (assigning a low urgency level to $28 \%$ of the patients with a TIA/stroke/LZ) and poorly in terms of efficiency (assigning a high urgency level to $52 \%$ of patients without TIA/stroke/LZ).

\section{Prediction of TIA/stroke with telephone triage at the OHS-PC}

In chapter 4 we evaluated whether the time of calling was helpful for differentiating callers with TIA/stroke from those with 'mimics' during telephone triage. Previous studies in ED settings reported that TIA/stroke more often occurs during daytime than at night, with a peak incidence in the morning hours (between 6am and noon).(13-17) Some studies also found a less prominent peak in the early evening hours.(15-24) However, whether the time of calling helps to triage calls of suspected acute neurological events in the OHS-PC setting was unknown.(25) We therefore calculated the risk of TIA/stroke per hour and the relative risk of TIA/stroke in the morning compared to other hours. Of the 1,269 patients with a known final diagnosis, 50.0\% had a TIA/stroke, and most of them called during the day, with a peak between $8-12$ am ( $22.0 \%$ of the total) and a second peak between $2-6 \mathrm{pm}$ (19.7\% of the total). The time of calling of patients with a 'mimic' followed the same pattern, with as a result that the relative risk of TIA/stroke in the morning between 8-12am hours was not increased compared to other hours (relative risk $1.13(95 \% \mathrm{Cl} 1.00-1.28, \mathrm{p}=0.070)$, and after correction for age and gender $0.94(95 \% \mathrm{Cl}$ $0.80-1.10, p=0.434))$. Based on these data, we concluded that the time of calling is not helpful for telephone triage of patients suspected of TIA/stroke in the OHS-PC setting.

In chapter $\mathbf{5}$ we described the development of a diagnostic prediction model for TIA/ stroke. Clearly, predicting the probability of presence or absence of TIA/stroke during telephone triage is a major challenge, because it is only based on verbal information about the patient's symptoms. Various diagnostic prediction models already exist, but these are developed and intended to use in the hospital, and include items for which patients need to be examined.(26-31) Because diagnostic prediction models are lacking for the OHS-PC setting, we aimed to develop a new diagnostic prediction model for telephone triage of patients with symptoms suggestive of TIA/stroke who call the OHS-PC. For this cross-sectional, observational study at nine OHS-PC locations in the Netherlands we used data from the period 2014-2017. The primary outcome - a final diagnosis of TIA/stroke or not - was retrieved from the electronic health records of the patients' own GPs, including hospital discharge letters. Information on 'candidate predictors' was collected from the triage recordings and the electronic health records of 
the OHS-PC. After multiple imputation for missing data, we applied multivariable logistic regression analyses to compare four pre-defined models with increasing complexity to predict the presence of TIA/stroke. We applied bootstrapping and shrinkage of the regression coefficients for internal validation and to prevent over-fitting of the models. Of 1,381 patients (median age 72.0 (interquartile range $57.5-83.0$ ) years, 56.6\% women) who called with symptoms suggestive of TIA/stroke, 703 (50.9\%) received the diagnosis TIA/stroke (34.5\% TIA/minor stroke, $16.4 \%$ major ischaemic or haemorrhagic stroke). The final model for TIA/stroke included 11 predictors, of which the strongest predictors were age, female sex, arm weakness, and speech problems The discriminative ability (c-statistic) of the model was 0.73 (95\% Cl 0.70-0.76). Our diagnostic prediction model for TIA/stroke showed good discrimination, and after external validation could be applied at the OHS-PC.

\section{Safety of telephone triage in patients suspected of an acute coronary syndrome (acute myocardial infarction or unstable angina pectoris)}

In chapter $\mathbf{6}$ of this thesis, we describe the results of our case-control study on serious adverse events (SAEs). The Dutch Healthcare Quality, Complaints and Disputes Act defined a SAE as: "an unintended or unexpected event related to the quality of care and resulting in death or a severe harmful event for the patient".(32) With an incidence of $0.006 \%$, SAEs at the OHS-PC are rare, but nevertheless they have a major impact on patients, family, and on the professionals involved.(12, 33, 34) SAEs often concern missed acute cardiovascular diseases, notably missed acute myocardial infarction/sudden cardiac death (30.4\% of all SAEs) and stroke (7.9\% of all SAEs).(12) An elaborate root cause analysis is required by Dutch law after each individual SAE. These analyses often highlight errors in the triage process, but such analyses are of limited value because of (i) hindsight bias, which is the "tendency to exaggerate the extent to which an event can be predicted beforehand if the outcome is known" (35-37), and because (ii) a causal relation with observational data is considered. Therefore, in this case-control study we compared triage calls of patients with chest discomfort contacting the OHS-PC in whom an ACS was missed (= cases), with triage calls of those with chest discomfort but without a missed ACS (= controls). We aimed to identify predictors of missed ACS. Triage recordings from the period 2013-2017 were used, and data collection was performed blinded to the final outcome (case or control). Cases were matched 1:8 with controls based on age and gender by one of the researchers who was not otherwise involved in data analysis. Data-analyses consisted of conditional logistic regression analysis. We were able to assess 15 SAEs and 120 matched controls. Our results showed that cases compared to controls used less cardiovascular medication ( $38.5 \%$ vs. 64.1\%, $p=0.05$ ), more often experienced non-retrosternal chest pain ( $63.3 \%$ vs. $24.7 \%, p=0.02)$, and the triage nurse consulted the supervising GP more often ( $86.7 \%$ vs. $49.2 \%, p=0.02)$. With these few 'characteristics' of 
missed ACS, that also occurred in at least $\approx 25 \%$ of the controls, we could not formulate a recommendation that could help to prevent future adverse outcomes in patients with chest discomfort.

In chapter 7 we investigated GP experts' assessments on quality and safety of these 135 calls, including 15 SAEs. In addition, their inter-rater reliability was assessed. From earlier research it is known that experts also fall prey to hindsight bias.(38-40) In this study, the GP experts were therefore blinded to the outcome (case or control). We asked the experts to individually listen to the recordings. For differences in experts' assessments of quality and safety of triage we used conditional logistic regression analysis. $(41,42)$ In order to quantify inter-rater reliability of the expert assessments (that is two assessments per triage recording with different experts; not every recording was listened to by the same two experts), we calculated intra-class correlation coefficients (ICC) as an approximation of weighted Kappa's.(43) A total of 270 expert assessments could thus be evaluated. Experts rated the triage of cases more often as 'unsafe' (73.3\% vs. 22.5\%, $p<0.001$ ), and of 'poor' quality (33.3\% vs. 10.9\%, $p=0.001)$ compared to controls, but with a low level of agreement (ICC between $0.16(95 \% \mathrm{Cl} 0.00-0.32)$ and $0.17(95 \% \mathrm{Cl} 0.00-0.33))$. In our study experts appeared to recognize unsafe triage even without knowledge of the final clinical outcome, illustrated by the observations that they allocated higher urgencies to cases and rated them more often as unsafe than controls. However, there was poor inter-rater reliability, and thus, the value of a single expert assessment - such as in root cause analysis - seems questionable. It is simply insufficient to base recommendations on a single expert's root cause analysis. A blinded case-control assessment with multiple experts provides a different and complementary view on root cause analysis and should be considered for future assessments of SAEs in clinical practice.

\section{Interactional effects of either/or-questions during telephone triage with the NTS}

During telephone triage, the NTS decision support tool impacts the interaction between triage nurses and callers. The NTS displays key diagnostic options, which encourages the triage nurse to use multiple-choice either/or-questions (e.g. "Is it an oppressive or stabbing or stinging pain?") to check these options.

In chapter $\mathbf{8}$ of this thesis, we report the results of a qualitative study in which we used conversation analysis to explore the interactional effects of multiple-choice either/orquestions on the interaction between callers and triage nurses using the NTS. This analysis showed that interactional difficulties mainly arise when (i) questions are poorly designed by the triage nurse, or when (ii) the caller's complaints are ambiguously presented, reflecting patient's difficulties to verbalize them. This has led to two recommendations for triage nurses in daily practice: (i) utilize short questions with fewer answer options in order to decrease the chance of unclear responses, and (ii) ask content questions to 
help the patient make the presentation of symptoms more specific (e.g. "What type of pain do you experience?"). The implications for everyday practice of this study are twofold. Firstly, more awareness among triage nurses is needed on the adverse effects of multiple-choice either/or-questions, e.g. by training based on research with real recordings such as the 'Conversation Analytic Role-play Method'.(44, 45) By re-listening to their own recordings, nurses can hear what actually happens during conversations, as practise turns out that people speak differently than they think they do. Secondly, the design of the NTS could be optimised to reduce the risk of communicational pitfalls, and in addition, the triage nurses could be trained to be more resilient to these pitfalls.

In chapter 9, we discuss our main findings, reflect on the clinical case presented in the introduction, and provide recommendations for future research. The case from the introduction gave rise to a number of dilemmas and additional questions regarding telephone triage with the NTS, some of which are listed below.

- What urgency level is most appropriate for patients suspected of TIA/stroke if the risk of TIA/stroke is estimated to be high (and taking into account treatment options)?

- Interactional workability dilemmas arise when the decision support tool misaligns with the triage nurse's clinical reasoning, and complicate telephone triage with the NTS. Examples of interactional workability dilemmas are choosing the 'main complaint' within the NTS when a patient mentions (i) multiple problems or (ii) has difficulties in choosing between 'yes' or 'no' in case symptoms have partly resolved.

- In the general practice setting, which includes the OHS-PC, the prevalence of emergent diseases is lower, and on average includes less severe cases than seen at the ED. Therefore, using the same decision support tool, e.g. the NTS, seems inadequate.

- Judging the quality of decision making by the triage nurse for a large part on compliance with the NTS as is now commonly done is inadequate due to (i) hindsight bias and (ii) the lack of comparison with the final diagnosis. Such a shift in approach is in line with recent developments in patient safety research, moving from "as few things go wrong as possible" to "as many things go right as possible".(46)

Clearly, telephone triage of acute cardiovascular symptoms brings many challenges to triage nurses, GPs, and patients, but also to researchers and educators in their search for ways to improve telephone triage, and thus ultimately the safety and quality of patient care. A promising organisational concept that fits in well with the Safety-II approach is that of a learning healthcare system. The overarching idea of a learning health care system as an organisational concept for telephone triage at the OHS-PC is that the focus is less on individual learning and more on learning as an organisation with workplace learning. This is an active process in which the experiences of triage nurses and GPs and scientific insights are transformed into learning and development through action and reflection on own actions and thoughts.(47-49) 


\section{References}

1) Smits $M$, Rutten $M$, Keizer $E$, Wensing $M$, Westert $G$, Giesen $P$. The Development and Performance of After-Hours Primary Care in the Netherlands: A Narrative Review. Annals of internal medicine. 2017;166(10):737-42.

2) Blank L, Coster J, O'Cathain A, Knowles E, Tosh J, Turner J, et al. The appropriateness of, and compliance with, telephone triage decisions: a systematic review and narrative synthesis. J Adv Nurs. 2012;68(12):2610-21.

3) National guidelines for telephone triage and advice in Family Practice [cited 2018 June 22]. Available from: https://www.nhg.org/winkel/producten/nhg-triagewijzer-versie-2016.

4) van lerland $Y$, van Veen $M$, Huibers $L$, Giesen $P$, Moll HA. Validity of telephone and physical triage in emergency care: the Netherlands Triage System. Family practice. 2011;28(3):33441.

5) Netherlands Triage Standard [Nederlandse Triage Standaard], 2019. Accessed at www. de-nts.nl on 7 October 2019.

6) Smits M, Verheij R. Changes in urgency of contacts with the out-of-hours services in primary care 2013-2016. [Veranderingen in de urgentie van contacten met de huisartsenpost 20132016.]. NIVEL, 2017.

7) Hoorweg BB, Willemsen RT, Cleef LE, Boogaerts T, Buntinx F, Glatz JF, et al. Frequency of chest pain in primary care, diagnostic tests performed and final diagnoses. Heart. 2017; 103(21):1727-32.

8) Plat FM, Peters YAS, Loots FJ, de Groot CJA, Eckhardt T, Keizer E, et al. Ambulance dispatch versus general practitioner home visit for highly urgent out-of-hours primary care. Family practice. 2017(Dec 20).

9) Rothwell PM, Giles MF, Chandratheva A, Marquardt L, Geraghty O, Redgrave JN, et al. Effect of urgent treatment of transient ischaemic attack and minor stroke on early recurrent stroke (EXPRESS study): a prospective population-based sequential comparison. Lancet. 2007;370(9596):1432-42.

10) Lavallee PC, Meseguer E, Abboud H, Cabrejo L, Olivot JM, Simon O, et al. A transient ischaemic attack clinic with round-the-clock access (SOS-TIA): feasibility and effects. Lancet Neurol. 2007;6(11):953-60.

11) Rothwell PM, Algra A, Chen Z, Diener HC, Norrving B, Mehta Z. Effects of aspirin on risk and severity of early recurrent stroke after transient ischaemic attack and ischaemic stroke: time-course analysis of randomised trials. Lancet. 2016;388(10042):365-75.

12) Rutten $\mathrm{MH}$, Kant J, Giesen P. What can we learn from calamities at out-of-hours services in primary care? [Wat kunnen we leren van calamiteiten op de huisartsenpost?]. Huisarts Wet. 2018;6(61).

13) Argentino $C$, Toni $D$, Rasura M, Violi F, Sacchetti ML, Allegretta A, et al. Circadian variation in the frequency of ischemic stroke. Stroke. 1990;21(3):387-9.

14) Muller JE. Circadian variation in cardiovascular events. Am J Hypertens. 1999;12(2 Pt 2):35S42S.

15) Ripamonti L, Riva R, Maioli F, Zenesini C, Procaccianti G. Daily Variation in the Occurrence of Different Subtypes of Stroke. Stroke Res Treat. 2017;2017:9091250.

16) Elliott WJ. Circadian variation in the timing of stroke onset: a meta-analysis. Stroke. 1998;29(5):992-6. 
17) Chaturvedi S, Adams HP, Jr., Woolson RF. Circadian variation in ischemic stroke subtypes. Stroke. 1999;30(9):1792-5.

18) Manfredini R, Boari B, Smolensky MH, Salmi R, la Cecilia O, Maria Malagoni A, et al. Circadian variation in stroke onset: identical temporal pattern in ischemic and hemorrhagic events. Chronobiol Int. 2005;22(3):417-53.

19) Feng J, Zhang JH, Qin $X$. Timing pattern of onset in hypertensive intracerebral hemorrhage patients. Acta Neurochir Suppl. 2011;111:327-31.

20) Omama S, Yoshida Y, Ogawa A, Onoda T, Okayama A. Differences in circadian variation of cerebral infarction, intracerebral haemorrhage and subarachnoid haemorrhage by situation at onset. J Neurol Neurosurg Psychiatry. 2006;77(12):1345-9.

21) Butt MU, Zakaria M, Hussain HM. Circadian pattern of onset of ischaemic and haemorrhagic strokes, and their relation to sleep/wake cycle. J Pak Med Assoc. 2009;59(3):129-32.

22) Sloan MA, Price TR, Foulkes MA, Marler JR, Mohr JP, Hier DB, et al. Circadian rhythmicity of stroke onset. Intracerebral and subarachnoid hemorrhage. Stroke. 1992;23(10):1420-6.

23) Manfredini R, Gallerani M, Portaluppi F, Salmi R, Fersini C. Chronobiological patterns of onset of acute cerebrovascular diseases. Thromb Res. 1997;88(6):451-63.

24) Elliott WJ. Cyclic and circadian variations in cardiovascular events. Am J Hypertens. 2001;14((9 Pt 2)):291S-5S

25) Manfredini R, La Cecilia O, Boari B, Steliu J, Michelinidagger V, Carlidagger P, et al. Circadian pattern of emergency calls: implications for ED organization. Am J Emerg Med. 2002;20(4):282-6.

26) Dawson J, Lamb KE, Quinn TJ, Lees KR, Horvers M, Verrijth MJ, et al. A recognition tool for transient ischaemic attack. QJM : monthly journal of the Association of Physicians. 2009;102(1):43-9.

27) Dutta D. Diagnosis of TIA (DOT) score--design and validation of a new clinical diagnostic tool for transient ischaemic attack. BMC Neurol. 2016;16:20.

28) Lebedeva ER, Gurary NM, Gilev DV, Christensen AF, Olesen J. Explicit diagnostic criteria for transient ischemic attacks to differentiate it from migraine with aura. Cephalalgia. 2018;38(8):1463-70.

29) Harbison J, Hossain O, Jenkinson D, Davis J, Louw SJ, Ford GA. Diagnostic accuracy of stroke referrals from primary care, emergency room physicians, and ambulance staff using the face arm speech test. Stroke. 2003;34(1):71-6.

30) Nor AM, Davis J, Sen B, Shipsey D, Louw SJ, Dyker AG, et al. The Recognition of Stroke in the Emergency Room (ROSIER) scale: development and validation of a stroke recognition instrument. Lancet Neurol. 2005;4(11):727-34.

31) Johnston SC, Rothwell PM, Nguyen-Huynh MN, Giles MF, Elkins JS, Bernstein AL, et al. Validation and refinement of scores to predict very early stroke risk after transient ischaemic attack. Lancet. 2007;369(9558):283-92.

32) Healthcare Quality, Complaints and Disputes Act (WKKGZ), 2016.

33) Vanhaecht K, Seys D, Schouten L, Bruyneel L, Coeckelberghs E, Panella M, et al. Duration of second victim symptoms in the aftermath of a patient safety incident and association with the level of patient harm: a cross-sectional study in the Netherlands. BMJ open. 2019;9(7):e029923.

34) Wu AW, Shapiro J, Harrison R, Scott SD, Connors C, Kenney L, et al. The Impact of Adverse Events on Clinicians: What's in a Name? J Patient Saf. 2017.

35) Henriksen K, Kaplan H. Hindsight bias, outcome knowledge and adaptive learning. Qual Saf Health Care. 2003;12 Suppl 2:ii46-50. 
36) Wears RL, Nemeth CP. Replacing hindsight with insight: toward better understanding of diagnostic failures. Ann Emerg Med. 2007;49(2):206-9.

37) Fischhoff $B$. Hindsight not equal to foresight: the effect of outcome knowledge on judgment under uncertainty. 1975. Qual Saf Health Care. 2003;12(4):304-11; discussion 11-2.

38) Arkes HR, Wortmann RL, Saville PD, Harkness AR. Hindsight bias among physicians weighing the likelihood of diagnoses. J Appl Psychol. 1981;66(2):252-4.

39) Dawson NV, Arkes HR, Siciliano C, Blinkhorn R, Lakshmanan M, Petrelli M. Hindsight bias: an impediment to accurate probability estimation in clinicopathologic conferences. Med Decis Making. 1988;8(4):259-64.

40) Marks Knoll MAZ. The Effects of Expertise on the Hindsight Bias [dissertation from the internet]. Ohio: The Ohio State University; 2009. Available from: https://etd.ohiolink. edu/!etd.send_file?accession=osu1242920562\&disposition=inline.

41) Pearce N. Analysis of matched case-control studies. BMJ. 2016;352:i969.

42) Grobbee DE, Hoes AW. Clinical Epidemiology: Principles, Methods, and Applications for Clinical Research. Second ed: Jones \& Bartlett Learning; 2015. Chapter 9: Case-Control Studies; p. 255-301.

43) Fleiss J, Levin B, Paik M. Statistical Methods for Rates and Proportions. Third Edition ed: John Wiley \& Sons Inc; 2003. p. 598-626.

44) Stokoe E. The Conversation Analytic Role-play Method (CARM): A Method for Training Communication Skills as an Alternative to Simulated Role-play. Res Lang Soc Interac. 2014;47(3):255-65.

45) Sikveland RO, Stokoe E. Effective telephone triage methods. Practice Management. 2017;27(6):20-2.

46) Hollnagel E, Wears R, Braithwaite J. From Safety-I to Safety-II: A white paper. The Resilient Health Care Net: Published simultaneously by the University of Southern Denmark, University of Florida, USA, and Macquarie University, Australia: 2015.

47) Kolb DA. Experiential Learning: Experience as the Source of Learning and Development. Englewood Cliffs, NJ: Prentice-Hall Inc; 1984.

48) Bransford JD, Brown AL, Cocking RR. How People Learn: Brain, Mind, Experience and School: Expanded Edition. Washington, DC: National Academy Press; 2001.

49) Schultz K, McEwen L, Griffiths J. Applying Kolb's Learning Cycle to Competency-Based Residency Education. Acad Med. 2016;91(2):284. 


\section{Nederlandse samenvatting}

Mensen met niet levensbedreigende klachten die medische zorg nodig hebben buiten de kantoortijden wordt verzocht om telefonisch contact op te nemen met de huisartsenpost. Op de huisartsenpost wordt vervolgens telefonische triage uitgevoerd door triagisten, onder supervisie van een dienstdoende huisarts.(1) Het doel van telefonische triage is om bellers te prioriteren op basis van de ernst van de gepresenteerde klachten en verschijnselen. Met andere woorden, het urgentieniveau van het toestandsbeeld dient door de triagist te worden bepaald. Het bepaalde urgentieniveau komt overeen met een tijdsduur waarbinnen medische hulp dient te worden geleverd.(2) Triagisten worden hierbij ondersteund door een semi-automatische digitale ondersteuning: de Nederlandse Triage Standaard (NTS).

De NTS is ontwikkeld door een expertpanel en is afgeleid van de reeds bestaande

(i) Nederlandse richtlijn voor telefonische triage in de huisartspraktijk (NHG-TriageWijzer), (ii) de Landelijke Standaard Meldkamer Ambulancezorg en (iii) de criteria van het Manchester Triage Systeem.(3-5) De NTS bestaat uit 56 'ingangsklachten' met elk een achterliggend algoritme dat bestaat uit hiërarchisch geordende vragen. Vragen naar de medisch meest kritische klachten en verschijnselen dienen als eerst te worden gesteld. Nadat de triagist de antwoorden van de beller heeft ingevuld, genereert de NTS automatisch een urgentieniveau: $\cup 0$ (reanimatie waarvoor direct een ambulance wordt gestuurd), U1 (levensbedreigende situatie waarbij een ambulance wordt gestuurd die binnen 15 minuten aanwezig moet zijn), U2 (spoedeisende situatie, medische hulp dient geleverd te worden binnen één uur), U3 (urgente situatie, medische hulp leveren binnen drie uur), U4 (niet-urgente situatie, medische hulp binnen 24 uur volstaat) en U5 (geen risico op schade, een telefonisch advies volstaat).(4, 5) Het automatisch gegenereerde NTS urgentieniveau kan door de triagist worden op- en afgeschaald ('overrulen'), wat meestal gebeurd na overleg met de superviserende huisarts.

Het oorspronkelijke doel van de NTS was om zowel efficiënte als veilige zorg te garanderen. Er bestaan echter aanwijzingen dat telefonische triage met de NTS inefficiënt verloopt en dat de urgentie wordt overschat, in het bijzonder bij vermoeden van een acute hart- en vaatziekte. Enerzijds krijgen bellers met klachten en verschijnselen verdacht voor een acute hart- en vaatziekte, bijv. een acuut coronair syndroom, een beroerte, en in mindere mate een transient ischaemic attack (TIA), over het algemeen hoge urgentieniveaus toegewezen (6), terwijl slechts een minderheid van de bellers daadwerkelijk een acute hart- en vaatziekte blijkt te hebben. Zo bleek uit recent Nederlands onderzoek dat van de mensen die de huisarts of huisartsenpost belden vanwege pijn op de borst ongeveer $70 \%$ werd ingestuurd naar het ziekenhuis met een ambulance, en dat circa $10 \%$ van hen daadwerkelijk een acuut coronair syndroom (acuut myocardinfarct of instabiele angina pectoris) had.(7, 8) Tevens werd gedurende de periode 2013-2016 een toename van toegewezen U1 urgenties gezien (in vergelijking met andere urgenties) bij patiënten die de huisartsenpost belden met klachten en verschijnselen verdacht voor een TIA/ 
beroerte.(6) Bij het beoordelen van deze inefficiëntie bij triage van mensen met verdenking op een TIA/beroerte dient wel meegenomen te worden dat met adequate triage en diagnostiek gevolgd door tijdige start van (preventieve) behandeling, de prognose van patiënten met een TIA/beroerte sterk te verbeteren valt.(9-11) Hiervoor is natuurlijk als startpunt dan wel een voldoende hoog urgentieniveau nodig. Ook van belang om te beseffen is dat calamiteiten op de huisartsenpost weliswaar zeldzaam zijn, maar dan wel vaak een gemiste of te laat onderkende acute hart- en vaatziekte betreft, met name gemiste myocardinfarcten, gemist abdominaal aneurysma en te late herkenning van een beroerte.(12) De potentiële schade van zowel onder-triage (onveilig) als over-triage (inefficiënt) van acute gebeurtenissen zoals TIA/beroerte maakt telefonische triage zeer uitdagend bij patiënten die bellen voor klachten en verschijnselen die kunnen passen bij neurologische uitvalsverschijnselen. Ook het belang van het meewegen van de uiteindelijke diagnose bij het beoordelen van de kwaliteit en veiligheid van de telefonische triage moge uit het voorgaande duidelijk zijn. Desondanks is het gebruik van de NTS in de eerste lijn nauwelijks geëvalueerd en dan ook nog tegen 'surrogaateindpunten'. Dat wil zeggen, afgezet tegen (i) verwijzingen naar het ziekenhuis (zonder het laten meewegen van de diagnose, een behandeling of een ziekenhuisopname) en (ii) telefonische zelfzorgadviezen. De accuratesse van de NTS is nog nooit afgezet tegen klinische uitkomsten. Dit proefschrift richt zich dan ook op het proces van urgentiebepaling met de NTS bij bellers met klachten verdacht voor acute hart- en vaatziekte, met name TIA/beroerte en het bepalen van determinanten die de diagnostiek naar TIA/beroerte verbeteren. Dit alles om de telefonische triage te verbeteren binnen het domein verdenking acute hart- en vaatziekte.

\section{Het Safety First project}

In hoofdstuk $\mathbf{2}$ van dit proefschrift beschrijven we de doelstellingen en de studie-opzet van het Safety First project. Dit project richt zich op een kennislacune ten aanzien van veiligheid en efficiëntie van telefonische triage met de NTS op de huisartsenpost van patiënten verdacht voor een acute hart- en vaatziekte; acuut coronair syndroom of TIA/ beroerte. Met Safety First willen we het diagnostisch proces en de urgentiebepaling bij bellers met klachten en verschijnselen verdacht voor een acuut coronair syndroom of $\mathrm{TIA} /$ beroerte beschrijven, begrijpen en verbeteren, om zo de efficiëntie en de veiligheid van telefonische triage in dit domein te verbeteren. Het proefschrift van Loes Wouters richt zich op het domein verdenking acuut coronair syndroom en dit proefschrift op met name het domein verdenking TIA/beroerte. Opnames van telefonische triagegesprekken van negen huisartsenposten in de omgeving van Utrecht uit de periode 20142017 werden geanalyseerd. Voor de dataverzameling werd gebruik gemaakt van (i) gesprekskenmerken, (ii) patiëntkenmerken en (iii) klachtpresentatie. Hiervoor werden de opnames van triagegesprekken beluisterd. 
De onderzoekers die de dataverzameling van de triagegesprekken uitvoerden wisten niet wat de uiteindelijke diagnose was van de patiënt. Deze diagnose werd opgevraagd bij de eigen huisarts van iedere patiënt en hierbij werden ook gegevens verkregen uit ontslagbrieven van het ziekenhuis (van de neuroloog, cardioloog en spoedeisende hulp). De data-analyse bestond uit zowel uni- als multivariabele logistische regressieanalyses. Daarnaast wordt in hoofdstuk 2 de studie opzet van drie aanvullende studies binnen het Safety First project beschreven: een case-control studie met calamiteiten waarbij een acuut coronair syndroom (met name het acute myocardinfarct) was gemist, een conversatie-analyse studie en een interviewstudie met triagisten. De resultaten van de eerste twee aanvullende studies zijn in dit proefschrift opgenomen en de resultaten van de interviewstudie zijn in het proefschrift van Loes Wouters opgenomen.

\section{Accuratesse van de NTS bij patiënten met klachten en verschijnselen verdacht voor $\mathrm{\dagger |} / \mathrm{A} /$ beroerte}

In hoofdstuk 3 presenteren we de resultaten van ons onderzoek naar de accuratesse van de NTS urgentiebepaling bij patiënten die de huisartsenpost belden met klachten en verschijnselen verdacht voor TIA/beroerte, waarbij we de uiteindelijke klinische uitkomsten TIA, beroerte en andere (neurologische) levensbedreigende ziekten als referentie gebruikten.

In deze cross-sectionele studie bij 1269 patiënten, bleken er 635 (50,0\%) een TIA/ beroerte te hebben; 434 (34,2\%) hadden een TIA/kleine beroerte, 201 (15,8\%) een grote beroerte en $61(4,8 \%)$ patiënten hadden andere (neurologische) levensbedreigende ziekte zoals sepsis, meningitis of herpes encefalitis. Zowel bloedige als ischemische beroertes zijn als grote beroerte meegeteld. De sensitiviteit, specificiteit en positief en negatief voorspellende waarde van de NTS urgentiebepaling voor TIA/beroerte/ andere (neurologische) levensbedreigende ziekte waren respectievelijk 0,72 (95\% betrouwbaarheidsinterval (BI) 0,68-0,75), 0,48 (95\% BI 0,43-0,52), 0,62 (95\% BI 0,60-0,64), en 0,58 (95\% BI 0,54-0,62). Hierbij vonden we voor het berekenen van de sensitiviteit een adequate urgentiebepaling als iemand met een TIA/kleine beroerte een U1, U2 of U3 kreeg en iemand met een grote beroerte of andere (neurologische) levensbedreigende ziekte een U1 of U2. Bij het berekenen van de specificiteit gingen we er vanuit dat een U3, U4 of U5 een adequate urgentie was voor de overgebleven niet ernstige/direct behandeling behoevende aandoeningen.

Concluderend: De NTS presteert matig wat betreft veiligheid; $28 \%$ van de patiënten die een TIA/beroerte/andere (neurologische) levensbedreigende ziekte bleken te hebben kregen een te lage urgentie toegekend. De NTS presteert slecht wat betreft efficiëntie; slechts $48 \%$ van de patiënten met niet ernstige/direct behandeling behoevende aandoeningen kreeg in onze ogen een terechte lage urgentie toegekend. 


\section{Predictie van TIA/beroerte middels telefonische triage op de huisartsenpost}

In hoofdstuk 4 richten we ons op één van de determinanten die de telefonische triage van TIA/beroerte patiënten mogelijk zou kunnen verbeteren, namelijk het tijdstip van bellen. Eerdere studies uitgevoerd op de spoedeisende hulp lieten zien dat TIA/beroerte vaker overdag voorkomt dan's nachts, met een piekincidentie in de ochtenduren tussen 6 en 12 uur.(13-17) Sommige studies vonden ook een minder prominente piek in de vroege avonduren.(15-24) Of het tijdstip van bellen helpt om tijdens telefonische triage van patiënten met verdenking neurologische uitval onderscheid te kunnen maken tussen wel en geen TIA/beroerte was onbekend.(25) Daarom onderzochten we in deze studie of het tijdstip van bellen een relatie had met de uiteindelijke diagnose TIA/ beroerte. We berekenden het risico op TIA/beroerte per uur en het relatieve risico van TIA/beroerte in de ochtend ten opzichte van de overige uren. Van de 1269 mensen waarbij de uiteindelijke diagnose bekend was, bleek dat 50,0\% een TIA/beroerte had. De meesten van hen belden overdag, met een piek tussen 8 en 12 uur (22,0\% van het totaal) en tweede piek tussen 14-18 uur (19,7\% van het totaal). Het tijdstip van bellen van patiënten die geen diagnose TIA/beroerte bleken te hebben volgde hetzelfde patroon. Daardoor was het relatieve risico op een TIA/beroerte in de ochtenduren tussen 8-12 uur ten opzichte van andere uren niet vergroot (relatieve risico 1,13 (95\% BI 1,00-1,28, $p=0,070$ ) en na correctie voor leeftijd en geslacht 0,94 (95\% BI 0,80-1,10, p=0,434)). Op basis van deze gegevens concludeerden we dat het tijdstip van bellen niet bruikbaar is bij telefonische triage van patiënten met verdenking neurologische uitval.

In hoofdstuk 5 beschrijven we hoe we een diagnostisch predictiemodel voor TIA/ beroerte hebben gemaakt. Het goed voorspellen van de kans op aan- of afwezigheid van $\mathrm{TIA} /$ beroerte tijdens telefonische triage is een grote uitdaging, omdat dit enkel gebaseerd is op de verbale informatie over de klachten en verschijnselen van de patiënt. Er bestaan weliswaar al verschillende diagnostische predictiemodellen, echter die zijn ontwikkeld en bedoeld voor gebruik in het ziekenhuis, waarbij de patiënt ook onderzocht kan worden. (26-31) Omdat dergelijke predictiemodellen ontbreken voor de huisartsenpost-setting, hebben we ons gericht op het ontwikkelen van een nieuw diagnostisch predictiemodel voor telefonische triage van patiënten met (neurologische) klachten en verschijnselen verdacht voor een TIA/beroerte die de huisartsenpost bellen. Voor dit cross-sectionele, observationele onderzoek op negen huisartsenposten in Nederland gebruikten we gegevens uit de periode 2014-2017. De primaire uitkomst, wel of geen uiteindelijke diagnose TIA/beroerte, werd opgevraagd bij de eigen huisartsen van patiënten en werden verkregen uit de elektronische patiëntendossiers, inclusief informatie uit ontslagbrieven van het ziekenhuis. Informatie over 'kandidaatpredictoren' werd verzameld uit de opnames van triagegesprekken en de elektronische patiëntendossiers van de huisartsenpost. Na aanvulling van missende gegevens (multiple imputation for missing data), hebben we multivariabele logistische regressieanalyses toegepast om vier 
vooraf gedefinieerde predictiemodellen voor TIA/beroerte te kunnen vergelijken. Het ontwikkelde model werd intern gevalideerd (middels bootstrapping en shrinkage van de regressiecoëfficiënten).

Van de 1381 patiënten (mediane leeftijd 72,0 (interkwartielafstand 57,5-83,0) jaar, $56,6 \%$ vrouw) die belden met klachten en verschijnselen verdacht voor TIA/beroerte, kregen 703 (50,9\%) de diagnose TIA/beroerte (34,5\% TIA/kleine beroerte, 16,4\% grote beroerte). Het uiteindelijke model voor TIA/beroerte bevatte 11 voorspellers, waarvan de sterkste voorspellers (i) leeftijd, (ii) vrouwelijk geslacht, (iii) zwakte van de arm en (iv) spraakstoornis waren. Het discriminerend vermogen (c-statistic) van het model was 0,73 (95\% BI 0,70-0,76). Het door ons ontwikkelde diagnostische predictiemodel voor $\mathrm{TIA} /$ beroerte toonde goede discriminatie, en zou na externe validatie kunnen worden toegepast op de huisartsenpost om de telefonische triage van patiënten die bellen met neurologische klachten en verschijnselen te verbeteren.

\section{Veiligheid van telefonische triage bij patiënten met klachten verdacht voor een acuut coronair syndroom (acuut hartinfarct of instabiele angina pectoris)}

In hoofdstuk 6 van dit proefschrift beschrijven we de resultaten van onze case-control studie naar calamiteiten op de huisartsenpost. Een calamiteit staat in de Wet kwaliteit, klachten en geschillen zorg (Wkkgz) gedefinieerd als: "een niet-beoogde of onverwachte gebeurtenis, die betrekking heeft op de kwaliteit van de zorg en die tot de dood van een cliënt of een ernstig schadelijk gevolg voor de patiënt heeft geleid".(32) Met een incidentie van $0,006 \%$ zijn calamiteiten op Nederlandse huisartsenposten zeldzaam. Desondanks hebben ze een grote weerslag op de patiënt, familie en betrokken zorgverleners.(12, 33, 34) Calamiteiten betreffen vaak gemiste acute hart- en vaatziekten, en in het bijzonder gemiste acute myocardinfarcten/plotselinge hartdood (30,4\% van alle calamiteiten) en te laat onderkende beroerte (7,9\% van alle calamiteiten).(12) In de Nederlandse wet is vastgelegd dat na afloop van elke calamiteit een uitgebreide analyse naar de oorzaak dient te worden uitgevoerd. Dergelijke analyses gaven aan dat er vaak fouten tijdens het triageproces waren 'aan te wijzen' als oorzaak voor de calamiteit. Maar zulke analyses zijn van beperkte waarde vanwege (i) hindsight bias oftewel "de neiging om de mate waarin een gebeurtenis van tevoren kan worden voorspeld te overdrijven als de uitkomst bekend is" (35-37) en (ii) onwetendheid over fouten die optreden in hetzelfde domein bij een steekproef van al die mensen (99,994\%) waarbij geen calamiteit optreedt. Misschien gebeuren daar wel dezelfde fouten en is er dus geen sprake van een oorzakelijk verband tussen die fouten en een dramatische afloop. Hindsight bias stimuleert bij beoordelaars van calamiteiten de verwachting dat degenen die betrokken zijn bij de calamiteit vooraf hadden kunnen weten wat er achteraf daadwerkelijk is geleerd. In deze studie vergeleken we daarom triagegesprekken van patiënten die naar de huisartsenpost belden vanwege pijn op de borst en waarbij een acuut coronair syndroom (in de praktijk waren dit acute 
hartinfarcten, met bij een aantal acute hartdood tot gevolg) werd gemist (= calamiteit) met triagegesprekken van patiënten met pijn op de borst maar zonder een gemist acuut coronair syndroom (= controles). Het doel van deze studie was het identificeren van voorspellers van een gemist acuut coronair syndroom. We gebruikten triagegesprekken uit de periode 2013-2017. De dataverzameling geschiedde geblindeerd voor de uitkomst (calamiteit of controle). De calamiteiten werden door een van de onderzoekers die verder niet betrokken was bij de beoordeling 1:8 gematched met controles op basis van leeftijd en geslacht. De data-analyse bestond uit conditionele logistische regressieanalyses. In totaal konden we 15 calamiteiten en 120 controles onderzoeken.

Uit onze resultaten bleek dat in vergelijking met de controlegroep, patiënten uit de calamiteitengroep minder vaak cardiovasculaire medicatie gebruikten (38,5\% vs. 64,1\%, $p=0,05)$, vaker pijn op de borst op andere locaties dan retrosternaal rapporteerden $(63,3 \%$ vs. $24,7 \%, p=0,02)$, en er vaker overleg plaats vond tussen de triagist en de superviserende huisarts $(86,7 \%$ vs. $49,2 \%, p=0,02)$. We konden met deze zeer beperkte 'kenmerken' van gemiste acuut coronair syndroom, die ook nog eens bij minimaal een kwart van de controles voorkwamen, geen advies formuleren om door aanpassing van de triage toekomstige calamiteiten bij patiënten met pijn op de borst te voorkomen.

In hoofdstuk 7 onderzochten we of een expertpanel van 15 ervaren huisartsen in staat was om (on)veiligheid in triagegesprekken te herkennen. Daarnaast vroegen we hen om de kwaliteit van de telefonische triage te beoordelen. Dit ook weer bij de 15 calamiteiten en de 120 controles, waarbij de experts niet wisten welk triagegesprek wel of geen calamiteit betrof. Eerder onderzoek had aangetoond dat experts ook ten prooi vallen aan hindsight bias.(38-40) Daarom zorgden we voor blindering van de experts voor de uitkomst. We vroegen de experts ieder voor zich de triagegesprekken te beluisteren en te beoordelen. Verschillen in beoordeling van gesprekken tussen calamiteiten en controles werden berekend middels conditionele logistische regressieanalyse. $(41,42)$ Elk triagegesprek werd door twee verschillende experts beoordeeld. Om de interbeoordelaarsbetrouwbaarheid van de experts te kwantificeren werd de intraclass correlation coefficient (ICC) berekend als een benadering van gewogen Kappa (de overeenkomst tussen beoordelaars waarbij slecht 0,0 is en perfect 1,0).(43) In totaal konden zo 270 expertbeoordelingen geëvalueerd worden.

Experts beoordeelden gemiddeld genomen de triage van calamiteiten vaker als 'onveilig' (73,3\% vs. 22,5\%, p<0,001), en van 'slechte' kwaliteit (33,3\% vs. 10,9\%, $p=0,001)$ dan de gesprekken bij controles, maar dit was wel met een zeer beperkte interbeoordelaarsbetrouwbaarheid (ICC tussen 0,16 (95\% BI 0,00-0,32) en 0,17 (95\% BI $0,00-0,33)$ ). In onze studie bleken de experts, indien hun oordeel samen werd genomen, onveilige triage vrij goed te herkennen. Ook bleken zij hogere urgenties aan calamiteiten toe te wijzen dan aan controles. Dit alles terwijl ze geblindeerd waren voor de uitkomst (calamiteit of geen calamiteit). Echter bleek dat er grote verschillen waren tussen de beoordelaars (een zeer beperkte interbeoordelaarsbetrouwbaarheid) en daarmee is de waarde van één expert en diens beoordeling (zoals meestal gebeurd bij de analyse naar 
oorzaken van een calamiteit) twijfelachtig. De resultaten van deze studie trekken dan ook de individuele casusgeoriënteerde benadering van een analyse naar oorzaken van een calamiteit in twijfel. Het lijkt simpelweg onvoldoende om zo tot een weloverwogen beoordeling te komen. De kans is dan ook klein dat de gevonden 'oorzaken' uit de individuele calamiteitenanalyse, inclusief de beperking van hindsight bias, ook werkelijk de oorzaken zijn voor het ontstaan van de calamiteit. Van de conclusies die getrokken worden uit zulke analyses valt dan weinig te leren en de hierop gebaseerde aanbevolen aanpassingen in het triagebeleid zijn gestoeld op 'ondeugdelijk bewijs'. Onze geblindeerde beoordeling door een expertpanel van meerdere calamiteiten in vergelijking met een controlegroep geeft een andere, minder 'gekleurde' en ook complementaire kijk op calamiteitenanalyse en laat zien hoe moeilijk het is om calamiteiten en de veiligheid en kwaliteit van telefonische triage in de context van de dagelijkse praktijk adequaat te beoordelen.

\section{Interactionele effecten van 'of-vragen' tijdens telefonische triage met de NTS}

Tijdens telefonische triage heeft de NTS invloed op de interactie tussen triagisten en bellers. De NTS geeft de belangrijkste te stellen vragen weer die als meerkeuze 'ofvragen' (bijv. "Is het een beklemmende, stekende of krampende pijn?") kunnen worden gesteld. In hoofdstuk $\mathbf{8}$ presenteren we de resultaten van onze kwalitatieve studie; een conversatie-analyse naar de effecten van meerkeuze 'of-vragen' in de interactie tussen bellers en triagisten. Onze conversatie-analyse toonde dat interactionele problemen voornamelijk ontstaan (i) in het geval dat de triagist een 'slecht ontworpen' vraag stelt of (ii) als de klachten van de beller dubbelzinnig worden gepresenteerd (het kost de patiënt soms moeite om te verwoorden wat hij/zij voelt of ervaart aan klachten).

Deze studie heeft geleid tot twee praktische aanbevelingen voor triagisten: (i) gebruik korte vragen met slechts één of een zeer beperkt aantal keuzeopties voor de patiënt om zo de kans op onduidelijke antwoorden te verkleinen; (ii) stel open vragen om de patiënt te helpen zijn of haar klachtenpresentatie specifieker te maken (bijv. "Wat voor soort pijn ervaar je?").

De gevolgen van deze studie voor de dagelijkse praktijk zijn tweeledig. Ten eerste is er meer bewustwording onder triagisten nodig over de ongunstige effecten van meerkeuze 'of-vragen' op de interactie. Dit kan door middel van trainingen die ontwikkeld zijn aan de hand van onderzoek met echte opnames, zoals de 'Conversation Analytic Roleplay Method'. $(44,45)$ Door terug te luisteren naar hun eigen triagegesprekken kunnen triagisten horen wat er daadwerkelijk gebeurt tijdens de gesprekken. In de praktijk blijkt namelijk dat mensen anders praten dan ze denken. Ten tweede kan het ontwerp van de NTS worden geoptimaliseerd om het risico op interactionele valkuilen te verminderen en tenslotte moeten triagisten worden opgeleid om beter bestand te zijn tegen dit soort valkuilen. 
In hoofdstuk 9 bespreken we de belangrijkste bevindingen, reflecteren we op de in de inleiding gepresenteerde klinische casus en doen we aanbevelingen voor toekomstig onderzoek. De casus uit de inleiding gaf aanleiding tot een aantal dilemma's en aanvullende vragen rondom telefonische triage met de NTS:

- Welk urgentieniveau past het beste bij patiënten verdacht voor een TIA/beroerte als de kans op TIA/beroerte hoog wordt ingeschat (en rekening houdend met behandelopties)?

- Interactionele workability dilemma's die ontstaan wanneer de digitale ondersteuning niet overeenkomt met de klinische redenatie van de triagist. Bijvoorbeeld het kiezen van de 'ingangsklacht' in de NTS wanneer een patiënt meerdere problemen presenteert, of het beantwoorden van het bestaan van een bepaalde klacht met 'ja' of 'nee' terwijl de patiënt meldt dat deze nog maar deels aanwezig is.

- In de huisartspraktijk en dus ook op de huisartsenpost is de prevalentie van urgente ziekten lager dan in het ziekenhuis. Daarnaast betreft het gemiddeld genomen minder ernstige gevallen dan op de spoedeisende hulp, waardoor op zijn minst vraagtekens kunnen worden geplaatst bij het gebruik van een en dezelfde beslisondersteuning met de NTS.

- Het beoordelen van de kwaliteit van besluitvorming door de triagist grotendeels baseren op het al dan niet naleven van de NTS, zoals nu gebeurt, is inadequaat. De uiteindelijke diagnose moet mee worden genomen in de beoordeling om de kwaliteit van de verrichte triage te beoordelen. Een dergelijke verschuiving in de aanpak past bij de recente wijziging in de visie van patiëntveiligheidsonderzoek; van benadrukken van "zo weinig mogelijk dingen gaan mis" naar "zo veel mogelijk dingen gaan goed").(46)

Het is duidelijk dat telefonische triage van klachten en verschijnselen verdacht voor acute hart- en vaatziekten veel uitdagingen met zich meebrengt voor triagisten, huisartsen en patiënten, maar ook voor onderzoekers en onderwijskundigen in hun zoektocht naar manieren om telefonische triage te verbeteren en uiteindelijk de veiligheid en kwaliteit van de patiëntenzorg te verbeteren. Een veelbelovende organisatievorm hierbij is een lerend gezondheidszorgsysteem (learning healthcare system). Het overkoepelende idee van een lerend gezondheidszorgsysteem bij telefonisch triage op de huisartsenpost, is dat de telefonische triage in zijn geheel wordt verbeterd met minder aandacht gericht op individueel leren en meer op leren als organisatie en dat op de werkplek zelf. Dit is een actief proces waarbij de ervaringen van triagisten en huisartsen samen met wetenschappelijke inzichten worden gebruikt om verder te leren en door te ontwikkelen door middel van actie en reflectie op hun eigen handelen en denken.(47-49) 


\section{Referenties}

1) Smits M, Rutten M, Keizer E, Wensing M, Westert G, Giesen P. The Development and Performance of After-Hours Primary Care in the Netherlands: A Narrative Review. Annals of internal medicine. 2017;166(10):737-42.

2) Blank L, Coster J, O'Cathain A, Knowles E, Tosh J, Turner J, et al. The appropriateness of, and compliance with, telephone triage decisions: a systematic review and narrative synthesis. J Adv Nurs. 2012;68(12):2610-21.

3) National guidelines for telephone triage and advice in Family Practice [cited 2018 June 22]. Available from: https://www.nhg.org/winkel/producten/nhg-triagewijzer-versie-2016.

4) van lerland $Y$, van Veen $M$, Huibers $L$, Giesen $P$, Moll HA. Validity of telephone and physical triage in emergency care: the Netherlands Triage System. Family practice. 2011;28(3):33441.

5) Netherlands Triage Standard [Nederlandse Triage Standaard], 2019. Accessed at www. de-nts.nl on 7 October 2019.

6) Smits M, Verheij R. Changes in urgency of contacts with the out-of-hours services in primary care 2013-2016. [Veranderingen in de urgentie van contacten met de huisartsenpost 20132016.]. NIVEL, 2017.

7) Hoorweg BB, Willemsen RT, Cleef LE, Boogaerts T, Buntinx F, Glatz JF, et al. Frequency of chest pain in primary care, diagnostic tests performed and final diagnoses. Heart. 2017;103(21):1727-32.

8) Plat FM, Peters YAS, Loots FJ, de Groot CJA, Eckhardt T, Keizer E, et al. Ambulance dispatch versus general practitioner home visit for highly urgent out-of-hours primary care. Family practice. 2017(Dec 20).

9) Rothwell PM, Giles MF, Chandratheva A, Marquardt L, Geraghty O, Redgrave JN, et al. Effect of urgent treatment of transient ischaemic attack and minor stroke on early recurrent stroke (EXPRESS study): a prospective population-based sequential comparison. Lancet. 2007;370(9596):1432-42.

10) Lavallee PC, Meseguer E, Abboud H, Cabrejo L, Olivot JM, Simon O, et al. A transient ischaemic attack clinic with round-the-clock access (SOS-TIA): feasibility and effects. Lancet Neurol. 2007;6(11):953-60.

11) Rothwell PM, Algra A, Chen Z, Diener HC, Norrving B, Mehta Z. Effects of aspirin on risk and severity of early recurrent stroke after transient ischaemic attack and ischaemic stroke: time-course analysis of randomised trials. Lancet. 2016;388(10042):365-75.

12) Rutten MH, Kant J, Giesen P. What can we learn from calamities at out-of-hours services in primary care? [Wat kunnen we leren van calamiteiten op de huisartsenpost?]. Huisarts Wet. 2018;6(61).

13) Argentino $C$, Toni $D$, Rasura $M$, Violi F, Sacchetti ML, Allegretta $A$, et al. Circadian variation in the frequency of ischemic stroke. Stroke. 1990;21(3):387-9.

14) Muller JE. Circadian variation in cardiovascular events. Am J Hypertens. 1999;12(2 Pt 2):35S42S.

15) Ripamonti L, Riva R, Maioli F, Zenesini C, Procaccianti G. Daily Variation in the Occurrence of Different Subtypes of Stroke. Stroke Res Treat. 2017;2017:9091250.

16) Elliott WJ. Circadian variation in the timing of stroke onset: a meta-analysis. Stroke. 1998;29(5):992-6. 
17) Chaturvedi S, Adams HP, Jr., Woolson RF. Circadian variation in ischemic stroke subtypes. Stroke. 1999;30(9):1792-5.

18) Manfredini R, Boari B, Smolensky MH, Salmi R, la Cecilia O, Maria Malagoni A, et al. Circadian variation in stroke onset: identical temporal pattern in ischemic and hemorrhagic events. Chronobiol Int. 2005;22(3):417-53.

19) Feng J, Zhang JH, Qin X. Timing pattern of onset in hypertensive intracerebral hemorrhage patients. Acta Neurochir Suppl. 2011;111:327-31.

20) Omama S, Yoshida Y, Ogawa A, Onoda T, Okayama A. Differences in circadian variation of cerebral infarction, intracerebral haemorrhage and subarachnoid haemorrhage by situation at onset. J Neurol Neurosurg Psychiatry. 2006;77(12):1345-9.

21) Butt MU, Zakaria M, Hussain HM. Circadian pattern of onset of ischaemic and haemorrhagic strokes, and their relation to sleep/wake cycle. J Pak Med Assoc. 2009;59(3):129-32.

22) Sloan MA, Price TR, Foulkes MA, Marler JR, Mohr JP, Hier DB, et al. Circadian rhythmicity of stroke onset. Intracerebral and subarachnoid hemorrhage. Stroke. 1992;23(10):1420-6.

23) Manfredini R, Gallerani M, Portaluppi F, Salmi R, Fersini C. Chronobiological patterns of onset of acute cerebrovascular diseases. Thromb Res. 1997;88(6):451-63.

24) Elliott WJ. Cyclic and circadian variations in cardiovascular events. Am J Hypertens. 2001;14((9 Pt 2)):291S-5S.

25) Manfredini R, La Cecilia O, Boari B, Steliu J, Michelinidagger V, Carlidagger P, et al. Circadian pattern of emergency calls: implications for ED organization. Am J Emerg Med. 2002;20(4):282-6.

26) Dawson J, Lamb KE, Quinn TJ, Lees KR, Horvers M, Verrijth MJ, et al. A recognition tool for transient ischaemic attack. QJM : monthly journal of the Association of Physicians. 2009;102(1):43-9.

27) Dutta D. Diagnosis of TIA (DOT) score--design and validation of a new clinical diagnostic tool for transient ischaemic attack. BMC Neurol. 2016;16:20.

28) Lebedeva ER, Gurary NM, Gilev DV, Christensen AF, Olesen J. Explicit diagnostic criteria for transient ischemic attacks to differentiate it from migraine with aura. Cephalalgia. 2018;38(8):1463-70.

29) Harbison J, Hossain O, Jenkinson D, Davis J, Louw SJ, Ford GA. Diagnostic accuracy of stroke referrals from primary care, emergency room physicians, and ambulance staff using the face arm speech test. Stroke. 2003;34(1):71-6.

30) Nor AM, Davis J, Sen B, Shipsey D, Louw SJ, Dyker AG, et al. The Recognition of Stroke in the Emergency Room (ROSIER) scale: development and validation of a stroke recognition instrument. Lancet Neurol. 2005;4(11):727-34.

31) Johnston SC, Rothwell PM, Nguyen-Huynh MN, Giles MF, Elkins JS, Bernstein AL, et al. Validation and refinement of scores to predict very early stroke risk after transient ischaemic attack. Lancet. 2007;369(9558):283-92.

32) Healthcare Quality, Complaints and Disputes Act (WKKGZ), 2016.

33) Vanhaecht K, Seys D, Schouten L, Bruyneel L, Coeckelberghs E, Panella M, et al. Duration of second victim symptoms in the aftermath of a patient safety incident and association with the level of patient harm: a cross-sectional study in the Netherlands. BMJ open. 2019;9(7):e029923.

34) Wu AW, Shapiro J, Harrison R, Scott SD, Connors C, Kenney L, et al. The Impact of Adverse Events on Clinicians: What's in a Name? J Patient Saf. 2017.

35) Henriksen K, Kaplan H. Hindsight bias, outcome knowledge and adaptive learning. Qual Saf Health Care. 2003;12 Suppl 2:ii46-50. 
36) Wears RL, Nemeth CP. Replacing hindsight with insight: toward better understanding of diagnostic failures. Ann Emerg Med. 2007;49(2):206-9.

37) Fischhoff B. Hindsight not equal to foresight: the effect of outcome knowledge on judgment under uncertainty. 1975. Qual Saf Health Care. 2003;12(4):304-11; discussion 11-2.

38) Arkes HR, Wortmann RL, Saville PD, Harkness AR. Hindsight bias among physicians weighing the likelihood of diagnoses. J Appl Psychol. 1981;66(2):252-4.

39) Dawson NV, Arkes HR, Siciliano C, Blinkhorn R, Lakshmanan M, Petrelli M. Hindsight bias: an impediment to accurate probability estimation in clinicopathologic conferences. Med Decis Making. 1988;8(4):259-64.

40) Marks Knoll MAZ. The Effects of Expertise on the Hindsight Bias [dissertation from the internet]. Ohio: The Ohio State University; 2009. Available from: https://etd.ohiolink. edu/!etd.send_file?accession=osu1242920562\&disposition=inline.

41) Pearce N. Analysis of matched case-control studies. BMJ. 2016;352:1969.

42) Grobbee DE, Hoes AW. Clinical Epidemiology: Principles, Methods, and Applications for Clinical Research. Second ed: Jones \& Bartlett Learning; 2015. Chapter 9: Case-Control Studies; p. 255-301.

43) Fleiss J, Levin B, Paik M. Statistical Methods for Rates and Proportions. Third Edition ed: John Wiley \& Sons Inc; 2003. p. 598-626.

44) Stokoe E. The Conversation Analytic Role-play Method (CARM): A Method for Training Communication Skills as an Alternative to Simulated Role-play. Res Lang Soc Interac. 2014;47(3):255-65.

45) Sikveland RO, Stokoe E. Effective telephone triage methods. Practice Management. 2017;27(6):20-2.

46) Hollnagel E, Wears R, Braithwaite J. From Safety-I to Safety-II: A white paper. The Resilient Health Care Net: Published simultaneously by the University of Southern Denmark, University of Florida, USA, and Macquarie University, Australia: 2015.

47) Kolb DA. Experiential Learning: Experience as the Source of Learning and Development. Englewood Cliffs, NJ: Prentice-Hall Inc; 1984.

48) Bransford JD, Brown AL, Cocking RR. How People Learn: Brain, Mind, Experience and School: Expanded Edition. Washington, DC: National Academy Press; 2001.

49) Schultz K, McEwen L, Griffiths J. Applying Kolb's Learning Cycle to Competency-Based Residency Education. Acad Med. 2016;91(2):284. 


\section{Curriculum Vitae}

Daphne Carmen Aimée Erkelens was born on $21^{\text {st }}$ of September 1990 in Rotterdam, the Netherlands. In 2008, she graduated from the Emmauscollege in Rotterdam, and started her study Medicine at Utrecht University. During her research internship on transitional patient safety at the Department of General Practice of the Julius Center her interest in research grew. After obtaining her medical degree in December 2014, she started working as a junior researcher in the field of patient safety at the Department of General Practice of the Julius Center. Subsequently, in January 2016 she started working as a PhD

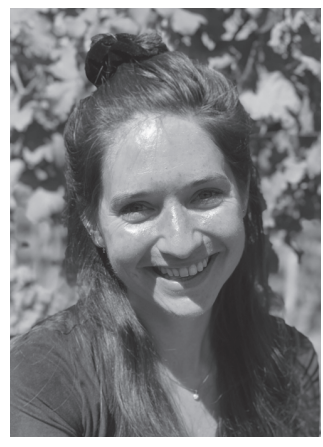
candidate. Under supervision of Prof. dr. Frans Rutten, Prof. dr. Roger Damoiseaux, Dr. Dorien Zwart and Dr. Esther de Groot she worked on the 'Safety First' project resulting in this thesis on safe telephone triage of acute cardiovascular symptoms in out-ofhours primary care. She combined her PhD research project with the General Practice Training in Utrecht and the Postgraduate Master of Epidemiology with the specialisation Clinical Epidemiology at the Utrecht University, the latter for which she obtained her degree in April 2020. In addition, she was both webmaster and secretary of the Scientific Working Group (2016-2018) and organizing member of the annual Conference Working Group (2019) of the Dutch National Organisation of General Practitioners in Training. Furthermore, she is a member of the scientific committee of the 2021 Conference of the European Society for Quality and Patient Safety in General Practice/Family Medicine. Currently, she is completing her General Practice Training. In the future she aims to combine research and working as a General Practitioner. 


\section{List of publications}

\section{This thesis}

Erkelens DC, Rutten FH, Wouters LT, De Groot E, Damoiseaux RA, Hoes AW, Zwart DL. Limited reliability of experts' assessment of telephone triage in primary care patients with chest discomfort. J Clin Epidemiol. 2020 July 28;127:117-124. doi: 10.1016/j. jclinepi.2020.07.016.

Erkelens DC, Van Charldorp TC, Vinck VV, Wouters LT, De Groot E, Damoiseaux RA, Rutten FH, Zwart DL, De Groot E. Interactional implications of either/or-questions during telephone triage of callers with chest discomfort in out-of-hours primary care: a conversation analysis. Patient Educ Couns. 2020 Jul 15;S0738-3991(20)30384-0. doi: 10.1016/j.pec.2020.07.011.

Erkelens DC*, Wouters LT*, Zwart DL, Damoiseaux RA, De Groot E, Hoes AW, Rutten $\mathrm{FH}$. Optimisation of telephone triage of callers with symptoms suggestive of acute cardiovascular disease in out-of-hours primary care: observational design of the Safety First study. BMJ Open. 2019 Jul 1;9(7):e027477. doi: 10.1136/bmjopen-2018-027477. * Shared first authorship

\section{Other Safety First related research}

Wouters LT, Rutten FH, Erkelens DC, De Groot E, Damoiseaux RA, Zwart DL. Accuracy of telephone triage in primary care patients with chest discomfort: A cross-sectional study. Open Heart. 2020 Aug;7(2):e001376. doi: 10.1136/openhrt-2020-001376.

Wouters LT, Zwart DL, Erkelens DC, Huijsmans M, Hoes AW, Damoiseaux RA, Rutten FH, De Groot E. Tinkering and overruling the computer decision support system: Working strategies of telephone triage nurses who assess the urgency of callers suspected of having an acute cardiac event. J Clin Nurs. 2020 Apr;29(7-8):1175-1186. doi: 10.1111/ jocn.15168.

Wouters LT, Zwart DL, Erkelens DC, Cheung NS, De Groot E, Damoiseaux RA, Hoes AW, Rutten $\mathrm{FH}$. Chest discomfort at night and risk of acute coronary syndrome: cross-sectional study of telephone conversations. Fam Pract. 2020 Jan 30:cmaa005. doi: 10.1093/ fampra/cmaa005.

\section{Other publications}

Van Balkum M*, Buijs B*, Donselaar EJ*, Erkelens DC*, Goulin Lippi Fernandes E*, Wegner I, Grolman W, Janssen LM. Systematic Review of the Diagnostic Value of Laryngeal Stroboscopy in Excluding Early Glottic Carcinoma. Clin Otolaryngol. 2017 Feb;42(1):123130. doi: 10.1111/coa.12678. *Shared first authorship 
Van Melle MA, Erkelens DC, Van Stel HF, De Wit NJ, Zwart DL. Pilot study on identification of incidents in healthcare transitions and concordance between medical records and patient interview data. BMJ Open. 2016 Aug 19;6(8):e011368. doi: 10.1136/ bmjopen-2016-011368.

Erkelens DC. Cognitieve bias bij telefonische triage. Huisarts Wet. 2016 Aug;59(8):355.

Van Geen K, De Groot E, Erkelens DC, Zwart DL. Raising awareness of cognitive biases during diagnostic reasoning. Perspect Med Educ. 2016 Jun;5(3):182-5. doi: 10.1007/ s40037-016-0274-4.

\section{Conference presentations and posters}

Winner of the International Research Award of the BJGP Research Conference 2020, London, the United Kingdom. Erkelens DC. Missed acute coronary syndrome during telephone triage at out-of-hours primary care: Lessons from a case-control study. (Award)

BJGP Research Conference 2020, London, the United Kingdom. Erkelens DC. Missed acute coronary syndrome during telephone triage at out-of-hours primary care: Lessons from a case-control study. (Presentation)

NHG Wetenschapsdag 2019, Nijmegen, the Netherlands. Erkelens DC. Calamiteiten bij patiënten met pijn op de borst in de eerste lijn: een case-control studie zonder hindsight bias. (Presentation)

AWIA Symposium 2018, Nijmegen, the Netherlands. Van Charldorp TC, Erkelens DC, Vinck VV, Zwart DL, de Groot E. "Either/or questions in general practice triage telephone conversations: should we send an ambulance or not?" (Presentation)

WONCA Europe 2018 Conference, Krakow, Poland. Erkelens DC. "Fatal adverse events after chest pain at out-of-hours primary care: a case-control study". (Presentation)

NHG Wetenschapsdag 2016, Amsterdam, the Netherlands. Wouters LT, Erkelens DC. Onderzoeksopzet Safety First: Optimalisatie van de telefonische triage op de huisartsenpost van patiënten met klachten verdacht voor een acute cardiovasculaire aandoening. (Pitch)

HartVaatHAG Congres 2016, Utrecht, the Netherlands. Erkelens DC. Safety First: "Telefonische triage op de huisartsenpost: diagnostiek van acute cardiovasculaire ziekten". (Pitch \& poster) 


\section{Dankwoord}

Tijdens mijn promotieonderzoek heb ik met veel verschillende mensen mogen samenwerken. Zonder een woord van dank aan allen die mij hebben begeleid en ondersteund is dit proefschrift niet compleet, want promoveren doe je zeker niet alleen!

Geachte prof. dr. F.H. Rutten, beste Frans, aan het begin van mijn promotieonderzoek gebruikte jij een plantje als metafoor voor een promovendus die mij altijd is bijgebleven. Sommige plantjes hebben bakken water en voeding nodig, terwijl je naar anderen nauwelijks hoeft om te kijken, maar uiteindelijk gaan ze allebei groeien. Je hebt mij nooit verteld wat ik er voor één was, maar ik weet wel dat ik dankzij jouw proactieve, kritische en positieve houding enorm ben gegroeid. Helaas is het plantje dat ik je gaf na het verkrijgen van jouw leerstoel vrij snel verdord ;-). Máár, jouw talenten liggen elders! Jouw uitgebreide kennis en ervaring op het gebied van cardiovasculaire ziekten gecombineerd met een pragmatische blik hebben mij geïnspireerd. In de overleggen met jou was er altijd ruimte voor (sterke) verhalen uit de praktijk en dat gaf mij het gevoel dat je als onderzoeker toch dicht bij de praktijk bleef. We zijn allebei "stronteigenwijs" (jouw woorden), liefhebbers van droge humor en beschikken over een behoorlijke dosis zelfspot, wat onze overleggen vaak erg gezellig maakte. Jouw prachtige oneliners zal ik ook niet snel vergeten (mijn favoriet: "soms is de oplossing het gewoon weg te laten"). Mooi om te zien dat er sinds jouw leerstoel eigenlijk niets is veranderd. Je blijft even nuchter, benaderbaar en betrokken. Dank voor jouw fantastische begeleiding!

Geachte prof. dr. R.A.M.J. Damoiseaux, beste Roger, dank dat ik dit promotieonderzoek onder jouw hoede als promotor mocht uitvoeren. Als hoofd van de huisartsopleiding hield jij niet alleen de voortgang van het promotieonderzoek in de gaten, maar dacht je ook aan het verloop van mijn huisartsopleiding. Je maakte altijd tijd vrij om mijn manuscripten van kritische feedback te voorzien en hebt nog nooit een deadline gemist. Jouw praktijkgerichte blik op wetenschap was van toegevoegde waarde voor het Safety First onderzoek en de vertaling van de resultaten naar onderwijsmogelijkheden en bruikbare adviezen voor de praktijk.

Geachte dr. Zwart, beste Dorien, onze samenwerking startte ruim in de zomer van 2014 toen ik mijn wetenschappelijke stage bij het TIPP project kwam doen. Jouw enthousiasme voor het wetenschappelijk onderzoek werkte aanstekelijk en je hebt mij geleidelijk in de richting van een promotieonderzoek gekletst. Dank dat jij altijd liet merken het volste vertrouwen in mij én in een goede afloop te hebben, ook als ik daar zelf wat minder van overtuigd was. Het was nogal eens een uitdaging om in jouw overvolle agenda tijd te vinden voor het lezen van mijn manuscripten, maar jouw scherpe blik en opbouwende suggesties zorgden altijd voor een verbetering. Ik heb veel van je geleerd en bewonder 
jouw relativeringsvermogen en netwerk skills. Dank dat je mij de afgelopen 6 jaar klaargestoomd hebt voor een carrière als huisarts-onderzoeker!

Geachte dr. de Groot, beste Esther, het was een verrijking om jou als 'kwalitatief' onderzoeker in de Safety First onderzoeksgroep te hebben. Dankzij jouw ervaring kon jij vanuit een ander perspectief kijken naar de studies en hield jij mij bij de les als een manuscript niet leesbaar genoeg was voor 'niet-huisarts-onderzoekers'. Het was erg leerzaam om mij samen met jou te verdiepen in de wondere wereld van conversatieanalyse. Ik waardeer jouw toewijding aan het project en je bijzonder snelle reacties op alle manuscripten. Ondanks dat niet alle hoofdstukken uit dit proefschrift in jouw straatje vallen, wist je toch bij elk stuk een waardevolle bijdrage te leveren. Bedankt voor je steun de afgelopen jaren!

Geachte prof. dr. A.W. Hoes, beste Arno, hoewel je formeel niet mijn promotor bent, heb ik je wel als zodanig beschouwd. Ik blijf het bijzonder vinden hoe jij, met misschien nog wel de volste agenda en soms na maanden zonder een Safety First overleg, toch in een split second op de hoogte was en het project weer de juiste kant op wist te sturen. Je weet altijd de knelpunten in een artikel of analyse te vinden, denkt in oplossingen en misschien nog wel het belangrijkst: je stelt de promovendus centraal. Dank voor jouw bijdrage, die mijn proefschrift naar een hoger niveau heeft getild.

Geachte leden van de beoordelingscommissie, prof. dr. M.L. Bots, prof. dr. L.J. Kappelle, prof. dr. Th.J.M. Verheij, prof. dr. S. Brinkkemper en prof. dr. M. de Bruijne, ik wil u allen hartelijk danken dat $u$ de tijd heeft genomen om dit proefschrift te lezen en te beoordelen.

Veel dank aan iedereen die zich vanuit (voormalig) stichting 'Primair Huisartsenposten' heeft ingezet voor het Safety First project en in het bijzonder Jan Gerritsen, Johnny Janssen, Chantal Peele en Dick van Brink. Dank voor de fijne samenwerking en het beschikbaar stellen van data en werkplekken. Daarnaast wil ik graag Sonja Oomkens bedanken. Je was altijd enthousiast over het Safety First project en jouw kennis over calamiteitenonderzoek op huisartsenposten was voor mij van grote waarde.

Stichting 'Nederlandse Triage Standaard' en stichting 'Stoffels-Hornstra', dank voor de financiële bijdrage aan het Safety First project en de vrijheid om onafhankelijk onderzoek te kunnen verrichten.

Beste leden van de klankbordgroep, Markus Kruyswijk (NTS), Tessa Postuma (NTS), Ludeke van der Es (InEen), Konca Artan (IGJ) en Ellen Spierings (IGJ), en Roderick Runne (Primair), dank voor jullie aanwezigheid en input tijdens de bijeenkomsten. 
Veel dank aan alle deelnemende huisartspraktijken, huisartsen, doktersassistenten en aios die follow-up formulieren voor de Safety First studie hebben ingevuld en alle huisartsen die deel hebben genomen aan het expert panel van de case-control studie. Zonder jullie inzet was dit proefschrift nooit tot stand gekomen. Daarnaast wil ik Marlies Huijsmans en Ineke Kagenaar bedanken voor jullie inzet voor het Safety First onderzoek bij de interviewstudie respectievelijk het expert panel.

Aan alle groepsdocenten en opleiders van de Huisartsopleiding Utrecht, in het bijzonder mijn eerstejaarsdocenten Victor van Duuren en Erik van Bruggen, dank voor jullie begrip, steun en flexibiliteit bij het combineren van de huisartsopleiding met mijn promotieonderzoek. Lieve Lisette, hoewel ik formeel maar één keer onderwijs van je heb gehad op de huisartsopleiding ben je voor mij een inspirerende huisartsdocent. Dank voor jouw hulp ook bij mijn expert-panel onderzoek en alle gezellige LOVAH/WONCAmomenten!

Beste Tessa en Vera, wat vond ik het ontzettend leuk om met jullie samen te werken! Tessa, jij hebt mij wegwijs gemaakt in de onderzoekswereld van conversatie-analyse. Zonder jouw hulp was ik nooit begonnen aan zo'n wezenlijk andere vorm van onderzoek doen en dankzij jouw heldere visie en begeleiding is het een prachtig stuk geworden. Vera, bedankt voor al jouw hulp bij de datasessies en conversatie-analyse. Wat ben ik blij dat jij na jouw stage bij het Julius Centrum terug bent gekomen als junior onderzoeker. Naast de fijne samenwerking, was het ook altijd heel gezellig met jou op de vrijdagen in het Van Geuns!

Beste Faas, Sander en Maarten, in een latere fase van het Safety First onderzoek zijn jullie te hulp geschoten en daar ben ik enorm blij mee! Faas, toen het einde van mijn promotietijd in zicht kwam kon jij de begeleiding van stagestudenten bij Safety first overnemen en dat scheelde enorm! Dank ook voor je feedback op enkele van mijn manuscripten! Sander, jij was de hoofdbegeleider van mijn research project voor de Postgraduate Master Epidemiology en hebt geholpen bij het analyseren en interpreteren van de TIA/stroke data waarvoor veel dank! Maarten, jouw uitgebreide kennis en ervaring op het gebied van predictiemodellen zijn van grote waarde geweest en jouw R-skills hebben mij veel frustratie bespaard. Dank voor al jouw hulp!

Ook veel dank aan de ruim 35 Safety First stagestudenten en werkstudenten Gerben, Rozemarijn en Gabi. Dank jullie wel voor alle inspanningen die jullie voor het Safety First onderzoek hebben verricht: van het beluisteren van de triagegesprekken tot het eindeloze bellen, faxen, mailen en bezoeken van huisartspraktijken tijdens het verzamelen van follow-up gegevens. In het bijzonder dank aan stagestudent Harmke; wat was het leuk en bijzonder om jou twee keer te mogen begeleiden! Ik heb veel waardering voor jouw doorzettingsvermogen en veerkracht. En Gerben, jouw excelskills 
en organisatievaardigheden zijn next level! Mooi dat jullie allebei een co-auteursplek hebben verworven.

Ik wil alle collega's van het Julius Centrum bedanken voor de prettige werkomgeving. Tijdens de Julius Seminars, het HAG-promovendi overleg en het onderwijs van de Postgraduate Master Epidemiology heb ik veel van jullie geleerd.

Lieve roomies van Str. 5.122 en MvG 5.10, Darren, Marieke, Stéphanie, Valentijn, Jolien, Daphne, Anne, Marjolein, Loes, Eveline, Inger, Carla, Feike, Birsen, Lufang en Tim, dankzij jullie was het elke dag weer een feestje om naar mijn werk te gaan! Bij jullie kon ik met alles terecht: van statische dilemma's uitpluizen tot het bespreken van de nieuwste achterklap. Bedankt voor de gezellige koffiepauzes, lunches, etentjes, kameruitjes en vrijmibo's. Wat heb ik genoten van de Party Committee activiteiten die we organiseerden en natuurlijk de memorabele promovenski's en club Tenne! Lieve mede-aioto's, heel fijn dat ik met alle aioto-perikelen altijd bij jullie terecht kon!

Lieve paranimfen, Loes en Eveline, wat ben ik blij dat ik mijn promotietijd met jullie heb mogen delen. Jullie waren in de afgelopen jaren het meest betrokken bij mijn promotietraject en daarom vind ik het een eer dat jullie mijn paranimfen willen zijn en op 27 november naast mij willen staan tijdens mijn verdediging! In de loop van mijn promotietraject zijn we naast collega's ook vriendinnetjes geworden. Ik ben super trots op wat jullie allebei bereikt hebben! Lieve Loes, ik vond het zó fijn om het Safety First onderzoek samen met jou op te tuigen. Ik zou niet weten hoe ik dat in mijn eentje had moeten doen. Vanaf het begin konden we het goed met elkaar vinden en werden we liefkozend Jut \& Jul genoemd. Het was heerlijk om elke stap in het promotieonderzoek met jou te kunnen delen, alle successen en frustraties kon ik bij jou kwijt en jij was er altijd om mij te steunen, dank daarvoor! Lieve Eveline, met jou op de kamer was eigenlijk veel te gezellig. Onze droge humor, gemeenschappelijke interesse in de nieuwste Amsterdamse eettentjes en feestjes en vele guilty pleasures (lees: any real-life serie van matige tot slechte kwaliteit) zorgden voor eindeloze gespreksstof. Toen duidelijk werd dat jij van junior onderzoeker naar promovendus kon doorstromen, was ik door het dolle, want extra jaren keten met jou!

Lieve 'sunny girls' Tamara en Ilse, lieve Pruisjes, we go way back en al in de wieg was het mij duidelijk: deze 'half'zusjes zijn voor altijd! Lieve Ta, dank voor het prachtige design van mijn proefschrift. Toen ik in 2016 begon met mijn promotie was nog vrij weinig duidelijk, behalve dat jij mijn cover moest ontwerpen! Jouw werk is van ongekende kwaliteit en dit is ook weer een pareltje! En lieve Pils, wat ben ik trots op jouw carrière en alles wat je bereikt hebt. Hoewel de COVID-19 pandemie roet in het eten gooit, hoop ik dat de verhuizing van Bas en jou naar NYC door kan gaan, want dan heb ik het perfecte excuus voor een terugkerende stedentrip! 
Lieve Suzanne, onze (ondertussen 17-jarige!) vriendschap is mij heel dierbaar, de gesprekken met jou zijn altijd open en eerlijk en onze avondjes uit eten gaan veel te snel voorbij. Je bent een prachtig mens met een hart van goud en ik ben trots op jou en je prachtige gezin. Lieve TaSuCarNoMie, Tamara van R., Suzanne, Anouk en Michelle, mijn Rotterdamse VVV-tjes, wat ben ik blij met onze vriendschap. Hoewel er soms wat meer tijd tussen onze dates zit dan we eigenlijk zouden willen, blijft het zo gezellig!

Lieve Spettertjes, Lizzie, Loes en Tessa, mijn roeimaten sinds 2009! Waar zou ik zijn zonder onze fantastische vakanties en weekendjes weg (mét never ending verkleedfeestjes), festivals en etentjes? Van een 'white cottage' in de regen tot Amsterdamse sterrenrestaurants: met jullie is werkelijk elk moment een feest! Lizzie, mijn tweeling vriendin, wat ben ik trots op jou! Ik ken geen slimmere en grappigere ziekenhuisapotheker mét zo'n schattige hond! Loes, buufje, wat heerlijk om twee straten achter jou te wonen en onze voorliefde voor Amsterdam te delen! Lekker varen door de grachten in een sloep of de omgeving per racefiets ontdekken! Tessa, mijn all-time favorite studiemaat, van geneeskunde tot de huisartsopleiding, met jou is een opleiding zóveel leuker! Je bent een voorbeeld; gewoon doen waar je echt gelukkig van wordt!

Lieve Leida, dit jaar hebben we ons jubileum: 10 jaar vriendschap! Begonnen als mede-co's en werkgroepgenootjes en nu geworden tot een van mijn meest bijzondere vriendschappen; bij jou kan en mag alles. Wat vond ik het geweldig om getuige te zijn tijdens jouw huwelijk met Jaapie. Ik heb diep respect voor wat jij hebt bereikt en ik ben er van overtuigd dat je de beste huisarts van de Achterhoek bent! Lieve Laura en Marank, hoewel de fysieke afstand is toegenomen en de frequentie van onze dates door drukke opleidingen niet meer is zoals vroeger, ben ik blij dat we bevriend zijn gebleven. Van lekker uit de bocht vliegen met een bestekladedansje naar serieuze KNO en SEHadviezen als ik het niet meer weet. Ik kijk nu alweer uit naar onze jaarlijkse kampeertrip in de Achterhoek!

Lieve Joop en Mick, wat ben ik blij dat jullie op de Springweg zijn komen wonen! Als huisgenootjes begonnen, maar als vriendinnetjes geëindigd. Tijdens de ups en downs die nu eenmaal horen bij een promotietraject is het ontzettend fijn om vriendinnetjes te hebben waar je ook mee hebt samengewoond, want jullie kennen mij door en door. Met niemand kan ik zo goed kletsen \& keten als met jullie en onze campingdisco-avonturen zijn het allerleukst! Wat zijn jullie belangrijk voor mij!

Lieve Amsterdamse maatjes, Rodny, Lindy \& Fabian, Veerle \& Ger, wat een genot om jullie te leren kennen te afgelopen jaren! Teveel mooie momenten om nooit te vergeten: dansend op Wildeburg, zeilend langs de kustlijn van Griekenland en Kroatië, wildlife spottend in Costa Rica en wijn proevend in Zuid-Afrika. Lieve Veer en Lin, daarnaast zijn jullie natuurlijk ook mijn rocycle buddies, dank voor jullie (sportieve) gezelligheid de afgelopen tijd! 
Lieve extended-VVV's, Aline \& Sirik met natuurlijk ook Feetje, Anne \& Julian, van Lowlands tot New Years Eve, wat is het toch gezellig om met jullie te zijn! Snel naar Épernay om het te vieren? Lieve wispo-maten, Frouke \& Roel, Nicole \& Jesse en Robin, je steiler je geiler! Met niemand kan ik beter vliegende herten spotten dan met jullie, wanneer gaan we weer?

Lieve Daan \& Guusje, wat is het toch fantastisch om met jullie bevriend te zijn. Ik heb enorm genoten van onze avonturen in Honduras, zomeravonden in de Corona periode en ons weekendje Friesland. Jullie bouwen de beste borrelplanken en na elke dubbeldate ga ik met spierpijn van het lachen naar huis. Nu al zo'n zin in jullie wedding party! Dank voor jullie steun en heerlijke afleiding de afgelopen periode!

Lieve Robbert en Manon, jullie zijn niet alleen vrienden, maar mijn extended (huisarts) familie. Manon, vanaf het eerste moment dat ik je ontmoette was ik fan: je bent positief, zorgzaam en een heerlijke flapuit met een goede dosis zelfspot. Ik ben ontzettend trots op hoe jij de spannende periode vlak na de geboorte van Ties hebt doorstaan. Jullie hebben een prachtige zoon! En Robbie, ruim 11 jaar geleden spraken we elkaar voor het eerst in het HvdB. Ik had nooit gedacht dat dat gesprek over Robbedoes \& Kwabbernoot zou leiden tot een vriendschap voor het leven! Dankzij jou leerde ik de liefde van mijn leven kennen en jij stoomde mij klaar voor de huisartsopleiding. Én, we vonden elkaar in een hysterische voorliefde voor kerst en Nederlandse hiphop. Dank voor alles!

Lieve Klaas, Lies en Ilja, wat bof ik met jullie als schoonfamilie. Jullie hebben mij vanaf het begin met open armen ontvangen. In de afgelopen jaren hebben we veel bijzondere, mooie en verdrietige momenten met elkaar gedeeld. Zo zal ik onze reis door Canada en de mooie tijd met Oma Sneek niet vergeten. Dankzij jullie ben ik ook nog eens een hele fijne familietraditie rijker; Sinterklaas bij de Kerkhofjes is ongekend. Na de eerste paar jaar met een online rijmwoordenboek, kom ik nu eindelijk een beetje in de buurt van jullie dichttalent. Klaas en Lies, dank voor jullie betrokkenheid de afgelopen periode. Ilja, ik had me geen fijner schoonzusje kunnen wensen. Je bent lekker eigenwijs en enthousiast, maar vooral helemaal jezelf: de leukste stadsboerin van Amsterdam!

Lieve papa, mama en Laris, wat ben ik blij met jullie om mij heen! Mijn dank voor jullie onvoorwaardelijke liefde, steun en betrokkenheid is bijna niet in woorden uit te drukken. Pap en mam, jullie zijn mijn inspiratie geweest voor het (huis)artsenvak en de eerstelijnszorg. Ik hoop dat ik ook zo goed voor mijn patiënten zal zorgen, als jullie voor jullie patiënten doen en hebben gedaan. Mam, bij jou kan ik alles kwijt, je bent de allerbeste! Pap, wat moet ik zonder jouw klustalent en briljante adviezen? Laris, jij bent de allerliefste zus en het zonnetje in huis. Jouw vrolijke en enthousiaste karakter maken mijn dagen altijd gezelliger. Van onze family time geniet ik enorm, met als kers op de taart natuurlijk onze vakanties: een jaarlijkse wintersport, een moeder-dochters 
citytrip en een vader-dochter klimtocht in de bergen. Ik hoop dat we dat nog heel lang kunnen blijven doen!

Allerliefste Tom, it's done! Mijn grootste dank gaat uit naar jou. Zonder jou was ik dit traject waarschijnlijk niet eens gestart. Jij bent mijn rots in de branding en jouw uitzonderlijke relativeringsvermogen hebben mij meer dan eens geholpen mijn zorgen in perspectief te plaatsen. Je stimuleert mij om het onderste uit de kan te halen, zonder dat ik dat als druk ervaar en je blijft in mij geloven. Ik bewonder jouw doorzettingsvermogen en je geweldige gevoel voor humor. Je bent slim en breed geïnteresseerd, iets wat ik enorm waardeer. Zoals je zelf ook wel weet: ik ben je allergrootste fan! Weet je nog aan het eind van 2019 toen we ons het aankomende jaar probeerden voor te stellen? 2020 werd pittig, want ik ging promoveren en jij was net gestart met een nieuwe baan in Londen, waar je wekelijks voor heen en weer vloog. En toen.. zaten we ruim vijf maanden samen thuis te werken. Stiekem heel fijn! Dank voor al je ondersteuning en aanmoediging tijdens dit promotieonderzoek. Het leven met jou is prachtig! 


